\title{
Genetic diversity and phenotypic variation of wild, feral and cultivated Coffea canephora in relation to drought stress
}
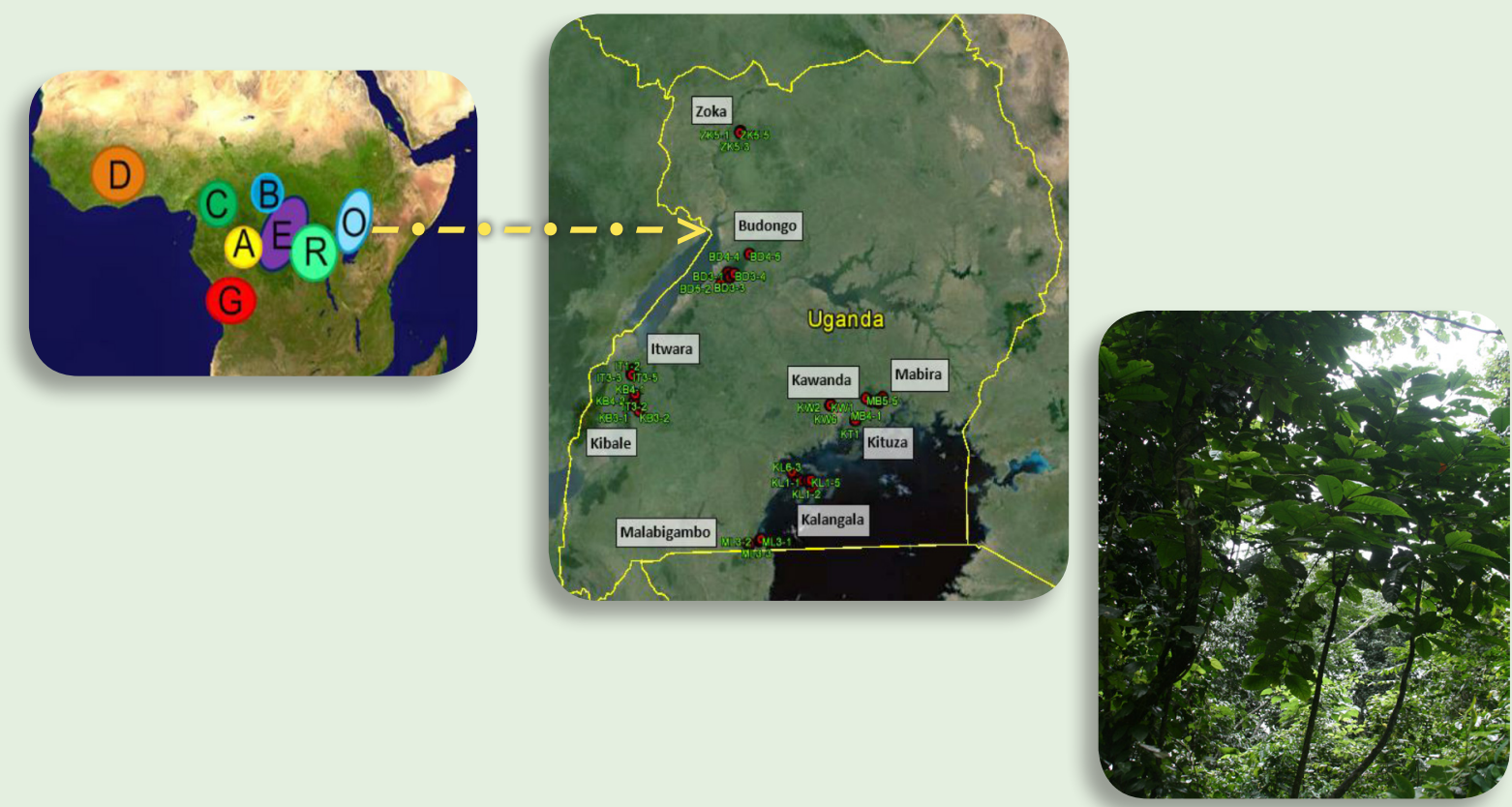


\section{Propositions}

1. Achievement of improved drought tolerance of Ugandan Coffea canephora Pierre ex A. Froehner genotypes requires an effective weakening of the growth-tolerance tradeoff (this thesis).

2. In Coffea canephora those plants that do not respond to changes in water availability are the ones most tolerant to drought (this thesis).

3. Ecologists seek for averages, breeders for outliers and farmers tend to prefer a balance between the two.

4. Learning is an exercise in objectivity.

5. The nutrition transition and its associated adverse health effects in urban Africa is due to food illiteracy rather than the changing food environment

6. Nurture a conscious generation and the future will be secured.

7. A weak institutional network deprives a nation of development.

8. To achieve success, the number of things one focusses on should decrease with the number of things one can potentially do.

Propositions belonging to the $\mathrm{PhD}$ thesis, entitled

'Genetic diversity and phenotypic variation of wild, feral and cultivated Coffea canephora in relation to drought stress'

Catherine Kiwuka

Wageningen, $19^{\text {th }}$, October 2020 
Genetic diversity and phenotypic variation of wild, feral and cultivated Coffea canephora in relation to drought stress

Catherine Kiwuka 


\section{Thesis committee}

\section{Promotor}

Prof. Dr N.P.R. Anten

Professor of Crop and Weed Ecology

Wageningen University and Research

\section{Co-promotors}

Dr J. Vos

Associate professor (em.), Centre for Crop Systems Analysis

Wageningen University and Research

Dr V. Poncet

Plant Biodiversity and Adaptation Research Group

Institute of Research for Development

Montpellier, France

\section{Other members}

Prof. Dr K.E. Giller

Dr P. Vaast

Dr ir HAM Van der Vossen

Prof. Dr G.H.J. Kema
Wageningen University and Research

Ministry of Europe and Foreign Affairs, France

Venhuizen, the Netherlands

Wageningen University and Research

This research was conducted under the auspices of the C.T. De Wit Graduate School of Production Ecology and Resource Conservation. 


\section{Genetic diversity and phenotypic variation of wild, feral and cultivated Coffea canephora in relation to drought stress}

\section{Catherine Kiwuka}

Thesis

submitted in fulfilment of the requirements for the degree of doctor

at Wageningen University

by the authority of the Rector Magnificus

Prof. Dr A.P.J. Mol,

in the presence of the

Thesis Committee appointed by the Academic Board

to be defended in public

on Monday $19^{\text {th }}$ October 2020

at $11.00 \mathrm{am}$ 
Catherine Kiwuka

Genetic diversity and phenotypic variation of wild, feral and cultivated Coffea canephora in relation to drought stress, 180 pages.

PhD thesis, Wageningen University, Wageningen, NL (2020)

With references, with summaries in English and Dutch

ISBN: 978-94-6395-537-9

DOI: $10.18174 / 530909$ 


\begin{abstract}
Catherine Kiwuka (2020). Genetic diversity and phenotypic variation of wild, feral and cultivated Coffea canephora in relation to drought stress. $\mathrm{PhD}$ thesis, Wageningen University, The Netherlands, with summaries in English and Dutch, 180 pp.
\end{abstract}

Coffea canephora Pierre ex A. Froehner (Robusta coffee) is an important crop sustaining millions of livelihoods in its production zone which is predominated by poor countries. Like the other commercially important coffee species, Coffea arabica, the production of Coffea canephora is threatened by the prevailing intense and frequent drought spells reported to be increasing in relation to climate change. There is thus an urgent need to develop drought resilient $C$. canephora cultivars especially for poor farmers who often lack irrigation options. Availability of $C$. canephora intraspecific diversity and occurrence of wild populations across an environmental gradient may indicate presence of valuable genetic material, which could be used directly as a new variety or as a parent in breeding climate resilient varieties. This thesis explored: (i) the genetic diversity of Ugandan Robusta coffee; (ii) linkages between allelic variation and environmental variables; (iii) phenotypic variation in drought tolerance and (iv) phenotypic plasticity to shifts in water availability and its relationship with drought tolerance. Results showed that: Uganda's C. canephora differentiates into five geographically delimited groups, and there is substantial phenotypic variation in relation to their response to water availability across locations and genetic groups but no significant phenotypic variation along the level of cultivation status. We observed a trade-off between drought tolerance and growth in ample water conditions. Drought tolerance of the genotypes was negatively associated to an index that indicated wetness of the climate at their locations suggesting some degree of local adaptation. Finally, our results also showed a negative correlation between plasticity in response to changes in water availability and drought tolerance. Generally, our study revealed the comprehensive genetic structure of Uganda's C. canephora, its differential response in to drought stress, growth-tolerance trade-off, plasticity-tolerance trade-off, the link between $\delta^{13} \mathrm{C}$ discrimination and water-use efficiency, and the probable implications of the findings to developing drought tolerant cultivars. Our findings can be used in further studies like association studies to identify putatively adapted genotypes and in breeding programs to develop climate resilient cultivars. 



\section{Table of contents}

Chapter 1 General introduction

Chapter 2 Genetic diversity of native and cultivated Uganda's Coffea canephora

Pierre ex A. Froehner. A perspective into potential utilization and conservation of the diversity

Chapter 3 Intraspecific variation in growth response to drought stress across geographic locations and genetic groups in Coffea canephora Pierre ex A. Froehner

Chapter 4 Phenotypic and genotypic variation in trait plastic responses to 95 drought and its relationship with drought tolerance in wild Coffea canephora Pierre ex A. Froehner

Chapter 5 General discussion 129

Summary 157

Samenvatting 161

Acknowledgements 165

Curriculum Vitae

List of publications

PE\&RC Education Statement 175

Funding 

Chapter 1

General introduction 


\section{Chapter 1}

\section{The coffee industry}

Coffee is a major global agricultural commodity (Lewin et al., 2004, ICO, 2019a). It is produced by about 25 million, mostly smallholder farmers distributed in over 50 developing countries, to whom, it is a major source of cash income (Wintgens, 2004, ICO, 2019a). In 2012/13 coffee year, the revenue from coffee exports in producing countries was estimated at US\$19.1 billion (ICO, 2014). World coffee production has increased steadily in the last few decades, and a global surplus of 3.11 million $60 \mathrm{~kg}$ bags was expected in the 2018/2019 coffee year (ICO, 2019b). Impressively, global coffee consumption is reported to be steadily growing by a rate of $2 \%-2.5 \%$ per year with emerging markets in Eastern Europe, Asia and within coffee producing countries themselves (ICO, 2019b, ICO, 2014). Consumption in importing countries grew by $2.4 \%$ to 114.51 million bags while exporting countries' consumption rose by $1.3 \%$ to 50.31 million $60 \mathrm{~kg}$ bags, which represents $30.5 \%$ of world consumption (ICO, 2019b).

While coffee consumption is increasing, several recent reports have pointed at the threats posed by climate change to coffee production (DaMatta, 2018, Bunn et al., 2015, ICO, 2014, Davis et al., 2006, Haggar and Schepp, 2012). A study by Bunn et al. (2015) projected that the direct (e.g. warming and drying) and indirect (increased impacts of pests and diseases) effects of climate change together may result in as much as a $50 \%$ reduction in mean yields in current coffee growing areas by 2050. There is thus an urgent need to develop and implement climate adaptive strategies to confer resilience to coffee production systems. Climate adaptive strategies can be categorized in two types. The first entails agronomic measures aimed at mitigating effects of climate change. Examples include the use of shade trees (e.g. agroforestry) that can reduce warming and vapour pressure deficits, soil mulching (reduce soil moisture loss) and disease and pest control measures (DaMatta and Ramalho, 2006, DaMatta, 2004, Beer et al., 1998), The second climate adaptive strategy entails identification of adapted genetic coffee material and subsequent development of cultivars tolerant to: heat, pests and diseases, and drought. This thesis deals with the second category and explores the overall diversity of Ugandan coffee genetic resources, and genotypic variation in drought responses that exist across wild, feral and cultivated coffee plants.

\section{Effects of climate change on global coffee production}

The global coffee production is almost entirely sustained by two species: Coffea arabica (Arabica coffee) and C. canephora (Robusta coffee) contributing 62\% and 38\%, respectively (ICO, 2018). C. arabica is mostly produced in Latin America, East Africa and India at altitudes 
ranging from 1300 to 2800 m.a.s.l. It prefers a well distributed rainfall varying from 1600 to more than $2000 \mathrm{~mm}$ and mean temperatures between $18{ }^{\circ} \mathrm{C}$ to $22{ }^{\circ} \mathrm{C}$ (Davis et al., 2012, Wintgens, 2004, DaMatta and Ramalho, 2006). C. canephora is mainly grown in Brazil, Vietnam, Indonesia, parts of Western and East Africa at altitudes below 1000 m.a.s.1 (Wintgens, 2004) except for Uganda where it thrives in some areas above 1400 m.a.s.l. It typically prefers annual precipitation of at least $2000 \mathrm{~mm}$ that is well distributed over the year with no more than three dry months (precipitation less than $100 \mathrm{~mm}$ ) and a mean temperature ranging from $22{ }^{\circ} \mathrm{C}$ to $26^{\circ} \mathrm{C}$ (Wintgens, 2004, DaMatta and Ramalho, 2006, Coste, 1992). Therefore, in the coffee (both $C$. arabica and C. canephora) production zones, the quantity and distribution of rainfall, temperature, and the interactions between these factors are reported to be the key environmental factors affecting development (e.g. time of flowering), growth and production (Bunn et al., 2015, Davis et al., 2012, DaMatta and Ramalho, 2006). Coffee production is typically characterized by a biennial production pattern (especially the unshaded plantations), a state where the plant alternates between high fruit load in one year followed by low fruit production in the next year (DaMatta, 2004, Cannell, 1985 ). The negative effects of biennial bearing are likely to be exacerbated by variation in environmental conditions.

Global predictions of climate change show increased frequency in the occurrence and severity of droughts, temperature rise ranging from 1.4 to $5.8^{\circ} \mathrm{C}$ between 1990 and 2100 (IPCC, 2014, IPCC, 2018). Similarly, Haggar and Schepp (2012) reported a predicted temperature increase of $2.1^{\circ} \mathrm{C}$ across the coffee production belt by 2050. Several studies (Bunn et al., 2015, Davis et al., 2012, Zullo et al., 2011, DaMatta et al., 2007) have reported that climate change, e.g. changes in temperature and shifts in rainfall patterns, may cause severe reductions in global coffee production. Shifts in rainfall patterns coupled with changes in temperature during seasons are found to have substantial impacts in the interval between flowering and ripening of coffee fruits (DaMatta, 2018, DaMatta and Ramalho, 2006, Charrier and Berthaud, 1985). For instance, fruit development is typically accelerated by high temperatures, resulting in shorter fruit filling periods with concomitant negative effects on yields as well as physical bean and cup quality (Willson, 1999, Coste, 1992). High temperatures are also known to impair photosynthesis with direct negative effects on assimilate supply (DaMatta and Ramalho, 2006). Other studies (Martins et al., 2016, Rodrigues et al., 2016) on the responses of C. arabica and C. canephora to increased temperatures, with adequate soil moisture, revealed that generally both species are considerably heat tolerant till $37 / 30^{\circ} \mathrm{C}$ (day/night) with adverse irreversible effects on the photosynthetic pathway observed only at rather extreme temperatures, $42 / 34^{\circ} \mathrm{C}$ (DaMatta et al., 2018). 


\section{Chapter 1}

The current consensus appears to be that drought stress rather than temperature will be the most important direct yield reducing effect associated with climate change (DaMatta et al., 2018), with the exception of indirect effects via diseases and pests that are triggered by change in temperature. Climate change will have two effects on the water status of the plant: (i) warming, resulting in increased vapour pressure deficits and thus increased potential transpiration water loss by the plant and (ii) shifts in rainfall patterns that have been projected to become more extreme with longer periods of drought (IPCC, 2014). Water is a primary driver of plant growth e.g. it is a main constituent of plant tissues, a medium in which vital metabolic and chemical reactions occur in the plants, a medium for transportation of solutes, while transpiration of water is a vital part of photosynthetic $\mathrm{CO}_{2}$ uptake and essential to cool plant surfaces (Lambers et al., 1998 ). When water losses exceed uptake for extended time, transport and physiology get disrupted leading to damage and even plant death.

Plants can deal with water limitation in roughly two ways. One is by reducing water losses e.g. through stomatal closure, production of fewer or smaller stomata per leaf area and reducing leaf area itself, e.g. producing smaller leaves or dropping leaves, but evidently this response also reduces photosynthesis and thus growth. The other strategy is by plants trying to secure water acquisition e.g. by producing more or deeper roots, securing stem water transport and adjusting leaf osmotic potential. But these adjustments require assimilates. Thus, water limitation typically results in reductions in growth and agricultural yields.

\section{Adaptive potential of coffee to drought stress}

The potential and actual use of crop wild relatives (CWRs) is increasingly viewed as pivotal in conferring climate adaptation to crop production systems (Dempewolf et al., 2017, Pironon et al., 2019). Since wild plant populations are subjected to changes in the environmental conditions within their habitats, they are continuously evolving and adapting to those changes, which makes them potentially a valuable source of genetic resource that can be used to confer resilience to crops. CWRs are wild plants that are genetically close to a domesticated crop plant. CWRs can be defined based on the relative crossing ability (hybridization level) between the crop itself (gene pool concept) and/or at different taxonomic levels (being either of the same species, the same genus or more remotely related (taxon group concept) (Maxted et al., 2006, Harlan and de Wet, 1971). CWRs are important because they possess genetic diversity that has naturally evolved, independent of direct anthropogenic selection. In the case of coffee, CWRs exist both at the con-specific level e.g. as wild populations of C. arabica and C. canephora and 
at the con-generic level, there being over 122 other known Coffea species present in the wild (Davis et al., 2006). In this thesis, I studied wild populations of C. canephora being con-specific CWRs of cultivated Robusta coffee. Evidence for the potential and actual use of wild coffee populations, to confer resilience for abiotic and biotic production constraints, has been documented in several studies, e.g. drought tolerance (Taye, 2006, Burkhardt et al., 2006) and pest and disease resistance (Davis et al., 2012, Silva et al., 2006). Despite, the substantial contribution of CWRs to the sustainability of the global coffee sector, wild genetic diversity is highly endangered with $60 \%$ of coffee species reported to be threatened with extinction (Davis et al., 2019). Considering climate change, the use of CWRs is likely to become more important to confer climate resilience in coffee production. It is thus prudent to secure the wild genetic diversity by employing efficient ex-situ and in-situ conservation strategies.

Coffea canephora is native to West and East African tropical rain forests and has a wide distribution range stretching from the Guinea to Uganda and from Cameroon to Angola, adapted to various forest types (Merot-l'Anthoene et al., 2019, Davis et al., 2006, Berthaud, 1986). The wild C. canephora populations are reported to be geographically and/or ecologically isolated from one another and they are currently known to comprise eight well-differentiated groups corresponding to different geographic origins: A (Conilon); C (Cameroun); G (Angola); D (Guinean); O (Uganda); R (Democratic Republic of Congo); B (Central African Republic) and E (Congolese) (Figure 1 A) (Merot-l'Anthoene et al., 2019). Most of the C. canephora distribution range occurs in areas with abundant and well-distributed rainfall, but it also extends to comparatively drier areas characterized by substantial variations in precipitation and temperature (Davis et al., 2006). The occurrence of $C$. canephora native populations along a climate wetness gradient offers potential for detecting new genetic variants related to drought adaptation. Local adaptation of $C$. canephora populations is expected because the environmental gradient that exists, provides a spatially heterogenous environment that may ultimately act as a selection force on the populations thereby influencing their genetic structure. For example, gradients in temperature and precipitation were identified as important drivers for local adaptation and genetic differentiation of pine species (Zhou et al., 2014). Results from Alberto et al. (2011) indicate also adaptation of Quercus petraea (sessile oaks) to an altitudinal gradient where populations at higher altitudes flush later than those in lower altitudes, when compared in a common garden experiment. Torang et al. (2015) demonstrated strong adaptive differentiation of Arabis alpina in relation to a latitudinal gradient with survival and fruit production of one population being higher than the other. 


\section{Chapter 1}

Coffee production areas deal with fluctuations in water availability (DaMatta and Ramalho, 2006). Substantial genetic variability in drought tolerance has been observed within C. canephora (Menezes-Silva et al., 2015, Pinheiro et al., 2005) and C. arabica (Tesfaye et al., 2014, Beining, 2008). The variation in drought tolerance is reportedly larger within $C$. canephora than in C. arabica ((Menezes-Silva et al., 2015, Tesfaye et al., 2014) and this could partially be attributed to the allogamous (predominantly self-incompatible) behaviour of $C$. canephora. In search for drought tolerant genotypes in C. canephora, researchers have identified functional traits e.g., wood density (Menezes-Silva et al., 2015), rooting depth (Pinheiro et al., 2005) and results show that the traits are differentially affected in susceptible and tolerant genotypes when subjected to drought stress. But to date, research on the variation in drought tolerance among $C$. canephora genotypes has been limited to cultivated material and there seems no study on the systematic analysis of variation in drought tolerance of the species' wild genotypes. This thesis purposes to bridge this gap by exploring the response of $C$. canephora across the whole range of cultivation status by studying wild, feral (second generation or higher of formerly cultivated material and abandoned for over 50 years) and cultivated genotypes in Uganda.

\section{Trade-off between drought tolerance and growth}

In considering the potential utility of crop genetic resource in relation to drought stress, it is not only crucial to explore the ability of genotypes to survive and sustain production in dry spells but also its productivity in wetter years. This ultimately raises a question about the extent to which variation in drought tolerance and productivity across different genotypes are correlated. As noted above, many plant adaptations to dry conditions either come at the expense of photosynthesis (e.g. stomatal closure or dropping leaves) or maximum water transport (i.e., narrower vessels) or require energy (production larger root systems). Drought tolerance traits are thus generally linked to a conservative resource use strategy; a strategy in which plants require greater carbon investment in tissues i.e. development of thicker leaves and high lignin concentration. The strategy consequently limits maximum photosynthetic rates of the plant ultimately resulting into reduced growth rate but increased longevity of the tissues during stress (Reich, 2014, Wright et al., 2004, Poorter et al., 2009, Markesteijn et al., 2011, Niinemets, 2001).

Based on the observed morphological and physiological responses of cultivated $C$. canephora genotypes to drought stress (DaMatta et al., 2018, Menezes-Silva et al., 2015, Silva 
et al., 2013, Praxedes et al., 2006, Pinheiro et al., 2005, DaMatta et al., 2003), one could expect a trade-off between drought tolerance and growth because, as response to drought stress, plants adjust their functional equilibrium i.e. the root-shoot ratio; and/or stomatal conductance and water use efficiency. Such changes are reported to slow growth and ultimately affect productivity. In this thesis, the relationship between drought tolerance and growth of genotypes in ample water conditions was examined. Exploration of the existence of a tolerance and growth trade-off across wild populations of $C$. canephora is crucial because it would have implications on how and which material could be used for breeding.

\section{Link between drought tolerance and trait plasticity}

Recognizing that the environmental conditions in coffee production systems are becoming increasingly variable (Bunn et al., 2015), it is important to understand how coffee plants cope with the changing environmental conditions. The capacity of plants to cope with the changing environmental conditions is known to be linked phenotypic plasticity; i.e. the ability to adjust a phenotype to varying conditions (Nicotra et al., 2010, Hamrick, 2004, Abrams, 1994 ). Since phenotypic plasticity is partially genetically controlled, this indicates that it can be acted upon by natural selection, thereby determining the fitness of the plant population (Marshall and Jain, 1968). However, under fluctuating conditions, phenotypic plasticity may not always be beneficial for plants, and in fact the question whether and when it is beneficial is the subject of much ecological research (Bongers et al., 2017, Dudley and Schmitt, 1995 ). One important issue is the extent to which plastic phenotypic changes in the plant can adequately track variation in environmental conditions. For instance, a plant may respond to wet conditions (e.g. a wet season or a wet year), through phenotypic trait adjustments (e.g. producing few roots and many leaves with large stomates) which help increase performance under wet conditions. But these responses may have a degree of permanence, that is, they cannot be instantaneously undone. For example, once plants produce larger or more stomates on a given leaf they cannot change those traits on the same leaf. Additionally, trait adjustment due to environmental change are not instantaneous and require some time to take effect. Therefore, when conditions at a given moment become dry again, plants that had just plastically responded to the wet condition up to that moment, will to some extent, have the wrong phenotype and adjusting this phenotype can be costly. This potential trade-off between plasticity to variation in water availability and tolerance has been studied mostly across species (e.g. (Bongers et al., 2017, Baquedano et al., 2008, van Kleunen and Fischer, 2005). But as far as I know, it has rarely been studied across different genotypes of a tropical tree species, which 


\section{Chapter 1}

is important if one wants to determine the extent to which trait plasticity contributes to local climate adaptation. In this thesis, therefore, explored the relationship between intra-specific variations in plasticity in response to changes in water supply and drought tolerance, across several wild and cultivated C. canephora genotypes were explored.

\section{Potential of molecular biology tools to identify putatively adapted material}

Advancements in molecular biology and genomics has allowed for the availability of a C. canephora reference genome (Denoeud et al., 2014), which can facilitate genetic characterization of populations (Merot-l'Anthoene et al., 2019, Dereeper et al., 2015) and can support the evaluation of the genetic basis of populations' response to drought stress. Findings from Merot-l'Anthoene et al. (2019) established a possible link between C. canephora genetic variation and the differences in the environmental conditions across the geographic distribution of wild populations with contrasted habitats (Figure $1 \mathrm{~A}$ ). Occurrence of wild populations in geographically distinct zones favours local adaption driven by natural selection (Galloway and Fenster, 2000) and thus development of phenotypic and genetic signatures (Nielsen, 2005). These signatures of natural selection may include phenotypic traits, genes or genomic regions that are targeted by natural selection (Nielsen, 2005). For example, signatures of natural selection have been identified in drought-tolerant Solanum chilense (wild tomato) and its CWR Solanum peruvianum (Bondel et al., 2018, Nosenko et al., 2016, Fischer et al., 2013). Identification of drought adapted genotypes is vital for future coffee production because it is pivotal in the development of resilient cultivars that are better suited to new climatic conditions. Development of climate-resilient cultivars is likely to benefit from use of population genomics tools which support and perhaps quicken efforts geared towards detecting signatures of natural selection and genotypes putatively more resilient to climatic change. This could be achieved through identification of associations between loci (SNPs) and environmental variables or phenotypes i.e. genome wide association studies (De Kochko et al., 2010). Information about the genetic diversity and differential phenotypic responses of Uganda's C. canephora populations generated in this thesis could be utilized to support genome wide association studies in relation to drought stress.

\section{Motivation for this thesis}

Uganda is the largest producer and exporter of C. canephora (Robusta coffee) in Africa. Uganda's coffee sector comprises $C$. arabica and C. canephora, together contributing about 20 - $25 \%$ to national foreign trade (UCDA, 2015) and the whole coffee value chain sustains 3.5 
million households (UCDA, 2015). C. canephora accounts for $80 \%$ of the total coffee produced and exported from Uganda. Similar to other coffee producing areas, Uganda's coffee production is currently constrained by the adverse effects of climate change most especially by frequent and severe droughts (UCDA, 2015, UCDA, 2017b, Bunn et al., 2019) which may be attributed to erratic precipitation patterns and rising temperatures. The detrimental effects of droughts on Uganda's coffee production are occuring at the time when the government is devoted to increase the national coffee production from the current 4.2 (previously 3.5) million $60 \mathrm{~kg}$ bags to 20 million bags by 2030 (UCDA, 2015, UCDA, 2017b). In order to realise the 20 million bags by 2030 , the Uganda coffee road map provides that there is need to improve the quality of planting materials and their resilience to adverse production challenges, e.g. drought.

As already mentioned, the ability of crops to adapt to environmental changes, such as the increased occurrence or more severe drought, depends on the genetic variation that exists within the crop. Uganda's C. canephora populations occur within the drier end (Figure 1 ) of the global natural distribution of the species diversity (Merot-l'Anthoene et al., 2019, Pegard et al., 2014, Gomez et al., 2009). Additionally, within Uganda, C. canephora occurs in constrasting climatic zones (Figure $1 \mathrm{C}$ ), which suggests that genotypes might be differentially adapted in regards to drought stress. The environmental gradient across the populations is expected to be the selection force to the genetic differentiation and thus morphological and physiological adaptation of the populations to drought stress. The research questions of this thesis are thus motivated by my need to contribute to sustainable coffee production in Uganda, amidst the frequent droughts, by unveiling the diversity and potential of locally available Uganda's C. canephora genetic resources to thrive under ample and restricted-water supply. In future research, a subset of potentially interesting diversity could be further studied and utilised by the breeding system to develop resilient $C$. canephora varieties for farmer adoption.

\section{Main research questions of the thesis}

The goal of this thesis is to characterize Ugandan's C. canephora diversity in relation to its response to drought stress. To achieve this goal, studies were undertaken to answer seven research questions:

1. What is the genetic diversity and population structure of Uganda's C. canephora natural populations (Chapter 2)?

2. Is there a relationship between allelic variation and the climatic profiles of Uganda's $C$. canephora populations (Chapter 2)? 
3. What is the phenotypic variation in C. canephora responses to drought stress (chapter 3)?

4. What is the relationship between performance in ample and restricted water conditions (Chapter 3)?

5. Is the drought tolerance of the genotypes related to the climatic gradient across their habitats (Chapter 3)?

6. What is the phenotypic variation in trait plastic responses to drought stress (Chapter 4)?

7. What is the relationship between drought tolerance and phenotypic plasticity (Chapter 4)?

\section{Outline of the thesis}

This thesis comprises five chapters: Chapter 1 is the General Introduction, which provides an overview of the thesis, Chapters 2 to 4 present findings of the specific studies answering the research questions of the thesis (Figure 2). Chapter 5 presents the General Discussion that conceptualizes the results of the thesis. In Chapter 2, using 19 diversity linked SSR markers, we genotyped a total of 275 Ugandan accessions collected from seven wild forests (occuring along a climatic gradient), one feral (second generation or higher of formerly cultivated material and abandoned for over 50 years) location and individuals under cultivation in two ex-situ conservation fields at two research institute (for cultivated material). We analysed the genetic diversity and the population structure of Uganda's $C$. canephora and its position within the species global genetic structure. We examined the extent to which wild populations were genetically distinct from feral and cultivated material and the relationship between allelic variation and the climatic envelope. In Chapter 3, using data from a large screen-house experiment, we analysed the intraspecific variation in selected growth-related traits of $C$. canephora in response to drought stress. The study material was categorized by level of cultivation status, genetic groups and location. We also explored differences in drought tolerance between genetic groups and between cultivated, feral and wild material. The latter study too provides insights into whether the level of cultivation status and breeding may have selected for or against drought tolerance. Finally, we explored the extent to which drought tolerance and growth potential were correlated and the link between drought tolerance and the climatic gradient across locations. In Chapter 4, using a green-house experiment on 15 selected genotypes, we explored the extent of phenotypic variation in trait plastic responses and the relationship between drought tolerance and trait plasticity. Finally, in Chapter 5 (General Discussion), we synthesize the main findings from Chapters 2, 3 and 4 in relation to other studies and the overall goal of this thesis. We provide recommendations for further research, 
conservation and utilization of Uganda's C. canephora populations in developing drought tolerant cultivars. 


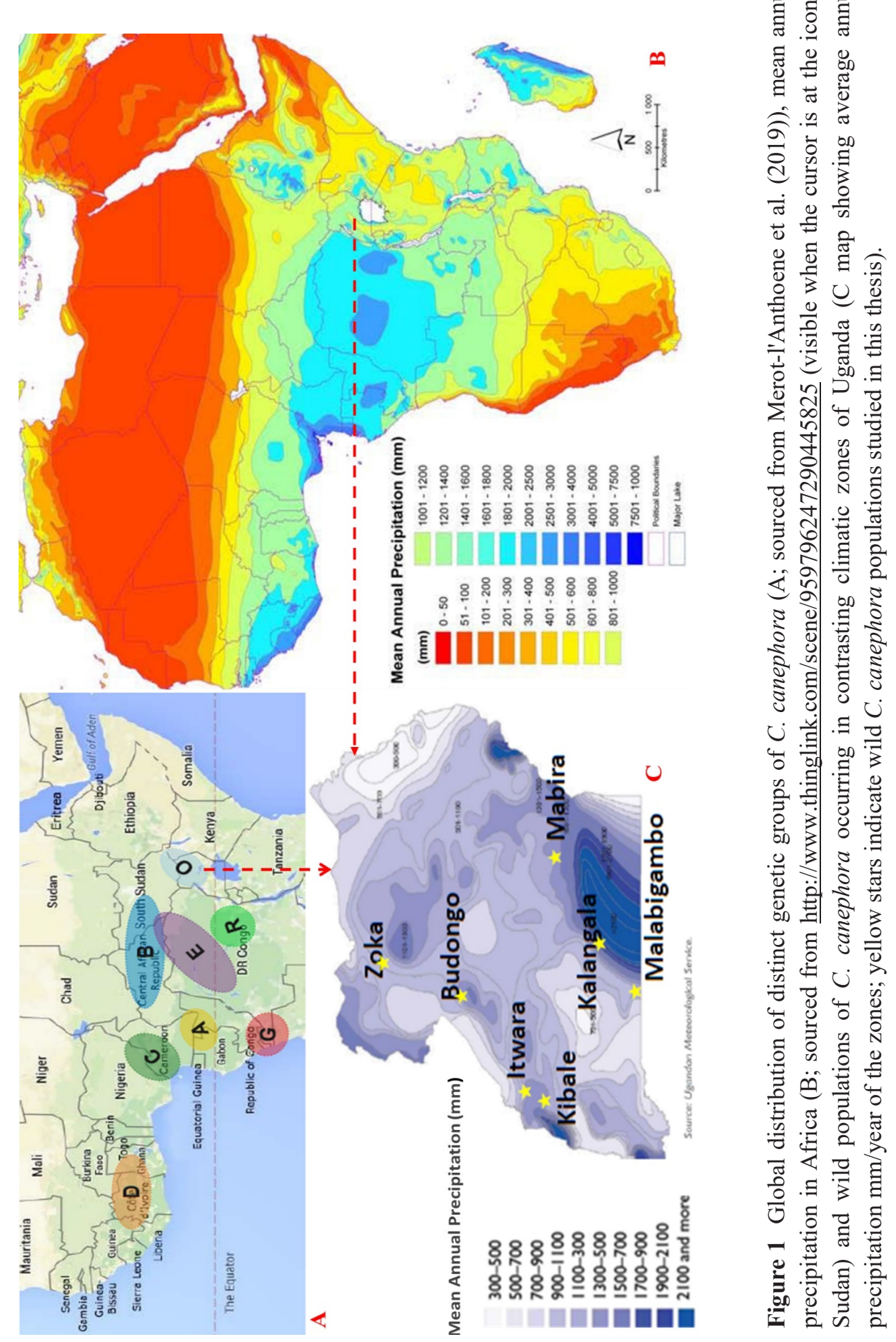




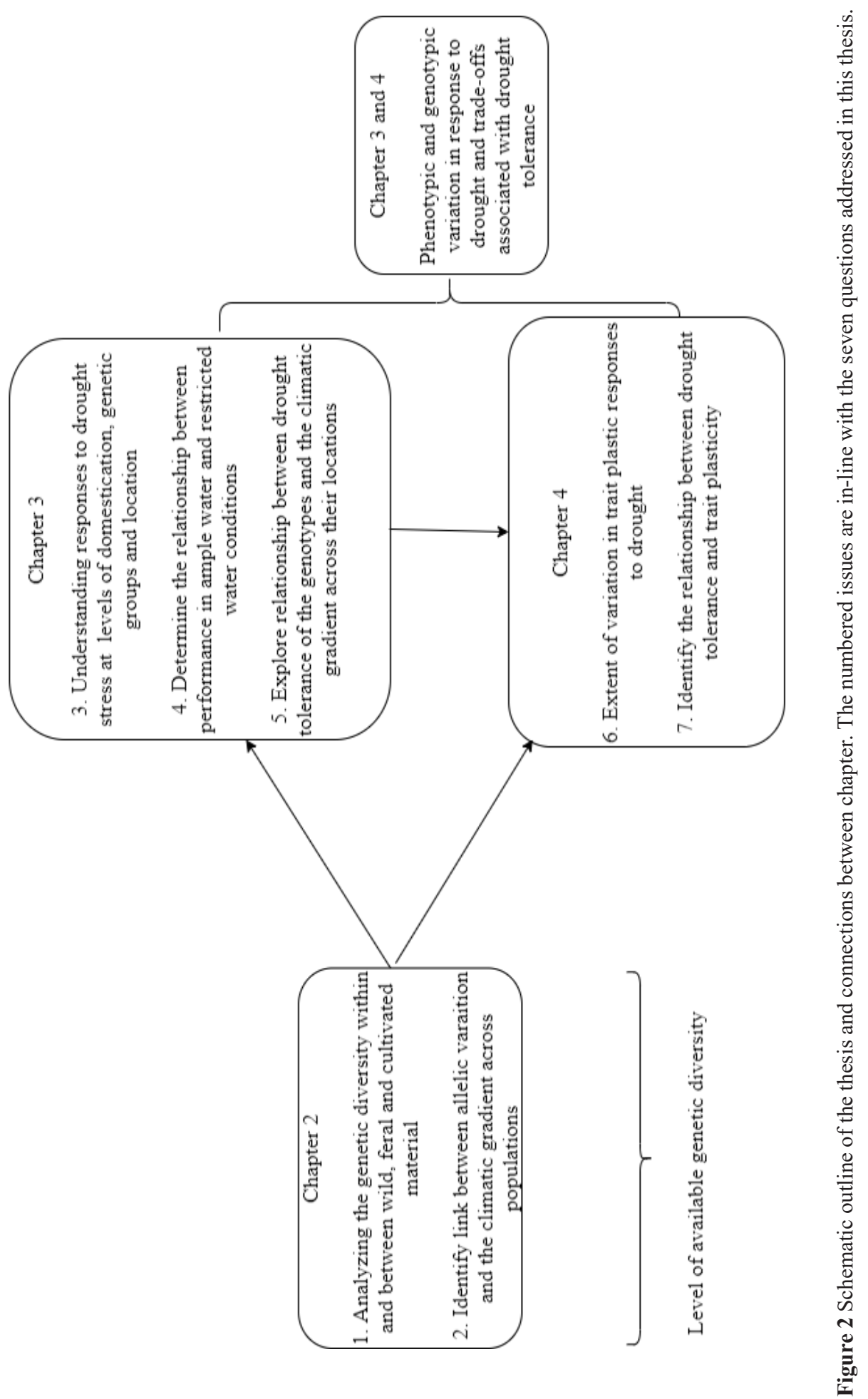




\section{References}

Abrams MD. 1994 Genotypic and phenotypic variation as stress adaptations in temperate tree species: a review of several case studies. Tree Physiology 14: 833-842.

Alberto F, Bouffier L, Louvet JM, Lamy JB, Delzon S, Kremer A. 2011. Adaptive responses for seed and leaf phenology in natural populations of sessile oak along an altitudinal gradient. Journal of Evolutionary Biology, 24: 1442-54.

Baquedano FJ, Valladares F, Castillo FJ. 2008. Phenotypic plasticity blurs ecotypic divergence in the response of Quercus coccifera and Pinus halepensis to water stress. European Journal of Forest Research, 127: 495-506.

Beer J, Muschler R, Kass D, Somarriba E. 1998. Shade management in coffee and cacao plantations. Agroforestry Systems, 38: 139-164.

Beining A. 2008. Ecophysiological diversity of wild Coffea arabica populations in Ethiopia: drought adaptation mechanisms. , Ph.D., University of Bonn, Germany.

Berthaud J. 1986. Les ressources genetiques pour l'amelioration des cafeires africains diploides: Orstom Paris.

Bondel KB, Nosenko T, Stephan W. 2018. Signatures of natural selection in abiotic stressresponsive genes of Solanum chilense. $R$ Soc Open Sci, 5: 171198.

Bongers FJ, Olmo M, Lopez-Iglesias B, Anten NPR, Villar R. 2017. Drought responses, phenotypic plasticity and survival of Mediterranean species in two different microclimatic sites. Plant Biology, 19: 386-395.

Bunn C, Läderach P, Ovalle Rivera O, Kirschke D. 2015. A bitter cup: climate change profile of global production of Arabica and Robusta coffee. Climatic Change, 129: 89101.

Bunn CL, M; Läderach, P; Fernández P; Castro-Llanos, F. 2019., Bunn C, Lundy M, Läderach P, Fernandez P, Castro-Llanos F. 2019. Climate-smart Coffee in Uganda. . International Center for Tropical Agriculture (CIAT), Cali, Colombia.

Burkhardt J, Beining AM, Kufa T, Goldbach H. 2006. Different drought adaptation strategies of Coffea arabica populations along a rainfall Gradient in Ethiopia. Prosperity and Poverty in a Globalised World - Challenges for Agricultural Research. Tropentag, Bonn.

Cannell MGR. 1985 Physiology of the Coffee Crop. . Coffee.

Charrier A, Berthaud J. 1985. Botanical Classification of Coffee. Coffee.

Coste R. 1992. Coffee; the plant and product. London: Macmillan Press Ltd.

DaMatta FM. 2004. Ecophysiological constraints on the production of shaded and unshaded coffee: a review. Field Crops Research, 86: 99-114.

DaMatta FM. 2018. Coffee tree growth and environmental acclimation. Achieving sustainable cultivaiton of coffee.

DaMatta FM, Avila RT, Cardoso AA, Martins SCV, Ramalho JC. 2018. Physiological and agronomic performance of the coffee crop in the context of climate change and global warming: A review. Journal of Agricultural and Food Chemistry, 66: 5264-5274.

DaMatta FM, Chaves ARM, Pinheiro HA, Ducatti C, Loureiro ME. 2003. Drought tolerance of two field-grown clones of Coffea canephora. Plant Science, 164: 111-117.

DaMatta FM, Ramalho JD, Cochicho,. 2006. Impacts of drought and temperature stress on coffee physiology and production: a review. Braz. J. Plant Physiol. , 18: 55-81.

DaMatta FM, Ramalho JDC. 2006. Impacts of drought and temperature stress on coffee physiology and production: a review. Brazilian Journal of Plant Physiology, 18: 55-81.

DaMatta FM, Ronchi PC, Maestri M, Barros SR. 2007. Ecophysiology of Coffee Growth and Production. Brazillian Journal Plant Physiology, 19: 485-510. 
Davis AP, Chadburn H, Moat J, O'Sullivan R, Hargreaves S, Lughadha EN. 2019. High extinction risk for wild coffee species and implications for coffee sector sustainability. Science Advances, 5.

Davis AP, Gole TW, Baena S, Moat J. 2012. The impact of climate change on indigenous Arabica coffee (Coffea arabica): predicting future trends and identifying priorities. PLoS One, 7.

Davis AP, Govaerts R, Bridson DM, Stoffelen P. 2006. An annotated taxonomic conspectus of the genus Coffea (Rubiaceae). Botanical Journal of the Linnean Society, 152: 465512.

De Kochko A, Akaffou S, Andrade AC, Campa C, Crouzillat D, Guyot R, Hamon P, Ming R, Mueller LA, Poncet V, Tranchant-Dubreuil C, Hamon S. 2010. Advances in Coffea Genomics.

Dempewolf H, Baute G, Anderson J, Kilian B, Smith C, Guarino L. 2017. Past and Future Use of Wild Relatives in Crop Breeding. Crop Science, 57.

Denoeud F, Carretero-Paulet L, Dereeper A, Droc G, Guyot R, Pietrella M, Zheng C, Alberti A, Anthony F, Aprea G, Aury JM, Bento P, Bernard M, Bocs S, Campa C, Cenci A, Combes MC, Crouzillat D, Da Silva C, Daddiego L, De Bellis F, Dussert S, Garsmeur O, Gayraud T, Guignon V, Jahn K, Jamilloux V, Joet T, Labadie K, Lan T, Leclercq J, Lepelley M, Leroy T, Li LT, Librado P, Lopez L, Munoz A, Noel B, Pallavicini A, Perrotta G, Poncet V, Pot D, Priyono, Rigoreau M, Rouard M, Rozas J, Tranchant-Dubreuil C, VanBuren R, Zhang Q, Andrade AC, Argout X, Bertrand B, de Kochko A, Graziosi G, Henry RJ, Jayarama, Ming R, Nagai C, Rounsley S, Sankoff D, Giuliano G, Albert VA, Wincker P, Lashermes P. 2014. The coffee genome provides insight into the convergent evolution of caffeine biosynthesis. Science, 345: 1181-4.

Dereeper A, Bocs S, Rouard M, Guignon V, Ravel S, Tranchant-Dubreuil C, Poncet V, Garsmeur O, Lashermes P, Droc G. 2015. The coffee genome hub: a resource for coffee genomes. Nucleic Acids Res, 43: D1028-35.

Dudley SA, Schmitt J. 1995 Genetic Differentiation in Morphological Responses to Simulated Foliage Shade between Populations of Impatiens capensis from Open and Woodland Sites. Functional Ecology, 9: 655-666.

Fischer I, Steige KA, Stephan W, Mboup M. 2013. Sequence evolution and expression regulation of stress-responsive genes in natural populations of wild tomato. PLoS One, 8: e78182.

Galloway FL, Fenster BC. 2000. Population differentiation in an annual legume: Local adaptation. Evolution, 54: 1173-1181.

Gomez C, Dussert S, Hamon P, Hamon S, Kochko A, Poncet V. 2009. Current genetic differentiation of Coffea canephora Pierre ex A. Froehn in the Guineo-Congolian African zone: cumulative impact of ancient climatic changes and recent human activities. BMC Evolutionary Biology, 9: 167.

Haggar J, Schepp K. 2012. Coffee and Climate Change

Impacts and options for adaption in Brazil, Guatemala, Tanzania and Vietnam. NRI Working Paper Series: Climate Change, Agriculture and Natural Resources.

Hamrick JL. 2004. Response of forest trees to global environmental changes. Forest Ecology and Management, 197: 323-335.

Harlan JR, de Wet JMJ. 1971. Toward a Rational Classification of Cultivated Plants. Taxon, 20: $50-517$.

ICO. 2014. World coffee trade (1963 - 2013): A review of the markets, challenges and opportunities facing the sector. International Coffee Organisation.

ICO. 2018. Trade Statistics. International Coffee Organization. 
ICO. 2019a. Coffee Development Report. Growing Prosperity - Economic viability as the catalyst for a sustainable coffee sector

London. International Coffee Organisation.

ICO. 2019b. Coffee market report June 2019. ICO: International Coffee Organization.

IPCC. 2014. Proceedings of the 5th Assessment Report, WGII, Climate Change 2014: Impacts, Adaptation, and Vulnerability. Cambridge, U.K.

IPCC. 2018. Global warming of $1.5^{\circ} \mathrm{C}$. An IPCC Special Report on the impacts of global warming of $1.5^{\circ} \mathrm{C}$ above pre-industrial levels and related global greenhouse gas emission pathways, in the context of strengthening the global response to the threat of climate change, sustainable development, and efforts to eradicate poverty In: V. Masson-Delmotte, P. Zhai, H. O. Pörtner, D. Roberts, J. Skea, P.R. Shukla, A. Pirani, W. Moufouma-Okia, C. Péan, R. Pidcock, S. Connors, J. B. R. Matthews, Y. Chen, X. Zhou, M. I. Gomis, E. Lonnoy, T. Maycock, M. Tignor, Waterfield T, eds.

Lambers H, Chapin FI, Pons T. 1998 Plant Physiological Ecology: Springer.

Lewin B, Giovannucci D, Varangis P. 2004. Coffee Markets: New Paradigms in Global Supply and Demand.

Markesteijn L, Poorter L, Bongers F, Paz H, Sack L. 2011. Hydraulics and life history of tropical dry forest tree species: coordination of species' drought and shade tolerance. New Phytol, 191: 480-95.

Marshall DR, Jain SK. 1968. Phenotypic Placticity of Avena fatua and A. barbata. The American Naturalist, 102: 457-467.

Martins MQ, Rodrigues WP, Fortunato AS, Leitão AE, Rodrigues AP, Pais IP, Martins LD, Silva MJ, Reboredo FH, Partelli FL, Campostrini E, Tomaz MA, ScottiCampos P, Ribeiro-Barros AI, Lidon FJC, DaMatta FM, Ramalho JC. 2016. Protective Response Mechanisms to Heat Stress in Interaction with High [CO2] Conditions in Coffea spp. Frontiers in Plant Science, 7.

Maxted N, Ford-Lloyd BV, Jury S, Kell S, Scholten M. 2006. Towards a definition of a crop wild relative. Biodiversity and Conservation, 15: 2673-2685.

Menezes-Silva PE, Cavatte PC, Martins SCV, Reis JV, Pereira LF, Ávila RT, Almeida AL, Ventrella MC, DaMatta FM. 2015. Wood density, but not leaf hydraulic architecture, is associated with drought tolerance in clones of Coffea canephora. Trees, 29: 1687-1697.

Merot-l'Anthoene V, Tournebize R, Darracq O, Rattina V, Lepelley M, Bellanger L, Tranchant-Dubreuil C, Coulee M, Pegard M, Metairon S, Fournier C, Stoffelen P, Janssens SB, Kiwuka C, Musoli P, Sumirat U, Legnate H, Kambale JL, Ferreira da Costa Neto J, Revel C, de Kochko A, Descombes P, Crouzillat D, Poncet V. 2019. Development and evaluation of a genome-wide Coffee $8.5 \mathrm{~K}$ SNP array and its application for high-density genetic mapping and for investigating the origin of Coffea arabica L. Plant Biotechnology Journal, 17: 1418-1430.

Nicotra AB, Atkin OK, Bonser SP, Davidson AM, Finnegan EJ, Mathesius U, Poot P, Purugganan MD, Richards CL, Valladares F, van Kleunen M. 2010. Plant phenotypic plasticity in a changing climate. Trends in Plant Science, 15: 684-692.

Nielsen R. 2005. Molecular signatures of natural selection. Annu Rev Genet, 39: 197-218.

Niinemets U. 2001. Global-scale climatic controls of leaf dry mass per area, density, and thickness in trees and shrubs. Ecology 82 453-469

Nosenko T, Bondel KB, Kumpfmuller G, Stephan W. 2016. Adaptation to low temperatures in the wild tomato species Solanum chilense. Mol Ecol, 25: 2853-69.

Pegard M, De Kochko A, Merot-L'anthoene V, Tranchant C, Rigoreau M, Bellanger L, Legnate H, Amoncho A, Akaffou S, Musoli P, Manel S, Crouzillat D, Poncet V. 2014. Genetic diversity of Coffea canephora and selection of genotypes potentially 
resilient to climatic changes. 25th International Conference on Coffee Science Armenia (Colombia).

Pinheiro HA, Damatta FM, Chaves AR, Loureiro ME, Ducatti C. 2005. Drought tolerance is associated with rooting depth and stomatal control of water use in clones of Coffea canephora. Ann Bot, 96: 101-8.

Pironon S, Etherington T, R., Borrell J, S., Nicola K, Macias-Fauria M, Ondo I, Tovar C, Wilkin P, Willis K, J. . 2019. Potential adaptive strategies for 29 sub-Saharan crops under future climate change. Nature Climate Change 758-763

Poorter H, Niinemets Ü, Poorter L, Wright IJ, Villar R. 2009. Causes and consequences of variation in leaf mass per area (LMA): a meta-analysis. New Phytologist, 182: 565-588.

Praxedes SC, DaMatta FM, Loureiro ME, G. Ferrão MA, Cordeiro AT. 2006. Effects of long-term soil drought on photosynthesis and carbohydrate metabolism in mature robusta coffee (Coffea canephora Pierre var. kouillou) leaves. Environmental and Experimental Botany, 56: 263-273.

Reich PB. 2014. The world-wide 'fast-slow' plant economics spectrum: a traits manifesto. Journal of Ecology, 102: 275-301.

Rodrigues WP, Martins MQ, Fortunato AS, Rodrigues AP, Semedo JN, Simões-Costa MC, Pais IP, Leitão AE, Colwell F, Goulao L, Máguas C, Maia R, Partelli FL, Campostrini E, Scotti-Campos P, Ribeiro-Barros AI, Lidon FC, DaMatta FM, Ramalho José C. 2016. Long-term elevated air [CO2] strengthens photosynthetic functioning and mitigates the impact of supra-optimal temperatures in tropical Coffea arabica and C. canephora species. Global Change Biology, 22: 415-431.

Silva MdC, Várzea V, Guerra-Guimarães L, Azinheira HG, Fernandez D, Petitot A-S, Bertrand B, Lashermes P, Nicole M. 2006. Coffee resistance to the main diseases: leaf rust and coffee berry disease. Brazilian Journal of Plant Physiology, 18: 119-147.

Silva PEM, Cavatte PC, Morais LE, Medina EF, DaMatta FM. 2013. The functional divergence of biomass partitioning, carbon gain and water use in Coffea canephora in response to the water supply: Implications for breeding aimed at improving drought tolerance. Environmental and Experimental Botany, 87: 49-57.

Taye KO. 2006. Ecophysiological diversity of wild Arabica coffee populations in Ethiopia Growth, water relations and hydraulic characteristics along a climatic gradient.

Tesfaye SG, Ismail MR, Ramlan MF, Marziah M, Kausar H. 2014. Effect of soil drying on rate of stress development, leaf gas exchange and proline accumulation in robusta coffee (Coffea Canephora Pierre Ex Froehner) Clones. Experimental Agriculture, 50: 458-479.

Torang P, Wunder J, Obeso JR, Herzog M, Coupland G, Agren J. 2015. Large-scale adaptive differentiation in the alpine perennial herb Arabis alpina. New Phytol, 206: 459-70.

UCDA. 2015. Corporate Plan 2015/16 - 2017/18. Kampala: Uganda Coffee Development Authority.

UCDA. 2017. Annual Report 2016/17. Kampala: Uganda Coffee Development Authority.

van Kleunen M, Fischer M. 2005. Constraints on the evolution of adaptive phenotypic plasticity in plants. New Phytologist, 166: 49-60.

Willson K. 1999. Coffee, cocoa and tea. Wallingford: CAB International.

Wintgens JN. 2004. Coffee: growing, processing, sustainable production, A guidebook for growers, processors, traders, and researchers. Weinhein, Alemania: WILEY-VCH Verlag GmbH \& Co. KGaA.

Wright IJ, Reich PB, Westoby M, Ackerly DD, Baruch Z, Bongers F, Cavender-Bares J, Chapin T, Cornelissen JHC, Matthias D, Flexas J, Garnier E, Groom PK, Gulias J, Hikosaka K, Lamont BB, Lee T, Lee W, Lusk C, Midgley JJ, Navas M-L, Niinemets Ul, Oleksyn J, Osada N, Poorter H, Poot P, Prior L, Pyankov VI, 
Roumet C, Thomas SC, Tjoelker MG, Veneklaas EJ, Villar R. 2004. Worldwide leaf economics spectrum. Nature $\mathbf{4 2 8}$.

Zhou Y, Zhang L, Liu J, Wu G, Savolainen O. 2014. Climatic adaptation and ecological divergence between two closely related pine species in Southeast China. Mol Ecol, 23: 3504-22.

Zullo J, Pinto HS, Assad ED, de Ávila AMH. 2011. Potential for growing Arabica coffee in the extreme south of Brazil in a warmer world. Climatic Change, 109: 535-548. 


\section{Chapter 2}

\section{Genetic diversity of native and cultivated Ugandan}

\section{Robusta coffee (Coffea canephora Pierre ex A. Froehner).}

A perspective into potential utilization and conservation of

the diversity.

This chapter status is revision invited for PLOS One as Kiwuka C, Goudsmit, de Aquino S, Douma, JC, Crouzillat D,Stoffelen P, de Kochko A, Sumirat U, Legante H, Andrade AC, Mulumba JW, A, Musoli M, Anten NPR, Poncet V Genetic diversity of native and cultivated Ugandan Robusta coffee (Coffea canephora Pierre ex. A, Froehner). A perspective into potential utilization and conservation of the diversity 


\title{
Chapter 2
}

\begin{abstract}
Wild genetic resources and their ability to adapt to environmental change are features of upmost importance in the current climate change setting, while constituting the foundation of agricultural sustainability. To address the expected negative effects of climate change on Robusta coffee trees (Coffea canephora), collecting missions were conducted to explore its present day native distribution in Uganda over a broad climatic range. Finally, material from seven forests was assessed, together with that from two ex-situ collections and from a feral location. We used 19 microsatellite (SSR) markers to assess their genetic diversity and structure and position Ugandan C. canephora diversity relative to the species' global diversity structure. Twenty-two climatic variables were used to explore variations in climatic zones across the sampled forests. Ugandan populations occurred in significantly divergent environmental conditions and 12 environmental variables significantly explained $16.3 \%$ of the total allelic variation across populations. Overall, Uganda's native C. canephora diversity differs from other known genetic groups of this species. Four distinct genetic clusters whose diversity was not represented in the collections were from Zoka, Budongo, Itwara and Kibale forests in North-western (NW) Uganda. A large Southern-central (SC) cluster included Malabigambo, Mabira, and Kalangala forest accessions, as well as feral and cultivated accessions, suggesting gene flow between wild and cultivated compartments. We also confirmed the introduction of Congolese varieties into the SC region where most Robusta coffee production takes place. This substantial genetic variation within and between Ugandan populations might contain adaptive traits that could be used to enhance the resilience potential of $C$. canephora production against the backdrop of climate change. For ex-situ conservation, accessions collected during our missions have enriched the diversity hosted in the Kituza and Entebbe collections. However, there is an urgent need to develop strategies to enhance complementary in-situ conservation of native forests in north western Uganda.
\end{abstract}

Keywords: Coffea canephora, Robusta, Uganda, conservation, common garden, Wild crop relatives (WCR) 


\section{Introduction}

Coffee is a major global commodity and the total value of its industry was estimated at estimated to surpass US\$200 billion in calendar year 2017 (Samper et al., 2017). The coffee industry is mainly (99\%) supported by two Coffea species Coffea arabica and Coffea canephora (DaMatta et al., 2018). Uganda accounts for 7\% of the global Coffea canephora exports and the whole coffee sector sustains about 8 million Ugandans (UCDA, 2017a). The sustainability of Uganda's C.canephora production is thus of major importance, globally and nationally particularly for the smallholder farmers (Millard, 2017). Unfortunately, the sustainability of the global coffee industry is threatened by adverse effects of climate change, especially drought, increasing temperature, pest and disease pressure (Davis et al., 2012, Moat et al., 2017, DaMatta et al., 2018). A global increase of $2.1^{\circ} \mathrm{C}$ in temperature has been predicted by 2050 (Parry et al., 2007, IPCC, 2014) while rainfall is expected to become more erratic, with more frequent and severe drought periods, which will render conditions in some coffee growing areas less suitable, seriously affecting coffee production (Bunn et al., 2015, Gay et al., 2006, Craparo et al., 2015, Ovalle-Rivera et al., 2015).

The ability of crops to adapt to environmental challenges, such as the effects of climate change, depends on the genetic variation that exists within the crop. The resilience potential of all crop production systems is anchored by the intraspecific trait diversity that has evolved in the species' natural habitat (Warschefsky et al., 2014). There has been a steady increase in the use of crop wild relatives (CWR) to improve the adaptive pontential and resistance of crops to pest and diseases and evidence can be seen in wheat and tomato whose improved cultivars include genes from their wild relatives (Hajjar and Hodgkin, 2007). As the effects of climate change set in, use of congeneric and conspecific wild coffee variants is becoming of primary importance to confer tolerance and resilience to C. arabica and C. canephora (Davis et al., 2019, Brozynska et al., 2016). To further the use of wild variants for coffee improvement, the genetic diversity that exists within the natural habitats needs to be explored.

C. canephora is a diploid $(2 \mathrm{n}=2 \mathrm{x}=22)$, self-incompatible species (Charrier and Berthaud, 1985). The natural distribution range of $C$. canephora stretches from Guinea in the West to Uganda in the East and to Angola in the South (Davis et al., 2006). Among the Coffea species, C. canephora has the widest distribution range and climatic range e.g. a 3-fold difference in the rainfall distribution range. Development of tools such as DNA marker (e.g. SSR, RFLP, RAPD) or SNP markers derived from DNA sequencing has enabled researchers to 


\section{Chapter 2}

further understand the phylogenetic relationships between different Coffea species (Davis et al., 2011, Hamon et al., 2017) and the relationships within wild populations of $C$. canephora (Merot-l'Anthoene et al., 2019, Gomez et al., 2009). Genetic characterization of C. canephora diversity has greatly been facilitated by availability of a large repository of simple sequence repeats (SSRs) based microsatellite markers, which provides efficiency and high-resolution in genetic analyses (Hendre and Aggarwal, 2014, Moncada and McCouch, 2004, Poncet et al., 2007). Globally, the genetic diversity C. canephora is linked to the geographical location (Merot-l'Anthoene et al., 2019, Gomez et al., 2009, Cubry et al., 2012, Berthaud, 1986, Dussert et al., 1999). Initially, using isoenzymes (allozymic surveys), the diversity of C. canephora was delimited into two different genetic groups namely: (i) Guinean group which includes wild populations from Ivory Coast and (ii) Congolese group which composed of samples from the Central African Republic and Cameroon (Berthaud, 1986). Using restriction length polymorphism markers (RFLP) and microsatellite markers, Gomez and al. (2009) delimited $C$. canephora genetic diversity into five genetic groups namely: A, B, C, D and E. Geographically, genetic group A comprised wild populations from Congo and Cameroon; group B: from East central Africa; group C: samples from West-Central Africa, Cameroon and North-East Congo; group E: samples from Congo and South Cameroon) while group D comprised wild populations from Ivory Coast and Guinea. Musoli et al. (2009a) further determined that some Ugandan wild populations clustered into another distinct group. Finally, Merot-l'Anthoene et al. (2019), using a genome-wide Coffee $8.5 \mathrm{~K}$ SNP array, established a description of C. canephora genetic diversity with eight distinct genetic groups, including the Ugandan one (group O) and thus identifying two new genetic groups; R (comprising samples from southern Democratic Republic of Congo) and G (comprising samples from Angola); although differentiation between groups $\mathrm{E}$ and $\mathrm{R}$ was weaker.

Uganda lies within a dry geographic range of the $C$. canephora distribution and the wild populations occur in five distinct precipitation climatic zones as described by Basalirwa (1995). Wild Ugandan $C$. canephora populations therefore, likely differentially evolved in respect to the environmental gradient. This suggests that there is substantial genetic variation within and across Ugandan populations that could be explored for its functional importance relative to climate change and other production challenges. Efforts to unravel Uganda's C. canephora genetic diversity have been partially accomplished by Musoli et al. (2009a), who reported that wild and cultivated individuals were clearly delineated and that genetic diversity (allelic richness and heterozygosity) was higher in cultivated than in wild compartments. However, 
Musoli et al. (2009a)'s studied only two wild populations (from Itwara and Kibale forests) and thus did not include the whole range of the wild Ugandan populations and could not link the genetic variation to the environmental gradient. In the present study, we collected samples representing most of the present day native distribution of C. canephora in Uganda across a broad climatic range and we also included material from the ex-situ collections that that underpin the on-going Ugandan coffee breeding program.

We aimed to decipher the genetic diversity, population structure of Uganda's $C$. canephora, while to characterizing the environmental envelopes that delineate the distribution the population distributions across the whole geographic range. We more specifically aimed to: (i) determine the level of genetic diversity, population structure and the genetic relationship between wild, feral and cultivated C. canephora genotypes (ii) position Uganda's C. canephora diversity into the global diversity structure of the species (iii) identify the relationship between the genetic structure of Ugandan C. canephora wild populations with their climatic profiles.

\section{Materials and Methods}

\section{Study area and field sampling}

The annual precipitation records broadly categorized Uganda into five distinct climatic zones (Matete and BakamaNume, 2010, Basalirwa, 1995, NEMA, 2009), namely: (i) Karamoja (receives 500 - $750 \mathrm{~mm}$ ), (ii) Acholi (receives 750 -1000 mm), Lake Victoria (receives 1000 $1500 \mathrm{~mm}$ ), Ankole Southern (1500 - $2000 \mathrm{~mm}$ ) and Western Uganda Zone (> $2500 \mathrm{~mm})$. Three of the five broad climatic zones: Lake Victoria, Ankole - Southern and Western Uganda are important for the occurrence of wild and cultivated populations of Coffea canephora. Following Musoli et al. (2009a), a hierarchical sampling strategy was applied to collect samples that represent $C$. canephora's distribution in these three distinct climatic zones. Wild samples were collected and geo-referenced from seven natural forests: Zoka, Budongo, Itwara, Kibale, Mabira, Malabigambo and Kalangala (Figure 1). In each targeted forest, samples were collected from five sub-sites that were separated by distances of at least $5 \mathrm{~km}$. At each sub-site, a minimum of five healthy trees were identified from which we collected leaves for DNA extraction. Additional individuals described as feral (formerly cultivated and abandoned for over 50 years) or cultivated were also collected. All the feral samples of the study were collected from two different islands; Bunyama and Bugala Islands of Kalangala district. The feral samples were collected from six different sub-sites separated by $10 \mathrm{~km}$ and they were located at least $0.5 \mathrm{~km}$ to $2 \mathrm{~km}$ from the edges of the Islands. Thus, Kalangala study site had both wild 


\section{Chapter 2}

and feral populations. The cultivated set was represented by a total of 52 samples collected from the assembled germplasm field collections of the National Agricultural Research Organization (NARO), comprised; 32 samples from Kituza and 20 samples from Kawanda. The sampled genotypes were selected based on their historical and passport data with the aim of representing the total range of traditional and commercially cultivated $C$. canephora diversity, including both Erecta and Nganda types. The 269 materials collected for the study are presented in Table 1. We assessed the genetic position of these Ugandan C. canephora accessions within the overall species diversity by comparing them with a representative set from the $C$. canephora diversity groups, as previously defined with the same SSR markers or the SNP array (Gomez et al., 2009, Merot-l'Anthoene et al., 2019) (Supplementary Table 1).

\section{DNA isolation and genotyping assay}

Silica dried leaves from all the 269 study samples were ground in liquid nitrogen by use of a mortar and pestle. DNA was extracted using the DNeasy® Plant Maxi kit; QIAGEN, with few adjustments to tailor it for dry leaf material. Extractions were performed by adding doubled amounts of both AP1 and P3 buffers. Nuclear genetic variation was assessed at 19 single sequence repeats (SSRs) loci (Supplementary Table 2). These markers were selected based on their capacity to discriminate a subset of C. canephora genotypes from different genetic groups. The PCR amplification conditions and all information on the markers are given in MoccaDB, an integrative database for functional, comparative and diversity studies in the Rubiaceae family (http://moccadb.ird.fr/ (Plechakova et al., 2009, Merot-l'Anthoene et al., 2019) and in the coffee genome hub (Dereeper et al., 2015).

\section{Data analysis}

\section{Climatic envelope of study sites}

Twenty-two environmental variables were retrieved for each georeferenced wild sample and used as predictors to characterize the climatic characteristics of each study site. Nineteen out of the 22 environmental variables were taken from a world-wide climatic database (WorldClim database see below), and the three others: altitude, aridity index (AI: which quantifies the availability of precipitation over atmospheric water demand) and potential evapotranspiration (PET: a measure of the ability of the atmosphere to remove water through evapotranspiration) (Supplementary Table 3).These variables were selected as they encompass primary climate factors and variation, so they have an important impact on the ecophysiology 
of the species (Graham and Hijmans, 2006). The 19 bioclimatic variables averaged for the years 1950-2000 were downloaded from WorldClim database (www.worldclim.org) at 30 arc-second resolution (Hijmans et al., 2005). Data for altitude was collected from the field using a Global positioning system (GPS; Garmin eTrex 10 Navigation device). Aridity index, and Potential Evapo-Transpiration (PET) values were sourced from the Global-Aridity dataset (Zomer et al., 2008). PET values were calculated following Hargreaves and Samani (1985) who used mean monthly temperature, mean monthly temperature range and mean monthly extra-terrestrial radiation, while Aridity Index was estimated as a ratio of Mean Annual Precipitation to Mean Annual Potential Evapo-Transpiration (Zomer et al. 2008). The formula for PET and AI are:

Evapo-Transpiration:

$P E T=0.0023 * \mathrm{RA} *\left(T_{\text {mean }}+17.8\right) * \mathrm{TD}^{0.5}(\mathrm{~mm} / \mathrm{d})$

where: $R A=$ Mean monthly extra-terrestrial radiation, $T_{\text {mean }}=$ Mean monthly temperature, $T D$ $=$ Mean monthly temperature range.

Aridity index:

$$
\mathrm{AI}=\frac{M A P}{M A E}
$$

where $A I=$ Aridity Index, $M A P=$ Mean Annual Precipitation, $M A E=$ Mean Annual Potential Evapotranspiration. Note that from here and in other sections of this thesis we choose to use wetness index (WI) instead of the confusing term aridity index.

Since locations had unequal sample sizes, we performed Welch's one-way tests to test whether there were significant differences in the means of the selected environmental variables across locations. We subsequently performed pairwise t-tests with no assumption of equal variances to determine if the mean difference between specific pairs of location are statistically significant. Moreover, Pearson correlation coefficients were calculated to test the relationship between all the studied environmental variables. All the tests were deemed significant at $\mathrm{p} \leq$ 0.05 and the analysis was performed in R software version 3.5.0 (Team, 2018).

A principal component analysis (PCA) was performed on the 22 above-mentioned environmental variables to describe the variation in environmental conditions across sites. Furthermore, a redundancy analysis (RDA) was conducted to investigate the amount of genetic variation that could be explained by the environmental conditions at the study sites (Oksanen 


\section{Chapter 2}

et al., 2018). Then forward and backward selection was carried out and only significant environmental variables were kept. PCA and RDA analyses were performed in the "vegan" library in R software version 3.5.0 (Oksanen et al., 2018).

To test whether there was isolation by distance (IBD) between each native individual, a Mantel test with 999 permutations was used to perform and test the correlation between the (linear) genetic distance and the geographical distance (from decimal degrees) implemented in GenAlex 6.5(Peakall and Smouse, 2012) and the correlation was reported significant if $\mathrm{p} \leq$ 0.01 .

\section{Genetic analyses}

Genetic diversity indices such as the number of alleles $(\mathrm{Na})$, number of effective alleles $(\mathrm{Ne})$, number of private alleles $(\mathrm{P})$, observed and expected heterozygosity $\left(\mathrm{H}_{o}\right.$ and $\left.\mathrm{H}_{e}\right)$ and inbreeding coefficient (fixation index, F) were estimated for each sampled locality using GenAlEx software version 6.5 (Peakall and Smouse, 2012). This package was also used to calculate the pairwise relatedness (genetic distance) between genotypes (Nei, 1972) and the genetic differentiation among populations $\mathrm{F}_{s t},($ Wright, 1965).

The genetic structure of the diversity was analyzed using the Bayesian clustering method of the STRUCTURE version 2.3.4 software package. This model-based clustering method uses a Bayesian approach to detect underlying genetic (sub)-populations within a group of individuals that are genotyped with multiple markers (Pritchard et al., 2000) . Furthermore, for each genotype, the program highlights the proportion of the genome originating from the inferred populations thus allowing the identification of hybrids between the genetic populations and migrants they host (Pritchard et al., 2000). The most likely number of genetic clusters was estimated for the wild individuals without feral/cultivated samples, based on methods described in Evanno et al. (2005). The default settings of the analysis were as follows: "admixture model" and "allele frequencies correlated". Each run was performed during 100,000 Markov Chain Monte Carlo iterations with a burn-in of 100,000 iterations.

To investigate the genetic relationships between accessions, either at the species level or within Ugandan sample set (wild samples either with or without feral/cultivated individuals), genetic dissimilarity matrices were computed in DARwin software6 (Perrier and JacquemoudCollet, 2006). The dissimilarity between samples was calculated by using simple matching based on the Sokal and Michener (1958) index. The dissimilarity formula is: 
$d_{i j}=1-\frac{1}{\mathrm{~L}} \sum_{\mathrm{I}=1}^{\mathrm{L}} \frac{\mathrm{m}_{l}}{\pi}$, with: dij is the genetic dissimilarity between units $i$ and $j, L$ is the number of loci and $\mathrm{ml}$ is the number of matching alleles for locus $1 . \pi$ represent the ploidy of the organisms. Dissimilarities were used for the construction of unweighted neighbour-joining trees.

Using the representative set of the reference groups defined by Merot-L'anthoene et al. (2019) (Supplementary Table 1), DARwin analyses were also performed to place the Ugandan C. canephora genetic diversity within the global C. canephora genetic diversity pool.

\section{Results}

\section{Study site environmental characterization}

Uganda's native C. canephora populations were distributed in forests with significantly varying environmental conditions, as reflected via five environmental variables (Table 1). The C. canephora populations occurred at different elevations, except Mabira and Kalangala whose elevations did not significantly differ. The Itwara and Zoka populations occurred at the highest and lowest elevations, respectively, with the elevation in Itwara being 562 m.a.s.l higher than that of Zoka. Consequently, Zoka had the highest annual mean temperature (BIO1), which was $4.7^{\circ} \mathrm{C}$ higher than that of the Itwara the population with the lowest BIO1. Similar BIO1 patterns and elevation values were observed across locations since both were correlated $(p<0.05)$ (Supplementary Figure 1). For precipitation, Kalangala had the highest annual precipitation (BIO12), which was $675.5 \mathrm{~mm}$ more than that of Zoka, i.e. the location with the lowest precipitation.

Pairwise comparisons showed that the annual precipitation significantly differed across locations, except between Itwara-Malabigambo and Zoka-Kibale (Supplementary Table 4). Potential evapotranspiration (PET) was highest in Zoka and lowest in Kalangala. The results showed that PET differed significantly between all sites, except between Itwara and Malabigambo (Supplementary Table 4). The wetness index (WI) was highest in Kalangala and was $45.6 \%$ higher than the lowest AI observed in Zoka. This implies that, among the study locations, Zoka was the driest and Kalangala the wettest. The AI also differed significantly between locations, except between Budongo and Kibale and between Malabigambo and Itwara (Supplementary Table 4). 


\section{Chapter 2}

Pairwise comparisons showed that the annual precipitation significantly differed across locations, except between Itwara-Malabigambo and Zoka-Kibale (Supplementary Table 4). Potential evapotranspiration (PET) was highest in Zoka and lowest in Kalangala. The results showed that PET differed significantly between all sites, except between Itwara and Malabigambo (Supplementary Table 4). The wetness index (WI) was highest in Kalangala and was $45.6 \%$ higher than the lowest AI observed in Zoka. This implies that, among the study locations, Zoka was the driest and Kalangala the wettest. The WI also differed significantly between locations, except between Budongo and Kibale and between Malabigambo and Itwara (Supplementary Table 4).

When all climatic variables were analyzed simultaneously through a principal component analysis (PCA), the populations in Zoka, Budongo, Kalangala, Mabira and Malabigambo occurred in distinct climatic envelopes, while the climatic envelopes in Itwara tended to overlap those of Kibale (Figure 1). In this figure, the first two axes captured $\sim 85 \%$ of the total variation in the environmental conditions. The first PCA axis (PC1) accounted for more than half $(64.7 \%)$ of the total variation and was mainly represented by, and negatively correlated with, temperature-related variables (BIO5, BIO9, BIO4, BIO10, ordered according to their contribution level) and PET. The PC1 axis mainly differentiated populations in warmer areas (Zoka and Budongo) from those in colder areas. The second PCA axis (PC2) accounted for $21.3 \%$ of the total variation and was mainly represented by, and negatively correlated with, precipitation-related variables (BIO16, BIO12, BIO13 and wetness (WI), ordered according to their contribution level. The climatic envelope of Kalangala was characterized by higher precipitation and WI, while the seemingly overlapping climatic envelopes of Itwara and Kibale populations were amongst the driest. 


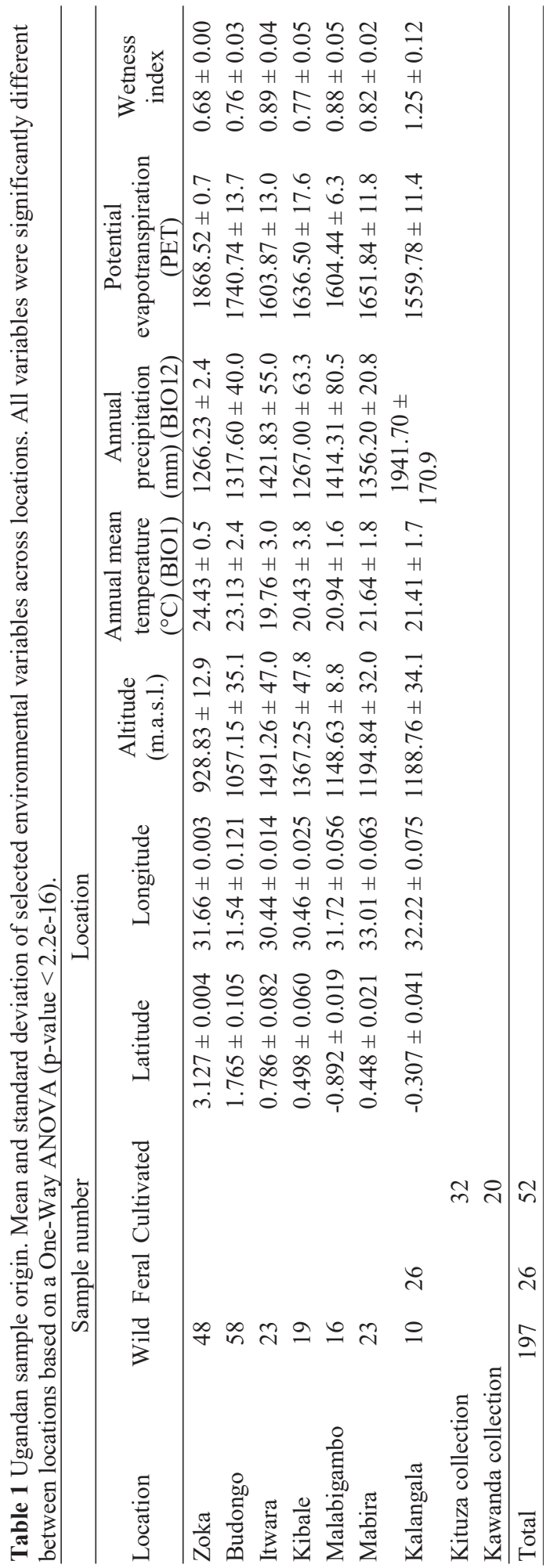



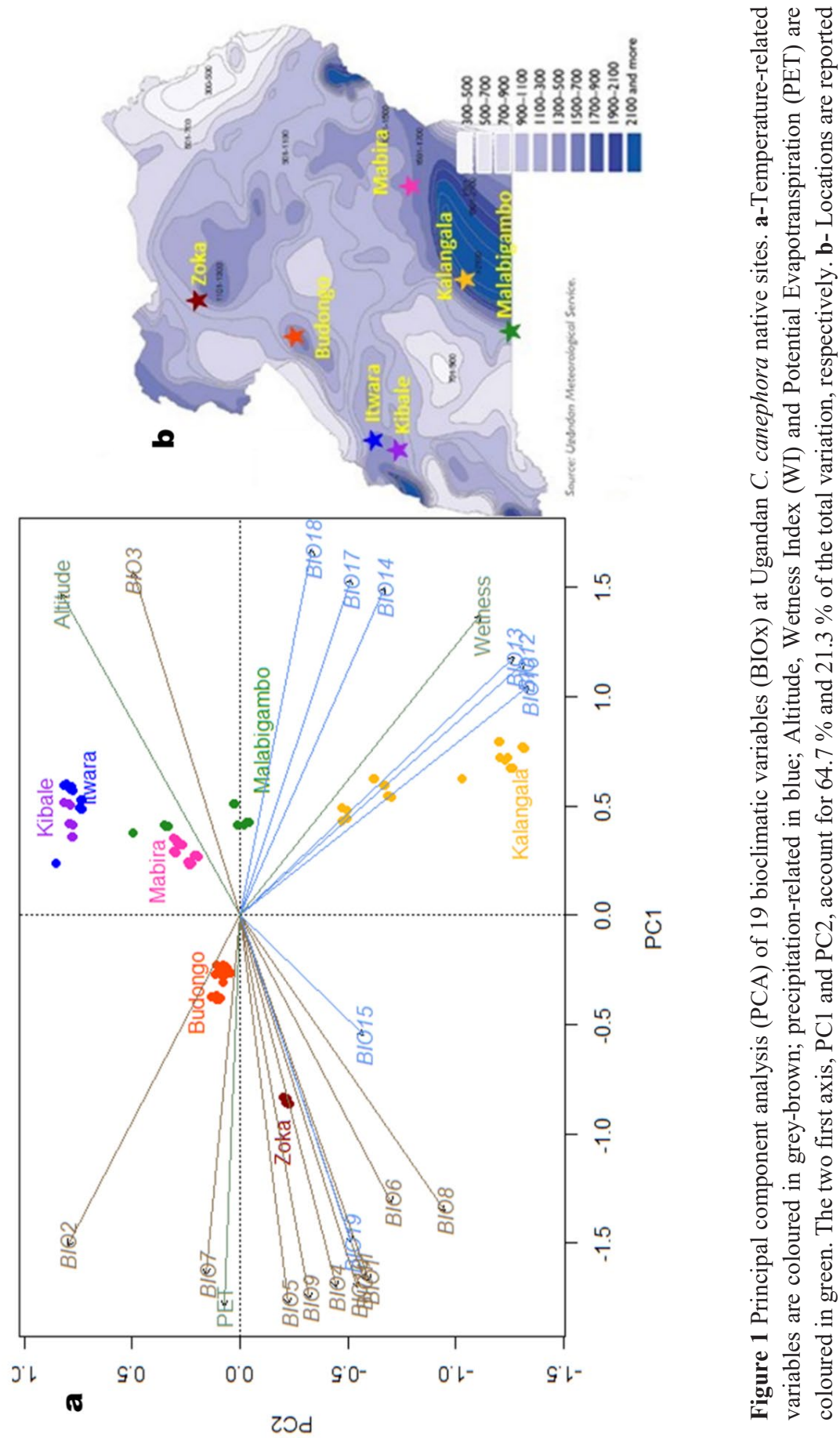

ई

है द्व

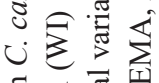

需要之

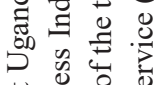

๘

สิ

월 응

总 吾

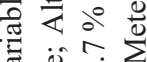

帘

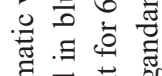

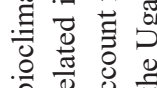

ভ

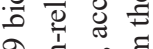

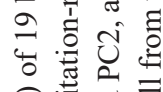

㐫愛㤩

品吉焉

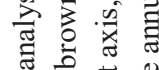

青交芯芯

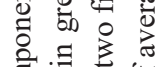

콩 च

흘 흥 छ

웡 ठ

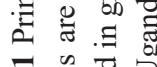

웡

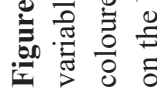


Relationship between genetic distances, geographic distances and climatic profiles in the native populations

The total genetic diversity within all Ugandan $C$. canephora populations was examined at the 19 SSR loci and in the 191 C. canephora accessions collected from wild populations (Tables $1 \& 2$ ). A total of 160 alleles were scored over the native populations. Comparisons between pairwise individual genetic distances and their geographical distances showed a significant but low isolation by distance effect $(\mathrm{R}=0.347$ with $p<0.001)$ (Supplementary Figure 2).

Table 2 Allelic pattern across populations. Mean values over loci are provided for each native forest and the two collections: Number of alleles, Number of effective alleles, observed and expected heterozygosities, and fixation index.

\begin{tabular}{lccccccccc}
\hline \multicolumn{1}{c}{ Population } & Status & $\mathrm{N}$ & $\mathrm{Na}$ & $\mathrm{Ne}$ & $\begin{array}{c}\text { Private } \\
\text { Alleles }\end{array}$ & $\begin{array}{c}\text { Total No } \\
\text { Private } \\
\text { Alleles }\end{array}$ & Ho & He & $\mathrm{F}$ \\
\hline Kituza & Collection & 32 & 6.1 & 3.5 & 0.2 & 3 & 0.6 & 0.63 & 0.04 \\
Kawanda & Collection & 20 & 5.5 & 3.6 & 0 & 0 & 0.63 & 0.63 & -0.02 \\
\hline Budongo & Wild & 54 & 5.1 & 3 & 0.3 & 6 & 0.52 & 0.57 & 0.07 \\
Itwara & Wild & 23 & 3.1 & 2.2 & 0 & 0 & 0.41 & 0.45 & 0.11 \\
Kalangala & Wild & 10 & 4.7 & 2.9 & 0.1 & 1 & 0.64 & 0.58 & -0.1 \\
Kibale & Wild & 19 & 3.3 & 2.1 & 0.1 & 1 & 0.33 & 0.41 & 0.2 \\
Mabira & Wild & 23 & 5.9 & 3.3 & 0.2 & 3 & 0.57 & 0.62 & 0.08 \\
Malabigambo & Wild & 16 & 4.8 & 2.9 & 0.1 & 2 & 0.56 & 0.55 & -0.01 \\
Zoka & Wild & 46 & 5.7 & 3.3 & 0.6 & 11 & 0.51 & 0.58 & 0.1 \\
& Mean \\
& over wild & pop.
\end{tabular}

Meanwhile, the constrained redundancy analysis (RDA) results showed that only 12 out of the 22 environmental variables used in this study significantly and collectively explained $16.3 \%$ of the total genetic diversity, as defined by the allelic composition (total of 160 alleles) across the study sites (Figure 2). The first constraining axis (RDA1) explained only $4.63 \%$ of the total genetic diversity and clearly differentiated the Zoka, Budongo, Kibale and Itwara populations from the Mabira, Malabigambo and Kalangala populations. RDA1 was mainly negatively correlated with the mean diurnal range, i.e. the mean of monthly (max temperature - min temperature) (BIO2) and PET, while being positively correlated with 
precipitation-related variables, e.g. precipitation of the driest quarter (BIO17), precipitation in the driest month (BIO14) and precipitation of the wettest month (BIO13). The second axis (RDA2) explained $3.33 \%$ of the total genetic diversity and was mainly positively correlated with three temperature-related variables, i.e. mean temperature of the wettest quarter (BIO8), mean temperature of the coldest quarter (BIO11), annual mean temperature (BIO1), and negatively correlated with precipitation in the warmest quarter (BIO18). RDA2 differentiated the genetic diversity of populations occurring in warmer zones (Zoka and Budongo) from others. Interestingly, the RDA projection structured individuals according to their forest of origin for north western (NW) populations (Zoka, Budongo, Kibale, Itwara), but individuals from southern-central (SC) populations (Kalangala, Mabira, and Malabigambo) all overlapped in the two first axis spaces.

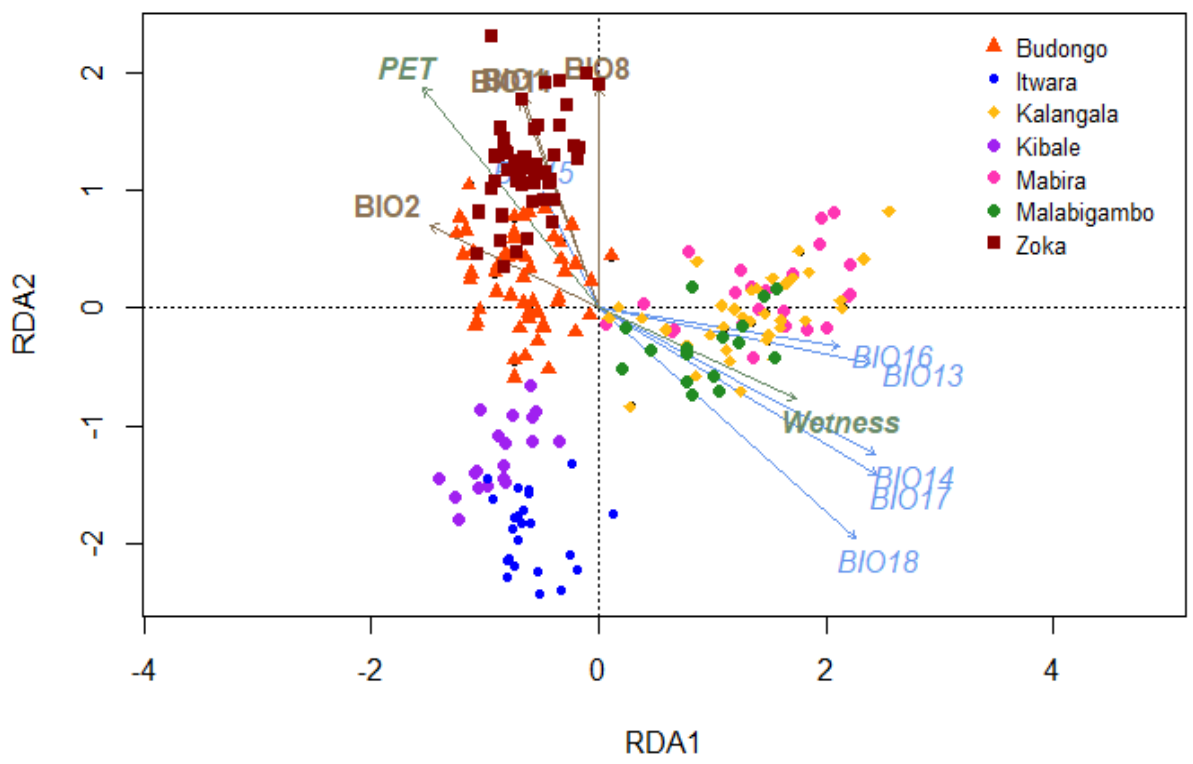

Figure 2 Constrained Redundancy analysis (RDA) of the effects of environmental parameters on the allelic diversity of Ugandan C. canephora wild populations. Twelve out of the 22 environmental variables used in this study significantly and collectively explained $16.3 \%$ of the total variation in the allelic diversity. Colour codes are the same as in figure 1 . The first and second constraining axes explained $4.63 \%$ and $3.33 \%$ of the total genetic diversity, respectively. 
Genetic structure over Uganda's C. canephora native range

The genetic diversity structure in Ugandan C. canephora native populations was further examined within locations (Table 2). An average of 4.7 alleles per locus $(\mathrm{Na})$ were detected over the native populations. Populations from Itwara and Kibale had the lowest allelic richness ( $\mathrm{Na}$ of 3.1 and 3.3, respectively) and heterozygosity ( $\mathrm{H}_{e}$ of 0.45 and 0.41 , respectively). In contrast, the population from Mabira had the highest mean allelic number $(\mathrm{Na}=5.9)$ and heterozygosity $\left(\mathrm{H}_{e}=0.62\right)$ among all of the wild populations. Notably, populations from Zoka and Budongo, with a high mean allelic number $(\mathrm{Na}=5.7$ and 4.7 , respectively) and expected heterozygosity $\left(\mathrm{H}_{e}=0.58\right.$ for both), appeared to be relatively unique among the study populations. They had the highest number of private alleles (11 and 6 , respectively) compared to Itwara, Kibale or Malabigambo with all less than two private alleles.

Clustering analysis findings for the whole set of native populations clearly revealed that the native diversity broadly differentiated a large group with the accessions from the SC forests (Malabigambo, Mabira and Kalangala) from accessions from the NW forests (Zoka, Budongo, Itwara and Kibale) (Figure 3a, b). In this cluster, all individuals were intermixed regardless of their forest of origin. Increasing the number of groups $(K)$ from $K=3$ to $K=4$ separated Zoka and Budongo individuals into two separate clusters, while an additional Structure analysis of the Itwara-Kibale cluster further distinguished individuals from these two forests (Figure 3a). Neighbour-joining analysis at the individual level exhibited a similar geographically structured distribution of wild accessions (Figure 3c). C. canephora wild genotypes were generally classified into clades according to their Structure clusters, with a clear separation between individuals from NW forests and those from SC forests. Furthermore, individuals from the four different NW forests (Zoka, Budongo, Itwara and Kibale) clustered according with their "forest" counterparts. Few intermixed clusters of individuals from Budongo and Zoka were observed, thus revealing probable gene flow and admixture between adjacent Budongo and Zoka populations. Accessions from SC forests (Malabigambo, Mabira and Kalangala) were spread within a large clade, suggesting population intermixing within the region. 


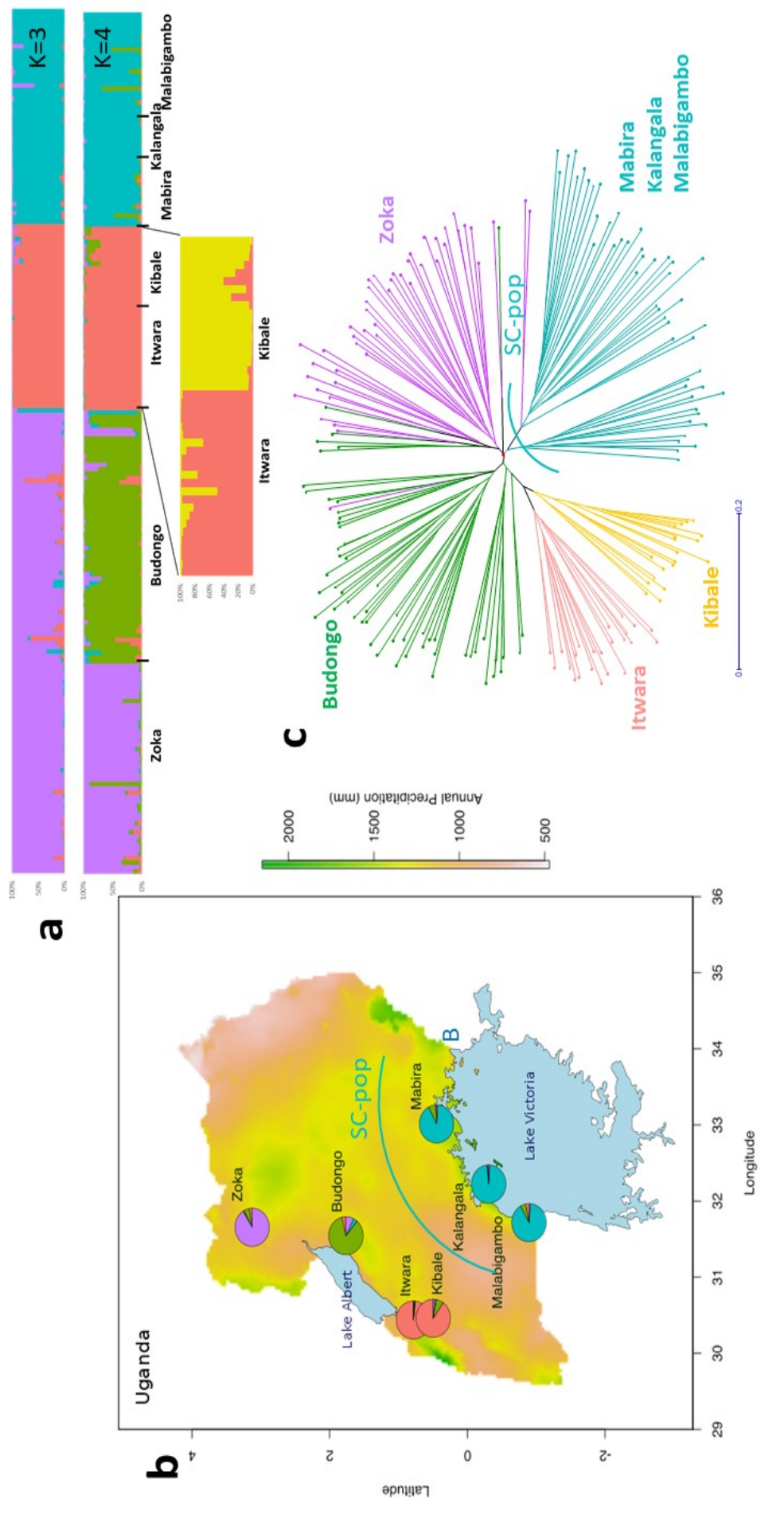

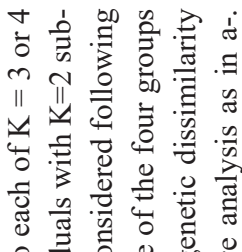

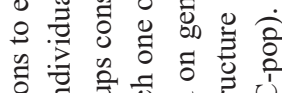

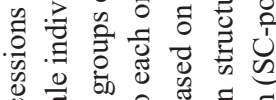
过

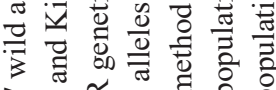
ลิ

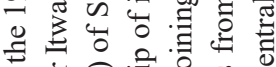

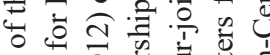

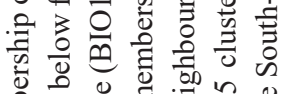

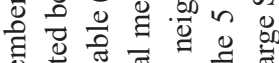

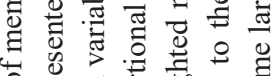

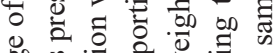

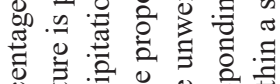

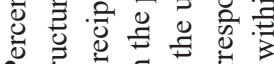

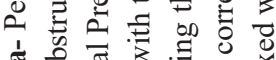

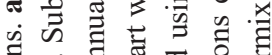

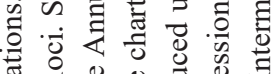

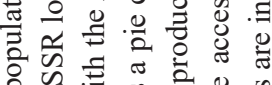

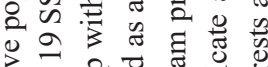

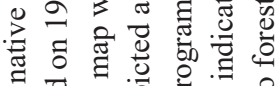
ธ

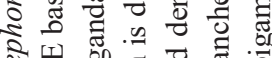

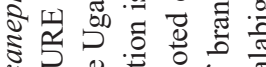
난 نํํ의

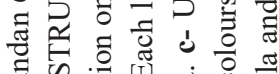

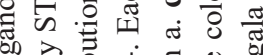
号荗吾

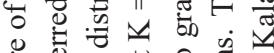

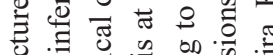

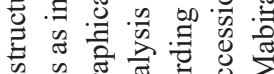

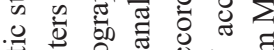

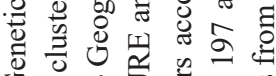

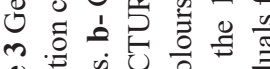

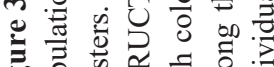

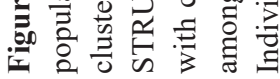


This observed genetic structure was supported by the population divergence $\left(\mathrm{F}_{s t}\right)$ values (Supplementary Table 5). The differentiation between the NW forests and other forests, ranging from 0.08 to 0.22 , was higher than that between the SC forests, ranging from 0.02 to 0.05 . The $\mathrm{F}_{s t}$ values of the population genetic differentiation within NW forests ranged from 0.05 (differences between Zoka and Budongo) to 0.18 (differences between Zoka and Itwara).

\section{Origin of feral and cultivated material and diversity maintained in collection}

Collections (from cultivated material) maintained in Kituza and Kawanda, when compared to wild populations, had amongst the highest number of detected alleles, with an average allelic richness of $\mathrm{Na}=6.1$ alleles per locus for material from the Kituza collection, and the highest and equal expected heterozygosity $\left(\mathrm{H}_{e}=0.63\right)$. However, they presented no or few private alleles (Table 2) that differentiated them from wild populations. The high heterozygosity and low numbers of private alleles indicated that the collections shared diversity with some wild populations (Supplementary Figure 3). Indeed, when comparing private alleles specific to each of the wild populations (without collection materials, data not shown), the number of private alleles for Mabira was similar to that of Zoka (i.e. a mean number of 0.5 private alleles over loci, with a total of 10 private alleles). Analyses including material in collections (Table 2) showed however that Mabira, with only three private alleles in that case, shared most of its alleles with individuals in collections. Conversely, private alleles present in Zoka and Budongo were not represented in the collections.

Neighbor-joining analysis combining cultivated (Kituza and Kawanda) and feral (Kalangala) individuals together with wild ones showed a closer genetic relationship between the cultivated/feral accessions and the wild ones from the southern-central forests (Figure 4). This cluster of SC forest and cultivated accessions tended to be genetically homogeneous, with individuals intermixed irrespective of origin, Nganda or Erecta-derived type (data not shown) and cultivation status. Finally, the cultivated material maintained in the Kituza and Kawanda collections appeared to be highly representative of the diversity found in the SC region, both at the wild and cultivated level, while differing from the other populations (Zoka, Budongo, Itwara and Kibale). Feral individuals (some samples from Kalangala) were also largely scattered within the wild populations from the SC forests (Figure 4). They did not have a closer relationship with their wild counterparts from the Kalangala islands than with other individuals from the SC region. 
Position of Ugandan accessions among the African C. canephora diversity

When Ugandan $C$. canephora genotypes were analyzed together with individuals from seven other diversity groups (A, B, C, D, E, R and G, as described by Merot-l'Anthoene et al. (2019)), they clustered within a distinct genetic group (group O), although a few samples clustered within genetic group B or genetic groups E/R (Figure 4 ). Indeed, some Ugandan $C$. canephora individuals from Zoka clustered with individuals from the Central African Republic (group B), suggesting their close genetic relationship together with their geographic proximity in northern region of Uganda. In addition, some samples from Mabira and Kalangala forests and from the Kituza and Kawanda collections were grouped together with material from genetic group E, suggesting that some cultivated material in Uganda was sourced from the Democratic Republic of the Congo (DRC). Notably, the distinct genetic structures (NW and SC groups, as described above) within native Ugandan $C$. canephora diversity were evident amidst other genetic groups (Figure 4).

\section{Discussion}

Unique climatic zones of Uganda's C. canephora native populations

Our findings have shown that Uganda's C. canephora populations occur across a considerable environmental range and except for Kibale and Itwara whose climatic envelops tended to overlap (Figure 1). This finding is in line with our expectation because Uganda's $C$. canephora diversity occurs in distinct precipitation climatic zones as described by Basalirwa (1995) and NEMA (2009). The Zoka population occurs in the driest climatic envelope with high temperatures and comparatively highly fluctuating amounts of precipitation while the Kalangala population occupies the wettest climatic envelope which is predominantly defined by high amounts of precipitation and comparatively low temperature fluctuations (Figure 1 and Table 1). Our results showed that Ugandan natural C. canephora populations occur in contrasting environmental conditions, which suggests that these populations might be specifically adapted to these conditions. Intraspecific variability of plant populations has been reported to enable species to thrive under new environmental conditions (Joshi et al., 2001, Byars et al., 2007). Such variation within and across populations is important as it may in turn provide material important for breeding climate adaptive varieties. 


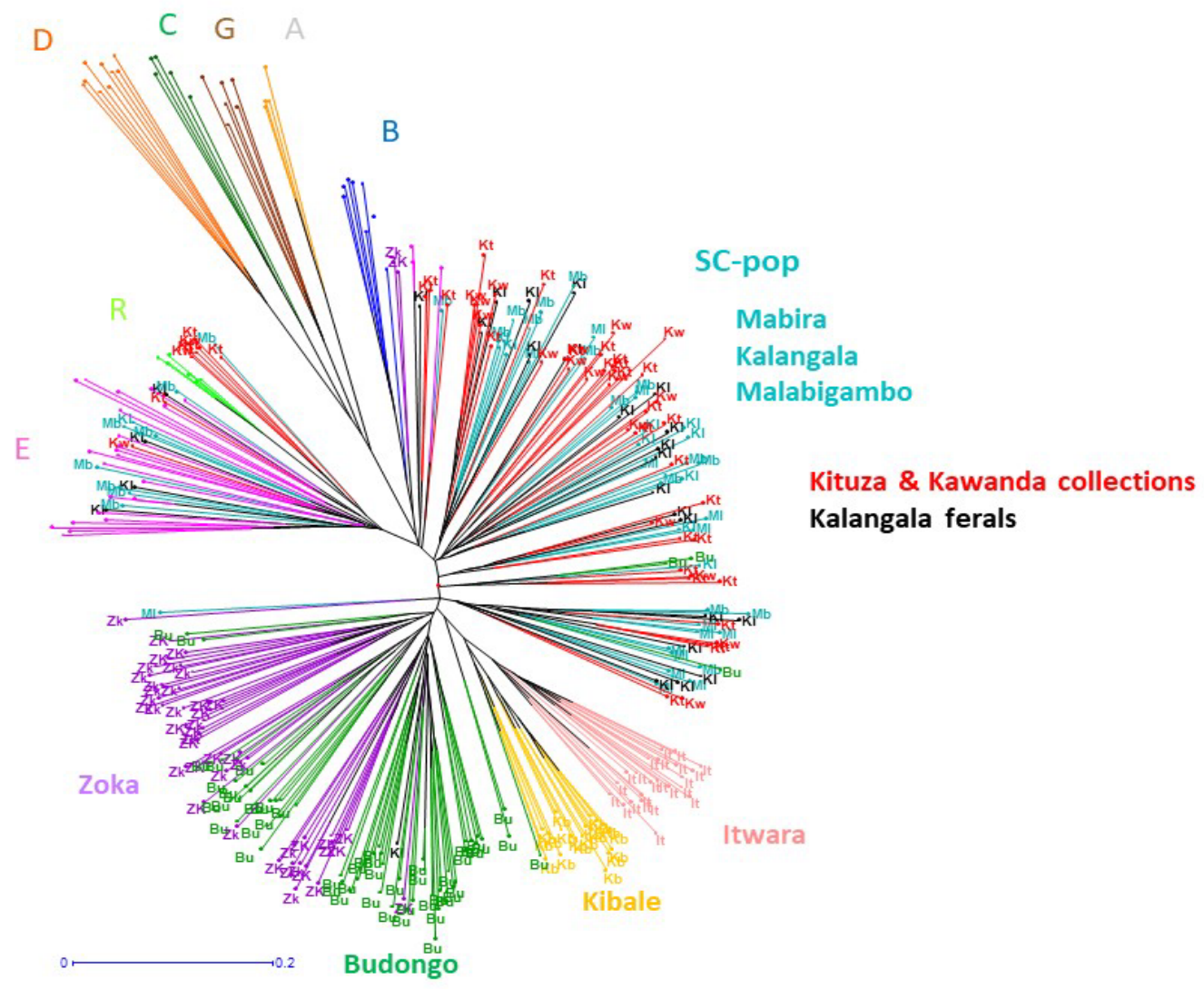

Figure 4 Neighbour-Joining of Ugandan wild C. canephora material together with feral accessions from Kalangala islands (in black) and material maintained in Kituza (Kt) and Kawanda (Kw) collections (in red). Wild material was collected from Zoka (Zk), Budongo (Bu), Kibale (Kb), Itwara (It), Malabigambo (Ml), Mabira (Mb) and Kalangala islands (Kl). The colors of branches of wild material corresponds to the 5 clusters from population structure analysis presented in figure 3 Individuals representative of other genetic groups (A, B, C, D, E, R) from the whole species diversity (Merot-l'Anthoene et al., 2019) are also presented as references.

\section{Genetic differentiation of Uganda's wild C. canephora populations}

Our results showed that Uganda's wild C. canephora populations represent a genetic diversity not present in the rest of the species distribution range. The studied material constitutes a well-differentiated genetic group as previously suggested by Merot-l'Anthoene et al. (2019) who studied a smaller sample set of Ugandan material. This diversity is broadly structured into five differentiated genetic groups, namely four populations in the north and western (NW) part of Uganda, which comprise individuals from Zoka, Budongo, Kibale and Itwara forests and the 


\section{Chapter 2}

southern-central group (SC), which groups samples from Malabigambo, Mabira and Kalangala wild populations.

The forest populations from the SC genetic group had higher allelic richness than those from the NW forests. They however constituted a large intermixed genetic group, and this could possibly be attributed to a high level of gene flow between each of the forest and the cultivated material (see below). The low allelic diversity for especially Itwara and Kibale populations might be due to geographical isolation and restricted gene-flow between these populations. Musoli et al. (2009a) and Nyakaana (2007) also found that populations from Itwara and Kibale were genetically distinct; with low allelic diversity possibly indicating inbreeding coupled with random genetic drift. Moreover, our sample collection surveys revealed a marked reduction in the spatial range occupied by the $C$. canephora populations in these forests compared to that previously described by Musoli et al. (2009a). Among all forest populations in our study, Zoka and Budongo are highly differentiated and showed the highest level of originality in terms of number of private alleles per locus. This indicates that these populations have unexplored genetic material, which may be of great potential and importance to the coffee breeding sector. Gene flow between spontaneous Southern-central populations and cultivated coffees of Uganda

Some feral and cultivated germplasm of Uganda were shown to be either introduced from Congo (genetic group E) or originated from the Southern-Central forests (Malabigambo, Kalangala, Mabira). The genetic similarity of the cultivated samples with the wild material from the SC forests is consistent the fact that in the late $19^{\text {th }}$ century, C. canephora cultivation started with smallholder farmers around the Lake Victoria Basin, probably using wild coffee material directly sourced from the wild (Thomas, 1935, UCDA, 2017a, Thomas, 1944). The location of the Mabira, Malabigambo and Kalangala forests coincides with the predominant and historically important $C$. canephora cultivation zones in Uganda. The genetic similarity of the SC wild samples with the cultivated material could also reflect gene flow between forest material and the cultivated fields indicating loss of a clear delimitation between SC wild and the cultivated samples. Additionally, human interaction too, in the form of gathering and transporting wild C. canephora plants from SC forests to use them for cultivation, allowed spread of seeds and/or cuttings over large distances within the C. canephora cultivation areas of Southern-Central Uganda (Thomas, 1935).

Meanwhile, some feral and cultivated genotypes clustered with Congolese genetic group E which very likely reflects the introduction of germplasm from Congo to Uganda. This corroborates Montagnon et al. (1998) who suggested that some cultivated coffee trees in 
Uganda might have resulted from natural crosses between wild endemic materials and introduced genotypes, hence giving rise to mixed genotypes. The relative contributions of the fore mentioned factors i.e. factors; (i) use of wild material by farmers, (ii) natural geneflow between wild population and (iii) lack of genetic difference between cultivated and wild material in the SC; is difficult to assess. But the lack of genetic differences between cultivated, local or introduced, and wild material SC region is of major concern as it may signal loss of natural unique biodiversity in coffee in this region.

\section{Feral and wild accessions from Kalangala}

We expected that wild samples from Kalangala would show a substantial level of originality due to the genetic material collected from the threatened Lutooboka central forest reserve. However, our results revealed that material from Kalangala was not genetically distinct from that collected from other SC forests and the cultivated collections. This lack of differentiation could have resulted from increased deforestation, hence reducing the extent of wild coffee populations in Kalangala. Most natural coffee populations in Kalangala have been cleared to make way for oil palm plantations (Piacenza, 2012). As a consequence, our wild accessions from the highly fragmented natural forests of Kalangala could have been cultivated C. canephora offspring or accessions introgressed with cultivated material. The finding that wild samples from Kalangala were not genetically distinct from material in the collections or from other Mabira and Malabigambo material may be evidence of probable genetic loss due to deforestation since Musoli et al. (2009a)'s found substantial genetic distinctiveness among samples from Kalangala and the cultivated material.

Utilization of Uganda's coffee genetic diversity and the need for a complementary conservation strategy

Uganda's $C$. canephora production is currently predominantly sustained by six elite genotypes namely: 257/53 (=KW13), 223/32(=KW14), 1s/6(Kw15), 1s/3(Kw16), 258/24(0) (KW18) and 1s/2 (KW19) (Musoli, personal communication). These are specially bred for their resistance to coffee wilt disease (CWD) and high productivity. In this study all the six cultivars were shown to be genetically similar to SC wild populations and this finding corroborates with Musoli et al. (2009), who reported that cultivated material cluster into one genetic group. Our results show that the genetic diversity in NW forests is distinct from the cultivated material and NW populations occur in comparatively contrasting climatic zones, thus posing as a new source of genetic diversity. This unexplored genetic diversity could be utilized in the coffee breeding 


\section{Chapter 2}

program to improve the resilience of cultivated material to a couple of adverse effects of climate change e.g. drought, temperature, pests and diseases.

In the light of the substantial level of Uganda's C. canephora diversity and the location of the populations distinct environmental conditions, there is need to devise an efficient complementary conservation strategy that allows for the in-situ and ex-situ conservation of Uganda's coffee genetic resources. As shown earlier, some populations like Itwara and Kibale are spatially isolated small populations and these populations could thus be more susceptible to ecological or genetic displacement (Ellstrand and Elam 1993). In our study, genotypes from Zoka forest, and to a lesser extent Budongo forest, were found to contain the highest number of private alleles, which could possibly be explained by the fact that these forests were in areas under the most arid environmental conditions, so the coffee populations likely have an adaptive potential. Hence both in-situ and ex-situ conservation of these populations is especially important. Conservation strategies should promote the prevention of deforestation and associated habitat destruction in these areas, while also prohibiting $C$. canephora cultivation within a certain range to prevent introgression from cultivated material to wild populations. For ex-situ conservation, our study enriched the diversity conserved by the National Agricultural Research Organization (NARO) at the National Coffee Resources Institute (NaCORI) in Kituza and the Plant Genetic Resources Centre (PGRC) in Entebbe. Our study material was safety duplicated at NaCORI and Kituza to enhance the ex-situ conservation of these resources and provide material for other related studies geared towards understanding the potential offered by Ugandan coffee genetic diversity.

In conclusion, our study revealed that Ugandan C. canephora populations thrived in contrasting environmental conditions and that the genetic structuring of wild populations was divided into two main environmentally and geographically bounded groups, i.e. the northwestern group (Zoka, Budongo, Itwara and Kibale) and the southern-central group, mainly comprising wild populations from Malabigambo, Mabira and Kalangala, and the cultivated collection material. We also demonstrated that the distinction between populations was partly correlated with the climatic differences in their habitats, suggesting that these populations might present an adaptive potential useful for breeding climate change resilient material. Most importantly, our study showed that the cultivated and current elite genotypes predominantly belonged to the same genetic group (SC group), while material from the NW group (especially from Zoka and Budongo) contained genetic material that has not yet been utilized but which could be very useful for coffee improvement in the current climate change setting. Ex-situ 
conservation strategies must be developed very quickly, and the material already collected in the national collections should be evaluated in more detail, for its physiological capacities to cope with the adverse effects of climate change, e.g. drought, higher temperatures or disease pressure.

\section{References}

Basalirwa CPK. 1995. Delineation of Uganda into climatological rainfall zones using the method of principal component analysis. International Journal of Climatology 15: $1161-1177$

Berthaud J. 1986. Les ressources genetiques pour l'amelioration des cafeires africains diploides: Orstom Paris.

Brozynska M, Furtado A, Henry RJ. 2016. Genomics of crop wild relatives: expanding the gene pool for crop improvement. Plant Biotechnol J, 14: 1070-85.

Bunn C, Läderach P, Ovalle Rivera O, Kirschke D. 2015. A bitter cup: climate change profile of global production of Arabica and Robusta coffee. Climatic Change, 129: 89101.

Byars SG, Papst W, Hoffmann AA. 2007. Local adaptation and cogradient selection in the alpine plant, Poa hiemata, along a narrow altitudinal gradient. Evolution, 61: 2925-41.

Charrier A, Berthaud J. 1985. Botanical Classification of Coffee. Coffee.

Cubry P, De Bellis F, Pot D, Musoli P, Leroy T. 2012. Global analysis of Coffea canephora Pierre ex Froehner (Rubiaceae) from the Guineo-Congolese region reveals impacts from climatic refuges and migration effects. Genetic Resources and Crop Evolution, 60: 483 501.

DaMatta FM, Avila RT, Cardoso AA, Martins SCV, Ramalho JC. 2018. Physiological and agronomic performance of the coffee crop in the context of climate change and global warming: A review. Journal of Agricultural and Food Chemistry, 66: 5264-5274.

Davis AP, Chadburn H, Moat J, O'Sullivan R, Hargreaves S, Lughadha EN. 2019. High extinction risk for wild coffee species and implications for coffee sector sustainability. Science Advances, $\mathbf{5}$.

Davis AP, Gole TW, Baena S, Moat J. 2012. The impact of climate change on indigenous Arabica coffee (Coffea arabica): predicting future trends and identifying priorities. PLoS One, 7.

Davis AP, Govaerts R, Bridson DM, Stoffelen P. 2006. An annotated taxonomic conspectus of the genus Coffea (Rubiaceae). Botanical Journal of the Linnean Society, 152: 465512.

Davis AP, Tosh J, Ruch N, Fay F, Michael. 2011. Growing coffee: Psilanthus (Rubiaceae) subsumed on the basis of molecular and morphological data; implications for the size, morphology, distribution and evolutionary history of Coffea. Botanical Journal of the Linnean Society, 167: 357-377.

Dereeper A, Bocs S, Rouard M, Guignon V, Ravel S, Tranchant-Dubreuil C, Poncet V, Garsmeur O, Lashermes P, Droc G. 2015. The coffee genome hub: a resource for coffee genomes. Nucleic Acids Res, 43: D1028-35.

Dussert S, Lashermes P, Anthony F, Montagnon C, Trouslot P, Combes M, C., , Berthaud J, Noirot M, Hamon S. 1999. Le caféier, Coffea canephora. Diversité génétique des plantes tropicales cultivées,.

Gomez C, Dussert S, Hamon P, Hamon S, Kochko A, Poncet V. 2009. Current genetic differentiation of Coffea canephora Pierre ex A. Froehn in the Guineo-Congolian 
African zone: cumulative impact of ancient climatic changes and recent human activities. BMC Evolutionary Biology, 9: 167.

Graham CH, Hijmans RJ. 2006. A comparison of methods for mapping species ranges and species richness. Global Ecology and Biogeography, 0: 060831043455001-???

Hajjar R, Hodgkin T. 2007. The use of wild relatives in crop improvement: a survey of developments over the last 20 years. Euphytica, 156: 1-13.

Hamon P, Grover CE, Davis AP, Rakotomalala JJ, Raharimalala NE, Albert VA, Sreenath HL, Stoffelen P, Mitchell SE, Couturon E, Hamon S, de Kochko A, Crouzillat D, Rigoreau M, Sumirat U, Akaffou S, Guyot R. 2017. Genotyping-bysequencing provides the first well-resolved phylogeny for coffee (Coffea) and insights into the evolution of caffeine content in its species: GBS coffee phylogeny and the evolution of caffeine content. Mol Phylogenet Evol, 109: 351-361.

Hendre PS, Aggarwal RK. 2014. Development of genic and genomic SSR markers of robusta coffee (Coffea canephora Pierre Ex A. Froehner). PLoS One, 9: e113661.

Hijmans RJ, Cameron SE, Parra JL, Jones PG, Jarvis A. 2005. Very high resolution interpolated climate surfaces for global land areas. International Journal of Climatology, 25: 1965-1978.

ICO. 2014. World coffee trade $(1963$ - 2013): A review of the markets, challenges and opportunities facing the sector. International Coffee Organisation.

IPCC. 2014. Proceedings of the 5th Assessment Report, WGII, Climate Change 2014: Impacts, Adaptation, and Vulnerability. Cambridge, U.K.

Jonathan K Pritchard MSaPD. 2000. Inference of Population Structure Using Multilocus Genotype Data. Genetics 945-959

Jonathan KP, Matthew S, Peter D. 2000. Inference of Population Structure Using Multilocus Genotype Data. Genetics 945-959

Joshi J, Schmid B, Caldeira MC, Dimitrakopoulos PG, Good J, Harris R, Hector A, HussDanell K, Jumpponen A, Minns A, Mulder CPH, Pereira JS, Prinz A, SchererLorenzen M, Siamantziouras A-SD, Terry AC, Troumbis AY, Lawton JH. 2001. Local adaptation enhances performance of common plant species. Ecology Letters 4: $536-544$.

Matete N, BakamaNume B. 2010. Climate of Uganda. In: BakamaNume B, ed. In Contemporary Geography of Uganda. Dares salaam: Mkuku Na Nyota.

Merot-l'Anthoene V, Tournebize R, Darracq O, Rattina V, Lepelley M, Bellanger L, Tranchant-Dubreuil C, Coulee M, Pegard M, Metairon S, Fournier C, Stoffelen P, Janssens SB, Kiwuka C, Musoli P, Sumirat U, Legnate H, Kambale JL, Ferreira da Costa Neto J, Revel C, de Kochko A, Descombes P, Crouzillat D, Poncet V. 2019. Development and evaluation of a genome-wide Coffee $8.5 \mathrm{~K}$ SNP array and its application for high-density genetic mapping and for investigating the origin of Coffea arabica L. Plant Biotechnology Journal, 17: 1418-1430.

Millard E. 2017. Value creation for smallholders and SMEs in commodity supply chains. . Enterprise Development and Microfinance

Moat J, Williams J, Baena S, Wilkinson T, Gole TW, Challa ZK, Demissew S, Davis AP. 2017. Resilience potential of the Ethiopian coffee sector under climate change. Nat Plants, 3: 17081.

Moncada P, McCouch S. 2004. Simple sequence repeat diversity in diploid and tetraploid Coffea species. Genome 47: 501-509.

Montagnon C, Leroy T, Eskes AB. 1998. Varietal improvement of Coffea canephora-II. Breeding programmes and their results. 
Musoli P, Cubry P, Aluka P, Billot C, Dufour M, De Bellis F, Pot D, Bieysse D, Charrier A, Leroy T. 2009. Genetic differentiation of wild and cultivated populations: diversity of Coffea canephora Pierre in Uganda. Genome, 52: 634-46.

NEMA. 2009. Uganda: atlas of our changing environment. Kampala, Uganda National Environment Management Authority (NEMA).

Nyakaana S. 2007 Microgeographical genetic structure of forest robusta coffee (Coffea canephora Pierre) in Kibale National Park Uganda. African Journal of Ecology 71-75.

Oksanen J, Blanchet FG, Friendly M, Kindt R, Legendre P, McGlinn D, Minchin PR, O'Hara RB, Simpson GL, Solymos P, Stevens MHH, Szoecs E, Wagner H. 2018. vegan: Community Ecology Package. R package version 2.5-2.

Parry M, Parry ML, Canziani O, Palutikof J, Van der Linden P, Hanson C. 2007. Climate Change 2007- Impacts, adaptation and vulnerability: Working Group II contribution of to the fourth assessment the IPCC. Cambridge, United Kingdom: Cambridge University Press.

Peakall R, Smouse PE. 2012. GenAlEx 6.5: genetic analysis in Excel. Population genetic software for teaching and research--an update. Bioinformatics, 28: 2537-9.

Peakall ROD, Smouse PE. 2006. genalex 6: genetic analysis in Excel. Population genetic software for teaching and research. Molecular Ecology Notes, 6: 288-295.

Piacenza C. 2012. Negotiating gendered property relations over land: oil palm expansion in Kalangala district, Uganda.

Plechakova O, Tranchant-Dubreuil C, Benedet F, Couderc M, Tinaut A, Viader V, De Block P, Hamon P, Campa C, de Kochko A, Hamon S, Poncet V. 2009. MoccaDB - an integrative database for functional, comparative and diversity studies in the Rubiaceae family. BMC Plant Biol, 9: 123.

Poncet V, Belzile F, Dufour M, Hamon P, Hamon S, de Kochko A, Leroy T. 2007. Development of genomic microsatellite markers in Coffea canephora and their transferability to other coffee species. Genome, 50: 1156-1161.

Thomas AS. 1935. Types of robusta coffee and their selection in Uganda. The East African Agricultural Journal 1: 193-197.

Thomas AS. 1944. The wild coffee of Uganda. Emp. J. Exp. Agric., 12: 1-12.

UCDA. 2017. 25 years of empowering lives; Uganda Coffee Developement Authority. Kampala, Uganda.

Warschefsky E, Penmetsa RV, Cook DR, von Wettberg EJ. 2014. Back to the wilds: tapping evolutionary adaptations for resilient crops through systematic hybridization with crop wild relatives. Am J Bot, 101: 1791-800.

Zomer RJ, Trabucco A, Bossio DA, Verchot LV. 2008. Climate change mitigation: A spatial analysis of global land suitability for clean development mechanism afforestation and reforestation. Agriculture, Ecosystems \& Environment, 126: 67-80. 


\section{Supplementary material}

Supplementary Table 1 Representative individuals from the genetic groups of C. canephora as defined by Merot-L'anthoene et al. (2019) and their origin.

\begin{tabular}{|c|c|c|c|c|}
\hline Genetic group & No & Country & Collection & No \\
\hline \multirow[t]{3}{*}{ A } & 4 & & & \\
\hline & & Congo & CNRA & 3 \\
\hline & & Gabon & Meise & 1 \\
\hline \multirow[t]{4}{*}{ B } & 8 & & & \\
\hline & & Central African Republic & CNRA & 3 \\
\hline & & & IRD & 3 \\
\hline & & Democratic Republic of the Congo & Meise & 2 \\
\hline \multirow[t]{4}{*}{$\mathrm{C}$} & 6 & & & \\
\hline & & Cameroon & CNRA & 4 \\
\hline & & Congo & CNRA & 1 \\
\hline & & Central African Republic & CNRA & 1 \\
\hline \multirow[t]{3}{*}{$\mathrm{D}$} & 9 & & & \\
\hline & & Côte d'Ivoire & CNRA & 8 \\
\hline & & Republic of Guinea & CNRA & 1 \\
\hline \multirow[t]{8}{*}{$\mathrm{E}$} & 23 & & & \\
\hline & & Cameroon & Meise & 1 \\
\hline & & & CNRA & 4 \\
\hline & & Congo & CNRA & 7 \\
\hline & & Côte d'Ivoire & CNRA & 3 \\
\hline & & Central African Republic & CNRA & 2 \\
\hline & & Democratic Republic of the Congo & Meise & 2 \\
\hline & & & ICCRI & 4 \\
\hline \multirow[t]{2}{*}{ G } & 6 & & & \\
\hline & & Angola & INCA & 6 \\
\hline \multirow[t]{2}{*}{$\mathrm{R}$} & 6 & & & \\
\hline & & Democratic Republic of the Congo & ICCRI & 6 \\
\hline Total & 62 & & & \\
\hline
\end{tabular}


Supplementary Table 2 Description of 19 the SSR markers used for DNA fingerprinting of the Ugandan Coffee samples including their forward and reverse primer sequences. The linkage group (LG) and the chromosome (Chr.) positions are indicated and complementary information can be found in MoccaDB: http://moccadb.ird.fr/ (Plechakova et al. 2009, Merot-L'anthoene et al. 2019) and in the coffee genome hub: http://coffee-genome.org/ (Dereeper et al.2014).

\begin{tabular}{lclllll}
\hline Marker & $\begin{array}{l}\text { Primer } \\
\text { code }\end{array}$ & Forward Primer & $\begin{array}{l}\text { MoccaDB } \\
\text { code }\end{array}$ & LG & Chr. \\
\hline R338 & R338 & CGAAGGCTGTCAACAACTGG & GGGATAAACAAGTTAAAGGA & NA & E & \\
SSR146 & 122850 & TCCAGTTTGATCAGCAACCA & CCATCTTGGGGATAGAGCAA & NA & F & \\
R278 & R278 & TGTAGATTTGAAACCCAATC & AAGTCTCGACAAGTTTTGAC & R278 & E & 5 \\
R339 & R339 & ATTATGCTCGCTGGGCTGT & TGGGATCACTCCTGTGTCGC & R339 & G & 7 \\
R336 & R336 & TTGCCTTTTTAGTGCGTGTA & GCAAAGCCCGAGGATT & NA & A & \\
R325 & R325 & CCTTGTTGTTGGGGAATGTC & GGCTGTTCTGGGCTTTGTG & R325 & F & 6 \\
SSR196 & 124195 & ATCCCCATCAGAAGACCTCA & CCTCCACCGCCTGTTTATTA & NA & NC & \\
R301 & R301 & CTCACCCAGCATTTAGAGT & GTTATTTGCCCATCAGG & R301 & D & 4 \\
R268 & R268 & GTATCCCACAATGAAATCAC & AGTAGAATTTTCAACATATAAG & R268 & G & 7 \\
R168 & R168 & CCTGGACTGGTAGAAACAAA & AAAGGTGTTCAATGCCTACA & R168 & A & 1 \\
R189 & R189 & GGAGTGAGAGGAGGGCGTAG & GAGAGAGGGACACTGCTGC & R189 & F & 6 \\
SSR495 & 124161 & TCGGCTCCCAAATATTCATC & CATGAGGCAAGAGGGTTTGT & ssr124161 & A & 1 \\
SSR497 & 123909 & AGGCTTGCTGGAACTCTTGA & GAAAGACTTGTCCTTTGCCG & ssr123909 & B & \\
R175 & R175 & GCAGTGACGCAGCAATG & AAAAGGAGAGCCAAAGCAGT & R175 & F & 6 \\
R250 & R250 & GCATCATTGGGTTGGTGG & CGACTTTCCGCACGCAAAC & R250 & I & 9 \\
R148 & R148 & CGTCGTTCGAGGACTTGTC & TTCGCAATCCCAGACCC & R148 & D & 4 \\
SSR209 & 119699 & GCCGTGGTGGAAGATGTACT & CGAGTTCACCAAGAACGTCA & ssr119699 & A & 1 \\
R342 & R342 & GCGAGAATAAGGAGTGACC & GTCCCTTTTTGTCTGGACC & NA & G & \\
SSR533 & 123557 & ATCTCCTCGTTCTTCCCCAT & GCTTGTAGCAGGCAGGAAAC & ssr123557 & B & 2 \\
\hline
\end{tabular}




\section{Chapter 2}

Supplementary Table 3 Environmental variables. The 19 bioclimatic (BIOx) variables averaged for the years (1950-2000) were downloaded from WorldClim database (www.worldclim.org) at 30 arcsecond resolution (Hijmans et al., 2005). Altitude was determined in the field by GPS (Garmin eTrex 10 Navigation device). The wetness index (WI) and potential evapotranspiration (PET) data were sourced from the Global-Aridity dataset (Zomer et al., 2008).

\begin{tabular}{|c|c|}
\hline Environmental variables & Abbreviation \\
\hline Annual mean temperature $\left({ }^{\circ} \mathrm{C}\right)$ & BIO1 \\
\hline Mean diurnal range $\left({ }^{\circ} \mathrm{C}\right)$ & $\mathrm{BIO} 2$ \\
\hline Isothermality $(\mathrm{BIO} / \mathrm{BIO} 7)(* 100)\left({ }^{\circ} \mathrm{C}\right)$ & $\mathrm{BIO} 3$ \\
\hline Temperature seasonality $\left({ }^{\circ} \mathrm{C}\right)$ & $\mathrm{BIO} 4$ \\
\hline Max temperature of the warmest month $\left({ }^{\circ} \mathrm{C}\right)$ & $\mathrm{BIO} 5$ \\
\hline Min temperature of the coldest month $\left({ }^{\circ} \mathrm{C}\right)$ & $\mathrm{BIO6}$ \\
\hline Temperature annual range $\left(\mathrm{BIO} 5\right.$-BIO6) $\left({ }^{\circ} \mathrm{C}\right)$ & $\mathrm{BIO} 7$ \\
\hline Mean temperature of the wettest quarter $\left({ }^{\circ} \mathrm{C}\right)$ & $\mathrm{BIO} 8$ \\
\hline Mean temperature of the driest quarter $\left({ }^{\circ} \mathrm{C}\right)$ & BIO9 \\
\hline Mean temperature of the warmest quarter $\left({ }^{\circ} \mathrm{C}\right)$ & $\mathrm{BIO} 10$ \\
\hline Mean temperature of the coldest quarter $\left({ }^{\circ} \mathrm{C}\right)$ & $\mathrm{BIO11}$ \\
\hline Annual precipitation (mm) & $\mathrm{BIO} 12$ \\
\hline Precipitation of the wettest month (mm) & $\mathrm{BIO13}$ \\
\hline Precipitation of the driest month (mm) & $\mathrm{BIO} 14$ \\
\hline Precipitation seasonality (mm) & $\mathrm{BIO} 15$ \\
\hline Precipitation of the wettest quarter (mm) & BIO16 \\
\hline Precipitation of the driest quarter $(\mathrm{mm})$ & $\mathrm{BIO} 17$ \\
\hline Precipitation of the warmest quarter (mm) & $\mathrm{BIO} 18$ \\
\hline Precipitation of the coldest quarter (mm) & BIO19 \\
\hline Altitude (m.a.s.l.: meter above sea level) & ALT \\
\hline Wetness index & WI \\
\hline Potential evapotranspiration & PET \\
\hline
\end{tabular}


Supplementary Table 4 Pairwise. t. test results to test the differences between locations across locations of variables.

\begin{tabular}{|c|c|c|c|c|c|c|}
\hline \multicolumn{7}{|c|}{ Altitude (m.a.s.l.) } \\
\hline & Budongo & Itwara & Kalangala & Kibale & Mabira & Malabigambo \\
\hline Itwara & 0.000 & & & & & \\
\hline Kalangala & 0.000 & 0.000 & & & & \\
\hline Kibale & 0.000 & 0.000 & 0.000 & & & \\
\hline Mabira & 0.000 & 0.000 & 0.480 & 0.000 & & \\
\hline Malabigambo & 0.000 & 0.000 & 0.000 & 0.000 & 0.000 & \\
\hline Zoka & 0.000 & 0.000 & 0.000 & 0.000 & 0.000 & 0.000 \\
\hline \multicolumn{7}{|c|}{$\begin{array}{l}\text { Annual mean } \\
\text { temperature }\left({ }^{\circ} \mathrm{C}\right)\end{array}$} \\
\hline & Budongo & Itwara & Kalangala & Kibale & Mabira & Malabigambo \\
\hline Itwara & 0.000 & & & & & \\
\hline Kalangala & 0.000 & 0.000 & & & & \\
\hline Kibale & 0.000 & 0.000 & 0.000 & & & \\
\hline Mabira & 0.000 & 0.000 & 0.000 & 0.000 & & \\
\hline Malabigambo & 0.000 & 0.000 & 0.000 & 0.000 & 0.000 & \\
\hline Zoka & 0.000 & 0.000 & 0.000 & 0.000 & 0.000 & 0.000 \\
\hline \multicolumn{7}{|c|}{$\begin{array}{l}\text { Potential } \\
\text { evapotranspiration }\end{array}$} \\
\hline & Budongo & Itwara & Kalangala & Kibale & Mabira & Malabigambo \\
\hline Itwara & 0.000 & & & & & \\
\hline Kalangala & 0.000 & 0.000 & & & & \\
\hline Kibale & 0.000 & 0.000 & 0.000 & & & \\
\hline Mabira & 0.000 & 0.000 & 0.000 & 0.002 & & \\
\hline Malabigambo & 0.000 & 0.858 & 0.000 & 0.000 & 0.000 & \\
\hline Zoka & 0.000 & 0.000 & 0.000 & 0.000 & 0.000 & 0.000 \\
\hline \multicolumn{7}{|l|}{ Wetness index } \\
\hline & Budongo & Itwara & Kalangala & Kibale & Mabira & Malabigambo \\
\hline Itwara & 0.000 & & & & & \\
\hline Kalangala & 0.000 & 0.000 & & & & \\
\hline Kibale & 0.213 & 0.000 & 0.000 & & & \\
\hline Mabira & 0.000 & 0.000 & 0.000 & 0.000 & & \\
\hline Malabigambo & 0.000 & 0.690 & 0.000 & 0.000 & 0.000 & \\
\hline Zoka & 0.000 & 0.000 & 0.000 & 0.000 & 0.000 & 0.000 \\
\hline
\end{tabular}


Chapter 2

Supplementary Table 5 Differentiation $\left(\mathrm{F}_{\mathrm{st}}\right)$ between native sites. $\mathrm{F}_{\text {st }}$ values are below the diagonal, and probabilities, i.e. $\mathrm{P}$ (rand $\geq$ data) based on 999 permutations, are shown above the diagonal.

\begin{tabular}{llccccccc}
\hline & & \multicolumn{3}{c}{ Southern-central (SC)-forests } & \multicolumn{3}{c}{ North-western (NW)- forests } \\
\hline & & Kalangala & Mabira & Malabigambo & Kibale & Itwara & Budongo & Zoka \\
\hline $\begin{array}{l}\text { SC- } \\
\text { forests }\end{array}$ & Kalangala & & 0.045 & 0.011 & 0.001 & 0.001 & 0.001 & 0.001 \\
& Mabira & 0.018 & & 0.001 & 0.001 & 0.001 & 0.001 & 0.001 \\
& Malabigambo & 0.036 & 0.053 & & 0.001 & 0.001 & 0.001 & 0.001 \\
NW- & Kibale & 0.216 & 0.205 & 0.170 & & 0.001 & 0.001 & 0.001 \\
forests & Itwara & 0.216 & 0.176 & 0.145 & 0.150 & & 0.001 & 0.001 \\
& Budongo & 0.115 & 0.119 & 0.084 & 0.127 & 0.152 & & 0.001 \\
& Zoka & 0.112 & 0.099 & 0.095 & 0.149 & 0.180 & 0.055 & \\
\hline
\end{tabular}




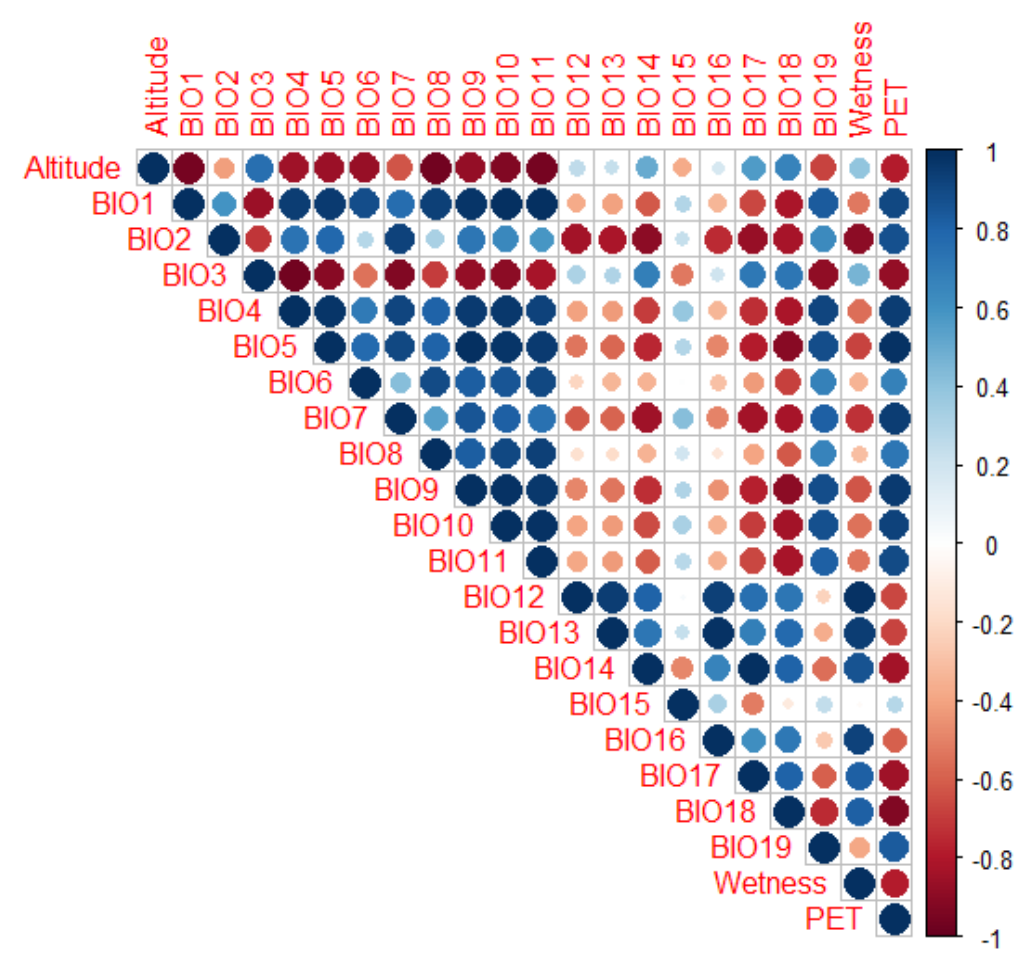

Supplementary Figure 1 Pearson correlation coefficients between 22 environmental variables. Altitude, Annual Mean Temperature (BIO1), Mean Diurnal Range (Mean of monthly (max temp - min temp)) (BIO2), Isothermality (BIO2/BIO7) (* 100) (BIO3), Temperature Seasonality (standard deviation *100) (BIO4), Max Temperature of Warmest Month (BIO5), Min Temperature of Coldest Month (BIO6), Mean Temperature of Wettest Quarter (BIO8), Mean Temperature of Driest Quarter (BIO9), Mean Temperature of Warmest Quarter (BIO10), Mean Temperature of Coldest Quarter (BIO11), Annual Precipitation (BIO12), Precipitation of Wettest Month (BIO13), Precipitation of Driest Month (BIO14), Precipitation Seasonality (Coefficient of Variation) (BIO15), Precipitation of Wettest Quarter (BIO16), Precipitation of Driest Quarter (BIO17), Precipitation of Warmest Quarter (BIO18), Precipitation of Coldest Quarter (BIO19), Wetness Index (Wetness),Potential evapotranspiration (PET). The blue and red colors indicate positive and negative correlations respectively while color intensity and the size of the circle are proportional to the correlation coefficients. The right side of the figure shows the legend displaying the correlation coefficients and the corresponding colors significant at $\mathrm{p} \leq 0.05$. 


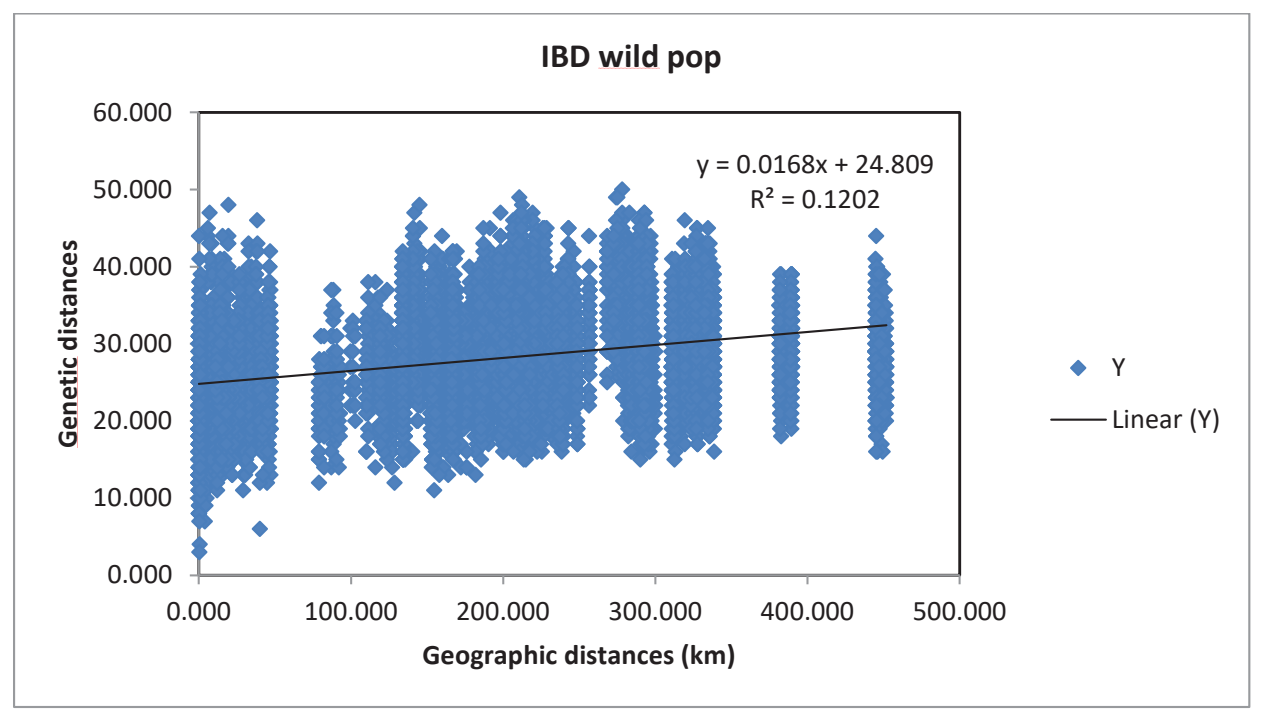

Supplementary Figure 2 Isolation by Distance (IBD): Correlation between pairwise genetic distances of Ugandan C. canephora wild individuals with pairwise geographical distances (Mantel test with 999 permutations at $\mathrm{p}=0.01$ ).

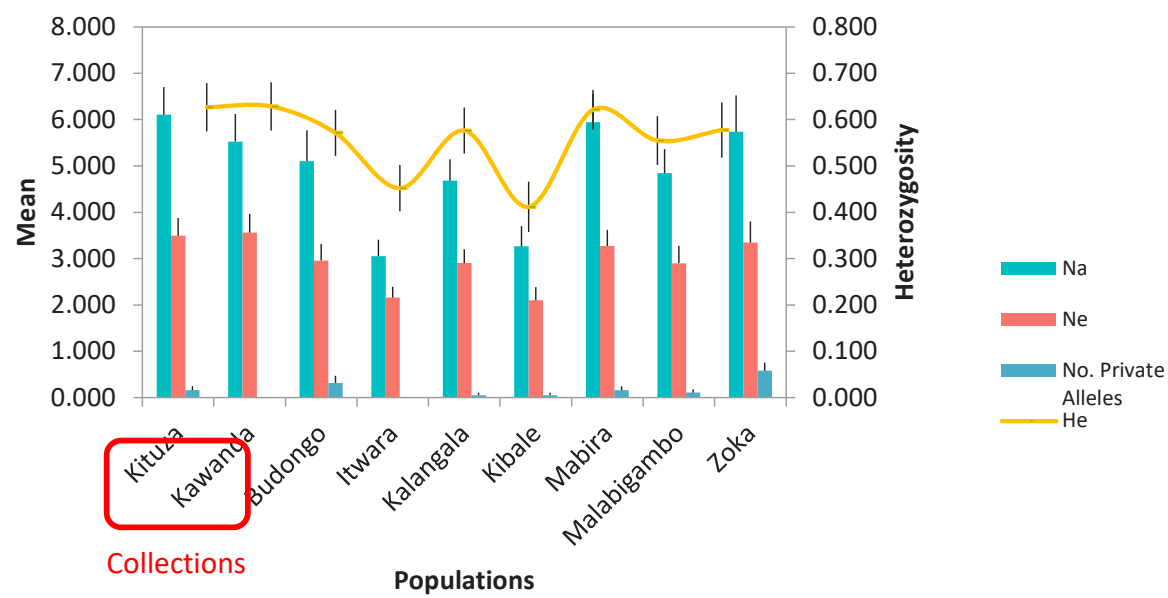

Supplementary Figure 3 Allelic pattern across wild populations and material maintained in common gardens. Mean values over loci are provided for each native forest and the two collections: number of alleles $(\mathrm{Na})$, number of effective alleles $(\mathrm{Ne})$, number of private alleles, and expected heterozygosity $\left(\mathrm{H}_{\mathrm{e}}\right.$ yellow curve). 


\section{Chapter 3}

\section{Intraspecific variation in growth response to drought stress across geographic locations and genetic groups in Coffea canephora Pierre ex A. Froehner}




\title{
Chapter 3
}

\begin{abstract}
Climate change is reported to escalate severity and frequency of drought spells, hence threatening global coffee production. Uganda lies within the drier end of the natural global distribution range of Coffea canephora and contains unexplored genetic material that could be drought adapted and thus a valuable resource for developing climate resilient varieties. We set up a large-scale screening experiment, involving 148 genotypes collected from seven native habitats and two research stations, and thus comprising wild, feral and cultivated C. canephora. Two water treatments, (i) ample and (ii) restricted, were imposed on 20-months-old plants for a four months period. Data on biomass allocation, standing leaf area and leaf area growth were collected. Linear mixed effect models were used to analyse the effect of drought on genotypes from different: (i) cultivation status, (ii) genetic groups and (iii) locations. We explored the relationship between absolute performance in ample and restricted water conditions; using relative growth rate in leaf area (RGRA $\left.\left[\mathrm{d}^{-1}\right]\right)$ as a proxy. Finally, we assessed the relationship between drought tolerance ratio of RGRA under restricted (RGRA $\left.A_{\text {restricted }}\right)\left(\right.$ RGRA $\left._{\text {ample }}\right)$ of genotypes and the wetness of their habitats. Restricted-water treatment resulted in reductions in RGRA that differed substantially across locations $(7.1-36.7 \%)$, genetic groups $(3.2-32.5 \%)$ but not between wild and cultivated genotypes. RGRA under ample-water was negatively correlated to tolerance in RGRA to restricted- water, indicating a growth tolerance trade off. Across locations, tolerance in RGRA was negatively correlated with the climate wetness index suggesting some degree of local climate adaptation in Uganda's C. canephora. Findings imply that breeding efforts towards drought tolerance should focus on weakening or breaking the negative association between tolerance and performance of genotypes in favourable conditions.
\end{abstract}

Key words: Coffea canephora, drought, intraspecific variation, growth tolerance trade-off, local adaptation 


\section{Introduction}

Water availability is a major factor limiting global coffee production largely because of the drought sensitivity of Coffea species and because a large fraction of the production is sustained by small-holder farmers who usually lack resources to establish irrigation facilities (DaMatta and Ramalho, 2006, Wintgens, 2004, Craparo et al., 2015). Problems of water limitation in coffee production may be aggravated by climate change. Across the coffee production belt, a temperature increase of $2.1^{\circ} \mathrm{C}$ has been predicted by 2050 (Parry et al., 2007, IPCC, 2014) and this warming can directly result in increased vapour pressure deficits, higher potential evapotranspiration and hence drought stress in plants. Indirectly, the increase in global average temperatures is expected to result in drastic shifts in the annual precipitation with more frequent occurence of severe droughts (Schiermeier, 2008). These changes together may have strong negative effects on coffee production (Bunn et al., 2015), but see Verhage et al. (2017). The global distribution and production of coffee is therefore likely to be significantly affected by climate change (DaMatta and Ramalho, 2006, Davis et al., 2012, Jassogne et al., 2013). There is thus a need for finding or developing drought tolerant genotypes, and one way of achieving this is to explore the natural diversity in wild coffee populations.

C. canephora is native to African tropical lowland forests stretching from Guinea in West Africa through the Congo River Basin to Uganda in East Africa (Berthaud, 1986, Montagnon et al., 1992, Coste, 1992, Davis et al., 2006). Generally, these tropical forests are characterized by abundant rainfall (precipitation $>2000 \mathrm{~mm}$ ) with a short or no dry season, high atmospheric humidity and stable average temperatures between $24{ }^{\circ} \mathrm{C}$ and $26{ }^{\circ} \mathrm{C}$ (Coste, 1992, DaMatta and Ramalho, 2006, DaMatta et al., 2018). However, even in these moist tropical forests there occur periodic water shortages due to dry spells (Engelbrecht et al., 2006). Furthermore, the natural geographical distribution of C. canephora extends into the somewhat drier areas (Masih et al., 2014), e.g. in Uganda. Tree growth is commonly observed to decrease with drought intensity (Grime and Hunt, 1975, Chapin III, 1980, Poorter and Remkes, 1990, Poorter and Garnier, 1999). Across species, drought tolerance (i.e., the ability of a plant to maintain its performance under dry conditions) was found to be subject to a trade-off between tolerance and growth: slow-growing species, using a conservative strategy, were the least sensitive to variations in water availability, while fast-growing species using an acquisitive 


\section{Chapter 3}

strategy were the most sensitive (Ouédraogo et al., 2013, Grime and Hunt, 1975, Chapin III, 1980, Poorter and Remkes, 1990, Poorter and Garnier, 1999).

While multispecies comparisons are useful to understand ecological strategies and community composition, questions regarding natural selection and applications for breeding require additional intra-specific comparisons across wild accessions of a species. When an environmental stress gradient such as water availability acts as a selective force, one may expect tolerance of a genotype to this stress factor to be related to the climate in the site of origin (Alberto et al., 2013). Analyzing such patterns is important as it may provide insights into natural selection but may also provide basic information to assess adaptive potential to climate change and, for crops, identify drought tolerant genotypes (Rungwattana et al., 2018, Alberto et al., 2013). However, relatively few studies comparing wild accessions from different climates have been done for tropical trees such as coffee. Rungwattana et al. (2018) compared wild accessions of rubber (Hevea brasiliensis) from different locations across a rainfall gradient in the Amazon forest and found no correlation between any of the traits investigated and either temperature or rainfall at the site of origin. In $C$. canephora's congener, $C$. arabica, comparisons between nine accessions from different Ethiopian forests showed that accessions from drier areas were more plastic in leaf gas exchange traits in response to changes in water availability (Beining, 2008) but other studies with a similar set of accessions found no correlations between water availability as an experimental factor and leaf gas exchange traits (Kufa and Burkhardt, 2011).

Uganda has a been reported to have substantial C. canephora diversity (Musoli et al., 2009a, Kiwuka et al., submitted, Ngugi and Aluka, 2019) which could be explored to identify functional diversity in regards to drought stress. But to our knowledge so far, intra-specific comparisons of drought related traits in C. canephora have been limited to cultivated material e.g. in DaMatta et al. (2003), Dias et al. (2007), King'oro et al. (2014), Menezes-Silva et al. (2015), Pinheiro et al. (2004) and Silva et al. (2013). While the forementioned studies give important insights into the morphological and physiological drivers of drought tolerance, exploration of the variation in drought tolerance across wild populations and potential correlations with climate still need to be accomplished. Furthermore, none of the studies on tropical trees has explored the extent to which drought tolerance is associated with genetic diversity, a link which would provide helpful information to interpret drought adaptation. Finally, as far as we know, drought tolerance in coffee has also not been explored in a 
cultivation status trajectory, i.e. comparing wild, feral (second generation or higher of formerly cultivated material and abandoned for over 50 years) and cultivated genotypes. It is thus unknown whether cultivation of $C$. canephora has unwittingly selected for or against drought tolerance.

This study was thus set out to determine: (i) the effect of drought on vegetative growth of $C$. canephora genotypes collected across a climatic gradient in Uganda and categorised by (a) cultivation status; (b) genetic groups as characterised by Kiwuka et al. (submitted) ; (c) and location, indicating the different climatic envelopes; (ii) the relationship between performance under restricted-water and performance under ample-water conditions; (iii) the relationship between drought tolerance of genotypes and wetness index (WI) at the collection location. WI, the ratio of mean annual precipitation to mean annual potential evapo-transpiration (PET) is a reasonable proxy for local climate wetness whereby high WI indicates wetter climates and vice versa (note that we do not use the original but confusing name aridity index Zomer et al. (2008)) We hypothesized that since Ugandan wild C. canephora populations occur in different climatic envelopes, genotypes from locations with high temperatures, low precipitation, and high PET (Potential evapotranspiration) and thus dry conditions (lower WI) will have comparatively higher growth and performance under restricted-water conditions than genotypes from locations with low to moderate temperatures, high precipitation, higher WI and low PET (wet location). Additionally, we expect a trade-off between drought tolerance and performance, whereby the mechanisms that underlie drought tolerance in material from dry locations are associated with slow growth and inability to exploit favourable conditions (McGill et al., 2006, Sade et al., 2012, Amissah et al., 2018).

\section{Materials and Methods}

\section{Plant material}

A total of 228 genotypes of C. canephora Pierre ex Froehner were collected from the wild and from the National coffee germplasm collection fields in 2014 (Kiwuka et al., submitted). Each genotype was categorized according to three main sets of determinants (factors) namely: (1) cultivation status, (2) genetic group and (3) location.

Cultivation status were defined based on where the material was collected from and included three levels: (i) wild; represented by material collected from tropical natural forests (natural system), (ii) feral; represented by material collected from formerly cultivated and 


\section{Chapter 3}

currently abandoned (abandoned for at least 50 years) coffee fields. Caution was taken not to collect from trees that were older than 15 years, to ensure that feral material is sampled from plants that were belonging to at least the second generation of the abandoned coffee fields and (iii) cultivated; a subset represented by material collected from assembled $C$. canephora germplasm fields at the National Agricultural Research Organisation (NARO) institutes located at Kawanda and Kituza. The sampled cultivated material represented the range of traditional and commercial C. canephora diversity in Uganda's Robusta coffee cultivation and breeding system.

The second main category was genetic groups. Ugandan C. canephora diversity (Genetic group $(\mathrm{O})$ ) has been reported to be distinct from other known genetic groups at species level (Musoli et al., 2009a, Merot-l'Anthoene et al., 2019, Kiwuka et al., submitted). Ugandan C. canephora diversity uniquely differentiates into two main sub groups namely: (i) The Southern Central (genetic group SC) and (ii) the North Western (genetic group NW) which further differentiates into four groups corresponding to four forest locations (Itwara, Kibale Budongo and Zoka). (see Table 2) (Kiwuka et al., submitted).

The third category was geographic location. Uganda is categorized into 16 homogeneous climatological zones based on precipitation patterns (Basalirwa, 1995) and the country's $C$. canephora diversity occurs in five of these 16 distinct climatic zones (see Table 1 and Supplementary Figure 1a). The study materials were collected from nine locations in the five distinct climatic zones (Table 1). Each location was defined based on its geographic position and administrative boundaries: (i) Budongo; (ii) Itwara; (iii) Kalangala; (iv) Kibale; (v) Mabira; (vi) Malabigambo and (vii) Zoka (Table 1; Supplementary Figure 1a and b). Material from Kituza and Kawanda were not included because plants grown there were collected from other places. Regarding the environmental gradient across locations, NEMA (2009) showed that Zoka is at the driest end of the range, while Kalangala is at wettest end of the range. 
Table 1 Details about locations of the study material.

\begin{tabular}{|c|c|c|c|c|c|c|c|c|}
\hline $\begin{array}{l}\text { Location } \\
\text { (Code) }\end{array}$ & $\begin{array}{l}\text { Geo- } \\
\text { reference }\end{array}$ & $\begin{array}{l}\text { Cultivation } \\
\text { status }\end{array}$ & $\begin{array}{l}\text { No. of } \\
\text { genotypes }\end{array}$ & $\begin{array}{l}\text { Climatic } \\
\text { zones }\end{array}$ & $\begin{array}{l}\text { PET } \\
\left(\mathrm{mm} \mathrm{y}^{-1}\right)\end{array}$ & WI & $\begin{array}{l}\text { Annua } \\
1 \text { mean } \\
\text { temper } \\
\text { ature } \\
\left({ }^{\circ} \mathrm{C}\right)\end{array}$ & $\begin{array}{l}\text { Annua } \\
1 \\
\text { precipi } \\
\text { tation } \\
(\mathrm{mm}) \\
\end{array}$ \\
\hline $\begin{array}{l}\text { Budongo } \\
\text { (BD) }\end{array}$ & $\begin{array}{l}01^{\circ} 43^{\prime} 27^{\prime \prime} \mathrm{N} \\
31^{\circ} 32^{\prime} 45^{\prime \prime} \mathrm{E}\end{array}$ & wild & 16 & $\mathrm{~K}$ & 1740 & 0.76 & 23 & 1322 \\
\hline $\begin{array}{l}\text { Itwara } \\
\text { (IT) }\end{array}$ & $\begin{array}{l}00^{\circ} 47^{\prime} 29^{\prime \prime} \mathrm{N} \\
30^{\circ} 28^{\prime} 19^{\prime \prime} \mathrm{E}\end{array}$ & wild & 10 & $\mathrm{~L}$ & 1604 & 0.89 & 20 & 1422 \\
\hline $\begin{array}{l}\text { Kalangala } \\
(\mathrm{KL})\end{array}$ & $\begin{array}{l}00^{\circ} 26^{\prime} \mathrm{S} \\
32^{\circ} 15^{\prime} \mathrm{E}\end{array}$ & wild \& feral & 19 & A1 & 1560 & 1.25 & 21 & 1942 \\
\hline $\begin{array}{l}\text { Kawanda } \\
(\mathrm{KW})\end{array}$ & $\begin{array}{l}0^{\circ} 24^{\prime} 30.42^{\prime \prime} \mathrm{N} \\
32^{\circ} 32^{\prime} 09^{\prime \prime} \mathrm{E}\end{array}$ & cultivated & 19 & $\mathrm{~B}$ & 1624 & 0.76 & 22 & 1238 \\
\hline $\begin{array}{l}\text { Kibale } \\
\text { (KB) }\end{array}$ & $\begin{array}{l}00^{\circ} 30^{\prime} \mathrm{N} \\
30^{\circ} 24^{\prime} \mathrm{E}\end{array}$ & wild & 9 & $\mathrm{~L}$ & 1637 & 0.77 & 20 & 1267 \\
\hline $\begin{array}{l}\text { Kituza } \\
(\mathrm{KT})\end{array}$ & $\begin{array}{l}0^{\circ} 15^{\prime} 26.81^{\prime \prime} \mathrm{N} \\
32^{\circ} 47^{\prime} 27.7^{\prime \prime} \mathrm{E}\end{array}$ & cultivated & 28 & B & 1573 & 0.93 & 21 & 1464 \\
\hline $\begin{array}{l}\text { Mabira } \\
(\mathrm{MB})\end{array}$ & $\begin{array}{l}0^{\circ} 23^{\prime} 54^{\prime \prime} \mathrm{N} \\
33^{\circ} 0^{\prime} 59^{\prime \prime} \mathrm{E}\end{array}$ & wild & 15 & B & 1652 & 0.82 & 22 & 1356 \\
\hline $\begin{array}{l}\text { Malabigambo } \\
(\mathrm{ML})\end{array}$ & $\begin{array}{l}00^{\circ} 57^{\prime} 7^{\prime \prime} \mathrm{S} \\
31^{\circ} 38^{\prime} 25^{\prime \prime} \mathrm{E}\end{array}$ & wild & 7 & A1 & 1604 & 0.88 & 21 & 1414 \\
\hline $\begin{array}{l}\text { Zoka } \\
(\mathrm{ZK})\end{array}$ & $\begin{array}{l}03^{\circ} 01^{\prime} 03.0^{\prime \prime} \mathrm{N} \\
31^{\circ} 39^{\prime} 21.0^{\prime \prime} \mathrm{E}\end{array}$ & wild & 25 & $\mathrm{~J}$ & 1869 & 0.68 & 24 & 1267 \\
\hline \multicolumn{9}{|c|}{$\begin{array}{l}\text { Climatic zones as classified by Basalirwa (1995): A1, B, K, L, J (see Supplementary Figure 1b); PET values } \\
\text { were estimated following Hargreaves and Samani (1985) who use mean monthly temperature, mean monthly } \\
\text { temperature range and mean monthly extra-terrestrial radiation (Zomer et al., 2008) while WI (wetness } \\
\text { index; (Aridity index in Zomer et al. (2008)) defined as a ratio of mean annual precipitation to mean annual } \\
\text { potential evapo-transpiration (PET). Note that the Kawanda and Kituza are not in the analysis of location } \\
\text { effects. }\end{array}$} \\
\hline
\end{tabular}


Table 2 Number of genotypes included in the study per genetic group per location.

\begin{tabular}{|c|c|c|c|c|c|}
\hline \multirow[t]{3}{*}{ Location } & \multicolumn{5}{|c|}{ Genetic groups } \\
\hline & \multirow[t]{2}{*}{$\mathrm{SC}$} & \multicolumn{4}{|c|}{ NW } \\
\hline & & Itwara & Kibale & Budongo & Zoka \\
\hline \multicolumn{2}{|l|}{ Budongo } & & & 11 & \\
\hline \multicolumn{2}{|l|}{ Itwara } & 10 & & & \\
\hline Kalangala & 18 & & & & \\
\hline Kawanda & 14 & & & & \\
\hline Kibale & & & 7 & & \\
\hline Kituza & 24 & & & & \\
\hline Mabira & 13 & & & & \\
\hline Malabigambo & 7 & & & & \\
\hline Zoka & & & & & 23 \\
\hline \multicolumn{6}{|c|}{$\begin{array}{l}\text { This genetic grouping is as per Kiwuka et al. (submitted). SC (Southern Central), NW (North Western; } \\
\text { which differentiates into four other distinct groups namely: Itwara, Kibale, Budongo and Zoka). Note: } \\
\text { genotypes that were misclassified and/or hybrids }\end{array}$} \\
\hline
\end{tabular}

\section{Sampling strategy}

Following Musoli et al. (2009a), a hierarchical sampling strategy was employed to collect samples (stem cuttings) from the different locations. Wild material was collected from seven tropical natural forests namely: (i) Budongo forest; (ii) Itwara Central Forest Reserve; (iii) Kalangala (Lutoboka central forest reserve); (iv) Kibale forest national park; (v) Mabira forest reserve; (vi) Malabigambo forest and (vii) Zoka forest. In each location (forest) except Kalangala, samples were collected from five sub-sites that were separated by distances of at least $5 \mathrm{~km}$. From each sub-site, five healthy $C$. canephora trees were identified from which we collected stem cuttings. Since C. canephora is an allogamous species, each sampled plant was considered to be genetically unique and thus each sampled tree was regarded as a distinct genotype in this study. This assumption that each sampled tree is a unique genotype was confirmed by genetic analysis in Kiwuka et al. (submitted). Contrary to other locations, the Kalangala site comprised remnants of natural forest systems and secondary forests regenerated from formerly cultivated coffee fields, and thus the coffee populations in Kalangala were considered wild or feral depending on where they were collected from. Samples that were collected from fragmented natural forest compartments were regarded as wild while samples from collected abandoned cultivation fields were considered as feral. 


\section{Stem cutting establishment}

All the collected stem cuttings were rooted in a screen house at the National Agricultural Research Laboratories (NARL), Kawanda at $0^{\circ} 25^{\prime}$ N, $32^{\circ} 32^{\prime}$ E, $1195 \mathrm{~m}$ a.s.1., starting on $30^{\text {th }}$ May 2015. The establishment of the material from stem cutting followed a tested protocol by the National Coffee Research Institute (NaCORI, unpublished). The collected stem cuttings were cut into smaller $7 \mathrm{~cm}$ internodal wood cuttings with one pair of leaves. A total of 7,419 internodal cuttings, for all the collected genotypes (230) were planted in polypots and placed in transparent plastic cages for root establishment. The number of cuttings per genotype ranged from 7-99 the median being 33. The polypots had a diameter of $5 \mathrm{~cm}$ and a height of $7 \mathrm{~cm}$ and were filled with a mixture of top soil, sand and manure in a ratio of 3:2:2 by volume. Before planting, each stem cutting was dipped in rooting hormone (Seradix ' 2 ', $0.8 \% \mathrm{w} . \mathrm{w}$, IBA, Twiga Chemicals Industries, Nairobi, Kenya) to boost their rooting potential. After seven months, the young plants that had grown from the cuttings were hardened off, transferred into $10 \mathrm{~L}$ pots. The potting medium comprised of black soil, lake sand and manure in the ratio of $3: 1: 1$, with a volumetric water content of $30 \%( \pm 0.22)$ at field capacity and $6 \%( \pm 0.16)$ and permanent wilting point respectively. Ten grams of NPKS (25:5:5 and 5) compound fertilizer was added per pot. Pots were optimally irrigated for six months before starting the experimental treatments.

\section{Experimental design}

Eighty two out of the 230 collected genotypes produced fewer than the five minimally required rooted plantlets, leaving 148 genotypes to start the experiment with. From October $10^{\text {th }}$ to $15^{\text {th }} 2016,16$ months after re-planting the stem cuttings, 1184 rooted plants were arranged into a split-plot design; with two watering regimes (ample vs restricted water) as the main factor and the different C. canephora genotypes as the sub-factors. Plants were grown in a 'rain out' screen house ( $40 \mathrm{~m}$ by $6.5 \mathrm{~m}$ ) that was blocked into four sections, based on the variation in radiation that was visually assessed (148 remaining genotypes $\mathrm{x} 4$ blocks (with each split into two) x 2 water regimes (ample and restricted).

To establish ample vs restricted water availability treatments, we assessed the potting medium's properties e.g. water content at field capacity, permanent wilting point and the daily evapotranspiration rates within the screen house by weighing over time a selection of 10 pots. Soil water loss was also estimated from monitoring soil moisture content in pots using a soil moisture sensor (Trime-Pico 64/32, HD2 IMKO Micromodultechnik, Ettlingen, Germany). The 


\section{Chapter 3}

ample-water treatment was set at $25 \mathrm{v} \%$ which was about $80 \%$ of soil moisture content at field capacity, while the drought stressed regime (restricted-water) was sustained at $10 \mathrm{v} \%$ which was about $60 \%$ more soil moisture than that present at permanent wilting point.

Plants in the ample-water treatment received on average $1000 \mathrm{ml}$ of water while plants in the restricted water treatment were given $300 \mathrm{ml}$ of water per watering interval. For the ample-water treatment the watering interval was, on average, once a week. Plants in the restricted water treatment were subjected to gradually increasing severity of drought stress and the basic regime (modulated according to plant size (see further next paragraph)) was that on average, plants received $300 \mathrm{ml}$ per week for the first month, $300 \mathrm{ml}$ per fortnight for the following month, a onetime $300 \mathrm{ml}$ water gift in the third month and finally a month without water.

To minimize the potential plant-size drought bias i.e., the fact that larger plants consume more water and are thus exposed on average to drier conditions, the following procedure was used: in the initial experimental phase, a sub-set of plants (54 plants; selected to represent the architectural [number of leaves, number of primary branches, number of suckers and leaf area], variation across the experiment) were monitored to determine their soil water content (both gravimetrically and with the soil moisture probe) every week and their corresponding number of leaves, number of primary branches, number of suckers and leaf area were non-destructively estimated. Leaf area of fully expanded leaves was estimated from leaf length and width using the linear model (area per leaf = leaf length $\mathrm{x}$ leaf width $\mathrm{x} \mathrm{k}(\mathrm{k}=$ correction factor $=0.66)$ ) of Schmildt et al. (2015). These data yielded a correlation between leaf area and water loss and the relation was used as a guide to determine the frequency of watering for every plant based on its leaf area. This procedure ensured that size dependent effects on the actual soil moisture experienced by plants were minimized. At the end of the experiment, it appeared that the amount of water supplied (WS (ml)) to each plant was described by the formula: WS $(\mathrm{ml})=$ $1479+0.178$ (leaf area) $\left.\left(\mathrm{cm}^{2}\right)\right), \mathrm{p}=0.000$ and $\mathrm{R}^{2}=0.27$.

The experimental treatment period lasted four months (from plant age 20 months to 24 months; age zero is when the stem cuttings were planted to root). Data on temperature and relative humidity in the screen-house were recorded by sensors with data logging (Tinytag logger Plus 2 Dual Channel Temperature/Relative Humidity, TGP-4500, Gemini data loggers Ltd., Chichester, Chichester West Sussex, UK) on an hourly basis. The average daily 
temperatures and relative humidity of the screen-house throughout the experimental treatment period were: $23.1^{\circ} \mathrm{C}( \pm 4.3)$ and $83.1 \%( \pm 18.0)$ respectively.

\section{Data collection}

Data were collected at three stages: (i) at the start of the treatment phase; (ii) during the treatment phase and at (iii) the end of the treatment phase (Supplementary Table 1). At the start of the treatment phase on $25^{\text {th }}$ May 2017 (plant age 20 months) several non-destructive measurements were done to provide a baseline for later size increment measurements: plant height, number of nodes, number of leaves (fully grown and proportion/fractions from estimated full size of developing ones), length and width of fully expanded leaves and stem diameter at $5 \mathrm{~cm}$ from the base. After these measurements, the youngest fully expanded leaf pair was marked, to establish a recognition point for measuring new growth. The second data collection stage (at the point when $10 \%$ of the material subjected to drought treatment started showing signs of drought stress), was taken 21-24 June 2017. The final measurement occasion, at the end of the treatment phase was conducted taken 12-26 September 2017, with measured traits as listed in Supplementary Table 1.

\section{Methods to measure plant properties}

Plant height was measured vertically using a meter ruler from the base (point of origin from the cutting) to the last node. To estimate area per leaf, we used the same model as that used for determining leaf area in relation to the watering regimes i.e. we measured length and width and then used the linear model (leaf length $\mathrm{x}$ leaf width $\mathrm{x} k$ (correction factor)) of Schmidt et al. (2015) on all fully unfolded leaves and obtained a correction factor ( $\mathrm{k}$ of 0.67 ) that was used on all measured leaves. Leaf area on the main stem was measured in this way for all plants. But due to the necessity to reduce the work load, leaf area of primaries and suckers was measured directly on all plants in one block only. For every genotype the leaf area of primaries and suckers in blocks 2, 3 and 4 were estimated from the ratio of fresh weight to leaf area, generated from the measured plants in block 1, yielding an estimate for the ratio between leaf area and leaf fresh weight. At the end of the experiment, for each plant, leaves were separated into leaves from main stem, primaries and suckers. Fresh weight of all leaves was estimated by weighing fresh leaves while leaf dry weights were measured after oven drying $\left(70{ }^{\circ} \mathrm{C}\right.$ to a constant weight). Specific leaf area was estimated from the leaf area and leaf dry weight. The roots of each plant were harvested and cleaned under running water and on a wire mesh. Using water displacement method, fine roots (excluding the tap root with diameter larger than $3 \mathrm{~mm}$ ) 


\section{Chapter 3}

were dipped in a $100 \mathrm{ml}$ measuring cylinder to estimate their root volume. The root volume and leaf area of each plant was used estimate the root volume to leaf area ratio (RL).

In this study, relative growth rate in leaf area (RGRA, i.e., the leaf area increments during the drought treatment period relative to the amount of standing leaf area) was taken as the main proxy to assess performance of the plants under restricted and ample availability of water. The use of relative- rather than absolute growth rates-was for two reasons: (i) to reduce confounding effects of initial plant size and (ii) we dealt with very young plants for which the assumption of them being in exponential growth phase was reasonable. We focused on leaf area because of practical reasons (measurable non-destructively; base measurements of biomass were not available) and because leaf area determines light interception capacity, photosynthesis and subsequent growth (Poorter and Remkes, 1990, Weraduwage et al., 2015). RGRA was calculated as

$\mathrm{RGRA}=\frac{\ln (\text { leaf area at end of the treatment phase })-\ln (\text { Leaf area at start of the treatment phase })}{\text { time end-time start }}$

(Eqn 1)

Drought tolerance in RGRA (DTRGRA) of each genotype, defined as the capacity of a genotype to maintain its growth under drought stress (restricted water), was computed per genotype as the ratio of the mean RGRA in restricted water to mean RGRA in ample water across blocks.

$$
D T(\text { RGRA })=\frac{\text { Mean RGRA }(\text { Restricted water })}{\text { Mean RGRA (Ample water })}
$$

In addition to RGRA a few other traits were used to further characterize material and their response to drought stress, namely: number of leaves (NL) leaf area (LA $\left.\left[\mathrm{cm}^{2}\right]\right)$, leaf dry weight (LDW $[\mathrm{g}]$ ), specific leaf area (SLA $\left[\mathrm{cm}^{2} \mathrm{~g}^{-1}\right]$ ) and root volume to leaf area ratio (RL $\left[\mathrm{cm}^{3} \mathrm{~cm}^{-}\right.$ $\left.{ }^{2}\right]$ ). Note that all traits, except root volume (and except when stated otherwise), refer to growth during the drought treatment period, excluding the biomass at the start of treatments. 


\section{Data analysis}

Linear mixed effect models, were applied to test the effects of water treatment on selected growth traits across (i) cultivation status, (ii) genetic group or (iii) location. Linear mixed effect models were used because mixed models account for unbalanced, nested designs (such as varying numbers of genotypes by cultivation status, genetic groups and location) that occurred in our data (Bates et al., 2015). To estimate the impact of water shortage on plant traits across of cultivation status genetic groups and locations, genotypes were considered a random effect both in terms of the intercept: i.e., the absolute trait value in ample water, and the slope: i.e., the response to drought (difference between the trait value in ample and restricted water conditions). To account for heterogeneity of variance in the observations, variances in the traits were dependent on the cultivation status, genetic group or location (Zuur et al., 2009).

The model with cultivation status had 12 parameters: three levels of cultivation status (CS) and two water treatments (making six parameters), three parameters of the random effect to model differences across genotypes: (i) a parameter to model the variation of traits in ample water conditions (intercept), (ii) a parameter related to the variation in the treatment effect (slope), and (iii) a parameter that models the correlation between the intercept and the slope, and three parameters to account for a different residual variance per cultivation status. The model with genetic group had 18 parameters: two for each genetic group (makes ten) and three parameters of the random effect to model differences across genotypes: (i) a parameter to model the variation of traits in ample water conditions (intercept), (ii) a parameter related to the variation in the effect of the treatment effect (slope), and (iii) a parameter that models the correlation between the intercept and the slope, and five parameters to account for a different residual variance per genetic group. Note that while testing the genetic group effect, all genotypes that were misclassified and/or hybrids were not considered.

Running the factor location analysis, we test both for differences in terms of environment but also for genetic basis, and thus, indirectly for putative local adaptation. Therefore, the model with location had in total 24 parameters, two for each location (14) and three parameters of the random effect to model differences across genotypes: a parameter to model the variation of traits in control (intercept), a parameter related to the variation in the 


\section{Chapter 3}

treatment effect (slope), a parameter that models the correlation between the intercept and the slope, and seven parameters to account for a different residual variance per location.

Post-hoc Tukey tests were performed to determine whether: (i) drought had significant effects on performance (RGRA) of genotypes across cultivation status, genetic groups and location; (ii) genotypes of different of cultivation status, genetic groups or location responded significantly differently to drought and (iii) absolute performance of genotypes in ample water and restricted water conditions differed across cultivation status, genetic groups and locations. Tukey adjustment to p-values was done in case of multiple comparisons. The analyses were performed in R version 3.5.0 statistical software using "me", "emmeans" and "ggplot2" packages. For all the analyses, any effect with $\mathrm{p}<0.05$ was considered statistically significant and non-significant at $\mathrm{p}>0.05$.

Type (II) regression was performed to determine the relationship between absolute performance in restricted and absolute performance in ample water conditions. Type II regression was used to account for both measurement error in the independent and the dependent variable (Warton and Weber, 2002) and tests whether the slope is different from zero. Additionally, we used it to test if the slope of this regression line was less than one, indicating that genotypes that perform well under ample water conditions perform relatively less in restricted water conditions. The analysis was performed in $\mathrm{R}$ version 3.5.0 statistical software using the packages "smatr".

In addition, a weighted linear regression analysis was performed to determine the relationship between drought tolerance and wetness index. The analysis was performed in $\mathrm{R}$ version 3.5.0 statistical software. Because the number of replicates varied across genotypes in locations, we introduced weights for replicates in the analysis. In this weighted linear regression analysis, we excluded genotypes from Kawanda and Kituza because the genotypes in these collections were sourced from different origins and assembled as ex-situ collections at NARO institutes, and thus we could not retrieve the wetness index of these genotypes. The probability of rejecting the null hypothesis that there is no relationship between performance in low-water conditions and wetness index (WI) or no relationship between drought tolerance and wetness index (WI) was at $p$-value $>0.05$. The weighted linear regression models were fitted with $\operatorname{lm}()$ functions in $\mathrm{R}$ version 3.5.0 statistical software. 


\section{Results}

The study results are presented in hierarchical order starting with: (i) the effect of experimental treatments on the grand mean of growth response traits (i.e., lumping genotypes together), (ii) the main effects of factors, i.e. cultivation status, genetic groups and location, on growth response traits, (iii) the detailed synthesis of the effect of drought on RGRA as our proxy trait for plant performance, (iv) the relationship between performance under ample and restricted water-conditions, (v) the relationship between performance under restricted water conditions and wetness index of the locations and (vi) the relationship between drought tolerance and wetness index of the locations.

\section{Overall mean effects of drought on growth response traits}

The experimental treatment significantly affected all the studied traits (Tables 3 and 4). Relative growth rate in leaf area (RGRA $\left[\mathrm{d}^{-1}\right]$ ), number of leaves (NL), leaf area (LA $\left[\mathrm{cm}^{2}\right]$ ), leaf dry weight (LDW $[\mathrm{g}]))$ and specific leaf area (SLA $\left.\left[\mathrm{cm}^{2} \mathrm{~g}^{-1}\right]\right)$ were on average $(12-38 \%)$ lower in the resticted water- than in the ample water (Table 3). The larger declines for NL, LA than in LDW in the restricted water treatment is consistent with the negative effect of restricted water on SLA. Root volume to leaf area ratio $\left(\mathrm{RL}\left[\mathrm{cm}^{3} \mathrm{~cm}^{-2}\right]\right)$ was higher in restricted water conditions than in ample water conditions (Table 3), indicating a shift in the partitioning of resources towards root growth in drought conditions.

\section{Significance of cultivation status, genetic group and location on growth response traits}

In the linear mixed model analysis, the effects of factors (i.e., cultivation status, genetic group and location) varied across growth response traits (Table 4). The cultivation statusdid not have significant effects on RGRA, NL and LDW ( $p>0.05)$ but did significantly affect SLA and RL (Table 4). On average, wild genotypes had the highest SLA $\left(244 \mathrm{~cm}^{-2} \mathrm{~g}^{-1}\right)$ but the difference was only significant with the feral and not with cultivated genotypes (Supplementary Table 4). For RL, cultivated genotypes had a significantly higher average value $\left(0.0087 \mathrm{~cm}^{3} \mathrm{~cm}^{-2}\right)$ than wild and feral genotypes and there were no significant differences between wild and feral RL values (Supplementary Table 6). There were no signficant interaction effects between cultivation status and treatment for any of the selected traits, except for LA indicating that only for LA the treatment effect differed cultivation status. Under ample water conditions, cultivation status had no significant effects on LA while under restricted water conditions wild genotypes had a significantly lower LA than feral and cultivated genotypes whose LA's were not significantly affected by water availability. 
Table 3 Effect of drought on mean and standard error of selected growth response traits of $C$. canephora.

\begin{tabular}{llll}
\hline Trait & $\begin{array}{l}\text { Ample water } \\
\text { grand mean }(\mathrm{se})\end{array}$ & $\begin{array}{l}\text { Restricted water } \\
\text { grand mean }(\mathrm{se})\end{array}$ & $\begin{array}{l}\text { Relative change } \\
(\%)\end{array}$ \\
\hline RGRA $\left[\mathrm{d}^{-1}\right]$ & $0.016(0.0001)$ & $0.012(0.0001)$ & -25.0 \\
NL & $21(0.5)$ & $13(0.3)$ & -38.1 \\
LA $\left[\mathrm{cm}^{2}\right]$ & $3653(94)$ & $2526(53)$ & -30.9 \\
LDW $[\mathrm{g}]$ & $17(0.5)$ & $13(0.4)$ & -23.5 \\
SLA $\left[\mathrm{cm}^{2} \mathrm{~g}^{-1}\right]$ & $251(5)$ & $221(3)$ & -12.0 \\
RL $\left[\mathrm{cm}^{3} \mathrm{~cm}^{-2}\right]$ & $0.007(0.0002)$ & $0.009(0.0002)$ & 28.6 \\
\hline
\end{tabular}

Relative growth in leaf area (RGRA $\left[\mathrm{d}^{-1}\right]$ ), Number of leaves (NL), Leaf area (LA $\left[\mathrm{cm}^{2}\right]$ ), Leaf dry weight (LDW $[\mathrm{g}]$ ), Specific Leaf area (SLA $\left[\mathrm{cm}^{2} \mathrm{~g}^{-1}\right]$ ), Root volume to leaf area ratio $\left(\mathrm{RL}\left[\mathrm{cm}^{3} \mathrm{~cm}^{-2}\right]\right.$ ), se: standard error.

In the restricted water treatment, wild genotypes had the lowest average LA which was $24.4 \%$ lower than the highest average LA observed in feral genotypes (Supplementary Table 6). These findings suggest that in terms of LA, wild genotypes might be more sensitive to low water availability than non-wild genotypes.

Genetic groups significantly differed in their LA, LDW and RT but not the other three traits (Table 4). Plants from the genetic group SC had the highest mean LA which was $60.9 \%$ higher than the lowest LA observed in genetic group Kibale (Supplementary Table 6). The effect of genetic group on LDW was similar to LA with genetic group SC having $67.6 \%$ higher mean LDW than genetic group Kibale which had the lowest LDW (Supplementary Table 6). For RL, Zoka had the highest RL which was $43.9 \%$ higher than the lowest RL observed in genetic group Kibale (Supplementary Table 6). Interaction effects between genetic groups and treatment were observed only in RGRA, implying that the magnitude of the response in this trait to the water treatment differed across genetic groups. The RGRA of genetic groups Budongo, SC and Zoka being significantly reduced due to restricted-water conditions but not genetic group Itwara and Kibale (Figure 1 and Supplementary Table 5).

Overall, location as a factor had stronger effects on growth response traits to ample and restricted water supply than the two other factors: cultivation status and genetic groups (Table 4). Location had significant main effect and interaction effects on all traits except on NL, LDW and SLA (Table 4). This implies that the growth response values significantly differed depending on the location from which the genotypes were collected. For example, for LA, i.e. the response trait with the stongest location effects (Table 4), location Malabigambo had the highest average LA which was 73.7 \% higher than the lowest LA observed in Kibale. Drought 
had no significant effects on the LA of genotypes collected from Zoka, Itwara, Kibale, Kituza and Kawanda, while it significantly reduced LA of genotypes collected from Malabigambo, Kalangala and Mabira (Supplementary Table 4). In absolute terms, under ample-water conditions, Malabigambo had a significantly higher LA $\left(7263( \pm 153) \mathrm{cm}^{2}\right)$ than all other locations while Kibale's LA $\left(1413( \pm 38) \mathrm{cm}^{2}\right)$ was significantly lower than LA's at all locations except Zoka (Supplementary Table 6). Similary, under restricted-water conditions; Malabigambo had the highest LA (3711 $\left.( \pm 62) \mathrm{cm}^{2}\right)$ compared to all other locations whereas Kibale had the lowest LA $\left(1469( \pm 42) \mathrm{cm}^{2}\right)$ which was significanty lower than LA of all other locations except Zoka (Supplementary Table 6).

Table 4 Significance of effects of the factors on the growth response traits of C.canephora. Numbers in the table are F- values of linear mixed models testing the effect of factors on performance.

\begin{tabular}{|c|c|c|c|c|c|c|}
\hline Factors & RGRA & NL & LA & LDW & SLA & RL \\
\hline \multicolumn{7}{|c|}{ Cultivation status (CS) } \\
\hline Treatment (2) & $136.367 * * *$ & $60.32 * * *$ & $27.19 * * *$ & $14.48 * * *$ & $15.93 * * *$ & $26.70^{* * *}$ \\
\hline CS (3) & 0.91 & 1.05 & 1.63 & 2.41 & $4.75^{*}$ & $3.33^{*}$ \\
\hline Treatment*CS & 0.74 & 0.71 & $3.25^{*}$ & 1.47 & 0.20 & 0.80 \\
\hline \multicolumn{7}{|l|}{ Genetic group } \\
\hline Treatment (2) & $117.79 * * *$ & $62.61 * * *$ & $35.67 * * *$ & $16.51 * * *$ & $12.03 * * *$ & $14.47 * * *$ \\
\hline Genetic group (5) & 1.29 & 2.32 & $6.37 * * *$ & $8.77 * * *$ & 1.66 & $7.58 * * *$ \\
\hline $\begin{array}{l}\text { Treatment*Genetic } \\
\text { group }\end{array}$ & $2.76^{*}$ & 2.02 & 1.18 & 0.93 & 0.34 & 0.48 \\
\hline \multicolumn{7}{|l|}{ Location } \\
\hline Treatment (2) & $111.17 * * *$ & $63.26^{* * *}$ & $46.20 * * *$ & $16.68 * * *$ & $8.79 *$ & $27.7 * * *$ \\
\hline Location (7) & $2.39 *$ & 2.00 & $9.31 * * *$ & $10.78 * * *$ & $5.50 * * *$ & 1.05 \\
\hline $\begin{array}{l}\text { Treatment } \\
\text { *Location }\end{array}$ & $3.20 *$ & $2.93 *$ & $3.85 * * *$ & 2.15 & 1.08 & 2.03 \\
\hline \multicolumn{7}{|c|}{ 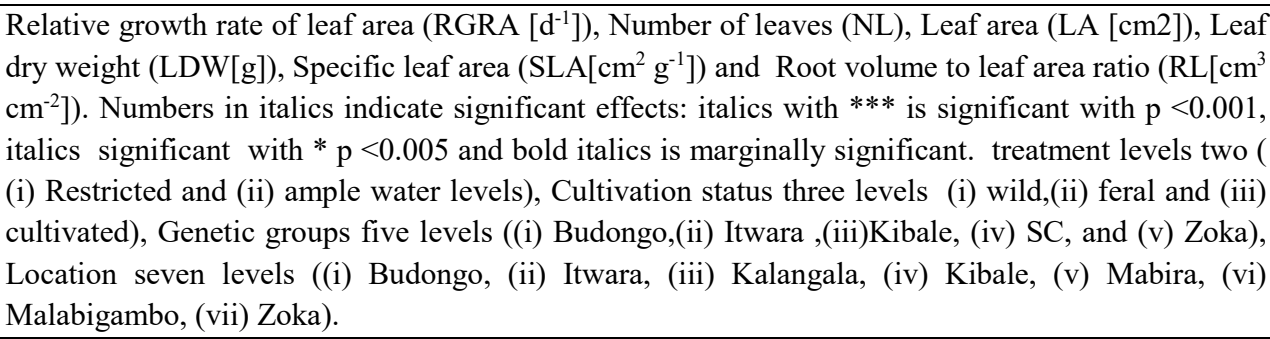 } \\
\hline
\end{tabular}


Chapter 3

Detailed effects of the experimental factors as illustrastred with RGRA (our proxy trait for performance)

Effect of drought on RGRA across cultiation status: wild, feral and cultivated

The relative effect of drought on RGRA was rather similar across cultivation status (Table 5), thus confirming the finding in Table 4 (no significant main effect and interaction effects for cultivation status on RGRA). In absolute terms, under ample-water conditions, wild genotypes had the highest RGRA which was significantly but only modestly (5.7\%) higher than the lowest RGRA which was observed among the cultivated genotypes (Table 5). Under restricted water treatment, wild genotypes still had the highest RGRA which was $5 \%$ higher than the lowest RGRA observed among feral genotypes (Table 5).

\section{RGRA across genetic groups}

Table 5 and Figure 1 show variation in the relative effect of drought on RGRA across genetic groups with genetic group Budongo being the most strongly affected and genetic group Kibale being least affected by drought (see also significant genetic group * treatment effect Table 4). Under ample-water conditions, the absolute RGRA did not differ significantly between genetic groups while under restricted-water conditions the RGRA significantly differed across genetic groups (Table 5 and Figure 1). Under restricted-water conditions, genetic group Zoka had the highest RGRA which was $12.0 \%$ higher than the lowest RGRA observed for genotypes from genetic group Budongo (Table 5). Additionally, Figure 1 and standard errors of means (Table 5) suggest that there was wider genotypic variation in RGRA across genetic groups under ample water conditons than there was under restricted-water conditions.

\section{RGRA across locations}

There was a large variation in the relative effect of drought on RGRA of genotypes collected from the different locations (Table 5 and Figure 2). The effect of drought was significant for all locations except for Kibale and Itwara (Table 5, Figure 2 and Supplementary Table 4). The mean percentage change in performance was highest among genotypes collected from Malabigambo, Budongo, Mabira, Kawanda and Kalangala, respectively, while the effect of resticted water supply was smallest for genotypes collected from Kibale, Itwara, Zoka and Kituza, respectively (Table 5 and slope of the black lines in Figure 2). 
Table 5 Mean values and standard error (se) of Relative growth rate in leaf area (RGRA[d $\left.{ }^{-1}\right]$ ) of $C$. canephora subjected to ample and restricted water treatments.

\begin{tabular}{llll}
\hline Factor & $\begin{array}{l}\text { Ample water } \\
\text { Mean }(\mathrm{se})\end{array}$ & $\begin{array}{l}\text { Restricted water } \\
\text { Mean }(\mathrm{se})\end{array}$ & $\begin{array}{l}\text { Relative change } \\
(\%)\end{array}$ \\
\hline Cultivation status & & & \\
\hline Cultivated & $0.0150(0.0001) \mathrm{a}$ & $0.0120(0.0001) \mathrm{a}$ & -20.0 \\
Feral & $0.0156(0.0001) \mathrm{a}$ & $0.0116(0.0001) \mathrm{a}$ & -25.6 \\
Wild & $0.0159(0.0001) \mathrm{a}$ & $0.0122(0.0001) \mathrm{a}$ & -23.3 \\
\hline Genetic group & & \\
\hline Budongo & $0.0163(0.0001) \mathrm{a}$ & $0.0110(0.0001) \mathrm{b}$ & -32.5 \\
Itwara & $0.0144(0.0001) \mathrm{a}$ & $0.0124(0.0001) \mathrm{ab}$ & -13.9 \\
Kibale & $0.0124(0.0001) \mathrm{a}$ & $0.0120(0.0001) \mathrm{ab}$ & -3.2 \\
SC & $0.0159(0.0001) \mathrm{a}$ & $0.0112(0.0001) \mathrm{ab}$ & -29.6 \\
Zoka & $0.0152(0.0001) \mathrm{a}$ & $0.0125(0.0001) \mathrm{a}$ & -17.8 \\
\hline Location & & & -26.5 \\
\hline Budongo & $0.0162(0.0001) \mathrm{abc}$ & $0.0119(0.0001) \mathrm{ab}$ & -13.9 \\
Itwara & $0.0144(0.0002) \mathrm{cd}$ & $0.0124(0.0001) \mathrm{a}$ & -24.4 \\
Kalangala & $0.0156(0.0001) \mathrm{bc}$ & $0.0118(0.0001) \mathrm{ab}$ & -7.1 \\
Kibale & $0.0127(0.0001) \mathrm{d}$ & $0.0118(0.0001) \mathrm{ab}$ & -26.3 \\
Mabira & $0.0175(0.0002) \mathrm{a}$ & $0.0129(0.0001) \mathrm{a}$ & -36.7 \\
Malabigambo & $0.0169(0.0002) \mathrm{ab}$ & $0.0107(0.0001) \mathrm{b}$ & -16.6 \\
Zoka & $0.0151(0.0001) \mathrm{c}$ & $0.0126(0.0001) \mathrm{a}$ & \\
\hline Numbers are means, standard deviations in brackets and letters show significantly different means at \\
0.05 of Relative growth rate (RGRA). & & \\
\hline \multicolumn{4}{l}{} \\
\hline
\end{tabular}
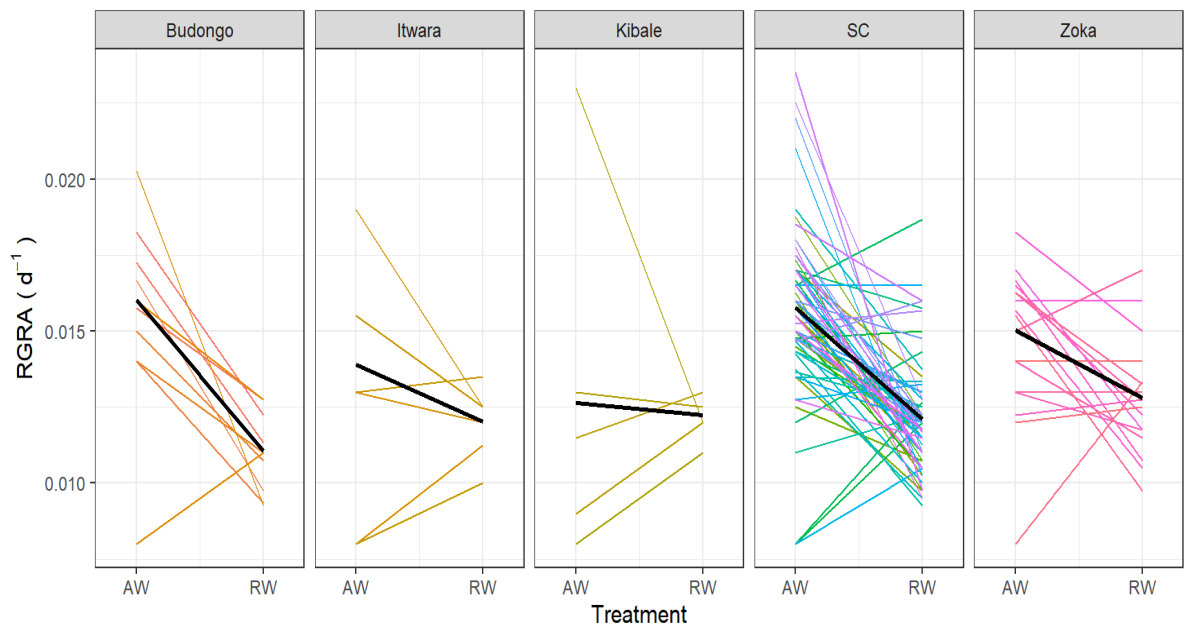

Figure 2 Mean RGRA $\left[\mathrm{d}^{-1}\right]$ as a function of treatment (ample-water (AW) and restricted-water (RW) across genetic groups (panels) and genotypes (lines). Solid black line shows the mean estimated response per genetic group. 
In absolute terms, under ample-water conditions, genotypes from Mabira had a significantly higher mean RGRA, which was $27.4 \%$ higher than the lowest mean RGRA in location Kibale (Table 5 and Figure 2). Similarly, in restricted-water conditions, Mabira had the highest and Kibale had the lowest RGRA but the difference was much smaller (8.5\%) (Table 5 and Figure 2). Thus differences between locations tended to converge in the restricted - water treatment.

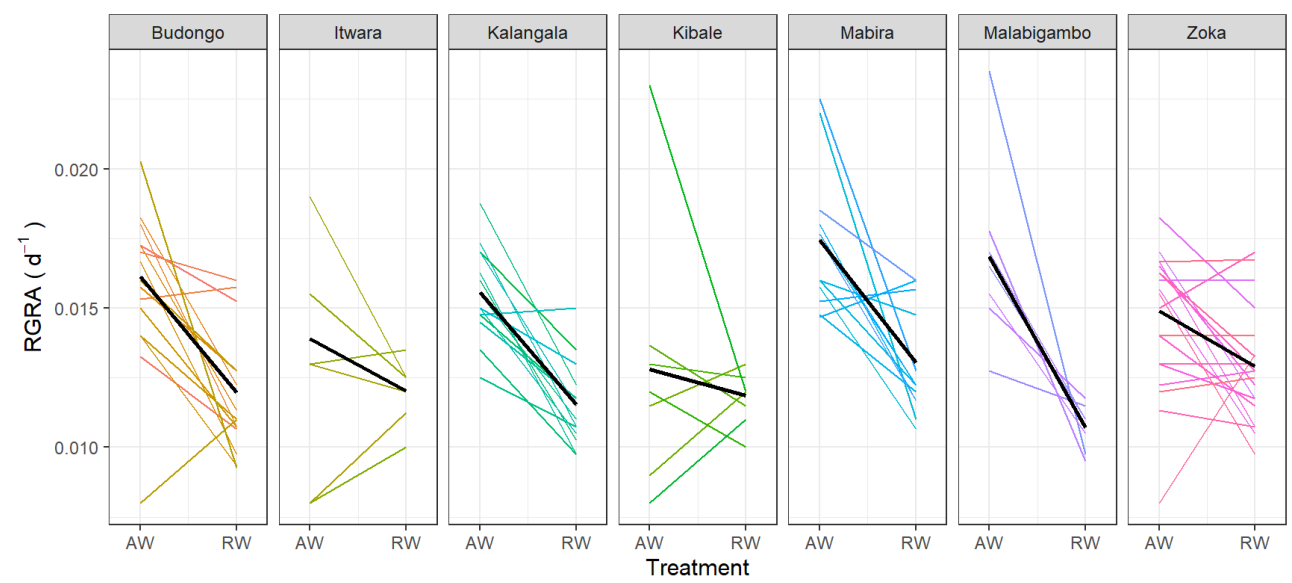

Figure 2 Mean RGRA [ $\left.\mathrm{d}^{-1}\right]$ as a function of treatment (ample-water (AW) and restricted-water (RW) across location (panels) and genotypes (lines). Solid black line shows the mean estimated response per location.

Across the studied experimental factors (cultivation status, genetic group and location), it is worth to note that results showed a tendency of some genotypes to have higher RGRA under restricted-water conditions than with ample water although this effect was not statistically significant in any of these cases $(\mathrm{p}>0.05)$ (Figures 1 and 2). The effect occurred in genotypes with both high and low RGRA values in the ample-water treatment and are thus very unlikely experimental artifact whereby the genotypes could not have been not adequately watered under ample water conditions.

\section{What is the relationship between performance in ample and restricted water conditions?}

Results show a non-significant positive relation $(\mathrm{p}=0.37)$ between average performance (as estimated by RGRA) of genotypes in restricted-water and ample-water conditions after natural logarithmic transformation of both axes (Figure 3). The slope (0.62) of 
the relationship was significantly different from zero $(p=0.000)$ and significantly $(p=0.000)$ smaller than 1 (Supplementary Box 2). Because RGRA was expressed on a log scale on both axes, it means that there is a curvilinear relationship between RGRA values under restricted and ample water availability i.e. of the form RGRA restricted water $=$ RGRA ample water $^{0.62}$ which entails that ratio RGRA restricted water /RGRA ample water, a measure for drought tolerance, is significantly negatively related to RGRA ample water , as expressed by: DTRGRA $=1.691-56.556$ RGRA $_{\text {ample water, }}$ S.E. $\left.=4.852, \mathrm{R}^{2}=0.63, \mathrm{~F}(1,80)=135.9, \mathrm{p}=0.000\right)$. The fitted slope $(-56.556)$ of the relationship between drought tolerance and performance under ample water conditions (RGRA ample water) is with a confidence interval of $(-66.210,-46.901)$ at $95.5 \%$ implying that genotypes that grow fast at high water availability tend to be less tolerant to stress from restricted-water supply. The low level of significance of the regression line suggests further that performance under ample-water conditions is a poor predictor performance under drought conditions.

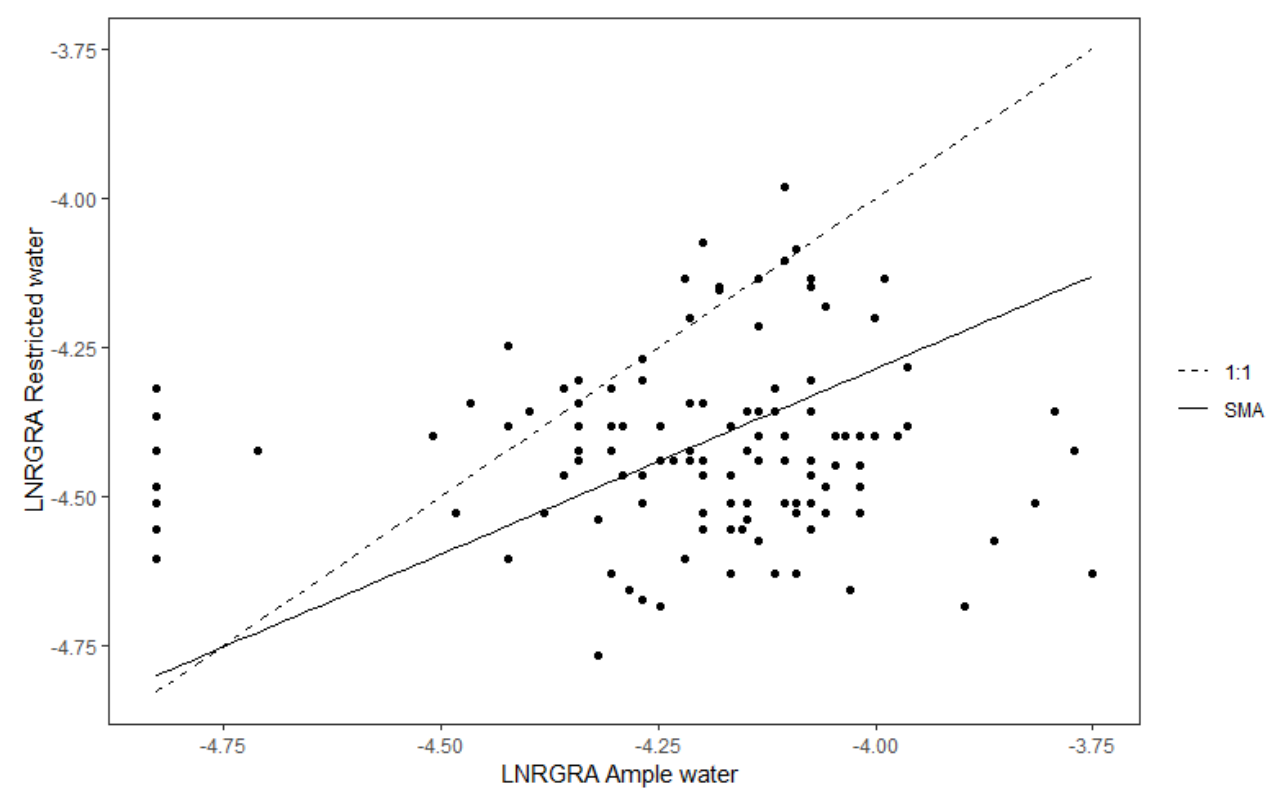

Figure 3 Relationship between natural $\log$ RGRA $\left(\mathrm{d}^{-1}\right)$ in restricted-water conditions and natural $\log$ RGRA in ample- water of $C$. canephora genotypes. The dotted line shows the 1:1 line and the solid line the relationship between performance in restricted-water and high-water conditions as fitted with typeII regression (standard major axis (SMA) regression). 
What is the relationship between performance and tolerance restricted-water conditions and wetness index of locations?

There was a significantly $\left(\mathrm{p}=0.03, \mathrm{R}^{2}=0.06\right)$ negative relationship between RGRA of genotypes in restricted-water conditions and the wetness index of the climate of a genotype's origin (Figure $4 \mathrm{~A}$ ), illustrating that genotypes from relatively wet areas (high wetness index) tended to have lower RGRA in the restricted-water treatment than those from drier locations. Performance of a genotype in restricted-water conditions could be predicted from the wetness index of its geographic location by the following formula: RGRA restricted water $\left(\mathrm{d}^{-1}\right)=0.014$ 0.002 (wetness index), S.E $\left.=0.001, \mathrm{R}^{2}=0.06, \mathrm{~F}(1,80)=4.85, \mathrm{p}=0.03\right)$. The fitted slope ($0.002)$ is with a confidence interval of $(-0.0040,-0.0002)$ at $95.5 \%$ thus implying that performance under restricted water conditions is truly negatively correlated with WI.

A

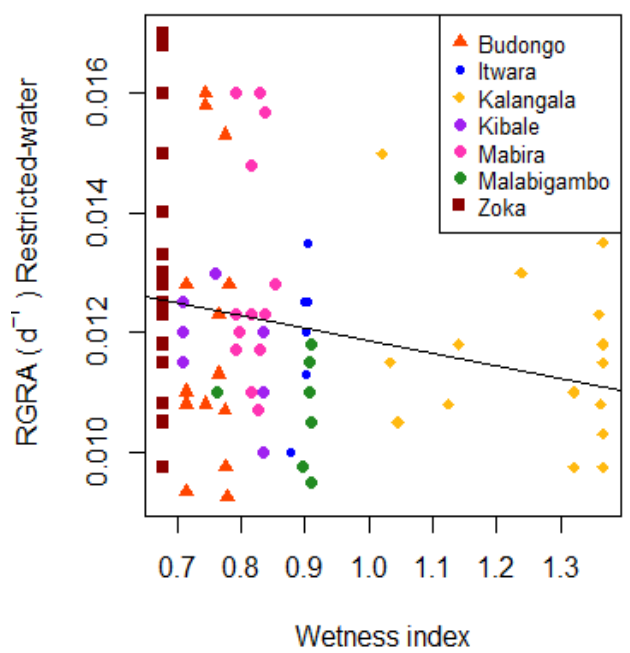

B

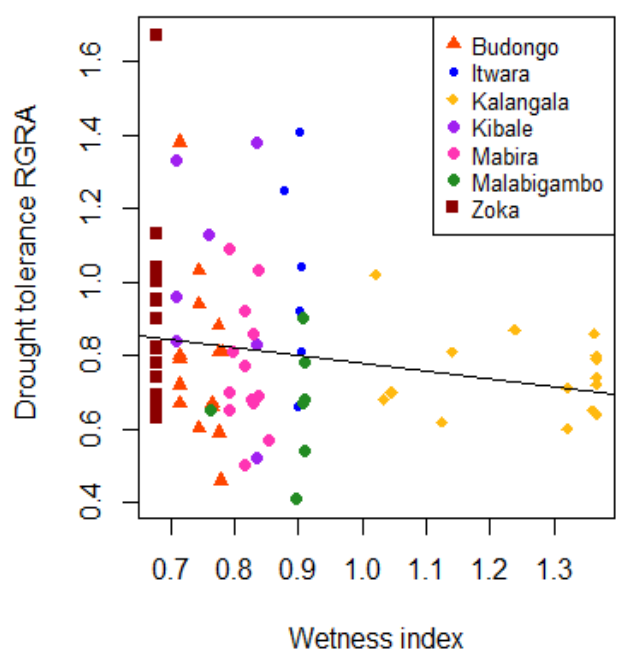

Figure 4 Relationship between performance of C. canephora genotypes in restricted-water conditions and wetness index of the location in which they were collected from (panel A) and the relationship between drought tolerance as estimated from RGRA and wetness index of the location (panel B); wetness index (WI), high WI values indicate moist conditions and low WI values indicate dry conditions). Both slopes were negative and significantly different from zero at $\mathrm{p}=0.05$. 
There was also a marginally significant negative $(\mathrm{p}=0.05)$ relationship between drought tolerance of genotypes and wetness index in their location (Figure 4 panel B), being defined by: Tolerance $=0.99-0.214$ (wetness index), $\mathrm{R}^{2}=0.05$ and S.E. $=0.106$. The negative relationship between tolerance and wetness index of the locations possibly indicates a climatic signature related to drought tolerance of the genotypes. This observed relationship between drought tolerance and wetness index suggests that on average, genotypes from the comparatively drier areas, e.g. Zoka, tended to be somewhat more drought tolerant than genotypes from the wetter area Kalangala. No difference in terms of goodness of fit was found between the linear, and the other two types of non-linear models.

\section{Discussion}

In this study, we explored Uganda's C. canephora genotypic diversity in a screening experiment with 148 genotypes. We specifically explored: (i) the effects of drought on growth categorised by: cultivation status (wild, feral and cultivated); genetic groups as characterised in Kiwuka et al. (submitted); and the geographic location, (ii) the relationship between performance under restricted-water and performance under ample-water conditions and iii) the relationship between drought tolerance and wetness index (WI). To our knowledge, this is the first study to explore intra-specific variation in drought responses for many genotypes $(>100)$ in a tropical tree species.

Effect of drought on C. canephora in growth response traits

Our results showed that drought significantly reduced the RGRA (relative growth rate), NL (number of leaves), LA (1 leaf area), LDW ( leaf dry weight), SLA (specific leaf area) and increased the RL (root volume to leaf area) (Table 3). The latter finding concurs with the optimal partitioning theory which entails that in response to stress, plants allocate proportionally more resources to the structure capturing the most limiting resources (Brouwer, 1963, Bloom et al., 1985). Other studies (Ryser and Eek, 2000, Shipley and Meziane, 2002 ) and reviews (Hoffmann and Poorter, 2002, Eziz et al., 2017) also established that, in response to stress, plants adjust their biomass allocation in accordance to whether the most limiting resource is above- or belowground. In our study, NL and LA were the most affected traits (Table 3) implying that genotypes responded to drought stress mainly by minimising transpirational water loss through reducing the number of leaves and leaf area. Differential reduction in leaf area as a response to drought stress among cultivated $C$. canephora genotypes has also been observed by others (DaMatta et al., 2003, Pinheiro et al., 2004, Dias et al., 2007, King'oro et 


\section{Chapter 3}

al., 2014). Our current findings extend these observations to a wider range of genotypes including wild and feral and cultivated material.

Variation in response across cultivation status, genetic groups and location

Our findings indicate that there is a clear genotypic variation in performance (RGRA) both under ample and restricted water conditions (Figure 1 and 2). The variation in RGRA was larger (more than two-fold) under ample water than restricted water conditions (Table 4, Figure 1 and 2). The different phenotypic responses of genotypes in ample and restricted water conditions (Figure 1 and 2) probably reflects an underlying genetic polymorphism which may drive different phenotypic responses to different environments (Stearns, 1989, Pigliucci, 2005, Forsman, 2015). The observed genotypic variation in our study in both growth and drought tolerance, can be utilised by breeding programs to develop drought tolerant varieties with adequate yield capacity (Table 4, Figure 1 and Figure 2).

Results did not show significant variations in RGRA between genotypes of different cultivation status (wild, feral and cultivated). This suggests that Uganda's breeding efforts have not addressed drought tolerance. Breeding efforts have been focusing on other factors e.g. yield and resistance to pests and diseases, in particular generating wilt disease resistant coffee varieties (Musoli et al., 2009b). Breeding efforts in C. canephora are relatively limited, partially due to the perennial nature of the crop (with an economic lifespan of about 20 years), which suggests that most of the cultivated material is still very similar to the wild trees (Montagnon et al., 1998, Thomas, 1935, Ngugi and Aluka, 2019). Indeed Kiwuka et al. (submitted) found that Uganda's cultivated genotypes were genetically similar to wild populations from Malabigambo, Mabira and Kalangala forests.

Across factors, location had the widest range of reductions in RGRA from $7.1 \%$ to $36.7 \%$ in Kibale and Malabigambo respectively (Table 5). The genetic distinctiveness of Uganda's wild $C$. canephora populations across locations as shown in Kiwuka et al. (submitted) (Table 2) and their differential phenotypic response to drought (Table 4; 5 and Figure 2) suggest that Uganda's $C$. canephora diversity could be locally adapted to the climatic conditions within the locations. The significant interaction effect between genetic group and treatment (Table 4) also provides evidence that the localisation of the genetic groups (i.e. the Zoka, Itwara, Kibale and Budongo genetic groups from the NW) could be associated with genetic effects and putatively to adaptive potential. However, the strong effect of location on response to drought could also 
be reflecting local differences in other factors such as soil types that may influence selection for difference in growth related traits.

Slow growth as a strategy to cope with drought stress and evidence of a trade-off between growth and drought tolerance.

Genotypes that had low RGRA in ample-water conditions were comparatively less affected by drought, a scenario which indicates a trade-off between growth and drought tolerance across the study populations (Figure 3). This finding concurs with an established ecological paradigm that there is a trade-off between the capacity of plants to grow fast when resources are abundant and their capacity to tolerate resource shortages (Bazzaz and Bazzaz 1996, Grime, 2001, Aerts and Chapin III, 1999). The trade-off between growth and tolerance has been linked to a conservative resource use strategy in which slow growth results in slow tissue turnover, conservative use of resources, and subsequently less dependency on the environment for acquisition of new resources. On the contrary fast growth is associated with high resource turnover rates, intensive resource acquisition, high dependency on the environment and ultimately shorter lifespan (Chapin III, 1980, Poorter and Remkes, 1990, Chapin III et al., 1993, Grime et al., 1997, Reich et al., 2003, Sterck et al., 2006, Sterck et al., 2011). Ecologically, slow growth has been reported as an adaptive strategy for plants in resource limiting conditions. Poorter (1989) studied the ecological consequences of the interspecific variation in relative growth rate (RGR) of plants and concluded that differences in potential RGR between species were habitat related whereby fast-growing species were found in resource rich habitats while slow growers could be found in any adverse environmental condition. In response to drought, a growth-tolerance trade-off could be expected because several traits and mechanisms that confer tolerance in dry conditions (e.g. low SLA, low stomatal size or number) reduce water loss but also reduce rates of net photosynthesis per unit area, which, in turn, ultimately results into slower growth under favorable water availability (Sterck et al., 2011).

Although, the growth-tolerance trade-off has been widely studied and established across species (interspecific), including tropical forest trees (Poorter, 1999, Sterck et al., 2006, Sterck et al., 2011, Amissah et al., 2018), much fewer studies (Pallardy and Kozlowski 1981, Silva et al., 2013, Menezes-Silva et al., 2015) have been conducted to explore the intraspecific variation of tropical trees to drought and the manifestation of the growth-tolerance trade-off. Pallardy and Kozlowski (1981) revealed a probable growth-tolerance trade-off among Populus clones: fast growing clones had a larger initial rate of decline in leaf water potential with transpirational 


\section{Chapter 3}

flux density but reduced the rate of decline more than slow-growing clones as the transpirational flux density increased. Similarly, Menezes-Silva et al. (2015) and Silva et al. (2013) studied eight clones of cultivated C. canephora (variety Conilon) and found that wood density, a trait that partially influences the plant's water conducting capacity, was key in identifying drought tolerant clones. Drought tolerant clones had higher wood densities and resistance to cavitation implying that the clones could thrive successfully under drought conditions, but the adaptation compromises their fitness under favourable conditions (Silva et al., 2013, Menezes-Silva et al., 2015). Here for the first time, we showed the existence of the growth-tolerance trade-off across a large set of wild accessions of a crop species, providing the insight that intra-specific variation in tolerance may be related to selection in natural environments.

In our study the relatively low RGRA and high tolerance of genotypes from Kibale, Itwara and Zoka locations (Table 5) suggests that those populations employ a more conservative resource use strategy, while genotypes from Mabira, Malabigambo, Kalangala and Budongo employ a more rapid resource acquisition strategy. Similar to our results, Silva et al. (2013) and Menezes-Silva et al. (2015) also found that across a set of cultivated C. canephora clones, the most drought tolerant ones tended to be slower growing. Slow growth in stressful conditions could in the long term be more adaptive than fast growth, because fast growth results into larger and more resource demanding plants that could eventually die off if the resource demand is not met.

The observed growth-tolerance trade-off poses a dilemma for breeding: which one to select for if one cannot have both. Selecting fast growth or acquisitive resource use strategy will result in low drought tolerance which poses a challenge especially for small scale coffee farmers who may not have irrigation facilities to deal with drought spells. Therefore, to sustain C. canephora production in drought prone environments, breeders should to break the negative correlation between poor performance and tolerance (Figure 3 and Table 5). This proposition agrees with DaMatta et al. (2018) who suggested that breeding for drought tolerance in coffee should aim at developing tolerant genotypes with "acceptable yields". Despite the adaptive advantage of slow growth (conservative resource use strategy), its positive association with low performance is also a challenge as farmers are interested in good yields. Selection for either 
slow or fast-growing genotypes should therefore be done in consideration whether the intended production is in stressful or optimal conditions.

\section{Link between drought tolerance and local climate}

Results (Fig. 4 and 5) indicated a weak but statistically significant climatic signal in relation to drought tolerance. There appears to be a trend where genotypes from wetter locations (higher wetness index) tended to be less drought tolerant than those from drier ones (lower wetness index) (Figure 4). Our findings thus seem to agree with our expectation that genotypes from drier areas would be more drought tolerant than genotypes from wetter areas, though the low $\mathrm{R}^{2}$ of our relationship indicates that the observed signal is not very strong. These results concur with Choat et al. (2007) who observed that differences in water availability across sites could drive intraspecific variation among Cordia species. Studies (Bongarten and Teskey, 1986, Peuke et al., 2002, Baquedano et al., 2008) documented that the ecotypes of Pinus taeda, Fagus sylvatica, Quercus coccifera respectively, have adaptive features which were probably driven by the local climate. In our results, wetness index explained approximately $5 \%$ of variation in drought tolerance across genotypes and further analysis preferably over a wider climate range as well as wetness index data obtained from higher resolution weather data is needed to verify the consistency of this trend. Next, other factors may affect drought tolerance such as soil hydraulic properties and local topology. Finally, drought tolerance as determined in the experiment may not fully reflect drought stress in the field (see next section).

\section{Considerations regarding the experimental set up}

This paper presented results from a large screening experiment where 148 genotypes comprising $61 \%$ wild, $7 \%$ feral and $32 \%$ cultivated, were subjected to modest drought and ample-water regimes (see supplementary Table 2). As such, for the feasibility of the experiment, we included maximally four replicates per genotype per treatment because this was the maximum manageable number, allowing the identification of the largest differences. Damage and mortality of some plants, caused variation in the real number of replicates across genotypes (Supplementary Table 3). Consequently, the mixed effects model that we applied could not estimate genotype effects very precisely and thus puts the genotype effects closer to the mean effect (an effect called shrinkage). It is thus important to note that in our analyses, 


\section{Chapter 3}

individual genotypes acted mostly as a replication at the genotypic level to test cultivation status, genetic group and location effects.

Cilas et al. (2006) reported a close relationship between vegetative growth and yield capacity of coffee plants and therefore our data from non-fruiting plants is relevant for adult plants because the amount of new vegetative growth in one year (year x) affects fruit yield in the next year $($ year $\mathrm{x}+1)$. Despite the close relationship between vegetative growth and yield capacity of coffee plants, our study focused on responses of comparatively juvenile plants and we did not include effects of ontogenetic changes on responses; yet certain ontogenetic changes may affect performance in later life stages. For instance, as mentioned above in the discussion about growth-tolerance trade-offs, relatively fast growth in young plants under dry conditions, could be maladaptive later in life as it can result in a larger more water demanding phenotype. To assess how drought responses, affect trees over a larger time of their life, more mature trees need to be considered

\section{Conclusion and implications}

Considering climate change and its adverse effects, this study showed that Uganda has substantial and potentially adapted $C$. canephora diversity upon which efforts could to be applied to develop drought tolerant genotypes with acceptable performance for cultivation. Breeders need to work towards weakening/breaking the trade-off between drought tolerance and performance. In this regard the Zoka population is of special interest, being at the drier end of the climatic gradient and exhibiting relatively high drought tolerance. Zoka is a small unique (the only tropical rainforest occurring in the dry northern Uganda) forest of about $12.59 \mathrm{~km}^{2}$; a state which makes this population especially vulnerable to habitat destruction. At a national level, there is need to foster the in-situ conservation and management of Uganda's C. canephora wild populations. Strategic in-situ conservation of these wild populations will allow for their evolution and adaptation to environmental stresses and consequently the continued use of the material to offer resilience to cultivated $C$. canephora material amidst the escalating effects of climate change. Strategies should involve restriction of C. canephora cultivation near any wild population to deter genetic introgression and to allow for functional adaption of the natural populations. 


\section{References}

Aerts R, Chapin III FS. 1999. The mineral nutrition of wild plants revisited: a re-evaluation of processes and patterns. Advances in Ecological Research 30: 1 - 67.

Alberto FJ, Aitken SN, Alia R, Gonzalez-Martinez SC, Hanninen H, Kremer A, Lefevre F, Lenormand T, Yeaman S, Whetten R, Savolainen O. 2013. Potential for evolutionary responses to climate change - evidence from tree populations. Global Change Biology, 19: 1645-61.

Amissah L, Mohren GMJ, Kyereh B, Agyeman VK, Poorter L. 2018. Rainfall seasonality and drought performance shape the distribution of tropical tree species in Ghana. Ecology and Evolution, 8: 8582-8597.

Baquedano FJ, Valladares F, Castillo FJ. 2008. Phenotypic plasticity blurs ecotypic divergence in the response of Quercus coccifera and Pinus halepensis to water stress. European Journal of Forest Research, 127: 495-506.

Basalirwa CPK. 1995. Delineation of Uganda into climatological rainfall zones using the method of principal component analysis. International Journal of Climatology 15: 1161-1177

Bates D, Mächler M, Bolker B, Walker S. 2015. Package 'lme4'. Convergence, 12: 2.

Bazzaz FA, Bazzaz F. 1996. Plants in changing environments: linking physiological, population, and community ecology. Cambridge, England: Cambridge University Press.

Beining A. 2008. Ecophysiological diversity of wild Coffea arabica populations in Ethiopia: drought adaptation mechanisms. , Ph.D., University of Bonn, Germany.

Berthaud J. 1986. Les ressources genetiques pour l'amelioration des cafeires africains diploides: Orstom Paris.

Bloom AJ, Chapin III FS, Mooney HA. 1985. Resource limitation in plants-an economic analogy. Annual Review of Ecology and Systematics, 16: 363-392.

Bongarten BC, Teskey RO. 1986. Water relations of loblolly pine seedlings from diverse geographic origins. Tree Physiology, 1: 265-276.

Brouwer R. 1963. Some aspects of the equilibrium between overground and underground plant parts. Jaarboek van het Instituut voor Biologisch en Scheikundig onderzoek aan Landbouwgewassen, 31-39: 31.

Bunn C, Läderach P, Ovalle Rivera O, Kirschke D. 2015. A bitter cup: climate change profile of global production of Arabica and Robusta coffee. Climatic Change, 129: 89101.

Chapin III FS. 1980. The Mineral Nutrition of Wild Plants. Annual Review of Ecology and Systematics, 11: 233-260.

Chapin III FS, Autumn K, Pugntaire F. 1993. Evolution of suites of traits in response to environmental stress. The American Naturalist, 142: 78 - 92.

Choat B, Sack L, Holbrook NM. 2007. Diversity of hydraulic traits in nine Cordia species growing in tropical forests with contrasting precipitation. New Phytologist, 175: 686698.

Cilas C, Bar-Hen A, Montagnon C, Godin C. 2006. Definition of architectural ideotypes for good yield capacity in Coffea canephora. Annals of Botany, 97: 405- 411.

Coste R. 1992. Coffee; the plant and product. London: Macmillan Press Ltd.

Craparo ACW, Van Asten PJA, Läderach P, Jassogne LTP, Grab SW. 2015. Coffea arabica yields decline in Tanzania due to climate change: Global implications. Agricultural and Forest Meteorology, 207: 1-10.

DaMatta FM, Avila RT, Cardoso AA, Martins SCV, Ramalho JC. 2018. Physiological and agronomic performance of the coffee crop in the context of climate change and global warming: A review. Journal of Agricultural and Food Chemistry, 66: 5264-5274. 
DaMatta FM, Chaves ARM, Pinheiro HA, Ducatti C, Loureiro ME. 2003. Drought tolerance of two field-grown clones of Coffea canephora. Plant Science, 164: 111-117.

DaMatta FM, Ramalho JDC. 2006. Impacts of drought and temperature stress on coffee physiology and production: a review. Brazilian Journal of Plant Physiology, 18: 55-81.

Davis AP, Gole TW, Baena S, Moat J. 2012. The impact of climate change on indigenous Arabica coffee (Coffea arabica): predicting future trends and identifying priorities. PLoS One, 7.

Davis AP, Govaerts R, Bridson DM, Stoffelen P. 2006. An annotated taxonomic conspectus of the genus Coffea (Rubiaceae). Botanical Journal of the Linnean Society, 152: 465512.

Dias PC, Araujo WL, Moraes GA, Barros RS, DaMatta FM. 2007. Morphological and physiological responses of two coffee progenies to soil water availability. Journal of Plant Physiology, 164: 1639-1647.

Engelbrecht BM, Dalling JW, Pearson TR, Wolf RL, Galvez DA, Koehler T, Tyree MT, Kursar TA. 2006. Short dry spells in the wet season increase mortality of tropical pioneer seedlings. Oecologia, 148: 258-69.

Eziz A, Yan Z, Tian D, Han W, Tang Z, Fang J. 2017. Drought effect on plant biomass allocation: A meta-analysis. Ecology and Evolution, 7: 11002-11010.

Forsman A. 2015. Rethinking phenotypic plasticity and its consequences for individuals, populations and species. Heredity 115: 276-284.

Grime JP. 2001. Plant strategies, vegetation processes, and ecosystem properties; 2 nd edition. Chichester, UK: John Wiley and Sons

Grime JP, Hunt R. 1975. Relative growth-rate: Its range and adaptive significance in a local flora. The Journal of Ecology: 393 -422.

Grime JP, Thompson K, Hunt R, Hodgson JG, Cornelissen JHC, Rorison IH, Hendry GAF, Ashenden TW, Askew AP, Band SR, Booth RE, Bossard CC, Campbell BD, Cooper JEL, Davison AW, Gupta PL, Hall W, Hand DW, Hannah MA, Hillier SH, Hodkinson DJ, Jalili A, Liu Z, Mackey JML, Matthews N, Mowforth MA, Neal AM, Reader RJ, Reiling K, Ross-Fraser W, Spencer RE, Sutton F, Tasker DE, Thorpe PC, Whitehouse J. 1997. Integrated screening validates primary axes of specialisation in plants. Oikos, 79: 259 - 281.

Hargreaves GH, Samani ZA. 1985. Reference crop evapotranspiration from temperature. Applied Engineering in Agriculture, 1: 96-99.

Hoffmann WA, Poorter H. 2002. Avoiding bias in calculations of relative growth rate. Annals of Botany, 90: 37-42.

IPCC. 2014. Proceedings of the 5th Assessment Report, WGII, Climate Change 2014: Impacts, Adaptation, and Vulnerability. Cambridge, U.K.

Jassogne L, van Asten PJA, Wanyama I, Baret PV. 2013. Perceptions and outlook on intercropping coffee with banana as an opportunity for smallholder coffee farmers in Uganda. International Journal of Agricultural Sustainability, 11: 144-158.

King'oro WM, Mushimiyamana D, Cheserek JJ, Gichimu MB. 2014. Effect of different watering regimes on agromorphology of selected coffee genotypes. American Journal of Experimental Agriculture, 4: 1016 - 1026.

Kiwuka C, Goudsmit E, Douma JC, Bellanger L, Crouzillat D, de Kochko A, Mulumba JW, Musoli P, Anten N, Poncet V. submitted. Genetic diversity of native and cultivated Uganda's Coffea canephora Pierre ex A. Froehner. A perspective into potential utilization and conservation of the diversity.

Kufa T, Burkhardt J. 2011. Stomatal characteristics in Arabica coffee germplasm accessions under contrasting environments at Jimma, Southwestern Ethiopia. International Journal of Botany, 7: 63-72. 
Masih I, Maskey S, Mussá FEF, Trambauer P. 2014. A review of droughts on the African continent: a geospatial and long-term perspective. Hydrology and Earth System Sciences, 18: 3635-3649.

McGill BJ, Enquist BJ, Weiher E, Westoby M. 2006. Rebuilding community ecology from functional traits. Trends in Ecology and Evolution, 21: 178-185.

Menezes-Silva PE, Cavatte PC, Martins SCV, Reis JV, Pereira LF, Ávila RT, Almeida AL, Ventrella MC, DaMatta FM. 2015. Wood density, but not leaf hydraulic architecture, is associated with drought tolerance in clones of Coffea canephora. Trees, 29: 1687-1697.

Merot-l'Anthoene V, Tournebize R, Darracq O, Rattina V, Lepelley M, Bellanger L, Tranchant-Dubreuil C, Coulee M, Pegard M, Metairon S, Fournier C, Stoffelen P, Janssens SB, Kiwuka C, Musoli P, Sumirat U, Legnate H, Kambale JL, Ferreira da Costa Neto J, Revel C, de Kochko A, Descombes P, Crouzillat D, Poncet V. 2019. Development and evaluation of a genome-wide Coffee 8.5K SNP array and its application for high-density genetic mapping and for investigating the origin of Coffea arabica L. Plant Biotechnology Journal, 17: 1418-1430.

Montagnon C, Leroy T, Eskes AB. 1998. Varietal improvement of Coffea canephora-II. Breeding programmes and their results.

Montagnon C, Leroy T, Yapo A. 1992. Diversité génotypique et phénotypique de quelques groupes de caféiers (Coffea canephora Pierre) en collection; conséquences sur leur utilisation en sélection. Café, Cacao, Thé (Francia), 36: 187-198.

Musoli P, Cubry P, Aluka P, Billot C, Dufour M, De Bellis F, Pot D, Bieysse D, Charrier A, Leroy T. 2009a. Genetic differentiation of wild and cultivated populations: diversity of Coffea canephora Pierre in Uganda. Genome, 52: 634-46.

Musoli PC, Kangire A, Leroy T, Nabaggala A, Nakendo S, Olal S, Ochugo J, Kabole C, Pande J, Cila C, Charrier A, Bieysse D, Ogwang JA, Kyetere DT. 2009b. Towards a variety resistant to coffee wilt disease (CWD): A case for robusta coffee (Coffea canephora) in Uganda. 22nd International Conference on Coffee Science (ASIC). Campinas, SP , Brazil ASIC.

NEMA. 2009. Uganda: atlas of our changing environment. Kampala, Uganda National Environment Management Authority (NEMA).

Ngugi K, Aluka P. 2019. Genetic and phenotypic diversity of robusta coffee (Coffea canephora L.). Caffeinated and Cocoa Based Beverages, 8: 89-130.

Ouédraogo D-Y, Mortier F, Gourlet-Fleury S, Freycon V, Picard N, Turnbull M. 2013. Slow-growing species cope best with drought: evidence from long-term measurements in a tropical semi-deciduous moist forest of Central Africa. Journal of Ecology, 101: 1459-1470.

Pallardy SG, Kozlowski TT. 1981. Water relations of populus clones. Ecology, 62: 159-169.

Parry M, Parry ML, Canziani O, Palutikof J, Van der Linden P, Hanson C. 2007. Climate Change 2007-Impacts, adaptation and vulnerability: Working Group II contribution of to the fourth assessment the IPCC. Cambridge, United Kingdom: Cambridge University Press.

Peuke AD, Schraml C, Hartung W, Rennenberg H. 2002. Identification of drought-sensitive beech ecotypes by physiological parameters. New Phytologist, 154: 373-387.

Pigliucci M. 2005. Evolution of phenotypic plasticity: where are we going now? Trends in Ecology and Evolution, 20: 481-486.

Pinheiro HA, DaMatta FM, Chaves ARM, Fontes EPB, Loureiro ME. 2004. Drought tolerance in relation to protection against oxidative stress in clones of Coffea canephora subjected to long-term drought. Plant Science, 167: 1307-1314. 
Poorter H. 1989. Interspecific variation in relative growth rate: on ecological causes and physiological consequences. Causes and consequences of variation in growth rate and productivity of higher plants, 24: 45-68.

Poorter H, Garnier E. 1999. Ecological significance of inherent variation in relative growth rate and its components. Handbook of functional plant ecology, 20: 81-120.

Poorter H, Remkes C. 1990. Leaf area ratio and net assimilation rate of 24 wild species differing in relative growth rate. Oecologia 83: 553 -559.

Poorter L. 1999. Growth responses of 15 rain-forest tree species to a light gradient: the relative importance of morphological and physiological traits. Functional Ecology 13: 396 410.

Reich PB, Wright IJ, Cavender-Bares J, Craine JM, Oleksyn J, Westoby M, Walters MB. 2003. The evolution of plant functional variation: traits, spectra, and strategies International Journal of Plant Sciences 164: 143 - 164.

Rungwattana K, Kasemsap P, Phumichai T, Kanpanon N, Rattanawong R, Hietz P, Timothy Paine CE. 2018. Trait evolution in tropical rubber (Hevea brasiliensis) trees is related to dry season intensity. Functional Ecology, 32: 2638-2651.

Ryser P, Eek L. 2000. Consequences of phenotypic plasticity vs. interspecific differences in leaf and root traits for acquisition of aboveground and belowground resources. American Journal of Botany, 87: 402-411.

Sade N, Gebremedhin A, Moshelion M. 2012. Risk-taking plants: anisohydric behavior as a stress-resistance trait. Plant Signaling Behavior, 7: 767-770.

Schiermeier Q. 2008. Water: a long dry summer. Nature 452: 270 - 273.

Schmildt ER, Amaral JATD, Santos JS, Schmildt O. 2015. Allometric model for estimating leaf area in clonal varieties of coffee (Coffea canephora). Revista Ciência Agronômica, 46: 740-748.

Shipley B, Meziane D. 2002 The balanced-growth hypothesis and the allometry of leaf and root biomass allocation. Functional Ecology, 16: 326-331.

Silva PEM, Cavatte PC, Morais LE, Medina EF, DaMatta FM. 2013. The functional divergence of biomass partitioning, carbon gain and water use in Coffea canephora in response to the water supply: Implications for breeding aimed at improving drought tolerance. Environmental and Experimental Botany, 87: 49-57.

Stearns SC. 1989. Trade-offs in life-history evolution. Functional Ecology 3: 259 -268.

Sterck F, Markesteijn L, Schieving F, Poorter L. 2011. Functional traits determine tradeoffs and niches in a tropical forest community. Proceedings of the National Academy of Sciences, 108: 20627-20632.

Sterck FJ, Poorter L, Schieving F. 2006. Leaf traits determine the growth-survival trade-off across rain forest tree species. The American Naturalist, 167: 758-765.

Thomas AS. 1935. Types of robusta coffee and their selection in Uganda. The East African Agricultural Journal 1: 193-197.

Verhage FYF, Anten NPR, Sentelhas PC. 2017. Carbon dioxide fertilization offsets negative impacts of climate change on Arabica coffee yield in Brazil. Climatic Change, 144: 671-685.

Warton DI, Weber NC. 2002. Common slope tests for bivariate errors-in-variables models. Biometrical Journal 44: 161-174.

Weraduwage SM, Chen J, Anozie FC, Morales A, Weise SE, Sharkey TD. 2015. The relationship between leaf area growth and biomass accumulation in Arabidopsis thaliana. Frontiers in Plant Science, 6: 167.

Wintgens JN. 2004. Coffee: growing, processing, sustainable production, A guidebook for growers, processors, traders, and researchers. Weinhein, Alemania: WILEY-VCH Verlag GmbH \& Co. KGaA. 
Zomer RJ, Trabucco A, Bossio DA, Verchot LV. 2008. Climate change mitigation: A spatial analysis of global land suitability for clean development mechanism afforestation and reforestation. Agriculture, Ecosystems \& Environment, 126: 67-80.

Zuur A, Ieno EN, Walker N, Saveliev AA, Smith GM. 2009. Mixed effects models and extensions in ecology with $R$. New York Springer Science and Business Media. 


\section{Supplementary material}
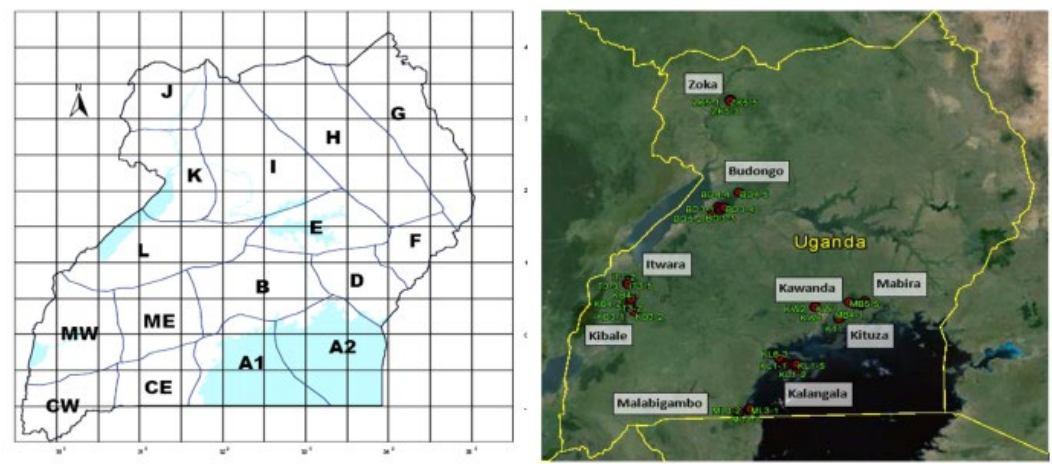

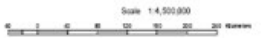

Supplementary Figure 1a Locations and the different climatic zones in which they occur; Location (climatic zone); Budongo (K), Itwara (L), Kalangala (A1), Kawanda (B), Kibale (L), Kituza (B), Mabira (B), Malabigambo (AI) and Zoka (J). Red and green indicate points of sample collection and codes of the samples respectively. 


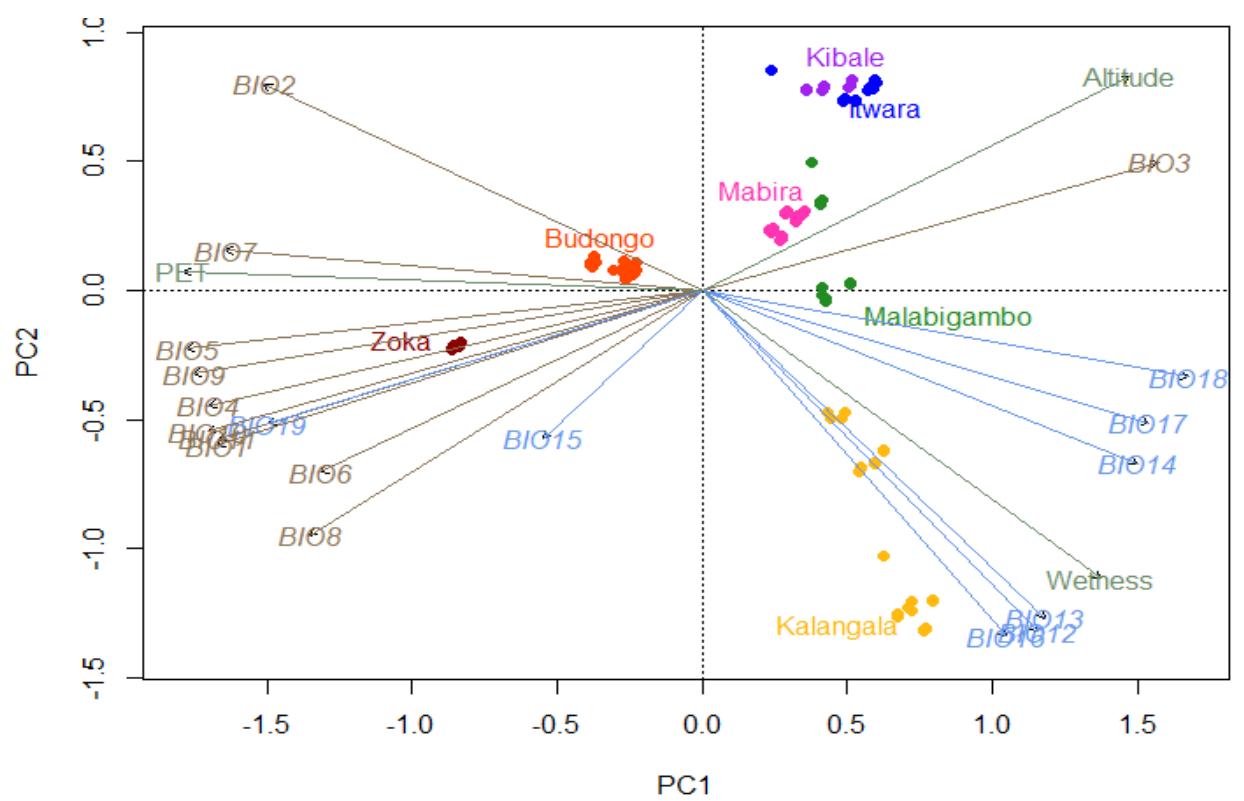

Supplementary Figure 1b Principal component analysis (PCA) of 19 bioclimatic variables: Temperature related variables coloured (cornflowerblue): Annual Mean Temperature (BIO1), Mean Diurnal Range (Mean of monthly (max temp - min temp)) (BIO2), Isothermality (BIO2/BIO7) (* 100) (BIO3), Temperature Seasonality (standard deviation *100) (BIO4), Max Temperature of Warmest Month (BIO5), Min Temperature of Coldest Month (BIO6), Mean Temperature of Wettest Quarter (BIO8), Mean Temperature of Driest Quarter (BIO9), Mean Temperature of Warmest Quarter (BIO10), Mean Temperature of Coldest Quarter (BIO11), precipitation related coloured (burlywood4): Annual Precipitation (BIO12), Precipitation of Wettest Month (BIO13), Precipitation of Driest Month (BIO14), Precipitation Seasonality (Coefficient of Variation) (BIO15), Precipitation of Wettest Quarter (BIO16), Precipitation of Driest Quarter (BIO17), Precipitation of Warmest Quarter (BIO18), Precipitation of Coldest Quarter (BIO19) and 3 other environmental variables, Altitude, Wetness Index (WI) and Potential Evapotranspiration (PET) coloured (darkseagreen4) at Ugandan C. canephora wild sites. The two first axis, $\mathrm{PC} 1$ and $\mathrm{PC} 2$, account for $64.7 \%$ and $21.3 \%$ of the total variation, respectively. 
Chapter 3

Supplementary Table 1 Traits measured to investigate response to drought stress.

\begin{tabular}{|c|c|c|}
\hline Collection phase & Trait & Units \\
\hline \multirow{4}{*}{$\begin{array}{l}\text { Start of the treatment } \\
\left(25^{\text {th }} \text { May 2017) }\right.\end{array}$} & plant height & $\mathrm{cm}$ \\
\hline & leaf area & $\mathrm{cm}^{2}$ \\
\hline & no. of main stem leaves & \\
\hline & $\begin{array}{l}\text { stem diameter } 5 \mathrm{~cm} \text { for above the mark, } \\
6 \mathrm{~cm} \text { for below the mark }\end{array}$ & $\mathrm{mm}$ \\
\hline \multirow{5}{*}{$\begin{array}{l}\text { During treatment } \\
\left.\text { June } 24^{\text {th }} \text { June } 2017\right)\end{array}$} & plant height & $\mathrm{cm}$ \\
\hline & leaf area & $\mathrm{cm}^{2}$ \\
\hline & no. of primaries & \\
\hline & no. of suckers & \\
\hline & $\begin{array}{l}\text { no. of leaves on main stem, primaries and } \\
\text { suckers }\end{array}$ & \\
\hline \multirow{9}{*}{$\begin{array}{l}\text { End of Treatment } \\
\left(12^{\text {th }} \text { to } 26^{\text {th }} \text { September } 2017\right)\end{array}$} & plant height, & $\mathrm{cm}$ \\
\hline & leaf area & $\mathrm{cm}^{2}$ \\
\hline & no. of primaries & \\
\hline & no. of suckers & \\
\hline & $\begin{array}{l}\text { no. of leaves on the main stem, primaries } \\
\text { and suckers }\end{array}$ & \\
\hline & fresh weight of all leaves & $\mathrm{g}$ \\
\hline & dry weight of all leaves & $\mathrm{g}$ \\
\hline & specific leaf area & $\mathrm{cm}^{2} \mathrm{~g}^{-1}$ \\
\hline & root volume & $\mathrm{cm}^{3}$ \\
\hline
\end{tabular}

Supplementary Table 2 Numbers of what individuals per treatment across cultivation status.

\begin{tabular}{llll}
\hline & Treatment & Total \\
\hline Ample-water & Restricted-water & \\
Feral & 121 & 178 & 299 \\
Wild & 28 & 41 & 69 \\
Grand total & 225 & 326 & 551 \\
\hline
\end{tabular}


Supplementary Box $1 \mathrm{R}$ scripts for the models used to analyse the data.

Model1 $=$ lme $($ Trait $\sim$ Treatment $*$ SC, random $=\sim$ Treatment $\mid$ Genotypes, weights $=$ varIdent $($ form $=\sim 1 \mid S C)$, data $=$ Al, na.actio $=$ na.omit, control $=$ ctrl)

Model2 $=$ lme $($ Trait $\sim$ Treatment $*$ Geneticgroup, random $=\sim$ Treatment $\mid$ Genotypes, weights $=$ varIde $n t($ form $=\sim 1 \mid$ Geneticgroup $)$, data $=$ A1, na.actio $=$ na.omit, control $=$ ctrl $)$

Model3 $=$ lme $($ Trait $\sim$ Treatment $*$ Location, random $=\sim$ Treatment $\mid$ Genotypes, weights $=$ varIdent $(f o$ $r m=\sim 1 \mid$ Location), data $=$ Al, na.actio $=$ na.omit, control $=$ ctrl $)$ 


\section{Chapter 3}

Supplementary Table 3 Number of replicates per treatment per genotype.

\begin{tabular}{|c|c|c|c|c|}
\hline \multirow[t]{2}{*}{ Location } & \multirow[t]{2}{*}{ Genotype } & \multicolumn{2}{|c|}{ Number of replicates per treatment } & \multirow[t]{2}{*}{ Total } \\
\hline & & Ample-water & Restricted-water & \\
\hline \multirow{17}{*}{ Budongo } & BD 1.1 & 4 & 4 & 8 \\
\hline & BD 1.5 & 4 & 3 & 7 \\
\hline & BD 2.1 & 2 & 4 & 6 \\
\hline & BD 2.2 & 3 & 4 & 7 \\
\hline & BD 2.3 & 4 & 4 & 8 \\
\hline & BD 2.4 & 4 & 4 & 8 \\
\hline & BD 2.5 & 4 & 3 & 7 \\
\hline & BD 3.1 & & 2 & 2 \\
\hline & BD 3.2 & 4 & 4 & 8 \\
\hline & BD 3.3 & 3 & 4 & 7 \\
\hline & BD 4.1 & 4 & 3 & 7 \\
\hline & BD 4.2 & 2 & 4 & 6 \\
\hline & BD 4.3 & 2 & 4 & 6 \\
\hline & BD 4.4 & 4 & 4 & 8 \\
\hline & BD 4.5 & 1 & 4 & 5 \\
\hline & BD 5.5 & 4 & 4 & 8 \\
\hline & IT 2.2 & 1 & 4 & 5 \\
\hline \multirow{8}{*}{ Itwara } & IT 2.3 & 3 & 4 & 7 \\
\hline & IT 3.3 & 3 & 4 & 7 \\
\hline & IT 4.2 & 4 & 4 & 8 \\
\hline & IT 4.3 & 1 & 4 & 5 \\
\hline & IT 4.4 & & 2 & 2 \\
\hline & IT 4.5 & & 4 & 4 \\
\hline & IT 5.1 & & 1 & 1 \\
\hline & IT 5.2 & & 1 & 1 \\
\hline \multirow{10}{*}{ Kibale } & IT 5.3 & 1 & 3 & 4 \\
\hline & KB 2.1 & 4 & 4 & 8 \\
\hline & KB 2.2 & & 2 & 2 \\
\hline & KB 2.4 & & 4 & 4 \\
\hline & KB 3.1 & 1 & 3 & 4 \\
\hline & KB 3.3 & 3 & 4 & 7 \\
\hline & KB 3.4 & 2 & 4 & 6 \\
\hline & KB 4.3 & 1 & 2 & 3 \\
\hline & KB 4.4 & 1 & 3 & 4 \\
\hline & KB 4.5 & 1 & 2 & 3 \\
\hline \multirow{6}{*}{ Kalangala } & KL 1.1 & 3 & 4 & 7 \\
\hline & KL 1.2 & 2 & 4 & 6 \\
\hline & KL 1.3 & 4 & 4 & 8 \\
\hline & KL 1.4 & 4 & 4 & 8 \\
\hline & KL 1.5 & 4 & 4 & 8 \\
\hline & KL 2.2 & 4 & 4 & 8 \\
\hline
\end{tabular}




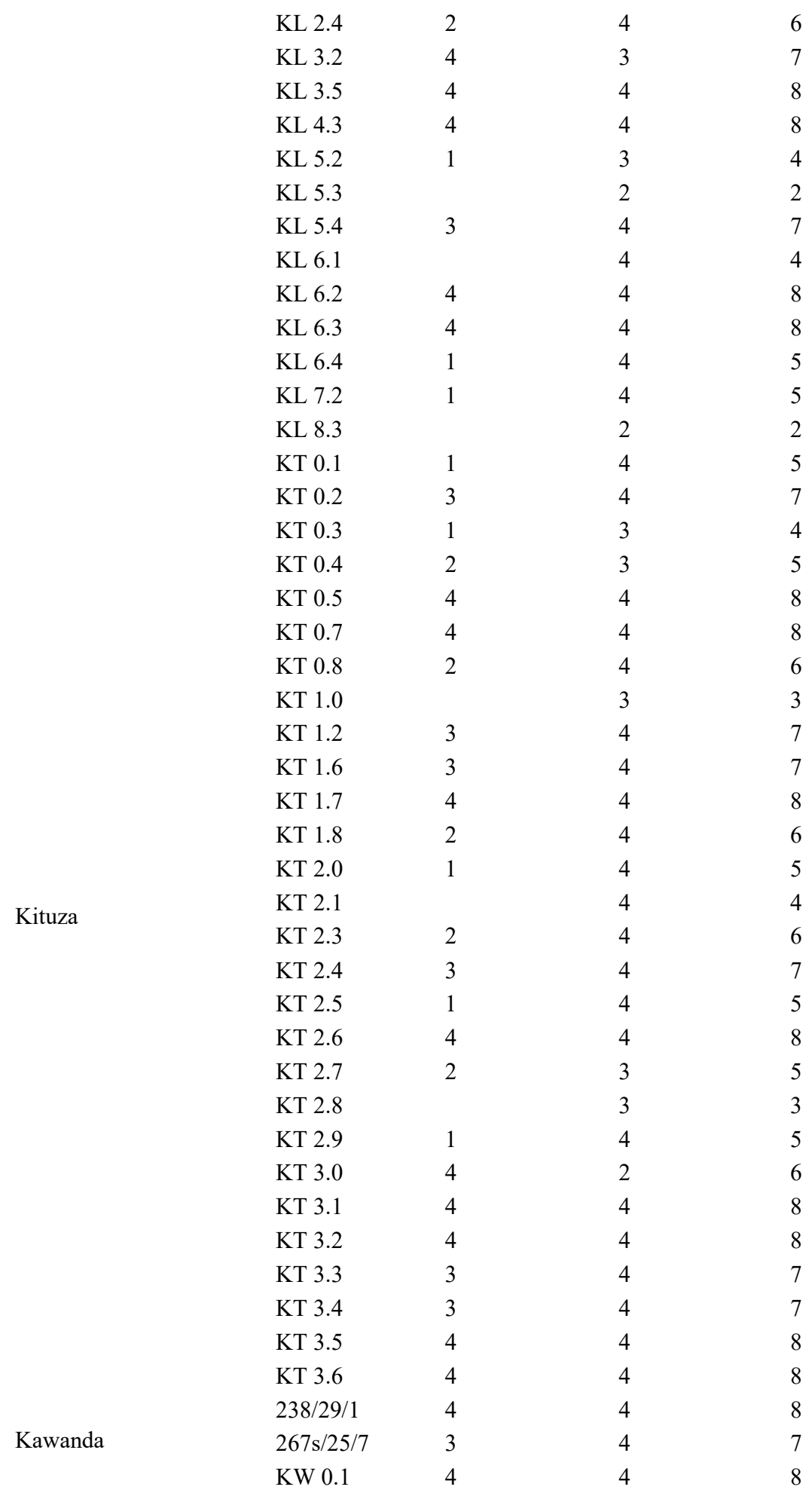




\section{Chapter 3}

\begin{tabular}{|c|c|c|c|c|}
\hline & KW 0.2 & 4 & 4 & 8 \\
\hline & KW 0.3 & 1 & 4 & 5 \\
\hline & KW 0.6 & 1 & 4 & 5 \\
\hline & KW 0.8 & & 4 & 4 \\
\hline & KW 0.9 & & 2 & 2 \\
\hline & KW 1.0 & 4 & 4 & 8 \\
\hline & KW 1.1 & 4 & 4 & 8 \\
\hline & KW 1.2 & 4 & 4 & 8 \\
\hline & KW 1.4 & 1 & 4 & 5 \\
\hline & KW 1.5 & 2 & 3 & 5 \\
\hline & KW 1.6 & 4 & 4 & 8 \\
\hline & KW 1.7 & 4 & 4 & 8 \\
\hline & KW 1.8 & & 4 & 4 \\
\hline & KW 1.9 & 4 & 4 & 8 \\
\hline & KW 2.0 & 4 & 4 & 8 \\
\hline & KW 2.1 & 4 & 4 & 8 \\
\hline & MB 1.4 & 4 & 3 & 7 \\
\hline & MB 2.3 & 3 & 4 & 7 \\
\hline & MB 2.4 & 2 & 4 & 6 \\
\hline & MB 2.5 & 2 & 4 & 6 \\
\hline & MB 3.1 & 4 & 4 & 8 \\
\hline & MB 3.2 & & 4 & 4 \\
\hline & MB 3.3 & 4 & 4 & 8 \\
\hline Mabira & MB 3.4 & 3 & 4 & 7 \\
\hline & MB 3.5 & 3 & 3 & 6 \\
\hline & MB 4.1 & 3 & 4 & 7 \\
\hline & MB 4.3 & 4 & 4 & 8 \\
\hline & MB 4.4 & & 3 & 3 \\
\hline & MB 4.5 & 4 & 4 & 8 \\
\hline & MB 5.1 & 4 & 3 & 7 \\
\hline & MB 5.2 & 4 & 4 & 8 \\
\hline & ML 2.1 & 4 & 4 & 8 \\
\hline & ML 2.3 & 4 & 4 & 8 \\
\hline & ML 2.4 & 4 & 4 & 8 \\
\hline Malabigambo & ML 5.1 & 4 & 4 & 8 \\
\hline & ML 6.1 & 4 & 4 & 8 \\
\hline & ML 6.2 & 4 & 4 & 8 \\
\hline & ML 6.3 & 4 & 4 & 8 \\
\hline & ZK 1.1 & 3 & 4 & 7 \\
\hline & ZK 1.2 & & 4 & 4 \\
\hline Zoka & ZK 1.3 & 3 & 4 & 7 \\
\hline & ZK 1.4 & 4 & 4 & 8 \\
\hline & ZK 1.5 & 3 & 4 & 7 \\
\hline & ZK 2.1 & 4 & 4 & 8 \\
\hline
\end{tabular}


Intraspecific variation in growth response to drought

\begin{tabular}{llll} 
ZK 2.2 & & 2 & 2 \\
ZK 2.3 & 3 & 4 & 7 \\
ZK 2.4 & 4 & 4 & 8 \\
ZK 2.5 & 2 & 4 & 6 \\
ZK 3.1 & & 4 & 4 \\
ZK 3.2 & 1 & 4 & 5 \\
ZK 3.3 & & 2 & 2 \\
ZK 3.4 & 4 & 4 & 8 \\
ZK 3.5 & 2 & 4 & 6 \\
ZK 4.1 & 4 & 4 & 8 \\
ZK 4.2 & 3 & 4 & 7 \\
ZK 4.3 & 4 & 4 & 8 \\
ZK 4.4 & & 4 & 4 \\
ZK 4.5 & 4 & 4 & 8 \\
ZK 5.1 & 2 & 3 & 5 \\
ZK 5.2 & 3 & 4 & 7 \\
ZK 5.3 & 1 & 4 & 5 \\
ZK 5.4 & 3 & 4 & 7 \\
ZK 5.5 & & $\mathbf{5 4 5}$ & $\mathbf{9 1 9}$ \\
\hline Grand Total & & &
\end{tabular}


Supplementary Table 4 Details of the effect of treatment and location on leaf area (LA).

\begin{tabular}{llllll}
\hline Factor & Value & Std. Error & DF & t-value & p-value \\
\hline Location: $\operatorname{trt}$ & & & & & \\
\hline Budongo: trt & -1025 & 360 & 708 & -2.8487 & 0.005 \\
Itwara: trt & -842 & 957 & 708 & -0.8803 & 0.379 \\
Kalangala: trt & -1443 & 401 & 708 & -3.5999 & 0.000 \\
Kibale: trt & 229 & 484 & 708 & 0.4744 & 0.635 \\
Mabira: trt & -1665 & 466 & 708 & -3.5709 & 0.000 \\
Malabigambo: trt & -3552 & 825 & 708 & -4.3070 & 0.000 \\
Zoka: trt & -500 & 318 & 708 & -1.5756 & 0.116 \\
\hline
\end{tabular}

trt denotes experimental treatment, experiment treatments have a significant effect when $\mathrm{p}<0.05$.

Supplementary Table 5 Effect of treatments on RGRA (relative growth in leaf area) material across locations and genetic groups.

\begin{tabular}{lccccc}
\hline Factor & Value & Std. Error & DF & t-value & p-value \\
\hline Location: trt & & & & & \\
\hline Budongo: trt & -0.0041 & 0.0009 & 474 & -4.865 & 0.000 \\
Itwara: trt & -0.0019 & 0.0014 & 474 & -1.306 & 0.192 \\
Kalangala: trt & -0.0040 & 0.0007 & 474 & -5.942 & 0.000 \\
Kibale: trt & -0.0009 & 0.0012 & 474 & -0.748 & 0.455 \\
Mabira: trt & -0.0044 & 0.0009 & 474 & -4.701 & 0.000 \\
Malabigambo: trt & -0.0061 & 0.0011 & 474 & -5.829 & 0.000 \\
Zoka: trt & -0.0020 & 0.0007 & 474 & -3.040 & 0.003 \\
\hline Genetic group: trt & & & & & \\
\hline Budongo: trt & -0.0050 & 0.0009 & 598 & -5.529 & 0.000 \\
Itwara: trt & -0.0019 & 0.0014 & 598 & -1.301 & 0.194 \\
Kibale: trt & -0.0004 & 0.0016 & 598 & -0.259 & 0.796 \\
SC: trt & -0.0037 & 0.0004 & 598 & -9.263 & 0.000 \\
Zoka: trt & -0.0022 & 0.0007 & 598 & -3.140 & 0.002 \\
\hline
\end{tabular}

trt denotes experimental treatment, experiment treatments have a significant effect when $\mathrm{p}<0.05$. 


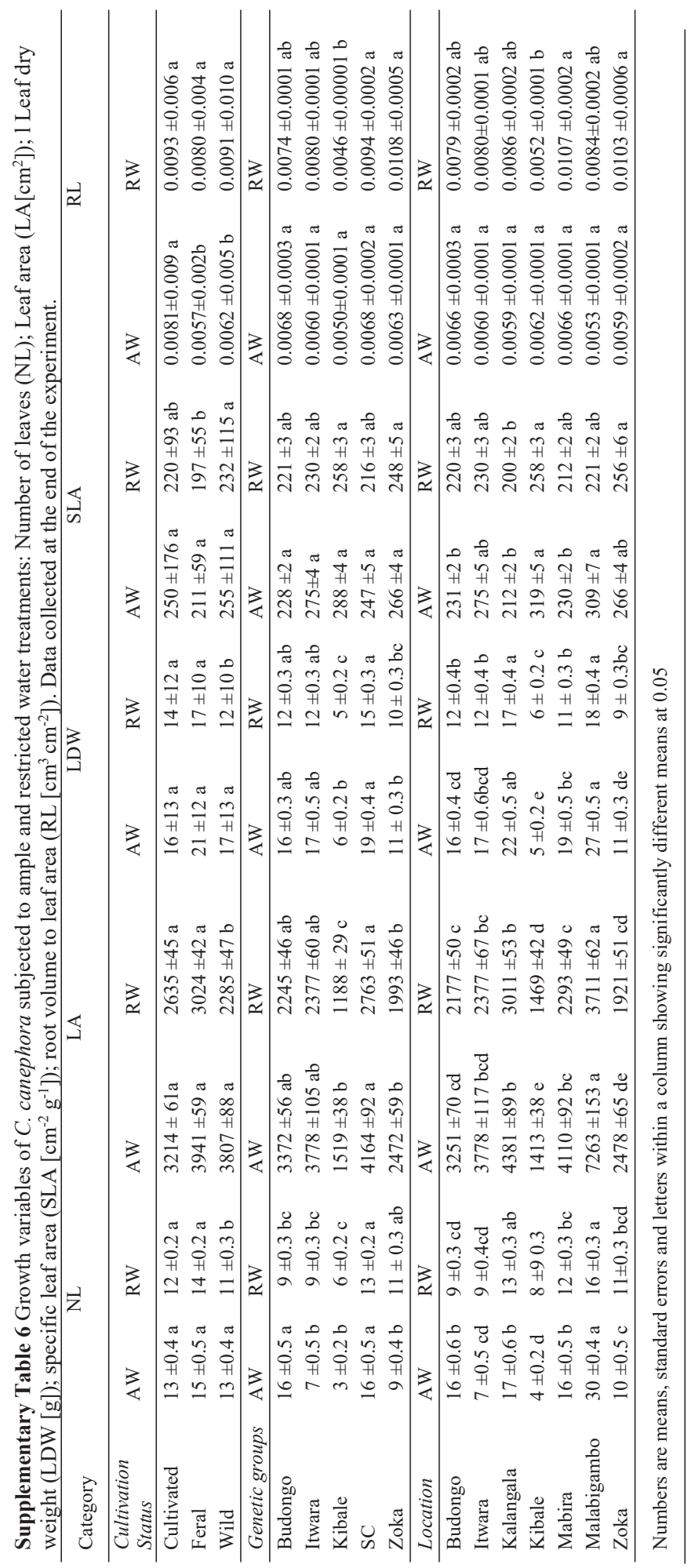


Supplementary Box 2 SMA Type 2 regression.

Call: sma(formula $=$ LNRGRA RW $\sim$ LNRGRA AW, data $=$ G, $\log =$ "", alpha $=0.05$, slope.test $=1$, elev.test $=0$ )

Fit using Standardized Major Axis

Coefficients: elevation slope

estimate $\quad-1.7975320 .6220464$

lower limit -2.2696220 .5203927$

upper limit -1.3254420 .7435571$

$\mathrm{H} 0$ : variables uncorrelated

R-squared: 0.006649153

P-value: 0.36993

H0 : slope not different from 1

Test statistic: $r=-0.4432$ with 121 degrees of freedom under $\mathrm{H} 0$

P-value: $2.8407 \mathrm{e}-07$

H0: elevation not different from 0

Test statistic: $\mathrm{t}=-7.538$ with 121 degrees of freedom under $\mathrm{H} 0$

P-value : $9.6443 \mathrm{e}-12$

$\operatorname{lm}\left(\right.$ formula $=$ P2\$DTRGRA $\sim$ P2\$RGRA ${ }_{\mathrm{AW}}$, data $=$ P2, weights $=$ Replicates $)$

Weighted Residuals:

Min 1Q Median 3Q Max

$\begin{array}{lllll}-0.60746 & -0.24336 & -0.02692 & 0.23012 & 0.86214\end{array}$

Coefficients:

Estimate Std. Error $\mathbf{t}$ value $\operatorname{Pr}(>|\mathbf{t}|)$

(Intercept) $1.691380 .07714 \quad 21.93<2 \mathrm{e}-16 * * *$

P2\$RGRA ${ }_{\mathrm{AW}}-56.55599$ 4.85158-11.66 <2e-16***

Signif. codes: 0 ‘***’ 0.001 '**’ 0.01 '*’ 0.05 '? 0.1 ' ' 1

Residual standard error: 0.332 on 80 degrees of freedom

Multiple R-squared: 0.6294， Adjusted R-squared: 0.6248

F-statistic: 135.9 on 1 and 80 DF, p-value: $<2.2 \mathrm{e}-1$ 
Chapter 4

\section{Phenotypic and genotypic variation in trait plastic responses to drought and its relationship with drought tolerance in wild Coffea canephora Pierre ex A. Froehner.}

This chapter is prepared for submission as: Kiwuka K, Vos J, Douma JC, Poncet V, Anten NPR Phenotypic and genotypic variation in trait plasticity to drought and its relationship with drought tolerance in wild Coffea canephora Pierre ex. A. Froehner. 


\title{
Chapter 4
}

\begin{abstract}
Precipitation and plant water availability is highly variable in many parts of the tropics, and this will likely increase under climate change. This makes it important to assess intraspecific variation in phenotypic plasticity to changes in water availability and the extent to which plasticity correlates with drought tolerance. If applied to wild populations of tropical tree crops, such knowledge could help identify climate resilient crop types. Here, we determined intraspecific variation in plasticity to water availability across 12 wild and three cultivated accessions of Coffea canephora (Robusta coffee) from different locations in Uganda. We conducted a split plot experiment in which plots were nested in two treatments (ample and restricted-water) and the 15 genotypes nested in plots. We collected data on performance, dry matter allocation and a host of morphological, and physiological traits to explore: (i) responses to drought and whether there is phenotypic and genotypic variation in these responses, (ii) the relationship between drought tolerance and trait plasticity to variation in water availability and (iii) the relationship between carbon isotope discrimination and water-use efficiency. Results showed considerable phenotypic and genotypic variation in trait responses to drought. We observed a negative relationship between drought tolerance and trait plasticity in response to changes in water availability. At leaf level, we found significant positive correlations between intrinsic water-use efficiency (WUEi photosynthesis/ transpiration) and carbon isotope signatures, whereby plants with high WUEi also had less negative leaf $\delta{ }^{13} \mathrm{C}$ discrimination values under both ample and restricted-water conditions. At shoot level, water use-efficiency (WUEp, measured as above ground growth/whole plant transpiration) showed positive correlations with $\delta^{13} \mathrm{C}$ although the relations were statistically significant only under ample-water conditions. Additionally, a correlation between WUEi and WUEp were also statistically significant only under ample-water correlations. This suggests that the use of $\delta^{13} \mathrm{C}$ discrimination values as proxies for WUEp is reliable only under ample-water conditions, indicating that the usefulness of $\delta^{13} \mathrm{C}$ as a WUE proxy depends on the water conditions imposed. Together, these results point to the challenges that breeders may face developing cultivars that are both tolerant to drought stress and responsive to ample-water conditions.
\end{abstract}

Keywords: drought tolerance, plasticity, trade-off, carbon isotope discrimination, water-use efficiency, 


\section{Introduction}

Tropical rain forests are characterized by annual dry seasons that span a wide range of intensity and seasonality. Even wet tropical forests, that normally get high precipitation yearround, are subjected to dry spells (Malhi and Wright, 2004, Richards et al., 1996). In addition, climate change is projected to potentially aggravate the intensity and frequency of droughts in tropical forests with most Intergovernmental Panel on Climate Change (IPCC) models predicting reduced precipitation and long-term droughts (Malhi and Phillips, 2004, Parry et al., 2007, Sheffield and Wood, 2008, Fauset et al., 2012). These changes have been predicted to strongly affect the distribution and survival of tropical forest tree species (Engelbrecht et al., 2007, Comita and Engelbrecht, 2014, Baltzer et al., 2008), raising the question to what extent tropical tree species can adapt to these changes.

The capacity of plant populations to cope with the changing environmental conditions is strongly linked to the genetic variation in functional traits and phenotypic plasticity within the population (Abrams, 1994 , Hamrick, 2004, Nicotra et al., 2010). Existence of genetic variation in functional traits is known to influence resource acquisition and thus underpins plant species survival under changing environmental conditions. Phenotypic plasticity, the extent to which a trait value changes across environments (Bradshaw, 1965, Grant, 1975, Abrams, 1994 , Hamrick, 2004, Pigliucci, 2005), is genetically controlled and may be under natural selection (Thoday, 1953, Levins, 1963, Bradshaw, 1965, Pigliucci, 2005).

As climate change is expected to occur over the next decades and given the generally decadal lifespan of tropical trees, phenotypic plasticity will likely play a key role in their ability to adjust to climate change. The question about adaptiveness of phenotypic plasticity, e.g. to what extent and under what set and pattern of environmental fluctuation does it increase plant growth, reproduction and/or survival, has been the subject of much debate (Sultan, 1987, Schmid, 1992, Dorn et al., 2000, van Kleunen et al., 2000). The adaptiveness of a plastic response may depend on the environmental dynamics in relation to the degree of irreversibility of a phenotypic response. For example, in the case of fluctuating water availability (i.e., intermittent wet and dry periods, which are very common in tropical environments), a response to wet conditions (e.g. a high leaf area to root or sapwood ratio, large xylem vessels or a high specific leaf area) may hamper plant growth and survival once conditions become dry again. The magnitude of this carry over effect depends both on the dynamics of dry and wet conditions and on the degree at which a phenotypic trait response modifies plant functioning. The latter probably differs between traits. For instance, opening and closure of stomates and its effects on 


\section{Chapter 4}

plant water use can be adjusted within an hour. While, changes in root vs shoot allocation and changes in wood anatomy may take much longer to adjust. Evidence from Bongers et al. (2017) revealed a negative correlation between plasticity and drought tolerance (i.e., the ability to maintain fitness under drought) in Mediterranean forest tree species and this corroborates van Kleunen and Fischer (2005) who established that a high degree of phenotypic plasticity often does not result in higher fitness in stressful habitats. Compared to these between-species comparisons, less work has been done to explore the relationship between drought plasticity and tolerance within a single species. Determining and understanding such variation within a species is important because it relates directly to the extent to which natural selection occurs (Allard, 1999). Such knowledge may also contribute to identifying material in crop species that is both drought tolerant and adequately responsive to favorable water supply (i.e., plant material that does well under dry and wet conditions). In this study, we compare plasticity in several functional traits to variation in water supply across a selection of wild and cultivated Coffea canephora Pierre ex A. Froehner genotypes.

C. canephora is indigenous to lowland African tropical forests, stretching from west Africa, central and eastern Africa. Those regions are characterized by abundant rainfall, high atmospheric humidity and a dry season not exceeding five months (Pohlan and Janssens, 2010, Wintgens, 2004). There is an environmental gradient along the natural distribution of $C$. canephora and this presents an opportunity for the species to adapt to different environmental conditions. Cultivated C. canephora also supports $30 \%$ of the global coffee consumption and its production is mostly sustained by poor countries depending on rainfed systems. Unfortunately, coffee production is threatened by the projected increased variability in environmental conditions arising from climate change, especially drought (Bunn et al., 2015). Since coffee production is sustained by resource-poor farmers with limited capacity to use irrigation to respond to water shortages predicted drought episodes, the best alternative is to avail them with drought tolerant genotypes. Development of drought tolerant genotypes entails an exploration and understanding of the genetic variation and phenotypic plasticity within the available genotypes, especially wild C. canephora genotypes.

Studies on cultivated genotypes have revealed substantial intraspecific trait variations and plastic responses of C. canephora in response to drought stress (DaMatta et al., 2002, Pinheiro et al., 2004, Praxedes et al., 2006, Silva et al., 2013, Tesfaye et al., 2014, King'oro et al., 2014, Erdiansyah et al., 2019 ). Despite the established knowledge about the high level of intraspecific variation and plastic response of C. canephora to drought (DaMatta et al., 2018), there exists a gap in the knowledge of the relationship between drought tolerance and plasticity. 
In addition, the previous studies were performed with cultivated materials that were, to some extent, selected, and the patterns observed may therefore differ from those present in wild populations.

Plastic responses in some traits can also be used as proxy for broader responses in performance. For instance, there is a negative relationship between water-use efficiency (defined as carbon gain per unit water loss) and carbon isotope discrimination (Farquhar and Richards, 1984, Hall et al., 1994, Condon and Hall, 1997). Since carbon isotope discrimination was found highly heritable trait (Condon and Richards, 1992), it is comparatively easy to use as a tool for selecting genotypes in $\mathrm{C}_{3}$ species that are more water-use efficient. Results for Coffea species (a $\mathrm{C}_{3}$ plant) in this regard are somewhat variable. Across genotypes of both $C$. arabica (Meinzer et al., 1990) and C. canephora (Silva et al., 2013) carbon isotope signatures were found to correlate with performance under water limited conditions, but performance of genotypes with greater water-use efficiency could not be predicted from the analysis of carbon isotopic signatures under ample-water conditions. In addition, mentioned studies were conducted with cultivated and not wild material, further studies are thus needed to establish the possibility of using carbon-isotope analysis to select water use-efficient genotypes in coffee. For this reason, our study purposes to extend this to wild coffee genotypes.

To contribute to the understanding of the extent of intraspecific variations and plasticity of wild C. canephora genotypes to drought, our paper seeks to determine: (i) trait responses to drought and whether there is an intra-specific variation in these responses, (ii) the relationship between drought tolerance and traits plasticity, (iii) the relationship between carbon isotope discrimination and water-use efficiency. To this end, we grew 15 C. canephora genotypes (wild and cultivated) in a greenhouse under two contrasting water availabilities. We measured a set of response traits associated with biomass allocation, plant architecture, leaf gas exchange (including ${ }^{13} \mathrm{C}$ abundances), plant performance expressed as biomass increment and water-use efficiency. We then correlated trait plasticity to drought tolerance (estimated as the genotype's ability to maintain growth under restricted-water conditions). We also assessed the relationship between ${ }^{13} \mathrm{C}$ abundances and water-use efficiency as a tool for selecting drought tolerant genotypes in breeding programmes. 


\section{Chapter 4}

\section{Material and Methods}

Study material

A total of 15 C. canephora genotypes were studied, comprising 12 wild genotypes selected based on provenance across native sites in Uganda and their genetic differentiation (Kiwuka et al., submitted), and three elite genotypes, sustaining the $C$. canephora production in Uganda (Table 1). After carefully following the required legal provisions, stem cuttings were sent to Wageningen University \& Research, The Netherlands, $51^{\circ} 97^{\prime} \mathrm{N}, 5^{\circ} 66^{\prime} \mathrm{E}$ on the $7^{\text {th }}$ of July 2017 for rooting, establishment and further experimentation.

The establishment of the plant material for the experiment followed three phases: rooting of the cuttings, a pre-experimental growth period and the experimental phase. The cuttings were raised in $7 \times 7 \times 8 \mathrm{~cm}$ pots with potting soil and placed under a plastic foil cage and managed following protocols developed by the National Coffee Research Institute (NaCORI) in Uganda. For each genotype, 20 to 30 single node stem cuttings (about 10-12 cm in length) were obtained from the bigger orthotropic branches of parent plants. Each single node (about $10 \mathrm{~cm}$ long) stem cutting was planted in a pot and rooting was stimulated by dipping the base of the stem in Pokon Cutting powder (Indolyl butter acid 2,5 g/Kg (Pokon Naturado B.V., Veenendaal, the Netherlands).

After five months (15 ${ }^{\text {th }}$ December 2017), 6-10 replicate rooted cuttings per genotype per treatment were transplanted to bigger pots. One genotype (KT17) had only three replicates per treatment but was it is one of the three elite cultivated genotypes in Uganda's $C$. canephora cultivation system (Table 1), but results for KT17 need more cautious interpretation. The plants were grown in a greenhouse compartment of $6 \times 5.5 \mathrm{~m}$ and allowed to adapt to local conditions and establish more roots in the bigger pots. The potting medium was a mixture of soil with a $\mathrm{pH}$ of 5.5 and $2.1 \%$ organic matter. Plants were regularly watered with spray irrigation and boosted with $1.7 \mathrm{~g}$ of NPK $+\mathrm{MgO}$ slow release fertilizer (Osmocote: $16 \% \mathrm{~N}-11 \% \mathrm{P}_{2} \mathrm{O}_{5}-10$ $\% \mathrm{~K}_{2} \mathrm{O}$ ) per pot. Day and night temperatures were $26^{\circ} \mathrm{C}$ and $23{ }^{\circ} \mathrm{C}$ while relative humidity was maintained at $70 \%$.

\section{Experimental design}

On the 20 March 2018, after three months of growing up in bigger pots, the experimental treatments comprising two differential water regimes were introduced. The experiment was conducted in a split plot design with plots nested in treatments and genotypes nested in plots. Treatments were randomly assigned to the plots. In total, we had 10 plots per treatment with 12 plants per block (240 plants in total). Each block contained 12 randomly selected genotypes 
from the selected 15 genotypes. Given the different number of replications in each genotype this led to an unbalance in the design (Supplementary Table 1).

Table 1 Details on the genotypes used in the experiment.

\begin{tabular}{lllllll}
\hline Genotype & $\begin{array}{l}\text { Level of } \\
\text { cultivation } \\
\text { status }\end{array}$ & $\begin{array}{l}\text { Location } \\
\text { of origin }\end{array}$ & $\begin{array}{l}\text { Location's } \\
\text { code }\end{array}$ & $\begin{array}{l}\text { No. of } \\
\text { replicates } \\
\text { per } \\
\text { treatment }\end{array}$ & $\begin{array}{l}\text { Location's } \\
\text { average } \\
\text { annual } \\
\text { rainfall } \\
\text { (mm/year) }\end{array}$ & $\begin{array}{l}\text { Location's } \\
\text { annual mean } \\
\text { temperature } \\
\left({ }^{\circ} \mathrm{C}\right)\end{array}$ \\
\hline KB4-4 & Wild & Kibale & KB & 6 & 1267 & 20 \\
KB3-4 & Wild & Kibale & KB & 10 & 1267 & 20 \\
ZK4-3 & Wild & Zoka & ZK & 10 & 1268 & 24 \\
ZK5-2 & Wild & Zoka & ZK & 10 & 1268 & 24 \\
ZK4-5 & Wild & Zoka & ZK & 7 & 1268 & 24 \\
ZK2-1 & Wild & Zoka & ZK & 10 & 1268 & 24 \\
ZK2-4 & Wild & Zoka & ZK & 10 & 1268 & 24 \\
BD1-1 & Wild & Budongo & BD & 7 & 1311 & 23 \\
BD2-5 & Wild & Budongo & BD & 7 & 1311 & 23 \\
BD3-2 & Wild & Budongo & BD & 10 & 1311 & 23 \\
IT2-3 & Wild & Itwara & IT & 10 & 1435 & 20 \\
IT4-3 & Wild & Itwara & IT & 9 & 1435 & 20 \\
KW18 & Cultivated & Kawanda & KW & 6 & 1377 & 22 \\
KW19 & Cultivated & Kawanda & KW & 10 & 1377 & 22 \\
KT17 & Cultivated & Kituza & KT & 3 & 1390 & 21 \\
\hline Cultivated & gntypes & Con & & & 23 \\
\hline
\end{tabular}

Cultivated genotypes comprise elite coffee wilt disease resistant material. Wild material was collected from natural forests at the location of origin. Note that the provided climatic data have somewhat different connotations for the wild (association with natural habitat) than for the cultivated material (habitat under which they are conserved ex-situ in field collections). Annual rainfall and temperature data averaged for the years 1950-2000 and were downloaded from WorldClim (www.worldclim.org) at 30 arc-second resolution (Hijmans et al., 2005).

The experimental treatment comprised two watering regimes: (i) ample-water (AW) and (ii) restricted-water (RW, also referred to as drought). Basing on the pF curve of the potting medium, the pot weights of the two experimental water regimes were estimated. The pot weights corresponding to field capacity (FC) and wilting point (WP) were $7.7 \mathrm{~kg}$ and $6.7 \mathrm{~kg}$, respectively. The average pot weights for the experimental treatments AW and RW were kept at $7.5 \mathrm{~kg}(0.2 \mathrm{~kg}$ lower than the pot weight at field capacity) and $6.8 \mathrm{~kg}(0.1 \mathrm{~kg}$ higher than the pot weight at wilting point), respectively. Irrigation under AW conditions was, on average, applied twice a week, based on the plant size and weather conditions (i.e. during hotter weeks, plants were irrigated more than twice a week). Plants in the RW treatment were frequently weighed and irrigated to maintain a stable pot weight which was pot weight at the wilting point (WP) + water loss by their evapotranspiration. The amount of water added to each pot was equal to the cumulative daily evapotranspiration since the previous irrigation. This was done to ensure 


\section{Chapter 4}

that plants within treatments experienced as much as possible the same soil moisture, but it did entail that plants that transpired more also received more water. Plant transpiration was estimated by subtracting the average weight loss of eight extra pots without plants (i.e. evaporation) from the total weight loss of each pot with a plant at each measurement day.

\section{Measurements}

Measurements were performed at four stages: (i) at the start of the differential treatment period (S1 day 0; initiation of the experimental treatments [20 March 2018]), (ii) during the experiment (S2; [30 April 2018]; after 39 days), (iii) close to the end of the experiment (S3; [21 June 2018]; after 80-87 days) and (iv) at the end of the experiment (S4; [25 June 2018] after 87 days). The details of the traits measured at the specific stages are presented in Table 2. On 20 March the youngest opened leaf on every branch was marked to be able to distinguish between the parts of the shoot that had been formed before and after initiation of treatments.

\section{Traits}

All the measured traits were categorized into: (i) performance, (ii) morphological, (iii) allocation and (iv) physiological traits (Table 2).

\section{Performance traits}

Relative growth in leaf area (RGRA $\left.\left[\mathrm{d}^{-1}\right]\right)$ and relative growth in height (RGRH $\left.\left[\mathrm{d}^{-1}\right]\right)$ of each plant were calculated as:

$$
\begin{aligned}
& \text { RGRA }=\frac{\ln (\text { leaf area at the end })-\ln (\text { leaf area at the start })}{\text { time }} \\
& \text { RGRH }=\frac{\ln (\text { plant height at the end })-\ln (\text { plant height at the start })}{\text { time }}
\end{aligned}
$$

equation 1

equation 2

with 'start' and 'end' referring to 20 March (S1) and the 25 June (S4) and 'time' period between those dates (87 days).

Leaf area was measured with a digital leaf area meter (LI-3100, LiCor, Lincoln, USA). Total leaf area (TLA $\left[\mathrm{cm}^{2}\right]$ ) data comprised: (i) leaf area present at initiation of the experimental treatments including senesced leaf area and (ii) leaf area that appeared during the treatment period (LA) ; estimated from main stem and primaries (distinction between leaf area pertaining to $i$ and ii could be done because we tagged the newest leaves at the start ofstart of the drought treatment period). Plant height measurements were performed, using a ruler, from the base of the plant to the highest node. At these times, total number of leaves (TNL) was also counted. Aerial dry weight (ADW [g]) was determined by weighing on a digital weighing scale oven 
dried $\left(24 \mathrm{~h}\right.$ at $\left.70^{\circ} \mathrm{C}\right)$ above ground plant material (leaves and stems), produced during the drought treatment period.

Table 2 Summary of the trait categories in the study.

\begin{tabular}{|c|c|c|c|c|}
\hline Category & Trait & $\begin{array}{l}\text { Trait } \\
\text { acronym }\end{array}$ & Units & $\begin{array}{l}\text { Stages of } \\
\text { Measure } \\
\text { ment }\end{array}$ \\
\hline \multirow[t]{6}{*}{ Performance } & Relative growth rate in leaf area* & RGRA & {$\left[\mathrm{d}^{-1}\right]$} & S1- S4 \\
\hline & Relative growth rate in plant height* & RGRH & {$\left[d^{-1}\right]$} & S1- S4 \\
\hline & Total number of leaves* & TNL & count & S1- S4 \\
\hline & \multirow{3}{*}{$\begin{array}{l}\text { Total leaf area* } \\
\text { Leaf area (produced during treatment period) } \\
\text { Aerial dry weight (produced during treatment } \\
\text { period) }\end{array}$} & TLA & {$\left[\mathrm{cm}^{2}\right]$} & S1- S4 \\
\hline & & LA & {$\left[\mathrm{cm}^{2}\right]$} & $\mathrm{S} 2-\mathrm{S} 4$ \\
\hline & & ADW & [g] & S2- S4 \\
\hline \multirow[t]{6}{*}{ Morphology } & Specific leaf area & SLA & {$\left[\mathrm{cm}^{2} \mathrm{~g}_{-}{ }^{1}\right]$} & S4 \\
\hline & Stomatal density & STD & {$\left[\mathrm{cm}^{-2}\right]$} & S4 \\
\hline & Stomatal index & STI & {$\left[\mathrm{cm}^{-2}\right]$} & S4 \\
\hline & Specific root length* & SRL & {$\left[\mathrm{cm} \mathrm{g-}^{-1}\right]$} & S4 \\
\hline & Stem diameter & SD & {$[\mathrm{mm}]$} & S4 \\
\hline & Wood density & WD & {$\left[\mathrm{g} \mathrm{cm}^{-3}\right]$} & S4 \\
\hline \multirow[t]{3}{*}{ Allocation } & & & dimensionles & S1- S4 \\
\hline & Root to shoot ratio* & $\mathrm{R}: \mathrm{S}$ & $\mathrm{s}$ & \\
\hline & Leaf area to plant dry weight ratio* & LAR & {$\left[\mathrm{cm} \mathrm{g-}^{-1}\right]$} & S1- S4 \\
\hline \multirow[t]{4}{*}{ Physiology } & Carbon isotope discrimination & $\delta^{13} \mathrm{C}$ & {$[\%$} & S4 \\
\hline & Intrinsic water-use efficiency & WUEi & {$\left[\mu \mathrm{ol} \mathrm{mol}{ }^{-1}\right]$} & S4 \\
\hline & Above ground-plant water-use efficiency & WUEp & {$\left[\mathrm{g} \mathrm{kg}^{-1}\right]$} & S4 \\
\hline & Transpired water & TRW & {$[\mathrm{kg}]$} & S1-S4 \\
\hline
\end{tabular}

\section{Morphological traits}

Specific leaf area (SLA $\left[\mathrm{cm}^{2} \mathrm{~g}^{-1}\right]$ ) was calculated as the ratio of the leaf area and dry weight of the single fully expanded leaf that developed during the drought treatment. Stomatal density (STD $\left[\mathrm{cm}^{-2}\right]$ ) samples were taken at the end of the experiment from the youngest fully developed main stem leaf that appeared during the drought treatment period. Nail polish was applied on the abaxial side and left to completely dry. Using cello tape, the layer of nail polish with the epidermal imprint was carefully removed. After that, two subsamples were taken and observed under a microscope. For each subsample, two images, representing the epidermal imprint, were taken, using a digital camera (Nikon DS-Ri1) mounted on a light microscope (Leica Leitz Aristoplan) with a 25x magnification. Stomata in each image were counted, using Image J (v 1.8.0) software. Due to restricted-water supply, plants in the RW treatment tended to 


\section{Chapter 4}

reduce their leaf size. For that reason, the stomatal density was corrected by the leaf area of the measured leaf to obtain a proxy of the stomatal index (STI $\left[\mathrm{cm}^{-2}\right]$; i.e. indicating the fraction of epidermal cells being stomata), by the following formula:

Stomatal index $_{\text {ig }}=$ stomatal density $_{\text {ig }} * \frac{\mathrm{LA}_{\text {ig }}}{\overline{\mathrm{LA}}(\text { ample-water })_{\mathrm{g}}}$ equation 3 where $\mathrm{g}=$ genotype, $\mathrm{i}=$ individual plant (replicate), $\mathrm{LA}=$ leaf area, bar above $\overline{\mathrm{LA}}=$ mean leaf area

Stem diameter (SD [mm]) was measured on the first node of the main stem with a digital calliper at the end of the experiment. Wood density (WD $\left[\mathrm{g} \mathrm{cm}^{-3}\right]$ ) was determined from the part of the main stem that appeared after the introduction of the experimental treatments. The volume of main stem samples was measured using a graduated cylinder and the mass of the oven dried samples was also determined to calculate wood density as:

$\rho=\frac{m}{V}$

equation 4

where $m$ is stem mass (in $\mathrm{g}$ ) and $v$ is stem volume (in $\mathrm{mm}^{3}$ ).

To estimate specific root length (SRL $\left[\mathrm{cm} \mathrm{g}^{-1}\right]$ ), plant roots were carefully extracted from the soil and cleaned under running water. Total root length $(\mathrm{cm})$ was measured on a randomly selected sample from the roots. The sample was scanned and analysed by WinRHIZO software (http://regent.qc.ca/assets/winrhizo_about.html). SRL was calculated as the ratio between total root length and root dry weight.

\section{Allocation traits}

Root: shoot ratio (R: S ratio) was estimated as the ratio of root biomass to the sum of total leaf dry weight and total stem dry weight produced pre and during the experimental phase. Root biomass could only be measured at the end of the experiment and no estimates of root biomass were made at the beginning of the experiment. This implies that the root biomass was estimated from the total roots since the establishment of the plants. Leaf area ratio (LAR [cm g- ${ }^{1}$ ) was determined from the ratio of total leaf area (TLA) to total biomass produced pre and during the experimental phase.

\section{Physiological traits}

Leaf gas exchange parameters were measured with a portable Photosynthesis System (Li-6800, LiCor, Lincoln, Nebraska USA) on the youngest, fully expanded and not shaded leaf of each plant. The following settings were used during the gas exchange measurements: cuvette area $2 \times 3 \mathrm{~cm}$, natural light (clear-top chamber), air flow of $500 \mu \mathrm{mol} \mathrm{s} \mathrm{s}^{-1}$, fan speed of 10000 $\mathrm{rpm}$, air temperature of $30{ }^{\circ} \mathrm{C}, 60 \%$ relative humidity and air $\mathrm{CO}_{2}$ concentration of $400 \mu \mathrm{mol}$ 
$\mathrm{mol}^{-1}$. The measurements were done following a survey approach: a survey is a way to characterize a population, maximizing the sample size in a given amount of time, providing a reasonable estimate of the actual rate of photosynthesis at ambient light of a leaf in the experiment. During the measurement, a leaf was clamped, and, after approximately $60 \mathrm{~s}$, the fluxes of $\mathrm{CO}_{2}$ and $\mathrm{H}_{2} \mathrm{O}$ were logged. These measurements were taken in three series a day (two in the morning and one in the afternoon) on the same leaves to correct for diurnal variation in light availability. Each measurement day, one individual leaf per genotype and treatment was measured. The measurements were carried out for eight days (Supplementary Table 4)

\section{Carbon isotope abundance}

Carbon isotope discrimination, a measure of the ratio of the stable isotopes of carbon $\left({ }^{13} \mathrm{C} /{ }^{12} \mathrm{C}\right)$ in plant material relative to the value of the relative to a standard; Vienna - Pee Dee Belemnite (V-PDB) (Farquhar and Richards, 1984, Adiredjo et al., 2014a) was measured on the youngest fully expanded leaf on each plant. Samples were taken on the $13^{\text {th }}$ of July 2018 , oven dried $\left(70{ }^{\circ} \mathrm{C}\right.$ for 72 hours), weighed with a precision scale and ground to powder. The dried powder was further dried $\left(70{ }^{\circ} \mathrm{C}\right.$ for 48 hours $)$ and subsamples of $2.00 \mathrm{mg}( \pm 0.15)$ were enclosed in tin capsules (Elemental Microanalysis, UK) and sent to the Leicester Environmental Stable Isotope Laboratory, Leicester, UK. The carbon isotope composition of the samples was determined using a Sercon 20-20 mass spectrometer coupled to an elemental analyzer. The stable isotope discrimination was expressed in \%o relative to Vienna - Pee Dee Belemnite (VPDB) and calculated as:

$\delta^{13} C=\left(\frac{R_{\text {sam }}}{R_{\text {std }}}-1\right) \times 1000$

equation 5

Where $\mathrm{R}_{\text {sam }}$ and $\mathrm{R}_{\text {std }}$ are the ${ }^{12} \mathrm{C} /{ }^{13} \mathrm{C}$ ratio of the leaf sample and the standard, respectively. The accuracy of measurements was assessed by repeated measurements of lab standards and was found to be $\pm 0.07 \%$.

\section{Expressing the effect of experimental treatment on traits}

Trait phenotypic plasticity index (PI) was calculated for each genotype using the formula by Valladares et al., (2000).

$$
\mathrm{PI}_{\mathrm{g}}(t)=\frac{\operatorname{abs}\left(t_{g, A W}-t_{g, R W}\right)}{\max \left(t_{g, A W}, t_{g, R W}\right)}
$$

equation 6 


\section{Chapter 4}

where $t_{g . A W}=$ mean trait value in ample-water conditions and $t_{g . R W}=$ mean trait value in restricted-water conditions. The coefficient of variation of the trait value per treatment was computed from the ratio of standard deviation to the mean.

We considered RGRA as an important performance trait, because: by determining RGRA we could correct for size differences at the start of the experiment, and leaf area was assumed to be a reasonable indicator of future growth. As the plants were small, it is reasonable to assume an exponential growth phase, and drought tolerance to restricted-water (DT) of RGRA was calculated using the following formula:

Drought tolerance to restricted-water (DT) of RGRA was calculated using the following formula:

$$
\mathrm{DT}(\mathrm{RGRA})_{\mathrm{gr}}=\frac{\text { RGRA (restricted-water) }}{\text { RGRA (ample-water) }}
$$

equation 7

Water-use efficiency

Instantaneous photosynthetic water-use efficiency (WUEi $\left[\mu \mathrm{mol} \mathrm{mol}^{-1}\right]$ ) was calculated as the ratio of leaf photosynthetic rate $\left(\mathrm{A}, \mu \mathrm{mol} \mathrm{m} \mathrm{m}^{-2} \mathrm{~s}^{-1}\right)$ and transpiration rate $\left(\mathrm{E}, \mathrm{mol} \mathrm{m}^{-2} \mathrm{~s}^{-1}\right)$ as measured with the LI6800. Above ground-plant water-use efficiency (WUEp) was calculated as the ratio between the aerial dry weight (ADW [g]) produced during the drought treatment period ([20 ${ }^{\text {th }}$ March 2018] $-\left[25^{\text {th }}\right.$ June 2018]) and the total amount of transpired water (TRW $[\mathrm{kg}])$ during over that same period.

\section{Data analysis}

Linear mixed-effects models (lme) were used to account for the random effect of plots. The fixed effects included were: genotype, water treatment and their interaction on measured traits. Four different models were tested, using the nlme package in R (Pinheiro et al., 2019). The first one assumed homogeneity of variance across treatments and genotypes (model 1), the second one assumed heterogeneity in variance across only genotypes (model 2), the third one assumed heterogeneity of variance across only treatments (model 3), the fourth one assumed heterogeneity across both treatments and genotypes (model 4). The model with the lowest Akaike Information Criterion (AIC) was used for further interpretation. Main effects by genotype, water treatment and their interactions were considered statistically significant whenever $\mathrm{p}$-value $<0.05$. The multiple comparisons with Tukey's method were performed on the best model using function emmeans of the R package 'emmeans' (Lenth et al., 2018) to test 
if treatment was significantly different between genotypes and statistically significant differences were considered at $\mathrm{p}$-value $<0.05$.

For each of the trait categories (performance, morphology, allocation and physiology) we calculated the mean plasticity index (equation 6) across all traits within a category. Besides, the Pearson correlation coefficients between drought tolerance and mean plasticity in each category were calculated. This analysis was also done for the mean plasticity index of all traits in the study.

Averaging plasticity indices within a category may be problematic when traits within a category are responding differently to drought. We therefore complemented the above analysis with a principal component analysis (PCA) to find major axes of variation in trait changes in response to drought. Input to the PCA were the mean genotypic trait values per treatment. Each trait was scaled to zero mean and a standard deviation of one. Next, we calculated the change in position of each genotype in ample-water vs restricted-water conditions along the PC1, PC2, PC3 and PC4 axes. A correlation test was performed to assess the relationship between the change in trait values along the first four PC axes and the drought tolerance. The correlation test was also used to explore the association between water-use efficiency and carbon isotope discrimination. All the analyses were performed in R version 3.5.0 (Team, 2018).

\section{Results}

\section{Effect of drought on traits}

Restricted-water had statistically significant effects on traits in all categories except for wood density (WD $\left[\mathrm{g} \mathrm{cm}^{-3}\right]$ ) (Table 3 and Table 4$)$. It reduced values of all traits except intrinsic water-use efficiency (WUEi $\left[\mu \mathrm{mol} \mathrm{mol}^{-1}\right]$ ), root to shoot ratio (R: S) and stomatal density (STD $\left[\mathrm{cm}^{-2}\right]$ ) whose values increased (Table 3 ). 
Table 3 Variation across genotypes in response to experimental treatments for the measured traits. Traits are categorized into: performance, morphology, allocation and physiology.

\begin{tabular}{|c|c|c|c|c|c|c|}
\hline \multirow[t]{2}{*}{ Category } & \multirow[t]{2}{*}{ Trait } & \multicolumn{2}{|c|}{ Ample-water } & \multicolumn{2}{|c|}{ Restricted-water } & \multirow{2}{*}{$\begin{array}{c}\text { Relative change } \\
\qquad(\%)\end{array}$} \\
\hline & & Mean & $\begin{array}{l}\mathrm{CV} \\
(\%)\end{array}$ & Mean & $\begin{array}{l}\text { CV } \\
(\%)\end{array}$ & \\
\hline \multirow[t]{6}{*}{ Performance } & RGRA $\left[d^{-1}\right]$ & 0.023 & 21.7 & 0.014 & 28.6 & -38.9 \\
\hline & $\mathrm{RGRH}\left[\mathrm{d}^{-1}\right]$ & 0.008 & 37.5 & 0.005 & 40.0 & -37.8 \\
\hline & TNL & 42.67 & 39.0 & 31.59 & 44.1 & -26.0 \\
\hline & TLA $\left[\mathrm{cm}^{2}\right]$ & 2823 & 46.9 & 1279 & 56.6 & -54.7 \\
\hline & $\mathrm{LA}\left[\mathrm{cm}^{2}\right]$ & 2432 & 48.0 & 899 & 62.1 & -63.0 \\
\hline & $\mathrm{ADW}[\mathrm{g}]$ & 23.23 & 55.1 & 11.75 & 57.2 & -49.4 \\
\hline \multirow[t]{7}{*}{ Morphology } & SLA $\left[\mathrm{cm}^{2} \mathrm{~g}_{-}{ }^{1}\right]$ & 168 & 15.3 & 142 & 13.4 & -15.6 \\
\hline & $\operatorname{STD}\left[\mathrm{cm}^{-2}\right]$ & 39.89 & 17.3 & 47.88 & 26.9 & 20.0 \\
\hline & STI $\left[\mathrm{cm}^{-2}\right]$ & 39.77 & 27.6 & 32.95 & 33.4 & -17.2 \\
\hline & $\mathrm{SRL}\left[\mathrm{cm} \mathrm{g}_{-}{ }^{1}\right]$ & 4479 & 31.6 & 3586 & 28.9 & -20.0 \\
\hline & $\mathrm{SD}[\mathrm{mm}]$ & 6.23 & 22.3 & 5.137 & 16.6 & -17.6 \\
\hline & $\mathrm{WD}\left[\mathrm{g} \mathrm{cm}^{-3}\right]$ & 0.261 & 27.1 & 0.244 & 23.7 & -6.7 \\
\hline & SRL [ $\left.\mathrm{cm} \mathrm{g}_{-}{ }^{1}\right]$ & 4479 & 31.6 & 3586 & 28.9 & -20.0 \\
\hline \multirow[t]{2}{*}{ Allocation } & $\mathrm{R}: \mathrm{S}$ & 0.209 & 26.8 & 0.271 & 22.5 & 29.6 \\
\hline & $\operatorname{LAR}\left[\mathrm{cm}^{2} \mathrm{~g}^{-1}\right]$ & 100 & 18.0 & 79.20 & 20.1 & -20.8 \\
\hline \multirow[t]{4}{*}{ Physiology } & $\delta^{13} \mathrm{C}[\% 0]$ & -30.29 & -3.8 & -28.95 & -4.2 & -4.4 \\
\hline & WUEi $\left[\mu \mathrm{mol} \mathrm{mol}{ }^{-1}\right]$ & 2622 & 58.2 & 3485 & 83.2 & 32.9 \\
\hline & WUEp $\left[\mathrm{g} \mathrm{kg}^{-1}\right]$ & 3.454 & 19.0 & 2.475 & 25.0 & -28.3 \\
\hline & TRW [kg] & 5.829 & 50.6 & 3.382 & 46.4 & -42.0 \\
\hline
\end{tabular}

Traits: RGRA (relative growth rate in leaf area), RGRH (relative growth rate in plant height), TNL (total number of leaves), TLA (total leaf area), LA (leaf area), ADW (aerial dry weight), SLA (specific leaf area), STD (stomatal density), STI (stomatal index), SRL (specific root length), SD (stem diameter), WD (wood density), R:S (root to shoot ratio for dry weight), LAR (leaf area ratio), GSW (stomatal conductance), $\delta^{13} \mathrm{C}$ (carbon isotope discrimination), WUEi (intrinsic water- use efficiency), WUEp (above ground -plant water-use efficiency), TRW (transpired water). Statistically significance levels of these differences are provided in Table 4.

Is there genotypic variation in trait responses to drought across categories?

There were statistically significant genotype effects across all traits and statistically significant genotype and treatment interactions for all traits, except for wood density (WD) (Table 4). The variation across genotypes of performance and physiological traits was comparatively higher under restricted-water than in ample-water conditions (Table 3). The variation across genotypes in morphology and allocation trait categories differed with some (e.g. SRL and R: S) traits showing a higher variation under ample-water conditions (Table 3). There was high variation in trait coefficient of variations within ample and restricted-water conditions, while individual traits tended to show comparatively stable variation across treatments (Table 3). 
Table 4 Anova results linear mixed-effects models for the traits. Traits are categorized into: performance, morphology, allocation and physiology. Numbers in the table are F-ratios: with "*" indicating significant effects with $\mathrm{p}<0.05$ and without "*" indicating non-significant effects with $\mathrm{p}$ $\geq 0.05$.

\begin{tabular}{|c|c|c|c|c|}
\hline Category & Trait & Factor & & Interaction \\
\hline & & Treatment $(\mathrm{T})$ & Genotype $(\mathrm{G})$ & $\mathrm{T} \times \mathrm{G}$ \\
\hline \multirow{6}{*}{ Performance } & RGRA $\left[d^{-1}\right]$ & $325.6^{*}$ & $6.8^{*}$ & $4.1^{*}$ \\
\hline & RGRH $\left[\mathrm{d}^{-1}\right]$ & $150.7 *$ & $8.2^{*}$ & $4.0^{*}$ \\
\hline & TNL & $90.4^{*}$ & $32.2 *$ & $2.0^{*}$ \\
\hline & TLA $\left[\mathrm{cm}^{2}\right]$ & $658.6^{*}$ & $95.4^{*}$ & $21.4^{*}$ \\
\hline & $\mathrm{LA}\left[\mathrm{cm}^{2}\right]$ & $588.9^{*}$ & $45.4 *$ & $9.0 *$ \\
\hline & $\mathrm{ADW}[\mathrm{g}]$ & $495.09 *$ & $84.4 *$ & $26.1 *$ \\
\hline \multirow[t]{6}{*}{ Morphology } & SLA $\left[\mathrm{cm}^{2} \mathrm{~g}^{-1}\right]$ & $146.0^{*}$ & $11.7^{*}$ & $3.5 *$ \\
\hline & $\operatorname{STD}\left[\mathrm{cm}^{-2}\right]$ & $39.1 *$ & $5.6^{*}$ & $2.0^{*}$ \\
\hline & STI $\left[\mathrm{cm}^{-2}\right]$ & $40.2 *$ & $1.9^{*}$ & $1.8 *$ \\
\hline & $\mathrm{SD}[\mathrm{mm}]$ & $147.9 *$ & $35.4 *$ & $4.2 *$ \\
\hline & $\mathrm{WD}\left[\mathrm{g} \mathrm{cm}^{-3}\right]$ & 3.1 & $9.1 *$ & 1.2 \\
\hline & $\mathrm{SRL}\left[\mathrm{cm} \mathrm{g-}^{1}\right]$ & $25.1 *$ & $11.5^{*}$ & $2.2 *$ \\
\hline \multirow[t]{2}{*}{ Allocation } & $\mathrm{R}: \mathrm{S}$ & $97.1 *$ & $8.5 *$ & $4.4^{*}$ \\
\hline & $\operatorname{LAR}\left[\mathrm{cm}^{2} \mathrm{~g}^{-1}\right]$ & $177.0^{*}$ & $14.0 *$ & $5.1^{*}$ \\
\hline \multirow[t]{4}{*}{ Physiology } & $\delta^{13} \mathrm{C}[\% 0]$ & $133.6^{*}$ & $18.0 *$ & $4.5^{*}$ \\
\hline & WUEi $\left[\mu \mathrm{mol} \mathrm{mol}{ }^{-1}\right]$ & $19.1^{*}$ & $8.5^{*}$ & $3.6^{*}$ \\
\hline & WUEp $\left[\mathrm{g} \mathrm{kg}^{-1}\right]$ & $53.6^{*}$ & $20.0 *$ & $9.5^{*}$ \\
\hline & TRW [kg] & $95.3 *$ & $51.2 *$ & $7.9^{*}$ \\
\hline
\end{tabular}

Traits: RGRA (relative growth rate in leaf area), RGRH (relative growth rate in plant height), TNL (total number of leaves), TLA (total leaf area), LA (leaf area), ADW (aerial dry weight), SLA (specific leaf area), STD (stomatal density), STI (stomatal index), SD (stem diameter), WD (wood density), SRL (specific root length), R:S (root to shoot ratio), LAR (leaf area ratio), $\delta^{13} \mathrm{C}$ (carbon isotope discrimination), WUEi (intrinsic water- use efficiency), WUEp (above ground- plant wateruse efficiency), TRW (transpired water).

Genotypic variation across performance traits in response to drought

All genotypes, except BD3-2, exhibited statistically significant reductions in their relative growth rate in leaf area (RGRA) in response to drought (Figure 1 panel (A) and Supplementary Table 1), ranging from $28.0 \%$ in ZK 2-1 to $62.5 \%$ in KB 4.4 (Figure 1 panel (A) and supplementary Table 2). Relative height growth (RGRH) was reduced by drought in most genotypes and the relative decrease due to restricted-water varied from $24.0 \%$ in $\mathrm{ZK} 2-1$ to $71.0 \%$ KB 4-4 (Supplementary Tables 1 and 2). Total number of leaves (TNL) was also reduced in all genotypes but BD 3-2 (supplementary Table 2). Leaf area attained during the drought treatment (LA) Figure 1 panel (A) and aerial dry weight (ADW) showed a similar trend with statistically significant reductions in all genotypes except BD 3-2 and IT 4-3 (Supplementary Tables 1 and 2). Total leaf area (TLA) displayed a trend similar to LA and ADW although significant reductions in TLA due to restricted-water supply were observed in all genotypes except BD 3-2 (Supplementary Tables 1 and 2). This indicates, as expected, 


\section{Chapter 4}

drought significantly reduced the growth in leaf area of most genotypes possibly as way of reducing water loss through leaves.

Genotypic variation across morphology traits in response to drought.

Restricted-water significantly decreased specific leaf area (SLA) in nine of the 15 genotypes (Figure 1 (panel B) and Supplementary Table 1). The relative decrease in SLA ranged from $12.3 \%$ in ZK 5-2 to $28.2 \%$ for IT 4-3. Stomatal density (STD) was generally higher under restricted-water than in ample-water conditions, however, statistically significant increases were observed in only five genotypes, namely BD1-1, IT4-3, ZK2-1, ZK4-3 and ZK 5-2 (Supplementary Tables 1 and 2). Conversely, stomatal index (STI) was comparatively lower under restricted-water than in ample-water conditions with statistically significant differences observed in five genotypes: KB3-4, KT17, KW19, ZK2-4 and ZK5-2 (Supplementary Tables 1 and 2).

Restricted-water reduced stem diameter (SD) in all genotypes except BD3-2, IT4-3 and KW18 (supplementary Tables 1 and 2). Genotypes had lower wood density (WD) under restricted-water than in ample-water conditions but the effect was not statistically significant in most genotypes except in ZK 5-2 (supplementary Table 1). Restricted-water conditions decreased specific root length (SRL) of most genotypes although statistically significant reductions were observed in only six genotypes (Figure 1 (panel C) and Supplementary Tables 1 and 2). The relative reductions in SRL across genotypes ranged from $28.3 \%$ in KW 18 to $44.2 \%$ in KB 4-4 (Supplementary Tables 1 and 2).

\section{Genotypic variation across allocation traits in response to drought}

In response to restricted-water supply, the $\mathrm{R}$ : $\mathrm{S}$ ratio increased in most genotypes and statistically significant increases were observed in eleven genotypes with relative increases ranging from $21.6 \%$ in ZK 2-1 to $88.8 \%$ in KB 3-4 (Figure 1 (panel D) and Supplementary Table 2). In comparison to ample-water, leaf area ratio (LAR) decreased under restricted-water conditions by $20-40 \%$ and statistically significant increases were observed in eight genotypes (Supplementary Tables 1 and 2).

\section{Genotypic variation across physiology traits in response to drought}

In comparison to ample-water, restricted-water decreased carbon-isotope discrimination thus increasing $\delta^{13} \mathrm{C}$ abundances (values becoming less negative) of all genotypes and 
statistically significant reductions were observed in ten genotypes with the relative effect ranging from a reduction of $0.7 \%$ in IT2-3 to $9.7 \%$ in KW19 (Figure 1 (panel F) and Supplementary Tables 1 and 2). Most genotypes had an increased intrinsic water-use efficiency (WUEi) under restricted-water when compared to ample-water conditions ranging from 10.4\% in IT2-3 to $142 \%$ in IT4-3 (Supplementary Tables 1 and 2). Conversely, above ground- plant water-use efficiency (WUEp) was lower under restricted-water than ample-water conditions but statistically significant in only eight genotypes (Supplementary Tables 1 and 2). As expected, the amount of transpired water (TRW) was lower under restricted-water than in ample-water conditions in all but three genotypes (Supplementary Tables 1and 2).

\section{Correlation between drought tolerance in RGRA and plasticity in a subset of traits}

There were negative correlations between drought tolerance in relative leaf area growth (DTRGRA) (i.e. RGRA in restricted-water divided by RGRA at ample-water) and the mean trait plasticity for all categories (Figure 2; Panel A), i.e. performance (Figure 2; Panel B), morphology (Figure 2; Panel C), allocation (Figure 2; Panel D) and physiology traits (Figure 2; Panel E). The consistency in the negative relationship across the categories suggests an overall pattern where highly plastic genotypes are less drought tolerant.

PCA results (Figure 3 and Supplementary Table 3) indicate that most traits are loaded on the first PCA axis (explaining 53.9\% of the total variation) and that the genotypic change along this axis is significantly negatively correlated with drought tolerance (DTRGRA). Changes along the first PCA axis of variation is significantly related to tolerance and only one genotype (BD3.2) seems to behave differently. This finding confirms the trend observed in Figure 2 where mean trait plasticity indices were negatively correlated with drought tolerance. The results of the PCA analysis suggests that the traits change systematically in response to drought.

\section{Relationship between carbon isotope discrimination and water-use efficiency}

There was a statistically significant positive correlation between intrinsic water-use efficiency (WUEi) and $\delta^{13} \mathrm{C}$ abundances both under ample-water and restricted-water conditions (Figures 4; Panel A). This implies that, at the leaf level, the genotypic differences in WUEi under ample-water and restricted-water conditions may be associated with carbon isotope discriminations whereby the higher the WUEi is the lower the carbon isotope discriminations hence higher $\delta^{13} \mathrm{C}$ abundances. At plant canopy level, we also observed positive trends between above ground-plant water-use efficiency (WUEp) (aboveground growth/water consumption) and $\delta^{13} \mathrm{C}$ under both ample and restricted-water conditions but these relations were statistically significant only under ample-water conditions (Figure 4; Panel B). 


\section{Chapter 4}
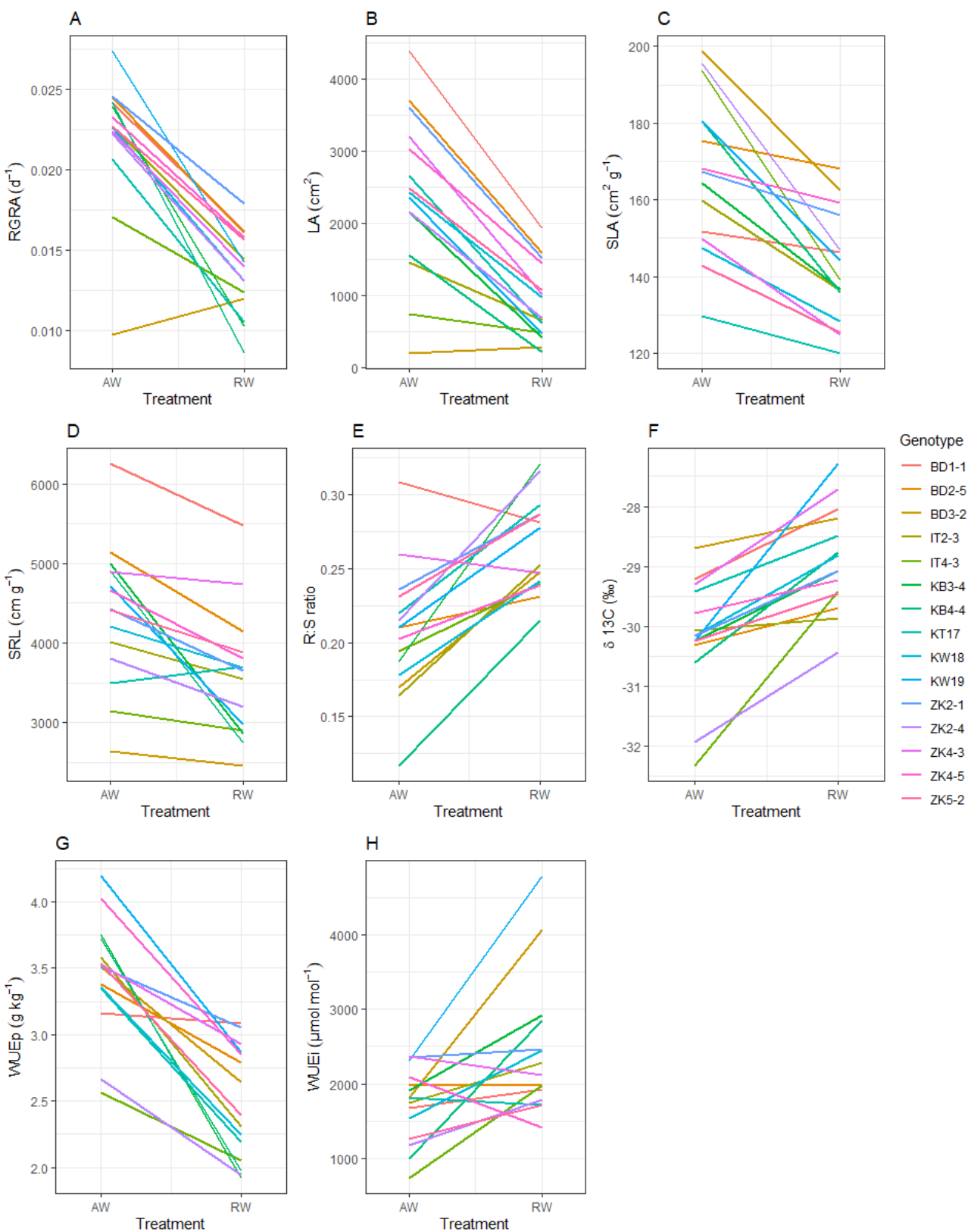

Figure 1 Genotypic means as a function of treatment (ample-water (AW) and restricted-water (RW) for

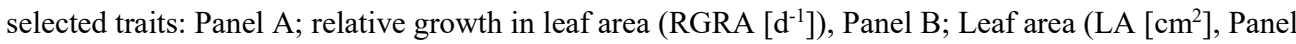
$\mathrm{C}$; specific leaf area (SLA $\left.\left[\mathrm{cm}^{2} \mathrm{~g}^{-1}\right)\right]$ ), Panel D; specific root length (SRL [ $\left.\mathrm{cm} \mathrm{g}^{-1}\right]$ ), Panel E; Root: shoot ratio R: S, Panel F; above ground- plant water-use efficiency (WUEp $\left[\mathrm{g} \mathrm{l}^{-1}\right]$ ), Panel G; carbon isotope discrimination $\left(\delta^{13} \mathrm{C}[\% 0]\right)$ and Pane $\mathrm{Hl}$; intrinsic water-use efficiency (WUEi).Coloured lines are genotypic means across treatments. 

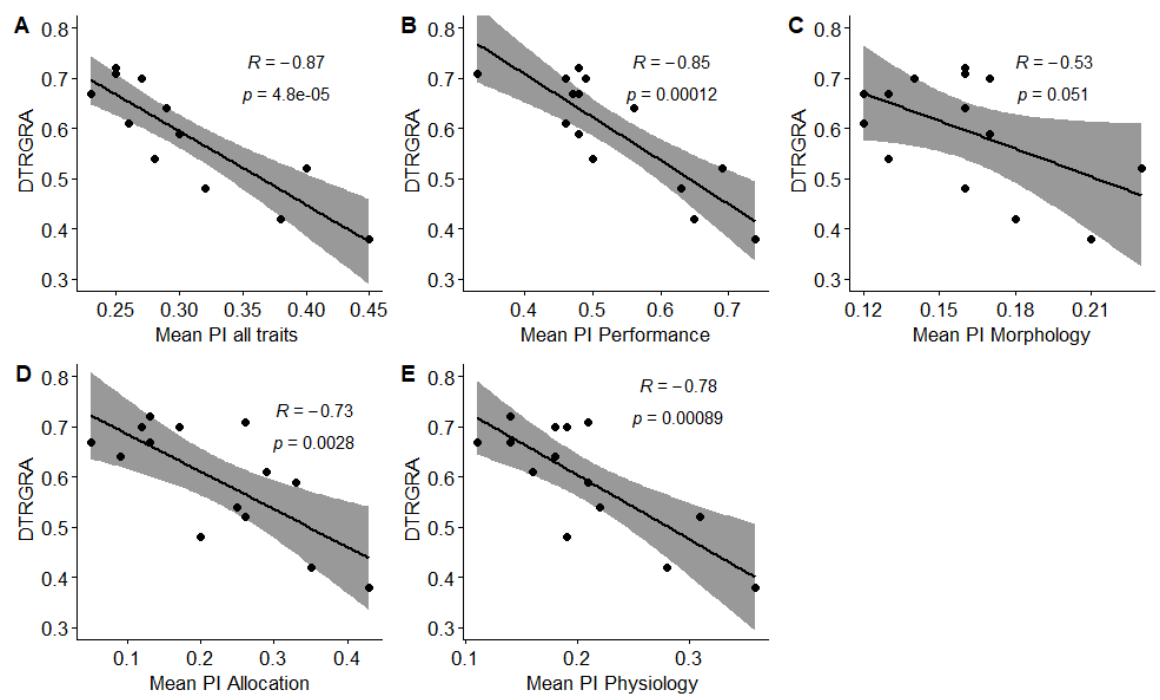

Figure 2 Relationship between drought tolerance in relative growth in leaf area (DTRGRA) and mean plasticity index (PI): Panel A of all traits (Table 2), Panel B performance traits, Panel C morphology traits, Panel D allocation traits, and Panel E physiology traits (Table 2). Grey zones indicate areas within the confidence interval at $95 \%$. $\mathrm{R}$ is the correlation coefficient and $\mathrm{p}$ are the $\mathrm{p}$-values and statistical significance is observed at $\mathrm{p} \leq 0.05$.
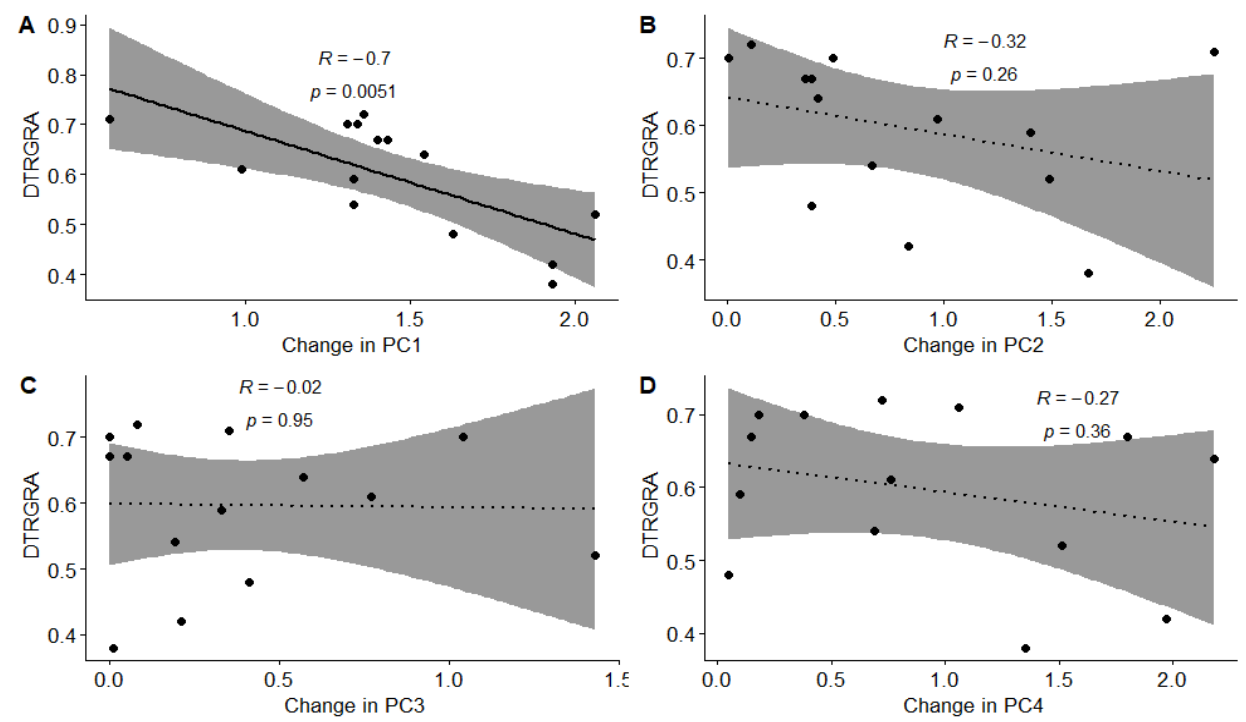

Figure 3 Relationship between drought tolerance in in Relative growth in leaf area (DTRGRA) and change in traits across ample and restricted-water conditions along principal components 1,2,3 and 4 for 15 genotypes; PC1, PC2, PC3 and PC4 as presented in panels A, B, C and D respectively. Bold and dotted line indicate statistically significant and non-significant relationships respectively while grey zones indicate areas within the confidence interval at 95\%. 


\section{Chapter 4}

A

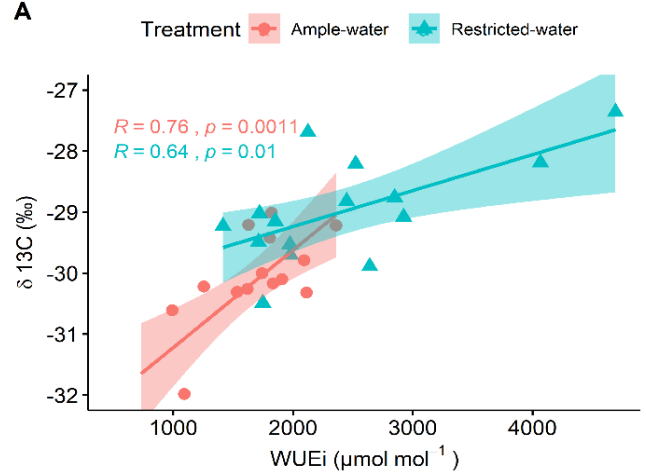

C

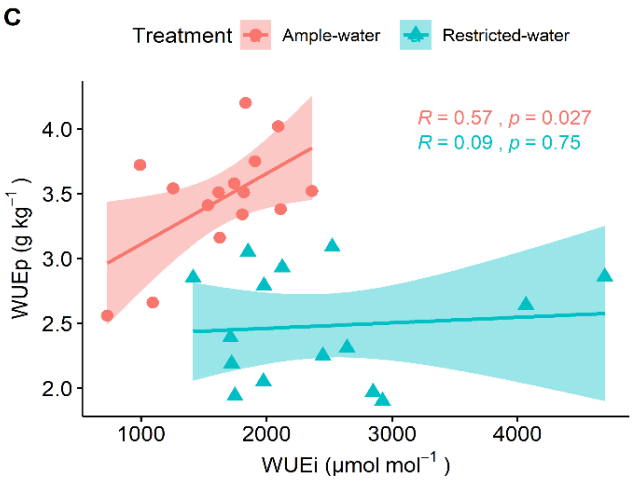

B

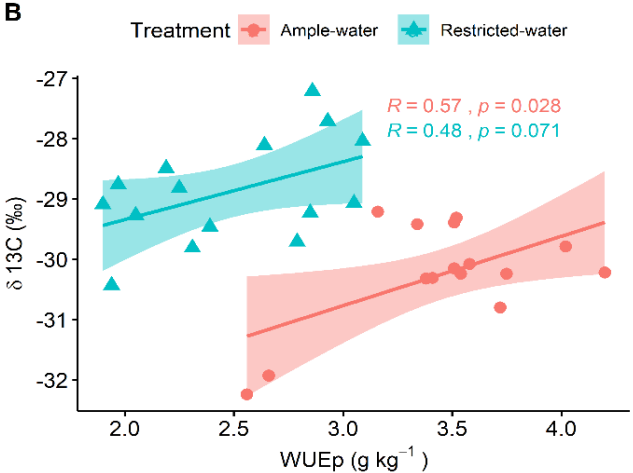

Figure 4 Relationship between intrinsic water-use efficiency (WUEi) and $\delta{ }^{13} \mathrm{C}$ isotope discrimination under ample-water and restricted-water conditions (Panel A), relationship between above ground- plant water-use efficiency (WUEp) and $\delta{ }^{13} \mathrm{C}$ isotope discrimination under ample-water and restricted-water conditions (Panel B) and relationship between WUEi and WUEp under ample-water and restrictedwater conditions (Panel B).

Additionally, a correlation between WUEi and WUEp revealed significantly positive relationships between water use-efficiency at leaf level (WUEi) and water use-efficiency at plant level (WUEp) under ample-water conditions but no correlation under restricted-ample water conditions (Figure 4; Panel C).

\section{Discussion}

This study analysed intra-specific variation in phenotypic plasticity of functional traits across 12 wild and three cultivated Coffea canephora genotypes from Uganda in response to variation in water availability. Particularly, it explored the extent to which this plasticity is correlated with drought tolerance, expressed as the ability of a plant to maintain relative leaf area growth under dry conditions. As expected, restricted water supply had negative effects on 
plant growth as expressed by statistically significant reductions on all performance traits (Tables 2 and 3). For most studied traits, a significant variation in phenotypic plasticity across genotypes was observed (Figure 1; Table 4). Overall, genotypes exhibiting the strongest plastic trait responses to a change in water availability also tended to be the least drought tolerant (Figures 2 and 3). As further discussed, these results have implications both for our understanding of drought adaptation in tropical trees and for genotype selection in crop breeding.

\section{Negative relationship between drought tolerance and plasticity}

The negative relationship between drought tolerance and phenotypic plasticity observed in our study is consistent with the idea presented that plants that are adapted to low resource habitats also respond less to variation in resource availability (van Kleunen and Fischer, 2005). Our findings also concur with results from Bongers et al. (2017) who found a negative relationship between phenotypic plasticity in some traits and drought survival across Mediterranean species. Conversely, another study, Amissah et al. (2015), found that plasticity was not related to survival under stressed conditions among Ghana's tropical forest species. However, to our knowledge ours is the first study that identified negative relationship in this regard across genotypes of a single tropical tree species (C. canephora). The finding that drought tolerance is negatively corelated with phenotypic plasticity is important to better understand how climate shapes intra-specific variation in trait responses.

The negative relationship (Figures 2 and 3) between phenotypic plasticity and tolerance in our study fits the existing theory on plant strategies. High phenotypic plasticity has been linked to generalists (usually fast-growing species) that optimize growth in favourable environments at the expense of developing traits for tolerance to stressful conditions. In contrast, low phenotypic plasticity is associated with specialists (usually slow growing species) which invest in traits and mechanisms that make the plant perform better in stressful conditions, but their slow growth may restrict their ability to utilize and compete under favourable conditions when competing with fast-growing species (Lortie and Aarssen, 1996, Tienderen, 1997, Balaguer et al., 2001, Valladares et al., 2007, Baquedano et al., 2008). Our findings concur with results from chapter 3 of this thesis where we found that drought tolerant C.canephora genotypes to be inherently slow growers in the population.

The negative correlations between plasticity in response to variation in water availability observed in our study indicates two plant strategies. At one end are genotypes that 


\section{Chapter 4}

are drought tolerant and have low plasticity. They seem to employ a conservative water savinggrowth strategy and employ a size and metabolism that fit a stressful environment (Grime, 1979), but compromises their ability to enhance growth once conditions are favourable. Genotypes with high tolerance and low plasticity would be beneficial in intermittent and highly variable environmental conditions. At the other end are genotypes that are drought sensitive and have high plasticity. These genotypes tend to show high reduction in performance under drought associated with due to high trait plasticity and they seem to employ a size and metabolism strategy that does not enable them to thrive under highly stressful environmental conditions.

We expected the relationship between mean trait plasticity and drought tolerance to could differ between traits. This is because responses in different traits may differ in their permanence and because conditions change. One could thus for instance imagine that the implications of plasticity in morphology and allocation for plant functioning are more difficult to adjust in response to environmental change, than the effects of changes in leaf gas exchange traits. If the effect of a trait response to e.g. wet conditions is more permanent, the negative implications of this response can be larger when conditions become drier. From this line of reasoning we expected that plasticity in allocational and morphological traits would be more negatively correlated with drought tolerance than plasticity in leaf physiological traits. Our findings, however, did not confirm this expectation, the strength of the negative correlation between trait plasticity and drought tolerance did not differ between trait categories.

\section{${ }^{13} \mathrm{C}$ discrimination and water-use efficiency}

There is evidence of a strong relationship between water-use efficiency and the carbon isotope discrimination during photosynthesis across several species (Farquhar et al., 1989, Hall et al., 1994, Condon and Hall, 1997, Lambers et al., 2008). In line with this, we found leaf-level instantaneous intrinsic water-use efficiency (WUEi) and $\delta{ }^{13} \mathrm{C}$ abundances to be significantly positively correlated (Figure 4; Panels A) indicating that carbon isotope discrimination decreases with increase in WUEi. The decrease in carbon isotope discrimination (increased, less negative $\delta{ }^{13} \mathrm{C}$ abundances) under restricted-water conditions in most genotypes (Table 2 and Figure 1; Panel E) reflected an increase in instantaneous WUEi (Table 2 and Figure 1; Panel G). These findings corroborates results from DaMatta et al. (2003) and Pinheiro et al. (2004) who found that discrimination against ${ }^{13} \mathrm{C}$ is driven by leaf intercellular $\mathrm{CO}_{2}$ concentration which is, in turn, determined by stomatal conductance and photosynthesis, which 
ultimately influences water-use efficiency. Additionally, since genotypic WUEi significantly increased in response to restricted-water supply (Table 3 and Supplementary Tables 1 and 2), the findings suggest a larger reduction in transpiration than in photosynthesis for the related stomatal conductance.

The observed significant positive correlations between above ground- plant water-use efficiency (WUEp) and $\delta$ 13C abundances (Figure 4; Panel B) under ample water conditions may also be attributed to the link between carbon isotope discrimination and leaf intercellular $\mathrm{CO}_{2}$ concentration, and the trend at leaf level seems to integrate to a similar whole-plant response, in ample-water conditions (Figure 4; Panel C). However, we found non-significant correlations between (WUEp) and $\delta{ }^{13} \mathrm{C}$ abundances under restricted-water conditions (Figure 4; Panel B) suggesting that $\delta{ }^{13} \mathrm{C}$ abundances may not be a very reliable proxy for WUEp under drought stress condition. Similar trends have been observed in other $\mathrm{C}_{3}$ species, e.g. wheat, where use of carbon isotope signatures to guide the improvement of WUEi showed that improvements of leaf-level water-use efficiency do not always translate into higher agronomic water-use efficiency (Condon et al., 2004), but contrary to Silva et al. (2013). This is usually attributed to the complexity of scaling leaf-level respiration and transpiration to shoot or wholeplant level respiration (Condon et al., 2004). It is possible that in a population high WUEi correlates with higher respiration rates or greater allocation to non-photosynthetic tissue which would entail that positive effects on leaf photosynthesis (and thus WUEi) do not translate to the whole-plant. The finding that WUEp was lower under restricted-water than under ample-water conditions, and that WUEp was not significantly correlated with WUEi under restricted-water conditions may also indicate that the severity of stress due to restricted-water supply was high such that WUE was determined by factors other than stomatal control. Lack of a significant relationship between WUEp and $\delta^{13} \mathrm{C}$ under restricted-water conditions in our data could also be attributed to measurement errors in estimating evaporation from the pot versus water transpired through the plant (TRW), and exclusion of root biomass in the computation of WUEp. Excluding root biomass from computation of the final biomass used to estimate WUEp could have contributed to under-estimation of the positive effect of drought on WUEp, since drought increases partitioning to root biomass.

In conclusion, this paper revealed substantial variation of $C$. canephora genotypes in response to ample and restricted-water conditions. Genotypes showed varying levels of plasticity in response to variation in water availability, and drought tolerance was negatively associated with the degree of plasticity across traits. This suggests that it is non-beneficial and 
probably costly for a plant to change traits in frequently changing environmental conditions or short drought stress period. This apparent trade-off between plasticity and drought tolerance may pose challenges to breeders. As small-holder coffee farmers have limited means to control water supply, their crop will be subjected to fluctuating conditions, and their plants should perform well under drought conditions and be able to adjust quickly once conditions improve (e.g. in wet years). The plasticity-tolerance trade-off observed in this study, suggests that finding such material in wild populations might be difficult. The correlations between $\delta^{13} \mathrm{C}$ abundances and water use efficiency at leaf(WUEi) and plant (WUEp) level suggest that carbon isotope signatures may be reliable proxies for WUEi in both ample and restricted water conditions and for WUEp in only ample-water conditions.

\section{References}

Abrams MD. 1994 Genotypic and phenotypic variation as stress adaptations in temperate tree species: a review of several case studies. Tree Physiology 14: 833-842.

Adiredjo AL, Navaud O, Lamaze T, Grieu P. 2014. Leaf carbon isotope discrimination as an accurate indicator of water-use efficiency in sunflower genotypes subjected to five stable soil water contents. Journal of Agronomy and Crop Science, 200: 416-424.

Allard RW. 1999. Principles of plant breeding: John Wiley \& Sons.

Amissah L, Mohren GM, Kyereh B, Poorter L. 2015. The effects of drought and shade on the performance, morphology and physiology of Ghanaian tree species. Plos One, 10: e0121004.

Balaguer L, Martínez-Ferri E, Valladares F, Pérezcorona ME, Baquedano FJ, Castillo FJ, Manrique E. 2001. Population divergence in the plasticity of the response of Quercus coccifera to the light environment. Functional Ecology 15: 124-135.

Baltzer JL, Davies SJ, Bunyavejchewin S, Noor NSM. 2008. The role of desiccation tolerance in determining tree species distributions along the Malay-Thai Peninsula. Functional Ecology, 22: 221-231.

Baquedano FJ, Valladares F, Castillo FJ. 2008. Phenotypic plasticity blurs ecotypic divergence in the response of Quercus coccifera and Pinus halepensis to water stress. European Journal of Forest Research, 127: 495-506.

Bongers FJ, Olmo M, Lopez-Iglesias B, Anten NPR, Villar R. 2017. Drought responses, phenotypic plasticity and survival of Mediterranean species in two different microclimatic sites. Plant Biology, 19: 386-395.

Bradshaw AD. 1965. Evolutionary significance of phenotypic plasticity in plants. Advances in genetics, 13: 115-155.

Bunn C, Läderach P, Ovalle Rivera O, Kirschke D. 2015. A bitter cup: climate change profile of global production of Arabica and Robusta coffee. Climatic Change, 129: 89101.

Comita LS, Engelbrecht BMJ. 2014. Drought as a driver of tropical tree species regeneration dynamics and distribution patterns. In: David A. Coomes, David F. R. P. Burslem, Simonson. WD, eds. Forests and Global Change.

Condon A, Hall A. 1997. Adaptation to diverse environments: variation in water-use efficiency within crop species. Agricultural Ecology: 79-116. 
Condon AG, Richards RA. 1992. Broad sense heritability and genotype x environment interaction for carbon isotope discrimination in field-grown wheat. Australian Journal of Agricultural Research, 43: 921-934.

Condon AG, Richards RA, Rebetzke GJ, Farquhar GD. 2004. Breeding for high water-use efficiency. Journal of Experimental Botany, 55: 2447-2460.

DaMatta FM, Avila RT, Cardoso AA, Martins SCV, Ramalho JC. 2018. Physiological and agronomic performance of the coffee crop in the context of climate change and global warming: A review. Journal of Agricultural and Food Chemistry, 66: 5264-5274.

DaMatta FM, Chaves ARM, Pinheiro HA, Ducatti C, Loureiro ME. 2003. Drought tolerance of two field-grown clones of Coffea canephora. Plant Science, 164: 111-117.

DaMatta FM, Loos AR, Silva AE, Loureiro EM, Ducatti C. 2002. Effects of soil water deficit and nitrogen nutrition on water relations and photosynthesis of pot-grown Coffea canephora Pierre ex A. Froehner. Trees, 16: 555-558.

Dorn LA, Pyle EH, Schmitt J. 2000. Plasticity to light cues and resources in Arabidopsis thaliana: testing for adaptive value and costs. Evolution, 54: 1982-1994.

Engelbrecht BM, Comita LS, Condit R, Kursar TA, Tyree MT, Turner BL, Hubbell SP. 2007. Drought sensitivity shapes species distribution patterns in tropical forests. Nature, 447: 80-2.

Erdiansyah NP, Wachjar A, Sulistyono E, Supijatno. 2019 Growth response of seedlings of four robusta coffee (Coffea canephora Pierre. Ex. A. Froehner) clones to drought stress. Pelita Perkebunan 35: 1 - 11

Farquhar GD, Ehleringer JR, Hubick KT. 1989. Carbon isotope discrimination and photosynthesis. Annual Review of Plant Physiology and Plant Molecular Biology, 40: 503-537.

Farquhar GD, Richards RA. 1984. Isotopic composition of plant carbon correlates with water-use efficiency of wheat genotypes. Australian Journal of Plant Physiology, 11: 539-52.

Fauset S, Baker TR, Lewis SL, Feldpausch TR, Affum-Baffoe K, Foli EG, Hamer KC, Swaine MD. 2012. Drought-induced shifts in the floristic and functional composition of tropical forests in Ghana. Ecology Letters, 15: 1120-1129.

Grant MC. 1975. Genetic properties of ecologically marginal populations of Anthoxanthum odoratum, Duke University.

Grime JP. 1979. Plant strategies and vegetation processes. Plant strategies and vegetation processes.

Hall AE, Richards RA, Condon AG, Wright GC, Farquhar GD. 1994. Carbon isotope discrimination and plant breeding. Plant breeding reviews, 12: 113.

Hamrick JL. 2004. Response of forest trees to global environmental changes. Forest Ecology and Management, 197: 323-335.

Hijmans RJ, Cameron SE, Parra JL, Jones PG, Jarvis A. 2005. Very high resolution interpolated climate surfaces for global land areas. International Journal of Climatology, 25: 1965-1978.

King'oro WM, Mushimiyamana D, Cheserek JJ, Gichimu MB. 2014. Effect of different watering regimes on agromorphology of selected coffee genotypes. American Journal of Experimental Agriculture, 4: 1016 - 1026.

Kiwuka C, Goudsmit E, Douma JC, Bellanger L, Crouzillat D, de Kochko A, Mulumba JW, Musoli P, Anten N, Poncet V. submitted. Genetic diversity of native and cultivated Uganda's Coffea canephora Pierre ex A. Froehner. A perspective into potential utilization and conservation of the diversity.

Lambers H, Stuart Chapin III F, Pons TL. 2008. Plant Physiological Ecology: Springer. 
Lenth R, Singmann H, Love J, Buerkner P, Herve M. 2018. emmeans: Estimated marginal means, aka least-squares means. R package. See https://CRAN. R-project. org/package= emmeans.

Levins R. 1963. Theory of fitness in a heterogeneous environment. II. Developmental flexibility and niche selection. The American Naturalist, 97: 75-90.

Lortie CJ, Aarssen LW. 1996. The specialization hypothesis for phenotypic plasticity in plants. International Journal of Plant Sciences, 157: 484-487.

Malhi Y, Phillips OL. 2004. Tropical forests and global atmospheric change: a synthesis. Philosophical Transactions of the Royal Society of London. Series B: Biological Sciences, 359: 549-555.

Malhi Y, Wright J. 2004. Spatial patterns and recent trends in the climate of tropical rainforest regions. Philosophical Transactions of the Royal Society of London, 359: 311-329.

Meinzer FC, Goldstein G, Grantz DA. 1990. Carbon isotope discrimination in coffee genotypes grown under limited water supply. Plant Physiology, 92: 130-135.

Nicotra AB, Atkin OK, Bonser SP, Davidson AM, Finnegan EJ, Mathesius U, Poot P, Purugganan MD, Richards CL, Valladares F, van Kleunen M. 2010. Plant phenotypic plasticity in a changing climate. Trends in Plant Science, 15: 684-692.

Parry M, Parry ML, Canziani O, Palutikof J, Van der Linden P, Hanson C. 2007. Climate Change 2007-Impacts, adaptation and vulnerability: Working Group II contribution of to the fourth assessment the IPCC. Cambridge, United Kingdom: Cambridge University Press.

Pigliucci M. 2005. Evolution of phenotypic plasticity: where are we going now? Trends in Ecology and Evolution, 20: 481-486.

Pinheiro HA, DaMatta FM, Chaves ARM, Fontes EPB, Loureiro ME. 2004. Drought tolerance in relation to protection against oxidative stress in clones of Coffea canephora subjected to long-term drought. Plant Science, 167: 1307-1314.

Pinheiro J, Bates D, DebRoy S, Sarkar D. 2019. R Core Team. 2019. nlme: linear and nonlinear mixed effects models. R package version 3.1-141. Available at $h$ Ttp://CRAN. R-Project. Org/Package $=$ Nlme.

Pohlan HAJ, Janssens MJJ. 2010. Growth and production of coffee.

Praxedes SC, DaMatta FM, Loureiro ME, G. Ferrão MA, Cordeiro AT. 2006. Effects of long-term soil drought on photosynthesis and carbohydrate metabolism in mature robusta coffee (Coffea canephora Pierre var. kouillou) leaves. Environmental and Experimental Botany, 56: 263-273.

Richards PW, Frankham R, Walsh R. 1996. The tropical rain forest: an ecological study: Cambridge university press.

Schmid B. 1992. Phenotypic variation in plants. Evolutionary trends in plants, 6: 45-60.

Sheffield J, Wood EF. 2008. Projected changes in drought occurrence under future global warming from multi-model, multi-scenario, IPCC AR4 simulations. Climate Dynamics, 31: 79-105.

Silva PEM, Cavatte PC, Morais LE, Medina EF, DaMatta FM. 2013. The functional divergence of biomass partitioning, carbon gain and water use in Coffea canephora in response to the water supply: Implications for breeding aimed at improving drought tolerance. Environmental and Experimental Botany, 87: 49-57.

Sultan SE. 1987. Evolutionary implications of phenotypic plasticity in plants. Evolutionary biology: Springer.

Team RC. 2018. R version 3.5. 0. $R$ : A language and environment for statistical computing. $R$ Foundation for Statistical Computing, Vienna, Austria. 
Tesfaye SG, Ismail MR, Ramlan MF, Marziah M, Kausar H. 2014. Effect of soil drying on rate of stress development, leaf gas exchange and proline accumulation in robusta coffee (Coffea Canephora Pierre Ex Froehner) Clones. Experimental Agriculture, 50: 458-479.

Thoday JM. 1953. Components of fitness. Symposia of the Society for Experimental Biology, 7: 113.

Tienderen PHV. 1997. Generalists, specialists, and the evolution of phenotypic plasticity in sympatric populations of distinct species. Evolution, 51: 1372-1380.

Valladares F, Gianoli E, Gomez JM. 2007. Ecological limits to plant phenotypic plasticity. New Phytolologist, 176: 749-763.

van Kleunen M, Fischer M. 2005. Constraints on the evolution of adaptive phenotypic plasticity in plants. New Phytologist, 166: 49-60.

van Kleunen M, Fischer M, Schmid B. 2000. Costs of plasticity in foraging characteristics of the clonal plant Ranunculus reptans. Evolution, 54: 1947-1955.

Wintgens JN. 2004. Coffee: growing, processing, sustainable production, A guidebook for growers, processors, traders, and researchers. Weinhein, Alemania: WILEY-VCH Verlag GmbH \& Co. KGaA. 


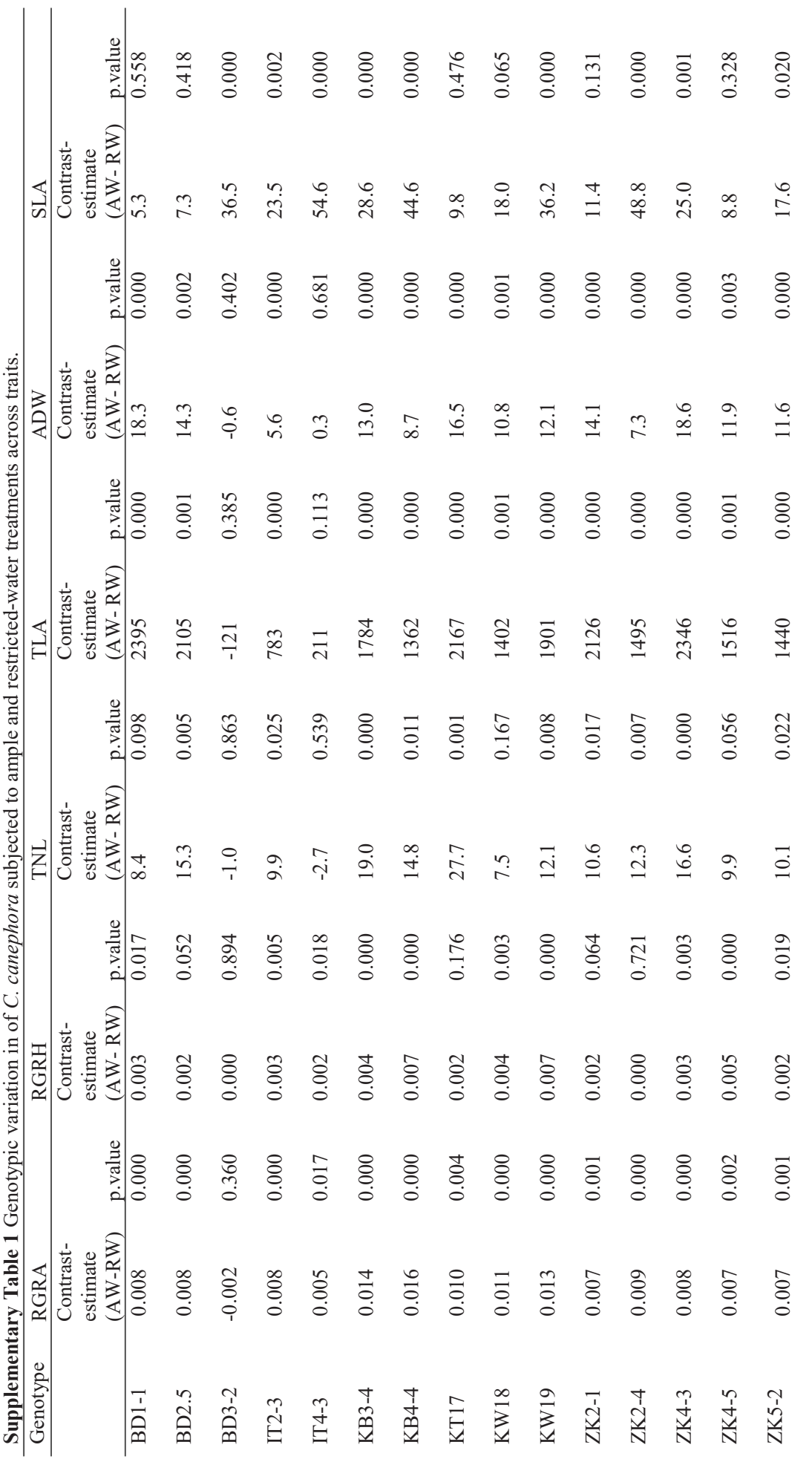




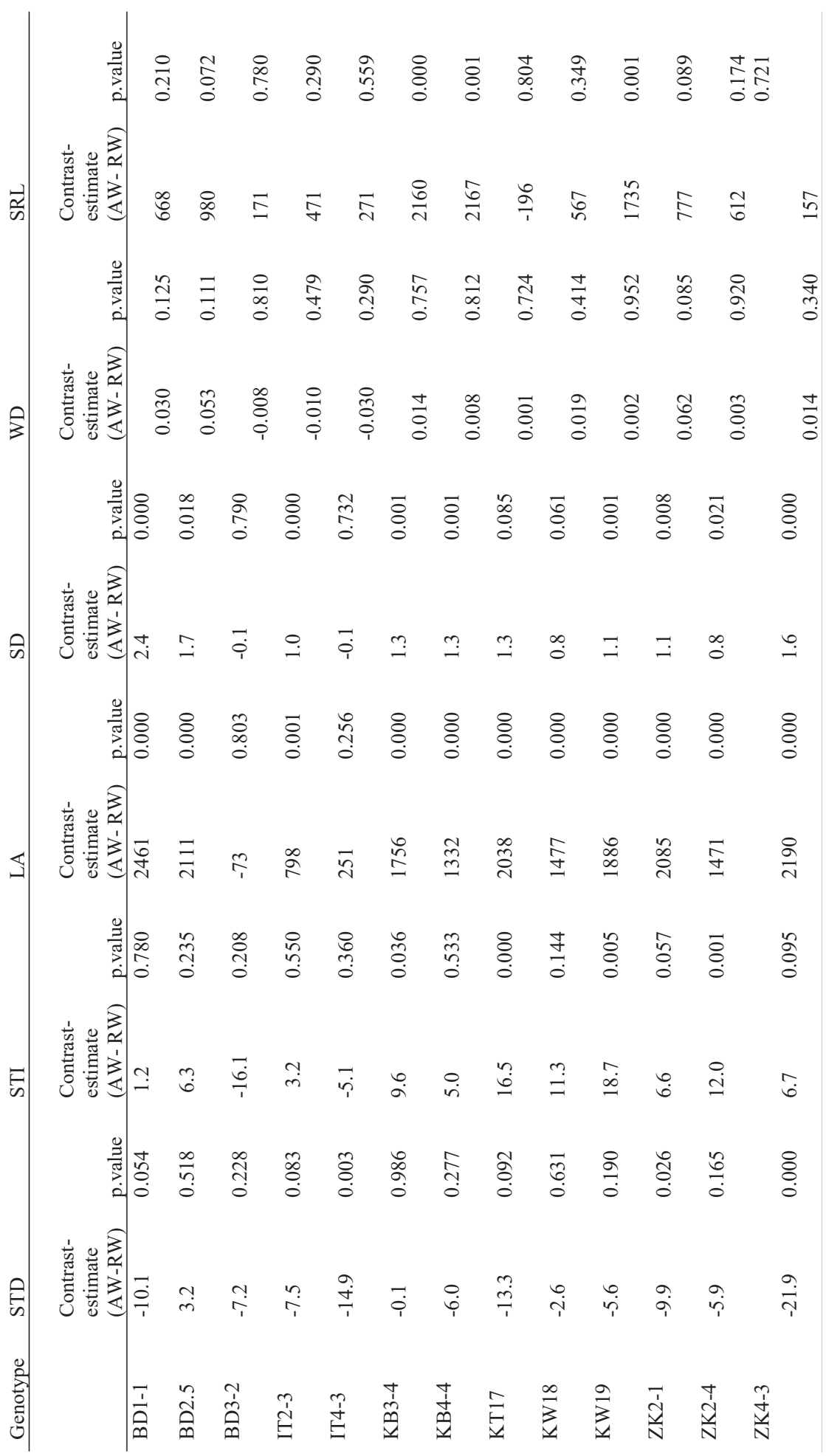




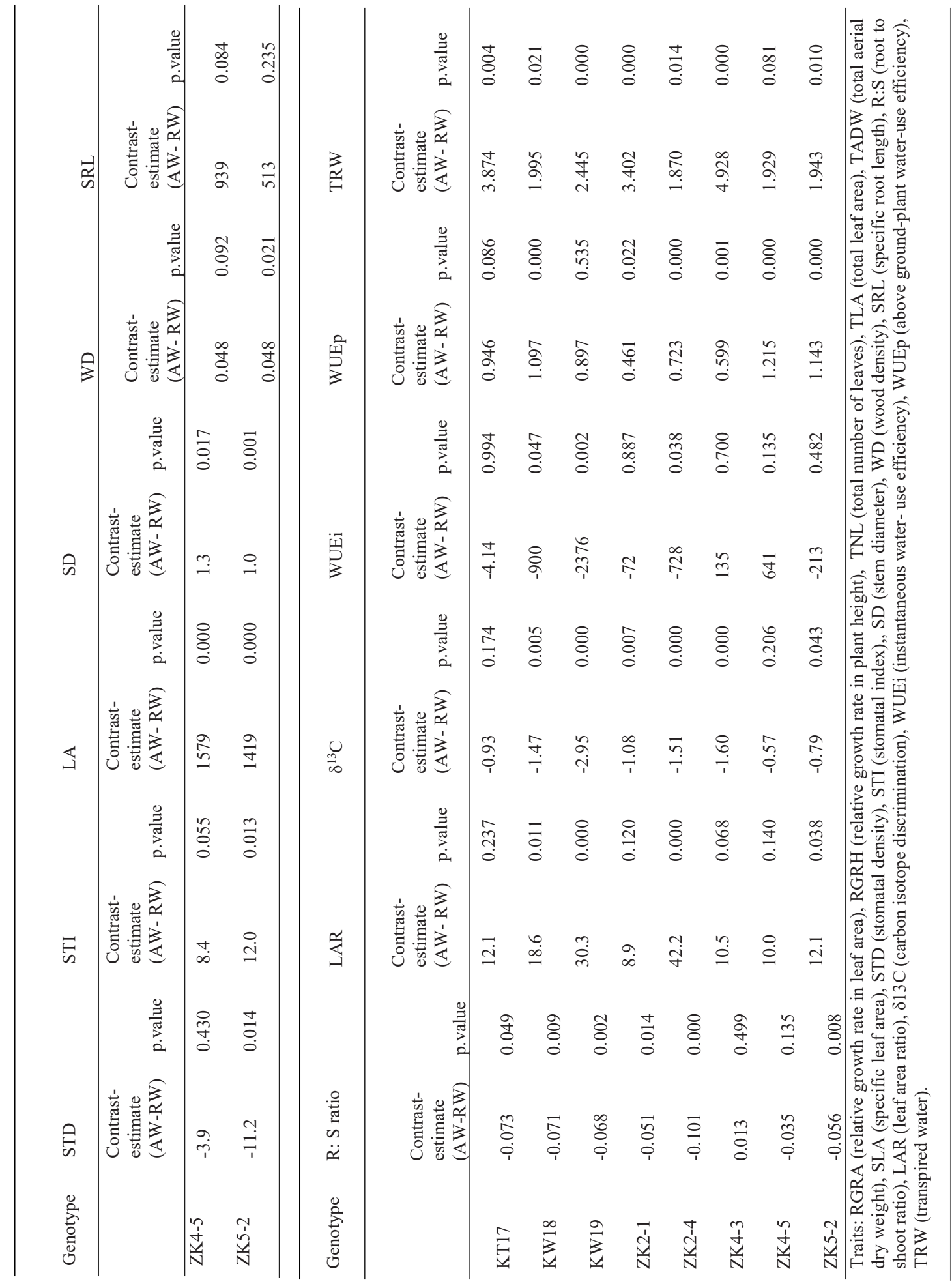




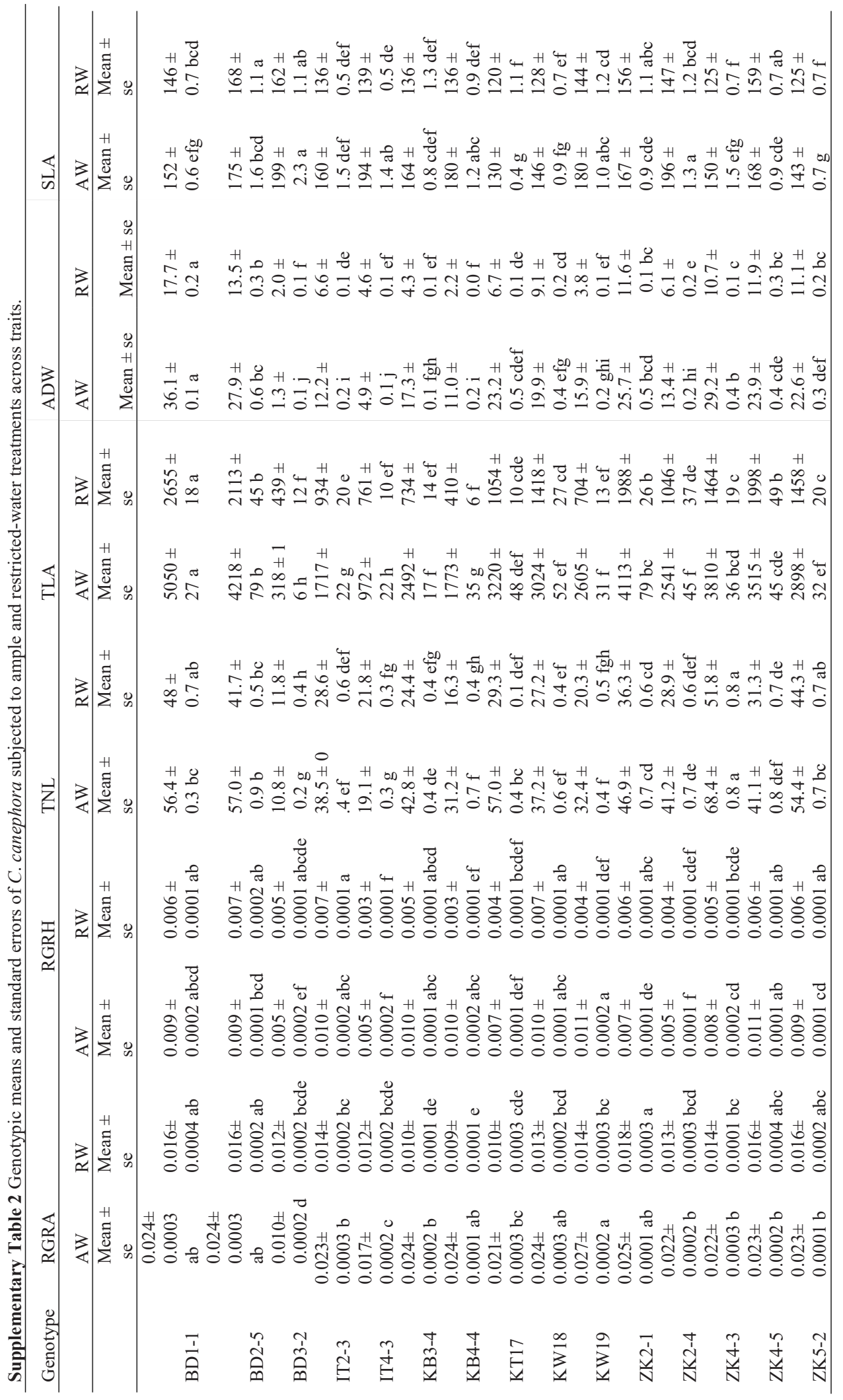




\section{Chapter 4}

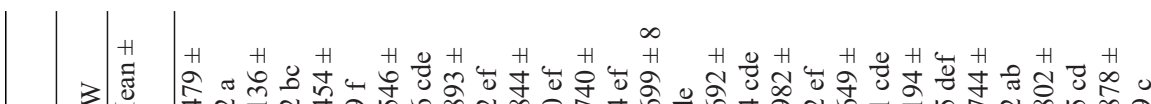

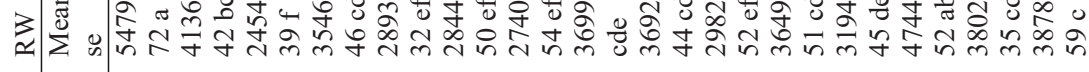

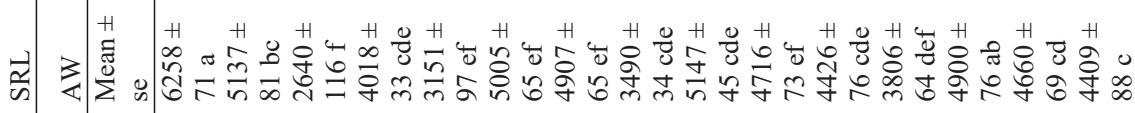

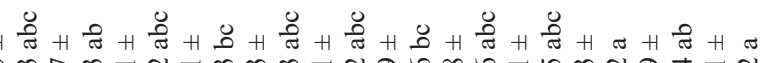
ॐ

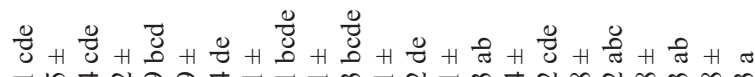

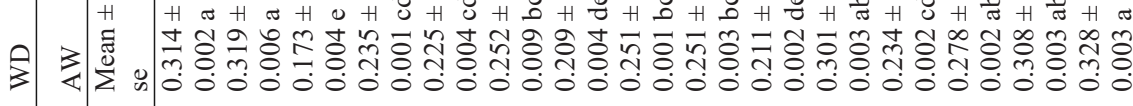

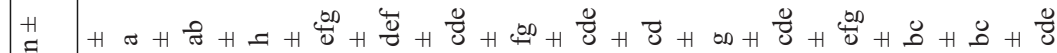

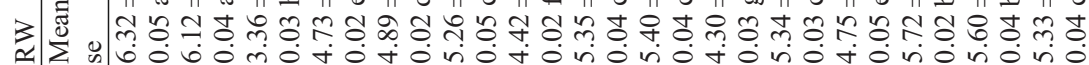

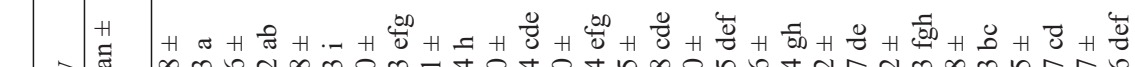

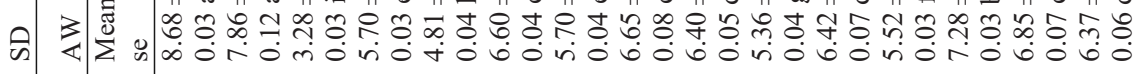

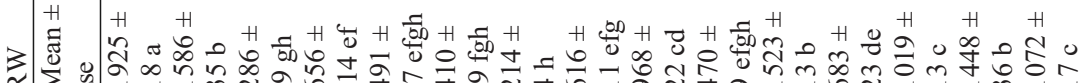

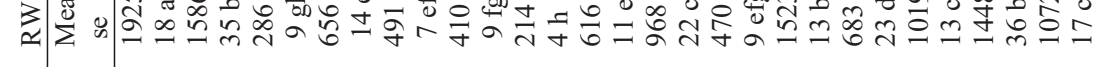

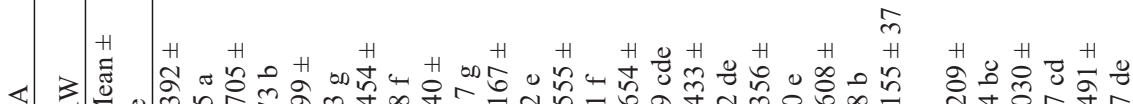

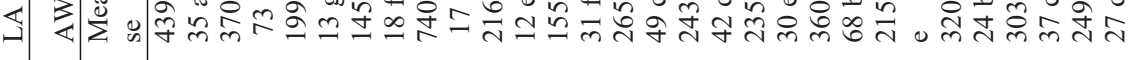

H

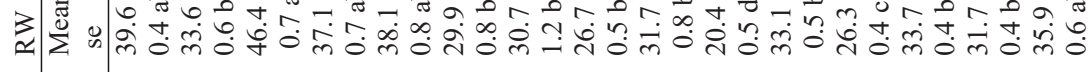

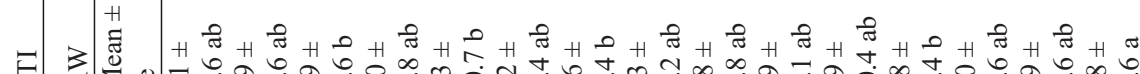

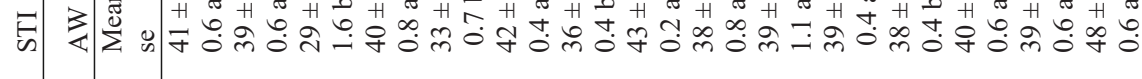

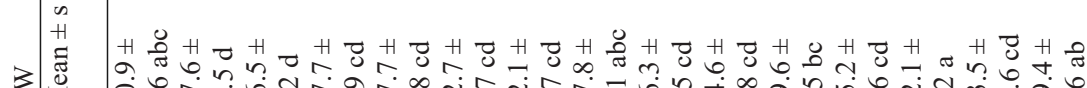

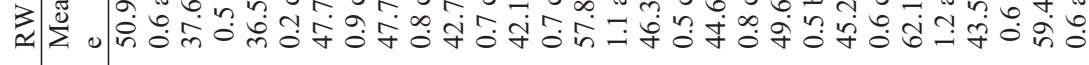

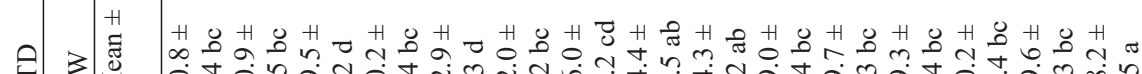

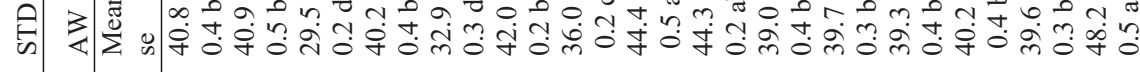

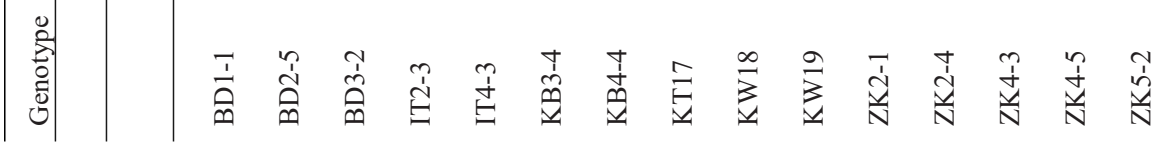




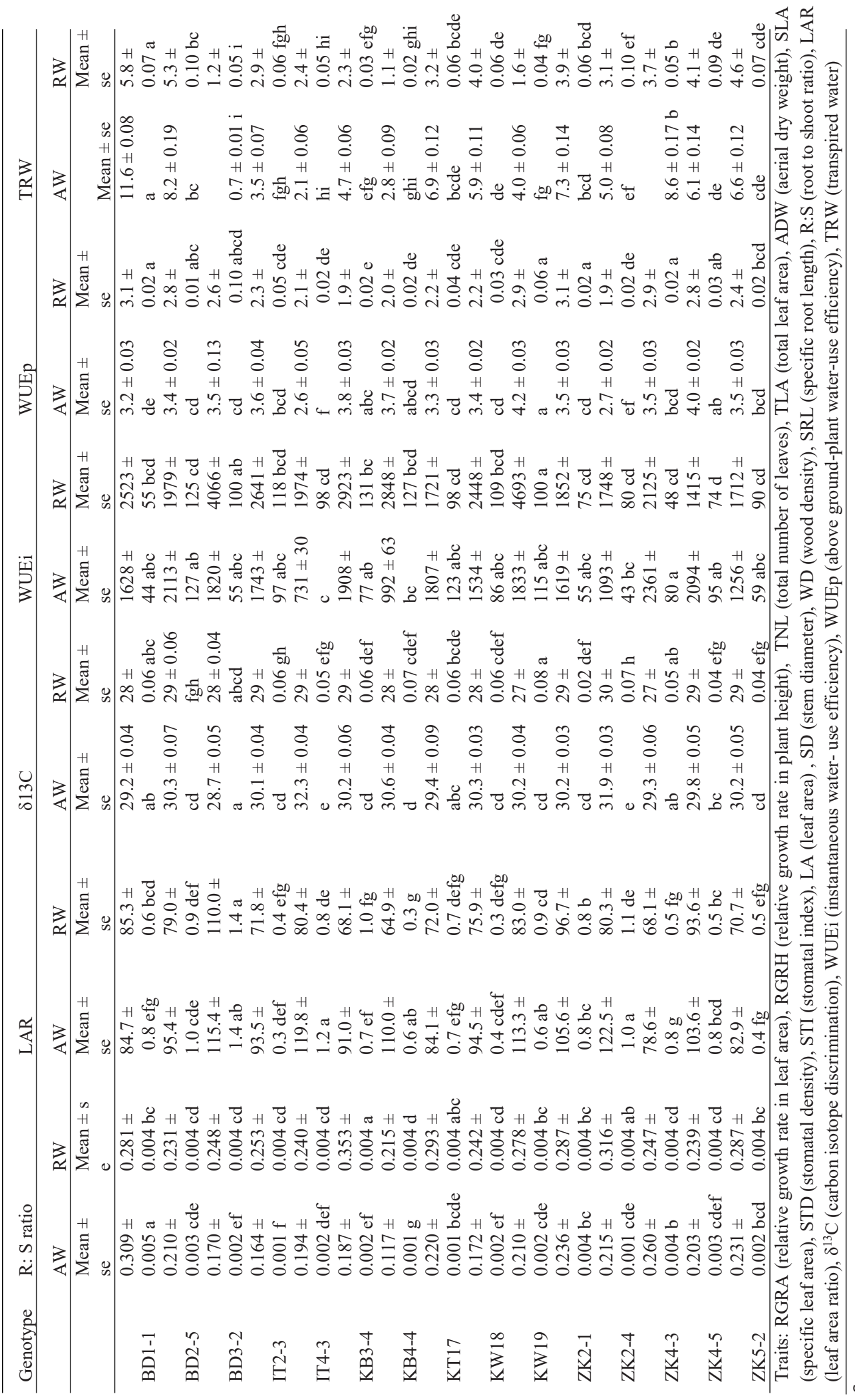



Chapter 5

General discussion 


\section{Introduction}

Coffee is a climate-sensitive perennial species whose growth and productivity are reported to respond strongly to seasonal variations in precipitation patterns and temperatures (DaMatta, 2018, Baca et al., 2014, Ghini et al., 2015). Precipitation and temperature are the key environmental factors that affect the complex sequence of physiological, biochemical and morphological process that determine growth, flowering and fruit ripening (DaMatta, 2018, DaMatta et al., 2007). The predicted higher temperatures due to climate change (IPCC, 2018, IPCC, 2014) are expected to increase the evapotranspiration rate, thus aggravating the effects of drought conditions in plant ecosystems (Mote and Salathé, 2010). Cognizant of the global importance of the coffee sector, there is need to develop climate-resilient genotypes and other feasible management options that can sustain the industry during the predicted adverse climatic conditions. Exploration of natural genetic diversity in coffee species could represent a means to this end. Coffea canephora Pierre ex A. Froehner diversity natively occurs across a wide geographical range with diverse climates. This presents an important resource for seeking populations/genotypes with useful climate-adapted traits. The relative importance of using natural diversity for coffee is particularly large because, being a perennial species, breeding in coffee is slow. The aim of this thesis was to study the genetic diversity of Ugandan $C$. canephora across the range cultivation status (wild, feral and cultivated) and, geographic locations to evaluate and its phenotypic variation in relation to drought stress. Specifically I explored: (i) the genetic diversity and population structure of Uganda's C. canephora spontaneous populations (Chapter 2); (ii) relationship between allelic variation and the climatic profiles of Uganda's C. canephora populations (Chapter 2); (iii) phenotypic variation in $C$. canephora responses to drought stress (Chapter 3); (iv) relationship between performance in ample- and restricted-water conditions (Chapter 3); (v) link between drought-tolerance of the genotypes and the climatic gradient across their habitats (Chapter 3); (vi) phenotypic variation in trait plastic responses to drought stress (Chapter 4) and (vii) the relationship between drought-tolerance and phenotypic plasticity (chapter 4). 


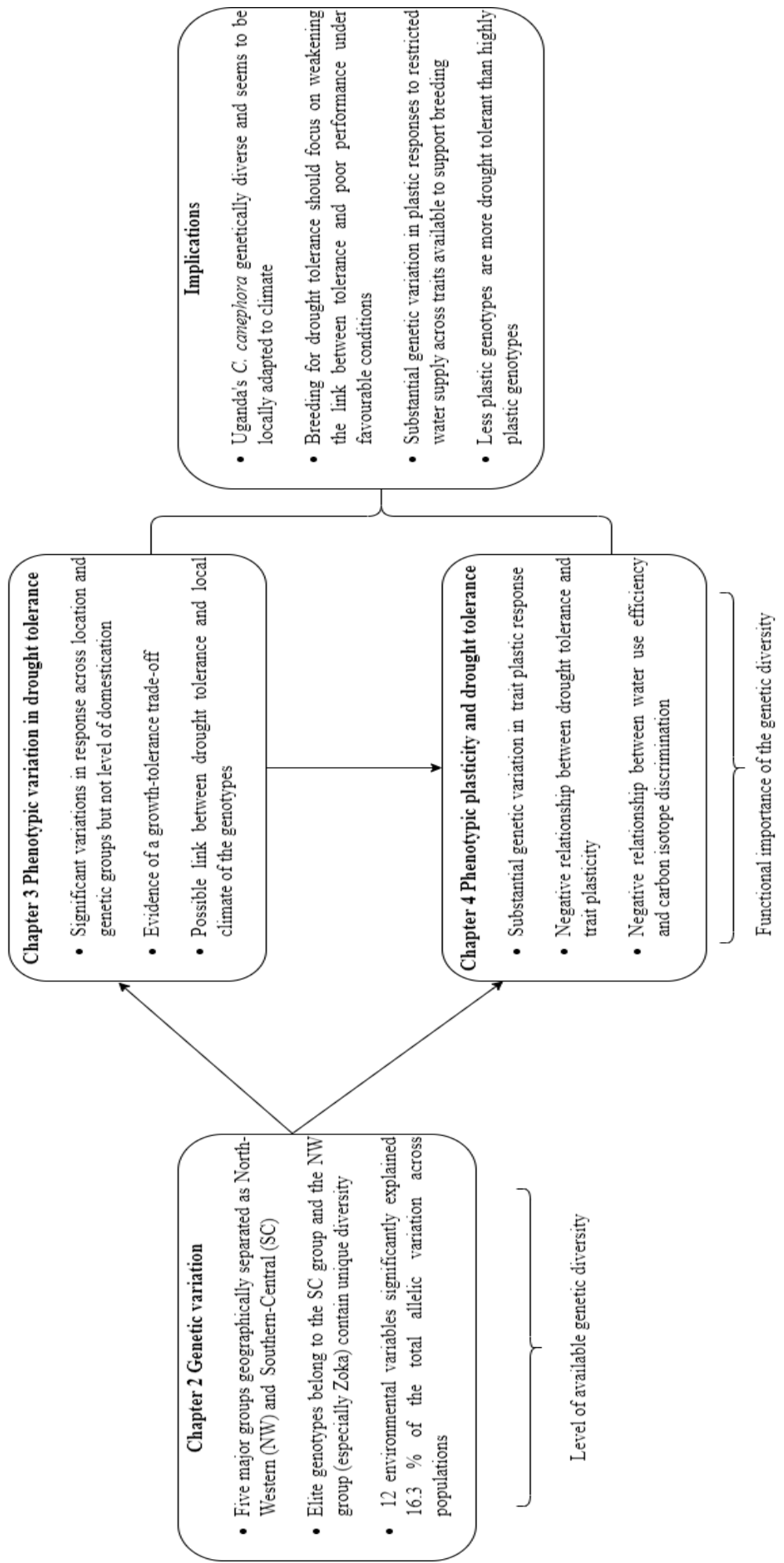

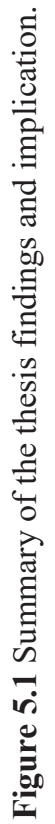




\section{Chapter 5}

This chapter (Chapter 5), synthesizes the main findings (also summarized in Fig. 5.1) of the studies conducted in this thesis and puts them in a broader scientific context. It also provides overall contribution of the findings to efforts geared towards improving C. canephora's resilience to drought-stress and recommendations regarding the conservation of Uganda's $C$. canephora diversity.

\section{Genetic diversity of $C$. canephora and its link to the existing climatic gradient}

Chapter 2 of this thesis was set out to unravel the genetic variation between and within Ugandan C. canephora populations, determining its relationship with known global genetic diversity groups of this species and climatic gradients of their habitat. Efforts to unveil Uganda's C. canephora diversity were started by (Thomas, 1944) and (Musoli et al., 2009a) who both revealed an enormous variation in C. canephora wild populations. Using 24, microsatellite markers, Musoli et al. (2009a) showed that Uganda's C. canephora populations differentiate clearly based on their origin with the wild genotypes being genetically different from other known $C$. canephora diversity groups. We built on these efforts by collecting and genotyping larger and more widely distributed populations across climatic zones (Chapter 2). Ugandan C. canephora diversity was revealed to be geographically structured into the four groups in the North western region (NW) and one group in the South-central region (SC). We found that the NW groups were more genetically distinct from the cultivated material, while the SC group showed high levels of introgression between the cultivated and the wild material from the Southern central forests. Comparatively, the NW groups occur in the drier zone with negligible $C$. canephora cultivation, while the SC group thrives in a wetter zone with predominant $C$. canephora cultivation (Chapter 2).

Additionally, we showed (Chapter 2) that 12 environmental variables explained $16.3 \%$ of the total allelic variation across $C$. canephora populations. Results in Chapter 3 also indicate differential responses of material across genetic groups and locations to drought stress. These findings indicate that there is a spatial genetic differentiation along the environmental gradient suggesting possibility of local adaptation and availability of ecotypes. Ecotypes as defined by (Hufford and Mazer, 2003), are genotypes that are adapted to their local environmental conditions. The evolution of ecotypes is driven by natural selection for specific functional traits which evolve as morphological and physiological adaptions to the local environment (Savolainen et al., 2007, Kawecki and Ebert, 2004). The spatial genetic differentiation along environmental gradients and development of ecotypes has been observed in other species e.g. 
Fagus sylvatica (Peuke et al., 2002), Pinus sylvestris (Palmroth et al., 1999), Pinus taeda (Bongarten and Teskey, 1986), Picea abies (Oleksyn et al., 1998) and Quercus coccifera (Baquedano et al., 2008).

In a related study (Aquino, Kiwuka et al. (un published)), using the same populations explored in this thesis, we corroborated our finding of spatial genetic differentiation along climatic gradients at candidate genes. In that study, we used latent factor mixed model (LFMM) to perform genome wide association studies (GWAS) and to test for linear associations between environmental factors and allele frequencies of the genotypes. LFMM can be used for fitting latent factor mixed models and evaluating associations between a response matrix (single nucleotide polymorphisms (SNP) genotype) and a variable of interest (phenotype) in genomewide association study (GWAS) (Caye et al., 2018). Eighty-nine SNPs (coming from approx. 20 - 30 genes) were found to be related to 14 bioclimatic parameters such as annual precipitations and putatively involved in drought-tolerance. To estimate the adaptive potential of Uganda's coffee populations to future local conditions, we assessed the extent to which the present allele frequencies at climate-related SNPs differ in average from those expected under modelled future climate. It was established that material from Zoka forest seems to be less vulnerable to the predicted climate change while material from Budongo forest seems to be the most vulnerable. These findings concur with our results in Chapter 3, which show that material from Budongo (the second driest location after Zoka) population was relatively intolerant to drought, even though the climate in Budongo is relatively dry. Additionally, in Chapter 3, while testing for the relationship between drought tolerance and wetness index, the statistical significance and $\mathrm{R}^{2}$ of the relationship improved when data from Budongo was removed. These results have interesting implications for wild coffee populations conservation. First, populations from Zoka (the driest location), which appeared to contain unique diversity (Chapter 2), tended to be most drought-tolerant (Chapter 3) and would thus need to be conserved for their uniqueness and probable tolerance to drought-stress. Second, Budongo populations could be containing other valuable traits and since it appears to be most vulnerable to climate change, it is imperative to conserve Budongo populations to avoid probable genetic diversity loss.

\section{Intraspecific phenotypic variation in response to drought}

Intraspecific variation is recognized as a key component of functional trait diversity (Siefert et al., 2015), which is found to be important in plant adaptation along environmental gradients (Kawecki and Ebert, 2004). In this thesis we showed how C. canephora plants from 


\section{Chapter 5}

different levels of cultivation status (wild, feral and cultivated), genetic groups and locations varied in their response to ample- and restricted-water supply (Chapter 3). Our findings show significant differences in phenotypic responses to restricted-water supply across locations and genetic groups. These responses were not significantly affected by the level of cultivation status (i.e. plants being wild, feral or cultivated). It is known that a substantial amount of Uganda's cultivated material was sourced from wild natural populations (Thomas, 1935). Our results thus suggest that performance under dry conditions did not play an important role in this selection process.

Our findings may also reflect the history of C. canephora cultivation in comparison to other major crop plants, whereby the timeframe over which the cultivation process occurred in coffee is short and thus it is likely that there is less intraspecific variation between the wild and the cultivated individuals (Davis et al., 2019). For instance, the lack of genetic differences between wild and cultivated populations found in SC region (Chapter 2), could reflect either gene flow from cultivated to wild material, or the simple fact that some of the plant material used by farmers was simply collected locally in the wild. On the contrary, the statistically significant variation in responses across locations and genetic groups (Chapter 3), is crucial because it possibly indicates availability of heritable intraspecific variation, which may be locally adapted in response to ecological interactions (Bolnick et al., 2011 ). Locally adapted intraspecific phenotypic variation provides valuable plant material for use in plant breeding and crop improvement to biotic and abiotic production constraints (Allard, 1999).

\section{Evidence of a growth-tolerance trade-off}

In this thesis, we defined drought-tolerance as the capacity for a genotype to maintain and sustain performance (estimated in this thesis as relative growth rate in leaf area) under restricted-water conditions in comparison to ample-water conditions (Chapters 3 and 4). As far as I know, this thesis is unprecedented, in that it explores variation in drought tolerance across $>100$, mostly wild genotypes, and complemented with several feral and cultivated genotypes of $C$. canephora. Previous studies on coffee were done with much fewer (maximally eight) mostly cultivated genotypes. Consistent with this thesis work, these previous studies show substantial variability in drought tolerance among C. arabica (Beining, 2008, Tesfaye et al., 2014, Tesfaye et al., 2013) and C. canephora (Menezes-Silva et al., 2015, Pinheiro et al., 2005, Pinheiro et al., 2004).

Having established the large genotypic variation in drought responses in our populations, I next addressed the question whether drought tolerance comes at the expense of 
performance under well-watered conditions. Drought-tolerance is known to be achieved through a suite of traits which plants employ to enhance their survival and sustain under the water-limiting scenarios (Lambers et al., 1998 ). These traits however, may limit a plant's growth rate when resources are abundant and this could lead to a growth-tolerance trade-off (Lambers et al., 2008, Bazzaz and Bazzaz 1996, Chapin III, 1980, Grime, 1977). For instance, when considering variation in water availability, tolerance to drought can be achieved through a smaller leaf area and thicker leaves, a higher sapwood to leaf area ratio, denser wood and smaller xylem vessels and have fewer and/or smaller stomates all of which contribute securing water and limiting water loss during drought-stressed conditions. But these traits also limit maximum transpiration and photosynthesis and thus growth.

The growth-drought-tolerance trade-off has been well established across species, including tropical trees (Poorter and Markesteijn, 2008, Ouédraogo et al., 2013, Sterck et al., 2011) and the findings revealed that the growth-tolerance trade-off could at least in part explain the distribution of tropical forest tree species across ranges from dry to moist tropical forests. However, to explore the potential for natural selection within a species, it is important to focus on intraspecific variation, which has, to my opinion, rarely been explored on a wide scale for a tropical tree. Chapter 3 of this thesis shows evidence of this trade-off within C. canephora, a tropical tree species. Our findings (Chapter 3; Figure 3) show a negative relationship between performance in ample-water conditions and drought-tolerance under restricted-water conditions. More evidence for this trade-off is further shown by the statistically significant negative correlations between trait plasticity and drought-tolerance (Chapter 4; Figure 2 and 3).

Evidence of a growth-tolerance trade-off within C. canephora is key, as it informs breeders about the likelihood of having low performing drought-tolerant material if the link between drought-tolerance and growth is not weakened. Addressing the link between droughttolerance and growth, through breeding for a perennial species like C. canephora, may be complex because environmental conditions, e.g. drought, vary in frequency, severity, onset and duration. For instance, farmers typically experience combinations of wetter and drier years, and often if the long-term average yields are important, then a slow-growing tolerant genotype may not be favoured. However, coffee is a perennial plant species with an economic lifespan of about 20 years and if tolerance is essential for survival of the trees in dry years, it might be desirable in some scenarios to forego some growth potential to enhance the chance that trees survive. 


\section{Chapter 5}

\section{Genetic variation in phenotypic trait plasticity}

Phenotypic trait plasticity is the ability of an organism to adjust its phenotype in response to environmental change (Valladares et al., 2006, Grime et al., 1986). As such phenotypic plasticity is often thought to be a major strategy by which plants are able to cope with heterogeneous environmental conditions (Nicotra et al., 2010, Valladares et al., 2006), especially as plants are sessile and thus unlike many animals, cannot escape from adverse conditions. In this thesis, results presented substantial genetic variation in trait plasticity within C. canephora as shown by statistically significant, Genotype X Treatment (often denoted as a $\mathrm{G}^{*} \mathrm{E}$ interaction in crop breeding literature) interactions across most traits (Chapter 4; Table 4). The basic patterns in trait plasticity observed in this thesis (Chapter 3; Figure 1 and 2, Chapter 4; Figure 1) are presented in Figure 5.2. Availability of large intraspecific genetic variation in trait plasticity, (as seen in Figure 5.2) is reported to indicate potential for a species to adjust its trait value as an adaption to changes in the environmental conditions (Reed et al., 2011, Jump and Penuelas, 2005) and this maybe either through local adaption or phenotypic plasticity.

However, it has been found e.g. in tropical and Mediterranean systems that species from more stressful conditions tend to exhibit lower levels of plasticity (Valladares et al., 2000, Valladares et al., 2002 , Baquedano et al., 2008). For instance, in a study on Mediterranean shrublands, Bongers et al. (2017) found that species from drier Southern slopes were less plastic in response to variation in water availability than those from wetter Northern slopes. There was also a negative link between plasticity in several traits and their growth and survival under drier conditions. This indicates that low phenotypic plasticity can be linked to plant's specialization to adverse environmental conditions. There is increasing evidence, showing that specialization to adverse environmental conditions is associated with phenotypic stability and a conservative resource-use strategy across species (Valladares et al., 2000, Valladares et al., 2002 , Baquedano et al., 2008, Bongers et al., 2017). The results discussed above involved comparisons across species. Here, I addressed the question whether the negative link between phenotypic plasticity to water availability and tolerance extends to variations within Coffea canephora? The results (Chapter 4; Figure 2 and 3) showed that genotypes that exhibited high plasticity in various traits to variation in water availability tended to perform less well under dry conditions. Addressing this question at the intraspecific level is important to determine implications for natural selection, but as far as I know, this is the first study having done this at least for a tropical tree species. 


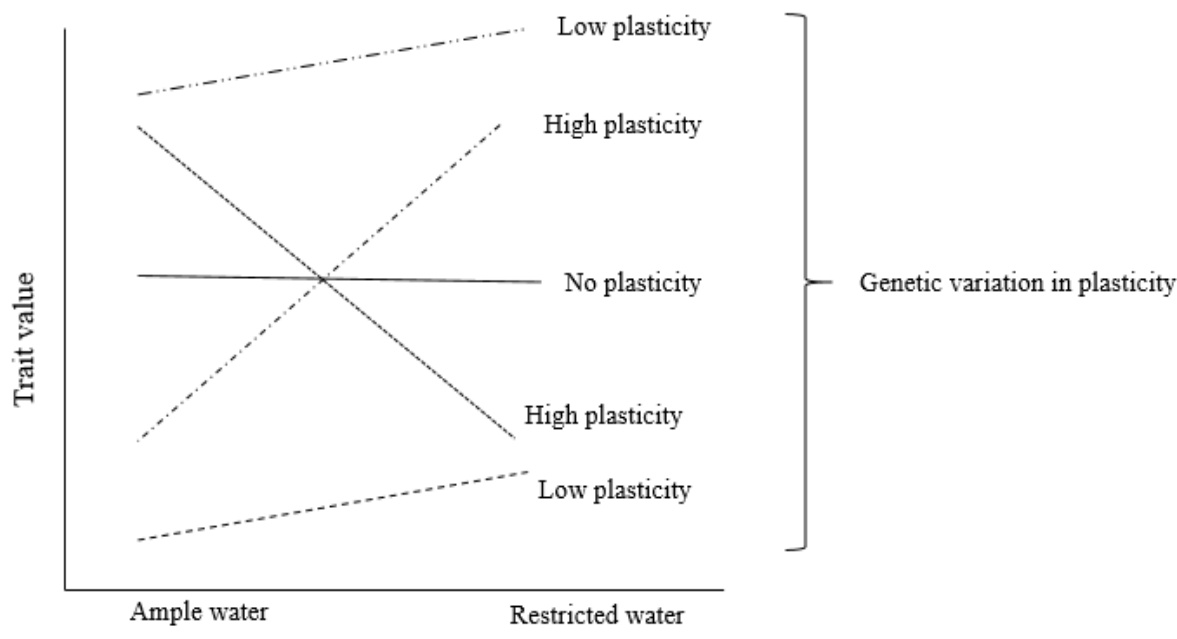

Environment

Figure 5.2 Basic trait plastic patterns observed in this thesis (Chapter 2 and Chapter 3). Different lines types represent different genotypes. Presentation of the figure is adapted from van Kleunen and Fischer (2005).

Evidence of the negative link between plasticity and drought tolerance within $C$. canephora genotypes may imply probable costs of phenotypic plasticity for genotypes occurring in fluctuating water availability conditions. For example, in optimal conditions (ample-water conditions in this thesis), lack of plasticity in drought-tolerant genotypes may prevent development of structures that will be non-beneficial or too costly to sustain in case the conditions become stressful (i.e. under restricted-water conditions in this thesis).

Additionally, another related study (Johnson et al. (unpublished)), exploring stomatal properties and response of the same coffee genotypes as those in this thesis, we found that one of the plastic response to drought (restricted-water conditions in this thesis) was the production of fewer and smaller stomates per leaf. However, the observed plasticity trend ran contrary to the trend across genotypes in their native sites, whereby genotypes from the drier location (Zoka) had larger (Figure 5.3) and more abundant stomata. Collectively, findings in Chapter 3; Figure 3 and Chapter 4; Figure 2 and 3, indicate probable presence of costs associated with trait plasticity (Dewitt et al., 1998), whereby less plastic genotypes may exhibit more fitness under stressful conditions (higher drought-tolerance in this thesis) than more plastic genotypes. 


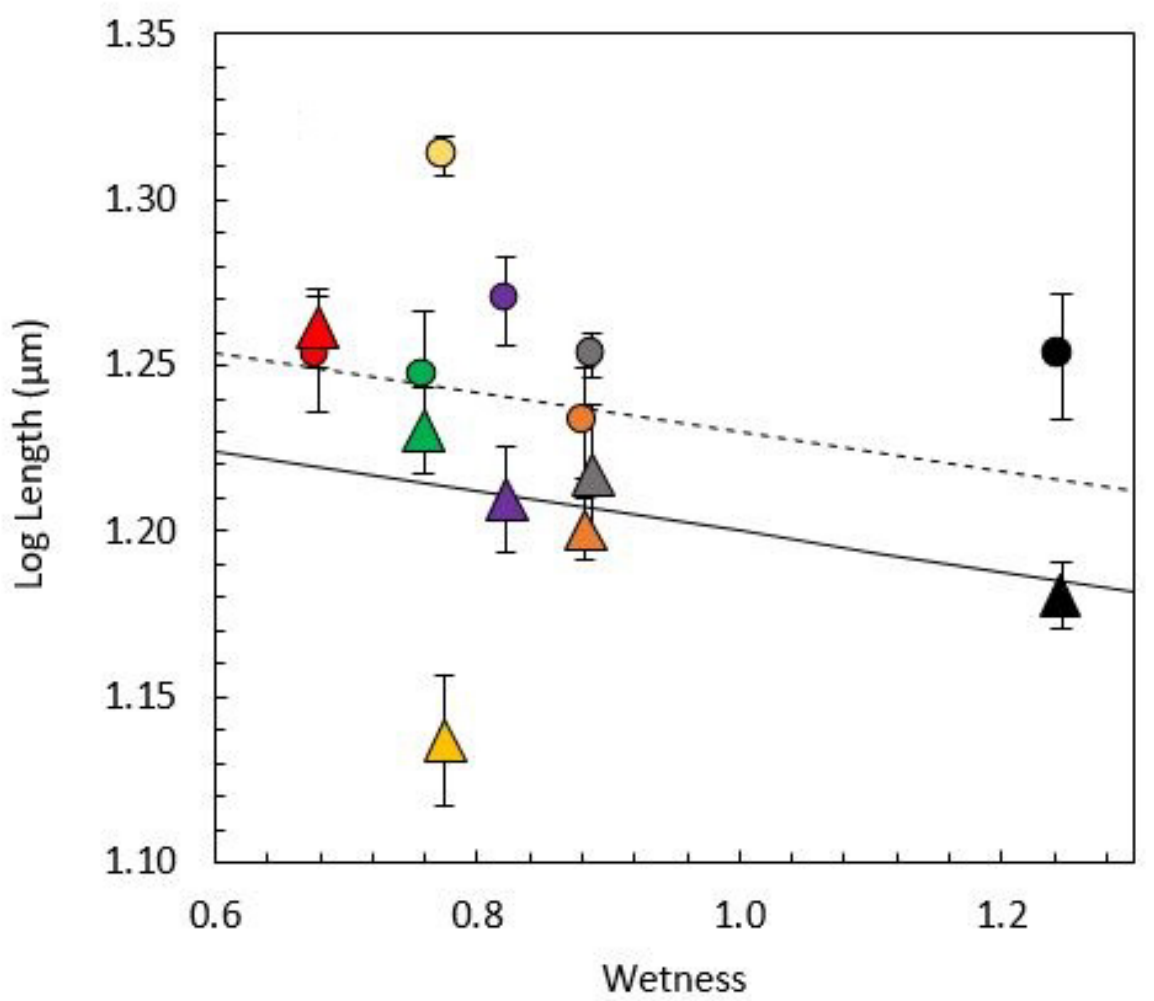

Figure 5.3 Relationship between log transformed stomatal length and wetness index of the native sites (locations in this thesis) of Uganda's C. canephora (same as those studied in this thesis) grown under different levels of water availability. Circles represent responses of plants subjected to ample -water (AW) conditions and triangles represent responses of plants subjected to restricted- water (RW) conditions. The different locations are colour coded as: Zoka $=$ red, Budongo $=$ green, Kibale $=$ yellow, Mabira $=$ purple, Malabigambo $=$ orange, Itwara $=$ grey and Kalangala $=$ black. The equations for the regression lines are $\mathrm{y}=-7.03 \mathrm{x}+1.31$ (Ample-water, dashed line), $\mathrm{y}=-7.03 \mathrm{x}+1.26$ (Restricted-water, solid line). The figure is adapted from (Johnson et al. (unpublished)). Note the difference between two lines reflects the treatment effect within genotypes (i.e., plasticity) being long stomata under wetter conditions. The negative of both lines indicate that genotypes from wetter locations have shorter stomata.

\section{Implications of the findings on the use of Uganda's C. canephora diversity}

Uganda's cultivated C. canephora comprises $88 \%$ of traditional ("nganda" and "erecta") landraces and $12 \%$ of the elite material (Aluka, 2013). The two traditional forms freely cross (Thomas, 1935), thus making it difficult to have distinct "nganda" or "erecta" types 
(Aluka, 2013). Similarly, our findings (Chapter 2) also show that 'nganda' and 'erecta' types are not genetically distinct and confirm that some of the cultivated material were introducted from Congo (C. canephora genetic group E) (Chapter 2). Coffee production in Uganda is predominantly rain-fed with a small proportion $(0.1 \%)$ of farms applying irrigation (ICO, 2019c). Given the increased drought stress that will be associated with warming in increasing irregularity in precipitation projected for coming decades, producing and sustaining Uganda's coffee sector, requires that farmers have climate resilient genotypes. Findings from this thesis (Chapter 3 and 4) provide the first quantitative assessment of genetic variation in responses to variation in water availability and drought tolerance across Uganda's C. canephora. With more detailed research, i.e. gene expression studies and combined stress (drought and heat), breeders will be able to identify superior genotypes which could be used in developing climate resilient genotypes.

In this thesis we collected and studied over 100 wild genotypes of $C$. canephora distributed along an environmental gradient in Uganda. The study material used in this thesis were duplicated and conserved ex-situ as field collections to enrich C. canephora germplasm base in the Entebbe Botanic gardens and the National Coffee research institute of National Research Agricultural Organization (NARO), ultimately enriching Uganda's C. canephora germplasm collection. Availability of these materials as centralized collections will support the proposed and other complementary studies on Uganda's C. canephora diversity. Although, the study genotypes are conserved ex-situ, I advocate for the in-situ conservations of the original populations to allow for their continued evolution and adaptation to environmental changes, thereby conserving a valuable genetic resource base for a sustainable $C$. canephora sub-sector. Wild coffee varieties are an important resource to derive climate and disease pest resistance in coffee ((Davis et al., 2012, Davis et al., 2019). In this thesis (Chapter 2) we show that wild coffee populations in Uganda's Southern-central forests are genetically not significantly different from the cultivated material. This could in part reflect that the cultivated materials were sourced from the Southern central forests and the occurrence of gene flow between wild populations and cultivated material. There is thus an urgent need to put in place measures that secure and allow for the adaption and evolution of wild coffee populations in predominant coffee cultivation areas. Such measures could entail directives not to grow C. canephora in proximity to protected forest reserves or national parks, increased protection of the forests coupled with periodic and intentional management of wild C. canephora populations. The presence of valuable wild coffee material may provide an incentive for forest conservation and 


\section{Chapter 5}

sustainable use of wild $C$. canephora through activities like ecotourism. There could also be potential in engaging local communities around the forests to sustainably harvest and market wild coffee at a premium as a way of tapping into the growing global quest for consumption of organic foods.

\section{Implication of the findings in the perceptive of field applications}

In an agricultural context, drought-tolerance is defined in terms of the plants' capacity to produce comparatively acceptable or higher harvestable yields when subjected to drought stress (Passioura, 1996). Due to time constraints, in this thesis I could only explore droughtresponses in young plants (20-month-old in Chapter 3 and 8-month-old in Chapter 4) and I did not obtain information about drought-responses in terms of yield. There may be limitations in the extent to which results of drought responses in young plants could be extrapolated to mature plants because a plant's sensitivity to drought stress varies during growth stages and young plants naturally have developing and relatively shallow roots. Drought affects the complex sequence of physiological, biochemical and morphological events between flowering and fruit ripening in coffee (DaMatta, 2018). For example, flowering and anthesis occur upon onset of occasional rains that were preceded by a dry period which initiated floral buds from dormancy (Drinnan and Menzel, 1994, Crisosto et al., 1992 , Gomez et al., 2016). Therefore, coffee flowering requires a timely dry period and rainfall on-set.

Exploring drought responses in young plants (seedlings) at least from an ecological perspective as it is done in this thesis is however, supported by some studies e.g. Aranda et al. (2012); Poorter and Markesteijn (2008) Engelbrecht and Kursar (2003); Veenendaal et al. (1996) who reveal that the ability of seedlings to grow under drought conditions is a major factor influencing seedling growth and ultimately species composition in dry and humid forests. As discussed in Chapter 3 of this thesis, there is a close relationship between vegetative growth and yield capacity of coffee plants (Cilas et al., 2006) and since coffee yield is strongly influenced by environmental conditions during the vegetative and reproductive phases of the plant (Tavares et al., 2018), the findings in this thesis may, to a certain degree, provide insights into how drought affects $C$. canephora trees. However, in view of the limitation that our findings were drawn from young plants, we recommend the need for a systematic study on the effects of drought on C. canephora intraspecific diversity while scaling from seedlings to mature trees in field conditions. Specifically, there is need for long-term (at least 5-year) 
drought experiments on the same genotypes studied in this thesis to understand their responses to drought on real -time basis.

Our findings (Chapter 4) showed genotypic variation in water-use efficiency (WUE) and a link between WUE and carbon isotope signatures. This observation concurs with Farquhar et al. (1989) who established that there are relationships between WUE and the carbon isotope discrimination during photosynthesis and this relationship has been reported across several species (Hall et al., 1994, Condon and Hall, 1997, Lambers et al., 2008). Findings in this thesis (Chapter 4. Figure 1; Panel E) show substantial genotypic variation in $\delta^{13} \mathrm{C}$ abundances in under ample and restricted- water conditions indicating an inherent variation in carbon isotope discrimination. There were significant positive correlations between genotypic $\delta^{13} \mathrm{C}$ abundances and WUE at leaf level in both ample-and restricted water conditions indicating that carbon isotope signatures may be reliable proxies for WUEi (Chapter 4, Figure 4; Panel A). Given the higher heritability of carbon isotope discrimination than WUE (Mckay et al., 2003 ) and the fact that carbon isotope signatures provide an integrated measure of plants' physiological properties i.e. photosynthetic rate and stomata conductance in relation to environmental conditions (Anderson et al., 1996), analysis of $\delta{ }^{13} \mathrm{C}$ abundances has been used as a tool for selecting drought tolerant genotypes (Condon et al., 2004). The use of $\delta^{13} \mathrm{C}$ abundances as a tool in identifying, breeding and selecting genotypes with superior WUE has been applied in several crops and tree species e.g. Solanum tuberosum (Vos and Groenwold, 1989), Helianthus annuus (Adiredjo et al., 2014b, Adiredjo et al., 2014a), Populus spp. ( (Monclus et al., 2006, Maier et al., 2019), Eucalyptus spp (Nunes et al., 2016, Pitaa et al., 2001, Li, 1999) , Coffea canephora (DaMatta et al., 2003); Coffea arabica (Meinzer et al., 1992, Meinzer et al., 1991). The finding in this thesis that $\delta^{13} \mathrm{C}$ abundances are linked to WUE at leaf level in both ample and restricted-water conditions and WUE at plant level under ample water conditions contributes to the available knowledge by identifying the potential of using carbon isotope signatures as a probable tool for selecting WUEi genotypes within of $C$. canephora including wild genotypes. It is important to note that in our findings, the correlations between $\delta^{13} \mathrm{C}$ abundances and WUE differed in respect to the level i.e. leaf and plant level (Chapter 4, Figure 4; Panel A and B). The correlations at plant level were significant only under amplewater conditions indicating a probable influence of the altered balance between photosynthesis and respiration at the whole plant level when plants are subjected to restricted-water conditions. Although our results suggest potential in use of $\delta^{13} \mathrm{C}$ abundances as proxies for WUEi at leaf level and WUEp in only under water conditions, it is worth noting the complexity in upscaling 


\section{Chapter 5}

the relationship between carbon isotope discrimination and WUE from leaf to canopy level (Medrano et al., 2015, Blum, 2009). It is thus recommended that as researchers targeting to use of carbon isotope discrimination as a tool technique for selecting water use-efficient genotypes, ought to put into consideration the need to address the cofounding effects associated with the processes (e.g. transpiration, biomass allocation and respiration) that influence carbon isotope discrimination and WUE from leaf to canopy level.

\section{Future research perspectives}

In this thesis we comprehensively explored the genetic diversity and population structure of Uganda's $C$. canephora. Since drought-tolerance is a quantitative trait, known to be controlled by a set of genes (Waseem et al., 2011, Marraccini et al., 2012, Vieira et al., 2013), there is need to further our work by conducting association studies to enhance the understanding of the functional importance of the genetic diversity in relation to drought stress. Association studies will also benefit from the sequencing of the $C$. canephora reference genome (Denoeud et al., 2014). Efforts to unravel the molecular mechanisms of coffee in response to drought stress have been accomplished elsewhere by (Mofatto et al., 2016, Vieira et al., 2013, Marraccini et al., 2012, Alves et al., 2018) and it is important that we conduct related studies with Ugandan $C$. canephora diversity to understand the molecular mechanisms and gene expressions in regard to drought stress.

\section{Concluding remarks}

The findings in this thesis demonstrate that there is substantial genetic and phenotypic variation linked to drought stress within Uganda's $C$. canephora. Our results indicate that Ugandan C. canephora genotypes naturally occurring in different locations differed genetically and in their response to drought stress. Results also show evidence of a growth - tolerance tradeoff, which should be addressed in efforts geared towards developing drought-tolerant genotypes. The variation in drought tolerance was linked to the resource acquisition strategies whereby slow growers with a conservative resource use acquisition strategy seemed more drought-tolerant than the fast growers. More evidence to the tolerance-growth trade-off was revealed by the negative relationship between trait plasticity and drought-tolerance. Use of the findings from this study to further the conservation of coffee genetic resources, and to develop drought-tolerant genotypes will contribute to the National effort aimed at increasing and sustaining coffee production for improved livelihoods. 


\section{References}

Abrams MD. 1994 Genotypic and phenotypic variation as stress adaptations in temperate tree species: a review of several case studies. Tree Physiology 14: 833-842.

Adiredjo AL, Navaud O, Lamaze T, Grieu P. 2014a. Leaf carbon isotope discrimination as an accurate indicator of water-use efficiency in sunflower genotypes subjected to five stable soil water contents. Journal of Agronomy and Crop Science, 200: 416-424.

Adiredjo AL, Navaud O, Munos S, Langlade NB, Lamaze T, Grieu P. 2014b. Genetic control of water use efficiency and leaf carbon isotope discrimination in sunflower (Helianthus annuus L.) subjected to two drought scenarios. PLoS One, 9: e101218.

Aerts R, Chapin III FS. 1999. The mineral nutrition of wild plants revisited: a re-evaluation of processes and patterns. Advances in Ecological Research 30: 1 - 67.

Alberto F, Bouffier L, Louvet JM, Lamy JB, Delzon S, Kremer A. 2011. Adaptive responses for seed and leaf phenology in natural populations of sessile oak along an altitudinal gradient. Journal of Evolutionary Biology, 24: 1442-54.

Alberto FJ, Aitken SN, Alia R, Gonzalez-Martinez SC, Hanninen H, Kremer A, Lefevre F, Lenormand T, Yeaman S, Whetten R, Savolainen O. 2013. Potential for evolutionary responses to climate change - evidence from tree populations. Global Change Biology, 19: 1645-61.

Allard RW. 1999. Principles of plant breeding: John Wiley \& Sons.

Aluka P. 2013. Genetic and Phenotypic diversity of cultivated Robusta coffee (Coffea canephora Pierre) in Uganda and effect of environmental factors on quality., Doctor of Philosophy in Plant Breeding and genetics, University of Nairobi, Nairobi- Kenya.

Alves GSC, Torres LF, de Aquino SO, Reichel T, Freire LP, Vieira NG, Vinecky F, This D, Pot D, Etienne H, Paiva LV, Marraccini P, Andrade AC. 2018. Nucleotide Diversity of the Coding and Promoter Regions of DREB1D, a Candidate Gene for Drought Tolerance in Coffea Species. Tropical Plant Biology, 11: 31-48.

Amissah L, Mohren GM, Kyereh B, Poorter L. 2015. The effects of drought and shade on the performance, morphology and physiology of Ghanaian tree species. Plos One, 10: e0121004.

Amissah L, Mohren GMJ, Kyereh B, Agyeman VK, Poorter L. 2018. Rainfall seasonality and drought performance shape the distribution of tropical tree species in Ghana. Ecology and Evolution, 8: 8582-8597.

Anderson JE, Williams J, Kriedemann PE, Austin MP, Farquhar GD. 1996. Correlations Between Carbon Isotope Discrimination and Climate of Native Habitats for Diverse Eucalypt Taxa Growing in a Common Garden. Functional Plant Biology, 23.

Aranda I, Gil-Pelegrín E, Gascó A, Guevara MA, Cano JF, De Miguel M, RamírezValiente JA, Peguero-Pina JJ, Perdiguero P, Soto A, Cervera MT, Collada C. 2012. Drought Response in Forest Trees: From the Species to the Gene. Plant Responses to Drought Stress.

Baca M, Laderach P, Haggar J, Schroth G, Ovalle O. 2014. An integrated framework for assessing vulnerability to climate change and developing adaptation strategies for coffee growing families in Mesoamerica. PLoS One, 9: e88463.

Balaguer L, Martínez-Ferri E, Valladares F, Pérezcorona ME, Baquedano FJ, Castillo FJ, Manrique E. 2001. Population divergence in the plasticity of the response of Quercus coccifera to the light environment. Functional Ecology 15: 124-135.

Baltzer JL, Davies SJ, Bunyavejchewin S, Noor NSM. 2008. The role of desiccation tolerance in determining tree species distributions along the Malay-Thai Peninsula. Functional Ecology, 22: 221-231. 
Baquedano FJ, Valladares F, Castillo FJ. 2008. Phenotypic plasticity blurs ecotypic divergence in the response of Quercus coccifera and Pinus halepensis to water stress. European Journal of Forest Research, 127: 495-506.

Basalirwa CPK. 1995. Delineation of Uganda into climatological rainfall zones using the method of principal component analysis. International Journal of Climatology 15: 1161-1177

Bates D, Mächler M, Bolker B, Walker S. 2015. Package 'lme4'. Convergence, 12: 2.

Bazzaz FA, Bazzaz F. 1996. Plants in changing environments: linking physiological, population, and community ecology. Cambridge, England: Cambridge University Press.

Beer J, Muschler R, Kass D, Somarriba E. 1998. Shade management in coffee and cacao plantations. Agroforestry Systems, 38: 139-164.

Beining A. 2008. Ecophysiological diversity of wild Coffea arabica populations in Ethiopia: drought adaptation mechanisms. , Ph.D., University of Bonn, Germany.

Berthaud J. 1986. Les ressources genetiques pour l'amelioration des cafeires africains diploides: Orstom Paris.

Bloom AJ, Chapin III FS, Mooney HA. 1985. Resource limitation in plants-an economic analogy. Annual Review of Ecology and Systematics, 16: 363-392.

Blum A. 2009. Effective use of water (EUW) and not water-use efficiency (WUE) is the target of crop yield improvement under drought stress. Field Crops Research, 112: 119-123.

Bolnick DI, Amarasekare P, Araújo MS, Bürger R, Levine JM, Novak M, Rudolf VHW, Schreiber SJ, Urban MC, Vasseur D. 2011 Why intraspecific trait variation matters in community ecology. Trends Ecol Evol., 26(183-192.

Bondel KB, Nosenko T, Stephan W. 2018. Signatures of natural selection in abiotic stressresponsive genes of Solanum chilense. $R$ Soc Open Sci, 5: 171198.

Bongarten BC, Teskey RO. 1986. Water relations of loblolly pine seedlings from diverse geographic origins. Tree Physiology, 1: 265-276.

Bongers FJ, Olmo M, Lopez-Iglesias B, Anten NPR, Villar R. 2017. Drought responses, phenotypic plasticity and survival of Mediterranean species in two different microclimatic sites. Plant Biology, 19: 386-395.

Bradshaw AD. 1965. Evolutionary significance of phenotypic plasticity in plants. Advances in genetics, 13: 115-155.

Brouwer R. 1963. Some aspects of the equilibrium between overground and underground plant parts. Jaarboek van het Instituut voor Biologisch en Scheikundig onderzoek aan Landbouwgewassen, 31-39: 31.

Brozynska M, Furtado A, Henry RJ. 2016. Genomics of crop wild relatives: expanding the gene pool for crop improvement. Plant Biotechnol J, 14: 1070-85.

Bunn C, Läderach P, Ovalle Rivera O, Kirschke D. 2015. A bitter cup: climate change profile of global production of Arabica and Robusta coffee. Climatic Change, 129: 89101.

Bunn CL, M; Läderach, P; Fernández P; Castro-Llanos, F. 2019., Bunn C, Lundy M, Läderach P, Fernandez P, Castro-Llanos F. 2019. Climate-smart Coffee in Uganda. . International Center for Tropical Agriculture (CIAT), Cali, Colombia.

Burkhardt J, Beining AM, Kufa T, Goldbach H. 2006. Different drought adaptation strategies of Coffea arabica populations along a rainfall Gradient in Ethiopia. Prosperity and Poverty in a Globalised World - Challenges for Agricultural Research. Tropentag, Bonn.

Byars SG, Papst W, Hoffmann AA. 2007. Local adaptation and cogradient selection in the alpine plant, Poa hiemata, along a narrow altitudinal gradient. Evolution, 61: 2925-41.

Cannell MGR. 1985 Physiology of the Coffee Crop. . Coffee. 
Caye K, Jumentier B, François O. 2018. LFMM 2.0: Latent factor models for confounder adjustment in genome and epigenome-wide association studies.

Chapin III FS. 1980. The Mineral Nutrition of Wild Plants. Annual Review of Ecology and Systematics, 11: 233-260.

Chapin III FS, Autumn K, Pugntaire F. 1993. Evolution of suites of traits in response to environmental stress. The American Naturalist, 142: 78 - 92.

Charrier A, Berthaud J. 1985. Botanical Classification of Coffee. Coffee.

Choat B, Sack L, Holbrook NM. 2007. Diversity of hydraulic traits in nine Cordia species growing in tropical forests with contrasting precipitation. New Phytologist, 175: 686698.

Cilas C, Bar-Hen A, Montagnon C, Godin C. 2006. Definition of architectural ideotypes for good yield capacity in Coffea canephora. Annals of Botany, 97: 405- 411.

Comita LS, Engelbrecht BMJ. 2014. Drought as a driver of tropical tree species regeneration dynamics and distribution patterns. In: David A. Coomes, David F. R. P. Burslem, Simonson. WD, eds. Forests and Global Change.

Condon A, Hall A. 1997. Adaptation to diverse environments: variation in water-use efficiency within crop species. Agricultural Ecology: 79-116.

Condon AG, Richards RA. 1992. Broad sense heritability and genotype x environment interaction for carbon isotope discrimination in field-grown wheat. Australian Journal of Agricultural Research, 43: 921-934.

Condon AG, Richards RA, Rebetzke GJ, Farquhar GD. 2004. Breeding for high water-use efficiency. Journal of Experimental Botany, 55: 2447-2460.

Coste R. 1992. Coffee; the plant and product. London: Macmillan Press Ltd.

Craparo ACW, Van Asten PJA, Läderach P, Jassogne LTP, Grab SW. 2015. Coffea arabica yields decline in Tanzania due to climate change: Global implications. Agricultural and Forest Meteorology, 207: 1-10.

Crisosto CH, Grantz DA, Osgood RV, Cid LR. 1992 Synchronization of fruit ripening in coffee with low concentrations of ethephon. Postharvest Biology and Technology, 1: 371-378.

Cubry P, De Bellis F, Pot D, Musoli P, Leroy T. 2012. Global analysis of Coffea canephora Pierre ex Froehner (Rubiaceae) from the Guineo-Congolese region reveals impacts from climatic refuges and migration effects. Genetic Resources and Crop Evolution, 60: 483501.

DaMatta FM. 2004. Ecophysiological constraints on the production of shaded and unshaded coffee: a review. Field Crops Research, 86: 99-114.

DaMatta FM. 2018. Coffee tree growth and environmental acclimation. Achieving sustainable cultivaiton of coffee.

DaMatta FM, Avila RT, Cardoso AA, Martins SCV, Ramalho JC. 2018. Physiological and agronomic performance of the coffee crop in the context of climate change and global warming: A review. Journal of Agricultural and Food Chemistry, 66: 5264-5274.

DaMatta FM, Chaves ARM, Pinheiro HA, Ducatti C, Loureiro ME. 2003. Drought tolerance of two field-grown clones of Coffea canephora. Plant Science, 164: 111-117.

DaMatta FM, Loos AR, Silva AE, Loureiro EM, Ducatti C. 2002. Effects of soil water deficit and nitrogen nutrition on water relations and photosynthesis of pot-grown Coffea canephora Pierre ex A. Froehner. Trees, 16: 555-558.

DaMatta FM, Ramalho JD, Cochicho,. 2006. Impacts of drought and temperature stress on coffee physiology and production: a review. Braz. J. Plant Physiol. , 18: 55-81.

DaMatta FM, Ramalho JDC. 2006. Impacts of drought and temperature stress on coffee physiology and production: a review. Brazilian Journal of Plant Physiology, 18: 55-81. 
DaMatta FM, Ronchi PC, Maestri M, Barros SR. 2007. Ecophysiology of Coffee Growth and Production. Brazillian Journal Plant Physiology, 19: 485-510.

Davis AP, Chadburn H, Moat J, O'Sullivan R, Hargreaves S, Lughadha EN. 2019. High extinction risk for wild coffee species and implications for coffee sector sustainability. Science Advances, 5.

Davis AP, Gole TW, Baena S, Moat J. 2012. The impact of climate change on indigenous Arabica coffee (Coffea arabica): predicting future trends and identifying priorities. PLoS One, 7.

Davis AP, Govaerts R, Bridson DM, Stoffelen P. 2006. An annotated taxonomic conspectus of the genus Coffea (Rubiaceae). Botanical Journal of the Linnean Society, 152: 465512.

Davis AP, Tosh J, Ruch N, Fay F, Michael. 2011. Growing coffee: Psilanthus (Rubiaceae) subsumed on the basis of molecular and morphological data; implications for the size, morphology, distribution and evolutionary history of Coffea. Botanical Journal of the Linnean Society, 167: 357-377.

De Kochko A, Akaffou S, Andrade AC, Campa C, Crouzillat D, Guyot R, Hamon P, Ming R, Mueller LA, Poncet V, Tranchant-Dubreuil C, Hamon S. 2010. Advances in Coffea Genomics.

Dempewolf H, Baute G, Anderson J, Kilian B, Smith C, Guarino L. 2017. Past and Future Use of Wild Relatives in Crop Breeding. Crop Science, 57.

Denoeud F, Carretero-Paulet L, Dereeper A, Droc G, Guyot R, Pietrella M, Zheng C, Alberti A, Anthony F, Aprea G, Aury JM, Bento P, Bernard M, Bocs S, Campa C, Cenci A, Combes MC, Crouzillat D, Da Silva C, Daddiego L, De Bellis F, Dussert S, Garsmeur O, Gayraud T, Guignon V, Jahn K, Jamilloux V, Joet T, Labadie K, Lan T, Leclercq J, Lepelley M, Leroy T, Li LT, Librado P, Lopez L, Munoz A, Noel B, Pallavicini A, Perrotta G, Poncet V, Pot D, Priyono, Rigoreau M, Rouard M, Rozas J, Tranchant-Dubreuil C, VanBuren R, Zhang Q, Andrade AC, Argout X, Bertrand B, de Kochko A, Graziosi G, Henry RJ, Jayarama, Ming R, Nagai C, Rounsley S, Sankoff D, Giuliano G, Albert VA, Wincker P, Lashermes P. 2014. The coffee genome provides insight into the convergent evolution of caffeine biosynthesis. Science, 345: 1181-4.

Dereeper A, Bocs S, Rouard M, Guignon V, Ravel S, Tranchant-Dubreuil C, Poncet V, Garsmeur O, Lashermes P, Droc G. 2015. The coffee genome hub: a resource for coffee genomes. Nucleic Acids Res, 43: D1028-35.

Dewitt TJ, Sih A, Wilson DS. 1998. Costs and limits of phenotypic plasticity. Tree, 13.

Dias PC, Araujo WL, Moraes GA, Barros RS, DaMatta FM. 2007. Morphological and physiological responses of two coffee progenies to soil water availability. Journal of Plant Physiology, 164: 1639-1647.

Dorn LA, Pyle EH, Schmitt J. 2000. Plasticity to light cues and resources in Arabidopsis thaliana: testing for adaptive value and costs. Evolution, 54: 1982-1994.

Drinnan JE, Menzel CM. 1994. Synchronization of anthesis and enhancement of vegetative growth in coffee (Coffea arabicaL.) following water stress during floral initiation. Journal of Horticultural Science, 69: 841-849.

Dudley SA, Schmitt J. 1995 Genetic Differentiation in Morphological Responses to Simulated Foliage Shade between Populations of Impatiens capensis from Open and Woodland Sites. Functional Ecology, 9: 655-666.

Dussert S, Lashermes P, Anthony F, Montagnon C, Trouslot P, Combes M, C., , Berthaud J, Noirot M, Hamon S. 1999. Le caféier, Coffea canephora. Diversité génétique des plantes tropicales cultivées,. 
Engelbrecht BM, Comita LS, Condit R, Kursar TA, Tyree MT, Turner BL, Hubbell SP. 2007. Drought sensitivity shapes species distribution patterns in tropical forests. Nature, 447: 80-2.

Engelbrecht BM, Dalling JW, Pearson TR, Wolf RL, Galvez DA, Koehler T, Tyree MT, Kursar TA. 2006. Short dry spells in the wet season increase mortality of tropical pioneer seedlings. Oecologia, 148: 258-69.

Engelbrecht BM, Kursar TA. 2003. Comparative drought-resistance of seedlings of 28 species of co-occurring tropical woody plants. Oecologia, 136: 383-93.

Erdiansyah NP, Wachjar A, Sulistyono E, Supijatno. 2019 Growth response of seedlings of four robusta coffee (Coffea canephora Pierre. Ex. A. Froehner) clones to drought stress. Pelita Perkebunan 35: 1 - 11

Eziz A, Yan Z, Tian D, Han W, Tang Z, Fang J. 2017. Drought effect on plant biomass allocation: A meta-analysis. Ecology and Evolution, 7: 11002-11010.

Farquhar GD, Ehleringer JR, Hubick KT. 1989. Carbon isotope discrimination and photosynthesis. Annual Review of Plant Physiology and Plant Molecular Biology, 40: 503-537.

Farquhar GD, Richards RA. 1984. Isotopic composition of plant carbon correlates with water-use efficiency of wheat genotypes. Australian Journal of Plant Physiology, 11: 539-52.

Fauset S, Baker TR, Lewis SL, Feldpausch TR, Affum-Baffoe K, Foli EG, Hamer KC, Swaine MD. 2012. Drought-induced shifts in the floristic and functional composition of tropical forests in Ghana. Ecology Letters, 15: 1120-1129.

Fischer I, Steige KA, Stephan W, Mboup M. 2013. Sequence evolution and expression regulation of stress-responsive genes in natural populations of wild tomato. PLoS One, 8: e 78182 .

Forsman A. 2015. Rethinking phenotypic plasticity and its consequences for individuals, populations and species. Heredity 115: 276-284.

Galloway FL, Fenster BC. 2000. Population differentiation in an annual legume: Local adaptation. Evolution, 54: 1173-1181.

Gay C, Estrada F, Conde C, Eakin H, Villers L. 2006. Potential impacts of climate change on agriculture: a case of study of coffee production in Veracruz, Mexico. Climatic Change, 79: 259-288.

Ghini R, Torre-Neto A, Dentzien AFM, Guerreiro-Filho O, Iost R, Patrício FRA, Prado JSM, Thomaziello RA, Bettiol W, DaMatta FM. 2015. Coffee growth, pest and yield responses to free-air CO2 enrichment. Climatic Change, 132: 307-320.

Gomez C, Despinoy M, Hamon S, Hamon P, Salmon D, Akaffou DS, Legnate H, De Kochko A, Mangeas M, Poncet V. 2016. Shift in precipitation regime promotes interspecific hybridization of introduced Coffea species. Ecol Evol, 6: 3240-55.

Gomez C, Dussert S, Hamon P, Hamon S, Kochko A, Poncet V. 2009. Current genetic differentiation of Coffea canephora Pierre ex A. Froehn in the Guineo-Congolian African zone: cumulative impact of ancient climatic changes and recent human activities. BMC Evolutionary Biology, 9: 167.

Graham CH, Hijmans RJ. 2006. A comparison of methods for mapping species ranges and species richness. Global Ecology and Biogeography, 0: 060831043455001-???

Grant MC. 1975. Genetic properties of ecologically marginal populations of Anthoxanthum odoratum, Duke University.

Grime JP. 1977. Evidence for the existence of three primary strategies in plants and its relevance to ecological and evolutionary theory. The American Naturalist 111.

Grime JP. 1979. Plant strategies and vegetation processes. Plant strategies and vegetation processes. 
Grime JP. 2001. Plant strategies, vegetation processes, and ecosystem properties; 2 nd edition. Chichester, UK: John Wiley and Sons

Grime JP, Crick JC, Rincon JE. 1986. The ecological significance of plasticity. Symposia of the Society for Experimental Biology, 40: 5-29.

Grime JP, Hunt R. 1975. Relative growth-rate: Its range and adaptive significance in a local flora. The Journal of Ecology: 393 -422.

Grime JP, Thompson K, Hunt R, Hodgson JG, Cornelissen JHC, Rorison IH, Hendry GAF, Ashenden TW, Askew AP, Band SR, Booth RE, Bossard CC, Campbell BD, Cooper JEL, Davison AW, Gupta PL, Hall W, Hand DW, Hannah MA, Hillier SH, Hodkinson DJ, Jalili A, Liu Z, Mackey JML, Matthews N, Mowforth MA, Neal AM, Reader RJ, Reiling K, Ross-Fraser W, Spencer RE, Sutton F, Tasker DE, Thorpe PC, Whitehouse J. 1997. Integrated screening validates primary axes of specialisation in plants. Oikos, 79: 259 - 281.

Haggar J, Schepp K. 2012. Coffee and Climate Change

Impacts and options for adaption in Brazil, Guatemala, Tanzania and Vietnam. NRI Working Paper Series: Climate Change, Agriculture and Natural Resources.

Hajjar R, Hodgkin T. 2007. The use of wild relatives in crop improvement: a survey of developments over the last 20 years. Euphytica, 156: 1-13.

Hall AE, Richards RA, Condon AG, Wright GC, Farquhar GD. 1994. Carbon isotope discrimination and plant breeding. Plant breeding reviews, 12: 113.

Hamon P, Grover CE, Davis AP, Rakotomalala JJ, Raharimalala NE, Albert VA, Sreenath HL, Stoffelen P, Mitchell SE, Couturon E, Hamon S, de Kochko A, Crouzillat D, Rigoreau M, Sumirat U, Akaffou S, Guyot R. 2017. Genotyping-bysequencing provides the first well-resolved phylogeny for coffee (Coffea) and insights into the evolution of caffeine content in its species: GBS coffee phylogeny and the evolution of caffeine content. Mol Phylogenet Evol, 109: 351-361.

Hamrick JL. 2004. Response of forest trees to global environmental changes. Forest Ecology and Management, 197: 323-335.

Hargreaves GH, Samani ZA. 1985. Reference crop evapotranspiration from temperature. Applied Engineering in Agriculture, 1: 96-99.

Harlan JR, de Wet JMJ. 1971. Toward a Rational Classification of Cultivated Plants. Taxon, 20: $50-517$.

Hendre PS, Aggarwal RK. 2014. Development of genic and genomic SSR markers of robusta coffee (Coffea canephora Pierre Ex A. Froehner). PLoS One, 9: e113661.

Hijmans RJ, Cameron SE, Parra JL, Jones PG, Jarvis A. 2005. Very high resolution interpolated climate surfaces for global land areas. International Journal of Climatology, 25: 1965-1978.

Hoffmann WA, Poorter H. 2002. Avoiding bias in calculations of relative growth rate. Annals of Botany, 90: 37-42.

Hufford KM, Mazer SJ. 2003. Plant ecotypes: genetic differentiation in the age of ecological restoration. Trends in Ecology \& Evolution, 18: 147-155.

ICO. 2014. World coffee trade (1963 - 2013): A review of the markets, challenges and opportunities facing the sector. International Coffee Organisation.

ICO. 2018. Trade Statistics. International Coffee Organization.

ICO. 2019a. Coffee Development Report. Growing Prosperity - Economic viability as the catalyst for a sustainable coffee sector

London. International Coffee Organisation.

ICO. 2019b. Coffee market report June 2019. ICO: International Coffee Organization.

ICO. 2019c. Country Coffee Profile: Uganda International Coffee Council. 
IPCC. 2014. Proceedings of the 5th Assessment Report, WGII, Climate Change 2014: Impacts, Adaptation, and Vulnerability. Cambridge, U.K.

IPCC. 2018. Global warming of $1.5^{\circ} \mathrm{C}$. An IPCC Special Report on the impacts of global warming of $1.5^{\circ} \mathrm{C}$ above pre-industrial levels and related global greenhouse gas emission pathways, in the context of strengthening the global response to the threat of climate change, sustainable development, and efforts to eradicate poverty In: V. Masson-Delmotte, P. Zhai, H. O. Pörtner, D. Roberts, J. Skea, P.R. Shukla, A. Pirani, W. Moufouma-Okia, C. Péan, R. Pidcock, S. Connors, J. B. R. Matthews, Y. Chen, X. Zhou, M. I. Gomis, E. Lonnoy, T. Maycock, M. Tignor, Waterfield T, eds.

Jassogne L, van Asten PJA, Wanyama I, Baret PV. 2013. Perceptions and outlook on intercropping coffee with banana as an opportunity for smallholder coffee farmers in Uganda. International Journal of Agricultural Sustainability, 11: 144-158.

Joshi J, Schmid B, Caldeira MC, Dimitrakopoulos PG, Good J, Harris R, Hector A, HussDanell K, Jumpponen A, Minns A, Mulder CPH, Pereira JS, Prinz A, SchererLorenzen M, Siamantziouras A-SD, Terry AC, Troumbis AY, Lawton JH. 2001. Local adaptation enhances performance of common plant species. Ecology Letters 4: $536-544$.

Jump AS, Penuelas J. 2005. Running to stand still: adaptation and the response of plants to rapid climate change. Ecology Letters, 8: 1010-1020.

Kawecki TJ, Ebert D. 2004. Conceptual issues in local adaptation. Ecology Letters, 7: 12251241.

King'oro WM, Mushimiyamana D, Cheserek JJ, Gichimu MB. 2014. Effect of different watering regimes on agromorphology of selected coffee genotypes. American Journal of Experimental Agriculture, 4: 1016 - 1026.

Kiwuka C, Goudsmit E, Douma JC, Bellanger L, Crouzillat D, de Kochko A, Mulumba JW, Musoli P, Anten N, Poncet V. submitted. Genetic diversity of native and cultivated Uganda's Coffea canephora Pierre ex A. Froehner. A perspective into potential utilization and conservation of the diversity.

Kufa T, Burkhardt J. 2011. Stomatal characteristics in Arabica coffee germplasm accessions under contrasting environments at Jimma, Southwestern Ethiopia. International Journal of Botany, 7: 63-72.

Lambers H, Chapin FI, Pons T. 1998 Plant Physiological Ecology: Springer.

Lambers H, Stuart Chapin III F, Pons TL. 2008. Plant Physiological Ecology: Springer.

Lenth R, Singmann H, Love J, Buerkner P, Herve M. 2018. emmeans: Estimated marginal means, aka least-squares means. R package. See https://CRAN. R-project. org/package= emmeans.

Levins R. 1963. Theory of fitness in a heterogeneous environment. II. Developmental flexibility and niche selection. The American Naturalist, 97: 75-90.

Lewin B, Giovannucci D, Varangis P. 2004. Coffee Markets: New Paradigms in Global Supply and Demand.

Li C. 1999. Carbon isotope composition, water-use efficiency and biomass productivity of Eucalyptus microtheca populations under different water supplies. Plant and Soil, 214: $165-171$.

Lortie CJ, Aarssen LW. 1996. The specialization hypothesis for phenotypic plasticity in plants. International Journal of Plant Sciences, 157: 484-487.

Maier, Burley, Cook, Ghezehei, Hazel, Nichols. 2019. Tree Water Use, Water Use Efficiency, and Carbon Isotope Discrimination in Relation to Growth Potential in Populus deltoides and Hybrids under Field Conditions. Forests, 10. 
Malhi Y, Phillips OL. 2004. Tropical forests and global atmospheric change: a synthesis. Philosophical Transactions of the Royal Society of London. Series B: Biological Sciences, 359: 549-555.

Malhi Y, Wright J. 2004. Spatial patterns and recent trends in the climate of tropical rainforest regions. Philosophical Transactions of the Royal Society of London, 359: 311-329.

Markesteijn L, Poorter L, Bongers F, Paz H, Sack L. 2011. Hydraulics and life history of tropical dry forest tree species: coordination of species' drought and shade tolerance. New Phytol, 191: 480-95.

Marraccini P, Vinecky F, Alves GS, Ramos HJ, Elbelt S, Vieira NG, Carneiro FA, Sujii PS, Alekcevetch JC, Silva VA, DaMatta FM, Ferrao MA, Leroy T, Pot D, Vieira LG, da Silva FR, Andrade AC. 2012. Differentially expressed genes and proteins upon drought acclimation in tolerant and sensitive genotypes of Coffea canephora. $J$ Exp Bot, 63: 4191-212.

Marshall DR, Jain SK. 1968. Phenotypic Placticity of Avena fatua and A. barbata. The American Naturalist, 102: 457-467.

Martins MQ, Rodrigues WP, Fortunato AS, Leitão AE, Rodrigues AP, Pais IP, Martins LD, Silva MJ, Reboredo FH, Partelli FL, Campostrini E, Tomaz MA, ScottiCampos P, Ribeiro-Barros AI, Lidon FJC, DaMatta FM, Ramalho JC. 2016. Protective Response Mechanisms to Heat Stress in Interaction with High [CO2] Conditions in Coffea spp. Frontiers in Plant Science, 7.

Masih I, Maskey S, Mussá FEF, Trambauer P. 2014. A review of droughts on the African continent: a geospatial and long-term perspective. Hydrology and Earth System Sciences, 18: 3635-3649.

Matete N, BakamaNume B. 2010. Climate of Uganda. In: BakamaNume B, ed. In Contemporary Geography of Uganda. Dares salaam: Mkuku Na Nyota.

Maxted N, Ford-Lloyd BV, Jury S, Kell S, Scholten M. 2006. Towards a definition of a crop wild relative. Biodiversity and Conservation, 15: 2673-2685.

McGill BJ, Enquist BJ, Weiher E, Westoby M. 2006. Rebuilding community ecology from functional traits. Trends in Ecology and Evolution, 21: 178-185.

Mckay JK, Richards JH, Mitchell-Olds T. 2003 Genetics of drought adaptation in Arabidopsis thaliana: I. Pleiotropy contributes to genetic correlations among ecological traits. Molecular Ecology $121137-1151$.

Medrano H, Tomás M, Martorell S, Flexas J, Hernández E, Rosselló J, Pou A, Escalona J-M, Bota J. 2015. From leaf to whole-plant water use efficiency (WUE) in complex canopies: Limitations of leaf WUE as a selection target. The Crop Journal, 3: 220-228.

Meinzer FC, Goldstein G, Grantz DA. 1990. Carbon isotope discrimination in coffee genotypes grown under limited water supply. Plant Physiology, 92: 130-135.

Meinzer FC, Ingamells JL, Crisosto C. 1991. Carbon Isotope Discrimination Correlates with Bean Yield of Diverse Coffee Seedling Populations. HORTSCIENCE, 26: 1413-1414.

Meinzer FC, Saliendra NZ, Crisosto CH. 1992. Coffee Carbon Isotope Discrimination and Gas Exchange during adjustment to different soil moisture regime. Plant Physiology 171-84.

Menezes-Silva PE, Cavatte PC, Martins SCV, Reis JV, Pereira LF, Ávila RT, Almeida AL, Ventrella MC, DaMatta FM. 2015. Wood density, but not leaf hydraulic architecture, is associated with drought tolerance in clones of Coffea canephora. Trees, 29: 1687-1697.

Merot-l'Anthoene V, Tournebize R, Darracq O, Rattina V, Lepelley M, Bellanger L, Tranchant-Dubreuil C, Coulee M, Pegard M, Metairon S, Fournier C, Stoffelen P, Janssens SB, Kiwuka C, Musoli P, Sumirat U, Legnate H, Kambale JL, Ferreira da Costa Neto J, Revel C, de Kochko A, Descombes P, Crouzillat D, Poncet V. 2019. 
Development and evaluation of a genome-wide Coffee $8.5 \mathrm{~K}$ SNP array and its application for high-density genetic mapping and for investigating the origin of Coffea arabica L. Plant Biotechnology Journal, 17: 1418-1430.

Millard E. 2017. Value creation for smallholders and SMEs in commodity supply chains. . Enterprise Development and Microfinance

Moat J, Williams J, Baena S, Wilkinson T, Gole TW, Challa ZK, Demissew S, Davis AP. 2017. Resilience potential of the Ethiopian coffee sector under climate change. Nat Plants, 3: 17081.

Mofatto LS, Carneiro Fde A, Vieira NG, Duarte KE, Vidal RO, Alekcevetch JC, Cotta MG, Verdeil JL, Lapeyre-Montes F, Lartaud M, Leroy T, De Bellis F, Pot D, Rodrigues GC, Carazzolle MF, Pereira GA, Andrade AC, Marraccini P. 2016. Identification of candidate genes for drought tolerance in coffee by high-throughput sequencing in the shoot apex of different Coffea arabica cultivars. BMC Plant Biol, 16: 94.

Moncada P, McCouch S. 2004. Simple sequence repeat diversity in diploid and tetraploid Coffea species. Genome 47: 501-509.

Monclus R, Dreyer E, Villar M, Delmotte FM, Delay D, Petit JM, Barbaroux C, Le Thiec D, Brechet C, Brignolas F. 2006. Impact of drought on productivity and water use efficiency in 29 genotypes of Populus deltoides x Populus nigra. New Phytol, 169: 76577.

Montagnon C, Leroy T, Eskes AB. 1998. Varietal improvement of Coffea canephora-II. Breeding programmes and their results.

Montagnon C, Leroy T, Yapo A. 1992. Diversité génotypique et phénotypique de quelques groupes de caféiers (Coffea canephora Pierre) en collection; conséquences sur leur utilisation en sélection. Café, Cacao,Thé (Francia), 36: 187-198.

Mote PW, Salathé EP. 2010. Future climate in the Pacific Northwest. Climatic Change, 102: 29-50.

Musoli P, Cubry P, Aluka P, Billot C, Dufour M, De Bellis F, Pot D, Bieysse D, Charrier A, Leroy T. 2009a. Genetic differentiation of wild and cultivated populations: diversity of Coffea canephora Pierre in Uganda. Genome, 52: 634-46.

Musoli PC, Kangire A, Leroy T, Nabaggala A, Nakendo S, Olal S, Ochugo J, Kabole C, Pande J, Cila C, Charrier A, Bieysse D, Ogwang JA, Kyetere DT. 2009b. Towards a variety resistant to coffee wilt disease (CWD): A case for robusta coffee (Coffea canephora) in Uganda. 22nd International Conference on Coffee Science (ASIC). Campinas, SP, Brazil ASIC.

Nei M. 1972. Genetic distance between populations. The American Naturalist, 106: 283-292.

NEMA. 2009. Uganda: atlas of our changing environment. Kampala, Uganda National Environment Management Authority (NEMA).

Ngugi K, Aluka P. 2019. Genetic and phenotypic diversity of robusta coffee (Coffea canephora L.). Caffeinated and Cocoa Based Beverages, 8: 89-130.

Nicotra AB, Atkin OK, Bonser SP, Davidson AM, Finnegan EJ, Mathesius U, Poot P, Purugganan MD, Richards CL, Valladares F, van Kleunen M. 2010. Plant phenotypic plasticity in a changing climate. Trends in Plant Science, 15: 684-692.

Nielsen R. 2005. Molecular signatures of natural selection. Annu Rev Genet, 39: 197-218.

Niinemets U. 2001. Global-scale climatic controls of leaf dry mass per area, density, and thickness in trees and shrubs. Ecology 82 453-469

Nosenko T, Bondel KB, Kumpfmuller G, Stephan W. 2016. Adaptation to low temperatures in the wild tomato species Solanum chilense. Mol Ecol, 25: 2853-69. 
Nunes FN, Barros NF, Novais RFd, Silva IRd, Stape JL. 2016. Carbon isotope discrimination and differential drought tolerance in eucalypt clones. Scientia Forestalis, 44.

Nyakaana S. 2007 Microgeographical genetic structure of forest robusta coffee (Coffea canephora Pierre) in Kibale National Park Uganda. African Journal of Ecology 71-75.

Oksanen J, Blanchet FG, Friendly M, Kindt R, Legendre P, McGlinn D, Minchin PR, O'Hara RB, Simpson GL, Solymos P, Stevens MHH, Szoecs E, Wagner H. 2018. vegan: Community Ecology Package. R package version 2.5-2.

Oleksyn J, Tjoelker MG, Reich PB. 1998. Adaptation to Changing Environment in Scots Pine Populations across a Latitudinal Gradient. Silva Fennica 32: $129-140$.

Ouédraogo D-Y, Mortier F, Gourlet-Fleury S, Freycon V, Picard N, Turnbull M. 2013. Slow-growing species cope best with drought: evidence from long-term measurements in a tropical semi-deciduous moist forest of Central Africa. Journal of Ecology, 101: 1459-1470.

Ovalle-Rivera O, Läderach P, Bunn C, Obersteiner M, Schroth G. 2015. Projected shifts in Coffea arabica suitability among major global producing regions due to climate change. PloS one, 10: $\mathrm{e} 0124155$.

Pallardy SG, Kozlowski TT. 1981. Water relations of populus clones. Ecology, 62: 159-169.

Palmroth S, Berninger F, Nikinmaa E, Lloyd J, Pulkkinen P, Hari P. 1999. Structural adaptation rather than water conservation was observed in Scots pine over a range of wet to dry climates. Oecologia, 121: 302-309.

Parry M, Parry ML, Canziani O, Palutikof J, Van der Linden P, Hanson C. 2007. Climate Change 2007- Impacts, adaptation and vulnerability: Working Group II contribution of to the fourth assessment the IPCC. Cambridge, United Kingdom: Cambridge University Press.

Peakall R, Smouse PE. 2012. GenAlEx 6.5: genetic analysis in Excel. Population genetic software for teaching and research--an update. Bioinformatics, 28: 2537-9.

Pegard M, De Kochko A, Merot-L'anthoene V, Tranchant C, Rigoreau M, Bellanger L, Legnate H, Amoncho A, Akaffou S, Musoli P, Manel S, Crouzillat D, Poncet V. 2014. Genetic diversity of Coffea canephora and selection of genotypes potentially resilient to climatic changes. 25th International Conference on Coffee Science Armenia (Colombia).

Peuke AD, Schraml C, Hartung W, Rennenberg H. 2002. Identification of drought-sensitive beech ecotypes by physiological parameters. New Phytologist, 154: 373-387.

Piacenza C. 2012. Negotiating gendered property relations over land: oil palm expansion in Kalangala district, Uganda.

Pigliucci M. 2005. Evolution of phenotypic plasticity: where are we going now? Trends in Ecology and Evolution, 20: 481-486.

Pinheiro HA, Damatta FM, Chaves AR, Loureiro ME, Ducatti C. 2005. Drought tolerance is associated with rooting depth and stomatal control of water use in clones of Coffea canephora. Ann Bot, 96: 101-8.

Pinheiro HA, DaMatta FM, Chaves ARM, Fontes EPB, Loureiro ME. 2004. Drought tolerance in relation to protection against oxidative stress in clones of Coffea canephora subjected to long-term drought. Plant Science, 167: 1307-1314.

Pinheiro J, Bates D, DebRoy S, Sarkar D. 2019. R Core Team. 2019. nlme: linear and nonlinear mixed effects models. R package version 3.1-141. Available at $h$ Ttp://CRAN. R-Project. Org/Package $=$ Nlme.

Pironon S, Etherington T, R., Borrell J, S., Nicola K, Macias-Fauria M, Ondo I, Tovar C, Wilkin P, Willis K, J. . 2019. Potential adaptive strategies for 29 sub-Saharan crops under future climate change. Nature Climate Change 758-763 
Pitaa P, Soriab F, CanÄasb I, Tovalb G, Pardosa JA. 2001. Carbon isotope discrimination and its relationship to drought resistance under field conditions in genotypes

of Eucalyptus globulus Labill. Forest Ecology and Management, 141: 211- 221.

Plechakova O, Tranchant-Dubreuil C, Benedet F, Couderc M, Tinaut A, Viader V, De Block P, Hamon P, Campa C, de Kochko A, Hamon S, Poncet V. 2009. MoccaDB - an integrative database for functional, comparative and diversity studies in the Rubiaceae family. BMC Plant Biol, 9: 123.

Pohlan HAJ, Janssens MJJ. 2010. Growth and production of coffee.

Poncet V, Belzile F, Dufour M, Hamon P, Hamon S, de Kochko A, Leroy T. 2007. Development of genomic microsatellite markers in Coffea canephora and their transferability to other coffee species. Genome, 50: 1156-1161.

Poorter H. 1989. Interspecific variation in relative growth rate: on ecological causes and physiological consequences. Causes and consequences of variation in growth rate and productivity of higher plants, 24: 45-68.

Poorter H, Garnier E. 1999. Ecological significance of inherent variation in relative growth rate and its components. Handbook of functional plant ecology, 20: 81-120.

Poorter H, Niinemets Ü, Poorter L, Wright IJ, Villar R. 2009. Causes and consequences of variation in leaf mass per area (LMA): a meta-analysis. New Phytologist, 182: 565-588.

Poorter H, Remkes C. 1990. Leaf area ratio and net assimilation rate of 24 wild species differing in relative growth rate. Oecologia 83: 553 -559.

Poorter L. 1999. Growth responses of 15 rain-forest tree species to a light gradient: the relative importance of morphological and physiological traits. Functional Ecology 13: $396-$ 410.

Poorter L, Markesteijn L. 2008. Seedling Traits Determine Drought Tolerance of Tropical Tree Species. Biotropica, 40: 321-331.

Praxedes SC, DaMatta FM, Loureiro ME, G. Ferrão MA, Cordeiro AT. 2006. Effects of long-term soil drought on photosynthesis and carbohydrate metabolism in mature robusta coffee (Coffea canephora Pierre var. kouillou) leaves. Environmental and Experimental Botany, 56: 263-273.

Pritchard J, K., Stephens M, Donnelly P. 2000. Inference of Population Structure Using Multilocus Genotype Data. Genetics 945-959

Reed TE, Schindler DE, Waples RS. 2011. Interacting effects of phenotypic plasticity and evolution on population persistence in a changing climate. Conserv Biol, 25: 56-63.

Reich PB. 2014. The world-wide 'fast-slow' plant economics spectrum: a traits manifesto. Journal of Ecology, 102: 275-301.

Reich PB, Wright IJ, Cavender-Bares J, Craine JM, Oleksyn J, Westoby M, Walters MB. 2003. The evolution of plant functional variation: traits, spectra, and strategies International Journal of Plant Sciences 164: 143 - 164.

Richards PW, Frankham R, Walsh R. 1996. The tropical rain forest: an ecological study: Cambridge university press.

Rodrigues WP, Martins MQ, Fortunato AS, Rodrigues AP, Semedo JN, Simões-Costa MC, Pais IP, Leitão AE, Colwell F, Goulao L, Máguas C, Maia R, Partelli FL, Campostrini E, Scotti-Campos P, Ribeiro-Barros AI, Lidon FC, DaMatta FM, Ramalho José C. 2016. Long-term elevated air [CO2] strengthens photosynthetic functioning and mitigates the impact of supra-optimal temperatures in tropical Coffea arabica and C. canephora species. Global Change Biology, 22: 415-431.

Rungwattana K, Kasemsap P, Phumichai T, Kanpanon N, Rattanawong R, Hietz P, Timothy Paine CE. 2018. Trait evolution in tropical rubber (Hevea brasiliensis) trees is related to dry season intensity. Functional Ecology, 32: 2638-2651. 
Ryser P, Eek L. 2000. Consequences of phenotypic plasticity vs. interspecific differences in leaf and root traits for acquisition of aboveground and belowground resources. American Journal of Botany, 87: 402-411.

Sade N, Gebremedhin A, Moshelion M. 2012. Risk-taking plants: anisohydric behavior as a stress-resistance trait. Plant Signaling Behavior, 7: 767-770.

Samper LF, Giovannucci D, Vieira LM. 2017. The powerful role of intangibles in the coffee value chain: WIPO.

Savolainen O, Pyhäjärvi T, Knürr i. 2007. Gene Flow and Local Adaptation in Trees. Annual Review of Ecology, Evolution, and Systematics, 38 595-619.

Schiermeier Q. 2008. Water: a long dry summer. Nature 452: 270 - 273.

Schmid B. 1992. Phenotypic variation in plants. Evolutionary trends in plants, 6: 45-60.

Schmildt ER, Amaral JATD, Santos JS, Schmildt O. 2015. Allometric model for estimating leaf area in clonal varieties of coffee (Coffea canephora). Revista Ciência Agronômica, 46: $740-748$.

Sheffield J, Wood EF. 2008. Projected changes in drought occurrence under future global warming from multi-model, multi-scenario, IPCC AR4 simulations. Climate Dynamics, 31: 79-105.

Shipley B, Meziane D. 2002 The balanced-growth hypothesis and the allometry of leaf and root biomass allocation. Functional Ecology, 16: 326-331.

Siefert A, Violle C, Chalmandrier L, Albert CH, Taudiere A, Fajardo A, Aarssen LW, Baraloto C, Carlucci MB, Cianciaruso MV, de LDV, de Bello F, Duarte LD, Fonseca CR, Freschet GT, Gaucherand S, Gross N, Hikosaka K, Jackson B, Jung V, Kamiyama C, Katabuchi M, Kembel SW, Kichenin E, Kraft NJ, Lagerstrom A, Bagousse-Pinguet YL, Li Y, Mason N, Messier J, Nakashizuka T, Overton JM, Peltzer DA, Perez-Ramos IM, Pillar VD, Prentice HC, Richardson S, Sasaki T, Schamp BS, Schob C, Shipley B, Sundqvist M, Sykes MT, Vandewalle M, Wardle DA. 2015. A global meta-analysis of the relative extent of intraspecific trait variation in plant communities. Ecol Lett, 18: 1406-19.

Silva MdC, Várzea V, Guerra-Guimarães L, Azinheira HG, Fernandez D, Petitot A-S, Bertrand B, Lashermes P, Nicole M. 2006. Coffee resistance to the main diseases: leaf rust and coffee berry disease. Brazilian Journal of Plant Physiology, 18: 119-147.

Silva PEM, Cavatte PC, Morais LE, Medina EF, DaMatta FM. 2013. The functional divergence of biomass partitioning, carbon gain and water use in Coffea canephora in response to the water supply: Implications for breeding aimed at improving drought tolerance. Environmental and Experimental Botany, 87: 49-57.

Stearns SC. 1989. Trade-offs in life-history evolution. Functional Ecology 3: 259 -268.

Sterck F, Markesteijn L, Schieving F, Poorter L. 2011. Functional traits determine tradeoffs and niches in a tropical forest community. Proceedings of the National Academy of Sciences, 108: 20627-20632.

Sterck FJ, Poorter L, Schieving F. 2006. Leaf traits determine the growth-survival trade-off across rain forest tree species. The American Naturalist, 167: 758-765.

Sultan SE. 1987. Evolutionary implications of phenotypic plasticity in plants. Evolutionary biology: Springer.

Tavares PdS, Giarolla A, Chou SC, Silva AJdP, Lyra AdA. 2018. Climate change impact on the potential yield of Arabica coffee in southeast Brazil. Regional Environmental Change, 18: 873-883.

Taye KO. 2006. Ecophysiological diversity of wild Arabica coffee populations in Ethiopia Growth, water relations and hydraulic characteristics along a climatic gradient.

Team RC. 2018. R version 3.5. 0. $R$ : A language and environment for statistical computing. $R$ Foundation for Statistical Computing, Vienna, Austria. 
Tesfaye SG, Ismail MR, Ramlan MF, Marziah M, Kausar H. 2014. Effect of soil drying on rate of stress development, leaf gas exchange and proline accumulation in robusta coffee (Coffea Canephora Pierre Ex Froehner) Clones. Experimental Agriculture, 50: 458-479.

Tesfaye SG, Razi Ismail M, Kausar H, Marziah M, Ramlan MF. 2013. Plant water relations, crop yield and quality in coffee (Coffea arabica L.) as influenced by partial root zone drying and deficit irrigation. Australian Journal of Crop Science, 7(9): 13611368 .

Thoday JM. 1953. Components of fitness. Symposia of the Society for Experimental Biology, 7: 113.

Thomas AS. 1935. Types of robusta coffee and their selection in Uganda. The East African Agricultural Journal 1: 193-197.

Thomas AS. 1944. The wild coffee of Uganda. Emp. J. Exp. Agric., 12: 1-12.

Tienderen PHV. 1997. Generalists, specialists, and the evolution of phenotypic plasticity in sympatric populations of distinct species. Evolution, 51: 1372-1380.

Torang P, Wunder J, Obeso JR, Herzog M, Coupland G, Agren J. 2015. Large-scale adaptive differentiation in the alpine perennial herb Arabis alpina. New Phytol, 206: 459-70.

UCDA. 2015. Corporate Plan 2015/16 - 2017/18. Kampala: Uganda Coffee Development Authority.

UCDA. 2017a. 25 years of empowering lives; Uganda Coffee Developement Authority. Kampala, Uganda.

UCDA. 2017b. Annual Report 2016/17. Kampala: Uganda Coffee Development Authority.

Valladares F, Balaguer L, Martinez-Ferri E, Perez-Corona E, Manrique E. 2002 Plasticity, instability and canalization: is the phenotypic variation in seedlings of sclerophyll oaks consistent with the environmental unpredictability of Mediterranean ecosystems? New Phytologist 156: 457 - 467.

Valladares F, Gianoli E, Gomez JM. 2007. Ecological limits to plant phenotypic plasticity. New Phytolologist, 176: 749-763.

Valladares F, Sanchez-Gomez D, Zavala MA. 2006. Quantitative estimation of phenotypic plasticity: bridging the gap between the evolutionary concept and its ecological applications. Journal of Ecology, 94: 1103-1116.

Valladares F, Wright J, Lasso E, Kitajima K, Pearcy RW. 2000. Plastic phenotypic response to light of 16 congeneric shrubs from a panamanian rainforest. Ecology, 81 1925-1936.

van Kleunen M, Fischer M. 2005. Constraints on the evolution of adaptive phenotypic plasticity in plants. New Phytologist, 166: 49-60.

van Kleunen M, Fischer M, Schmid B. 2000. Costs of plasticity in foraging characteristics of the clonal plant Ranunculus reptans. Evolution, 54: 1947-1955.

Veenendaal EM, Swaine MD, Blay D, Yelifari NB, Mullins CE. 1996. Seasonal and longterm soil water regime in West African tropical forest. Journal of Vegetation Science 7: 473-482.

Verhage FYF, Anten NPR, Sentelhas PC. 2017. Carbon dioxide fertilization offsets negative impacts of climate change on Arabica coffee yield in Brazil. Climatic Change, 144: 671-685.

Vieira NG, Carneiro FA, Sujii PS, Alekcevetch JC, Freire LP, Vinecky F, Elbelt S, Silva VA, DaMatta FM, Ferrão MAG, Marraccini P, Andrade AC. 2013. Different Molecular Mechanisms Account for Drought Tolerance in Coffea canephora var. Conilon. Tropical Plant Biology, 6: 181-190.

Vos J, Groenwold J. 1989. Genetic differences in water-use efficiency, stomatal conductance and carbon isotope fractionation in potato. Potato Research 32 113-121. 
Warschefsky E, Penmetsa RV, Cook DR, von Wettberg EJ. 2014. Back to the wilds: tapping evolutionary adaptations for resilient crops through systematic hybridization with crop wild relatives. Am J Bot, 101: 1791-800.

Warton DI, Weber NC. 2002. Common slope tests for bivariate errors-in-variables models. Biometrical Journal 44: 161-174.

Waseem M, Ali A, Tahir M, Nadeem MA, Ayub M, Tanveer A, Ahmad R, Hussain M. 2011. Mechanism of drought tolerance in plant and its management through different methods. Continental J. Agricultural Science 5: 10 - 25.

Weraduwage SM, Chen J, Anozie FC, Morales A, Weise SE, Sharkey TD. 2015. The relationship between leaf area growth and biomass accumulation in Arabidopsis thaliana. Frontiers in Plant Science, 6: 167.

Willson K. 1999. Coffee, cocoa and tea. Wallingford: CAB International.

Wintgens JN. 2004. Coffee: growing, processing, sustainable production, A guidebook for growers, processors, traders, and researchers. Weinhein, Alemania: WILEY-VCH Verlag GmbH \& Co. KGaA.

Wright IJ, Reich PB, Westoby M, Ackerly DD, Baruch Z, Bongers F, Cavender-Bares J, Chapin T, Cornelissen JHC, Matthias D, Flexas J, Garnier E, Groom PK, Gulias J, Hikosaka K, Lamont BB, Lee T, Lee W, Lusk C, Midgley JJ, Navas M-L, Niinemets Ul, Oleksyn J, Osada N, Poorter H, Poot P, Prior L, Pyankov VI, Roumet C, Thomas SC, Tjoelker MG, Veneklaas EJ, Villar R. 2004. Worldwide leaf economics spectrum. Nature $\mathbf{4 2 8}$.

Wright S. 1965. The interpretation of population structure by F-statistics with special regard to systems of mating. Evolution: 395-420.

Zhou Y, Zhang L, Liu J, Wu G, Savolainen O. 2014. Climatic adaptation and ecological divergence between two closely related pine species in Southeast China. Mol Ecol, 23: 3504-22.

Zomer RJ, Trabucco A, Bossio DA, Verchot LV. 2008. Climate change mitigation: A spatial analysis of global land suitability for clean development mechanism afforestation and reforestation. Agriculture, Ecosystems \& Environment, 126: 67-80.

Zullo J, Pinto HS, Assad ED, de Ávila AMH. 2011. Potential for growing Arabica coffee in the extreme south of Brazil in a warmer world. Climatic Change, 109: 535-548.

Zuur A, Ieno EN, Walker N, Saveliev AA, Smith GM. 2009. Mixed effects models and extensions in ecology with R. New York Springer Science and Business Media. 
Summary 
Uganda is the $10^{\text {th }}$ and second largest coffee producer in the world and in Africa, respectively. Uganda predominantly (95\%) exports all its coffee and the sector contributes total annual earnings worth 350- 400 million USD an amount substantially important to national development. Like other coffee producing countries, the sustainability of Uganda's coffee sector is being threatened by the adverse effects of climate change, e.g., increasing temperatures and erratic precipitation patterns, leading to more frequent and severe drought episodes. The vulnerability of Uganda's coffee production systems to effects of climate change directly affects the livelihoods of 1.7 million smallholder farmers whose capacity to adapt their farms to environmental stresses is constrained by poverty. For instance, in case of severe droughts, these farmers have no financial capacity to establish adaptive strategies like irrigation facilities. One way to enhance farmers capacity to sustain coffee production in the face of the adverse effects of climate change is to avail them climate resilient varieties. Development of climate resilient varieties is a long-term strategy which most times entails exploration of the available genetic diversity and its functional importance in relation to the stress factor.

Of the three (Coffea arabica, Coffea canephora and Coffea liberica) commercially important coffee species, Uganda's coffee sector is mainly sustained by Coffea canephora Pierre ex A. Froehner. C. canephora is native to Uganda's tropical moist wild forests and these forests occur in comparatively distinct climatic zones. This presents opportunities for adaptation of the species to variable and different, prevailing environmental conditions. To avail information about the genetic diversity of Uganda's $C$. canephora and its differential response to drought stress, three major studies were conducted and presented in this thesis. Since genetic diversity is the basis for plants adaptability to abiotic and biotic stress and for crop improvement, chapter 2 of this thesis unravelled the genetic variation within and across Ugandan C. canephora diversity. Using 19 SSR markers, a total of 275 leaf samples, comprising wild (from seven different locations), feral and cultivated plant material, were genotyped to assess the genetic diversity within Ugandan C. canephora material. We also explored the link between allelic variation and the environmental variables. Results showed that Uganda's $C$. canephora Ugandan C. canephora diversity was revealed to be geographically structured into the four groups in the North western region (NW) and one group in the Southcentral region (SC). We observed that the SC group is genetically mixed comprising cultivated and wild populations from Malabigambo, Mabira, Kalangala. All the elite (recommended coffee wilt resistant and high yielding genotypes) were genetically similar to the material in the SC group. The NW group (especially Zoka) contained unique diversity which may be useful 
for C. canephora improvement. We also showed that twelve environmental variables significantly explained $16.3 \%$ of the total allelic variation across populations implying that populations could be adapted to the existing environmental gradient.

In our second study (Chapter 3) we explored the differential response of the diversity to drought stress. Using a large scale screening experiment, involving 148 genotypes from the seven native habitats, feral and cultivated C. canephora. Twenty-months-old coffee plants were subjected to two water treatments: (i) ample and (ii) restricted water for four months. We assessed biomass allocation, standing leaf area and leaf area growth for plant material across (i) levels of cultivation status, (ii) genetic groups and (iii) locations. Responses to restrictedwater treatment that differed substantially across locations (e.g., reductions in relative growth rate in leaf area [RGRA] ranged from $7.1-36.7 \%)$ and across genetic groups $(3.2-32.5 \%)$. However, no statistically significant differences were observed across levels of cultivation status. We also observed a growth-tolerance trade-off whereby RGRA under ample-water was negatively correlated to tolerance in RGRA to restricted-water. This finding implies that breeding efforts towards drought tolerance should focus on weakening the link between tolerance and poor performance of genotypes in favourable conditions. We also identified a possible link between drought tolerance and wetness of the local climate of the genotypes, a finding which suggests that Uganda's $C$. canephora seems to be locally adapted to climate.

Plasticity is commonly valued as a beneficial strategy plants use to adapt to changes in their environmental conditions. In Chapter 4, we investigate, among others, whether trait plasticity contributes to drought tolerance within $C$. canephora diversity. In a green-house experiment, a subset was studied, comprising 15 genotypes (12 wild and three elite genotypes). The eight-months-old plants were subjected to ample and restricted-water conditions to further explore the phenotypic differences in response to differential water supply and the relationship between trait plasticity and drought tolerance. We observed substantial phenotypic variation across traits in both ample and restricted-water conditions; this finding indicates availability of functionally important genetic diversity in relation to drought stress. We also identified a tradeoff between trait plasticity and tolerance implying that plasticity may not be beneficial for $C$. canephora during comparatively shorter drought spells or intermittent environmental conditions. Evidence of the trade-off between trait plasticity and drought tolerance could suggest difficulty of the plant's plastic phenotypic changes to track the frequent variation in environmental conditions and thus failure to develop the suitable phenotype to enhance its fitness. In Chapter 4, we also investigated the relationship between water use efficiency (WUE) 


\section{Summary}

and carbon isotope abundances discrimination at both leaf (WUEi) and plant (WUEp) level. We observed significant positive correlations between WUEi and carbon isotope signatures in both ample and restricted-water conditions, and significant positive correlations between WUE and carbon isotope signatures plant level under only ample water conditions but a statically non-significant positive relation for plants under restricted-water conditions. The trends between $\delta^{13} \mathrm{C}$ and WUE observed in this thesis suggest that, like in other crop species, $\delta^{13} \mathrm{C}$ can be used as a proxy for WUEi in both ample and restricted-water conditions, and WUEp in only ample-water conditions to ease the process of selecting superior genotypes in C. canephora improvement studies. However, there is need to explore and optimise the dynamics associated with upscaling the relationship between $\delta^{13} \mathrm{C}$ and WUE from leaf to plant level particularly under drought stress conditions

In conclusion, the findings from this thesis show that Uganda has substantial genetic diversity and phenotypic variation within C. canephora in relation to drought stress. We observed that some diversity, e.g. material from Zoka, may contain useful genetic diversity for developing drought tolerant cultivars. The phenotypic and genotypic variation in relation to drought stress is an important output of this thesis, and the data can be further utilised to conduct association studies to advance our understanding, especially the identification of putatively drought adapted genotypes. Conducting gene expression experiments on our study material will also support our understanding of the molecular mechanisms and their mediating effect on phenotypic responses to drought. We recommend special conservation of Uganda's wild $C$. canephora populations to have a source of genes possibly allowing for breeding for tolerance to environmental stresses. Identification of growth-tolerance and plasticity-tolerance trade-offs in this thesis, may inform $C$. canephora breeders about the best mechanisms to target as they work towards developing drought tolerant varieties. 
Samenvatting 


\section{Samenvatting}

Oeganda is de 10e grootste koffieproducent van de wereld en de op één grootste producent in Afrika. Het land exporteert het grootste deel (95\%) van deze koffie naar het buitenland en dit levert jaarlijkse netto-inkomsten van 350-450 miljoen Amerikaanse dollars. Deze inkomsten zijn van groot belang voor de ontwikkeling van het land. Net als bij andere koffieproducerende landen, wordt de koffiesector in Oeganda echter bedreigt door de negatieve effecten van klimaatverandering, waaronder stijgende temperaturen, en het steeds wisselvalliger wordende regenvalpatroon, waarbij periodes van droogte steeds vaker optreden. De kwetsbaarheid van de Oegandese koffiesector voor de effecten van klimaatverandering kan op zijn beurt een grote negatieve invloed hebben op het levensonderhoud van de 1,7 miljoen voornamelijk kleinschalige, arme boeren, die de Oegandese koffie produceren en die niet over de middelen beschikken om hun teelt aan klimaatverandering aan te passen. Zo zijn ze bijvoorbeeld meestal niet in staat om bij het optreden van droogte te irrigeren. Eén van de manieren om koffieboeren bestendiger te maken voor klimaatveranderingen is om ze de beschikking te geven over klimaat veerkrachtige koffievariëteiten. Het ontwikkelen van dat soort koffievariëteiten kost tijd en vereist een verkenning van beschikbare genetische diversiteit en de relatie hiervan met stressfactoren zoals droogte.

Van de drie commercieel gebruikte koffie soorten (Coffea arabica, C. canephora en C. liberica) wordt Coffea canephora Pierre ex A. Froehner in Oeganda het meest geteeld. $C$. canephora komt van nature in Oeganda 's natte tropische bossen die zich in verschillende klimatologische zones bevinden. Het is daarom goed mogelijk dat de verschillende populaties zich aan lokale klimaatomstandigheden hebben aangepast. Om een beter beeld te krijgen van genetisch diversiteit van de Oegandese C. canephora en mogelijke genetische verschillen in responsen op klimaatfactoren, zijn in deze dissertatie een drietal studies uitgevoerd. In hoofdstuk 2 werd de genetische variatie binnen en tussen Oegandese $C$. canephora populaties onderzocht omdat deze genetische variatie de basis vormt voor het aanpassingsvermogen aan klimaatverandering. Met behulp van 19 SSR markers werden bladeren van 275 wilde (uit zeven verschillende boslocaties), verwilderde en gecultiveerde planten gegenotypeerd. Hierbij werd ook de relatie tussen de allelische variatie en omgevingsvariabelen bekeken. De resultaten gaven aan dat de Oegandese $C$. canephora populaties in vier genetische groepen kunnen worden opgedeeld waarvan zich er drie in noordwestelijke regio (NW-groep) bevinden en één in de centraal zuidelijke regio (SC-groep, naar het Engelse 'South Central'). In de SC regio, was er een sterke genetische vermenging tussen de wild populaties uit de bossen in Malabigambo, Mabira en Kalangala en het gecultiveerde materiaal. Al de zgn. elite variëteiten (variëteiten die 
vanwege hun hoge opbrengst en ziekteresistentie aanbevolen worden) bleken genetisch zeer verwant te zijn aan de wilde planten in de SC-groep. De NW-groep (vooral de planten uit het Zoka bos) bleek uniek genetisch materiaal te bevatten, dat van nut zou kunnen zijn in C. canephora veredelingsprogramma's. Verder bleek dat 16,3\% van de allelische variatie tussen de wilde populaties verklaart kon worden door zeven omgevingsvariabelen, hetgeen impliceert dat deze populaties zich aan de lokale milieuomstandigheden hebben aangepast.

In de tweede studie (hoofdstuk 3) werd onderzocht hoe de verschillende populaties reageren op droogtestress. Dit werd gedaan met behulp van een zgn. screening experiment met 148 wilde, verwilderde en gecultiveerde genotypes. Twintig maand oude koffieplanten kregen hierbij een behandeling met ruim voldoende water (ample-water) of een behandeling waarbij vier maanden lang veel minder water werd gegeven (restricted-water). Vervolgens, werd de biomassa allocatie, het totale bladoppervlak, en de aangroei van bladoppervlak gemeten en er werd geanalyseerd in hoeverre dit gerelateerd kon worden aan; (i) of de planten wild of verwilderd waren, of gecultiveerd werden; (ii) genetische groepen en (iii) locaties. Responsen op de restricted-water behandeling verschilde enorm tussen locaties (reducties in relatieve bladoppervlaktegroei [RGRA] variërend tussen de 7,1 en 36,7\%) en tussen genetische groepen (RGRA reductie 3,2-32,5\%). De cultivatie status bleek echter geen significant effect te hebben op de droogterespons. Er bleek sprake te zijn van een negatieve relatie tussen groei en tolerantie; genotypes met een hoge RGRA in de ample-water behandeling ondervonden een grotere reductie in RGRA in restricted-water behandeling. Dit impliceert dat veredeling van koffie er op gericht moet zijn om deze negatieve relatie te doorbreken. Een interessante bevinding was verder dat genotypes uit drogere locaties gemiddeld ook droogte toleranter waren, hetgeen suggereert dat $C$. canephora populaties in Oeganda zich enigszins aan het lokale klimaat aan kunnen passen.

Fenotypische plasticiteit wordt over het algemeen gezien als een belangrijke strategie waarmee planten zich aan kunnen passen aan veranderingen in omgevingsfactoren. In de derde studie (hoofdstuk 4) onderzochten we daarom o.a. in welke mate plasticiteit in eigenschappen kan bijdragen droogte tolerantie in C. canephora. Hiertoe werden acht maanden oude planten van 15 genotypes in een kas experiment blootgesteld aan een ample-water of een restrictedwater behandeling. De mate van plasticiteit in verschillende eigenschappen bleek substantieel te verschillen tussen de genotypes, wat de functionele diversiteit in de Oegandese $C$. canephora onderschrijft. Een interessante bevinding was dat er een negatieve relatie bleek te zijn tussen 


\section{Samenvatting}

de mate van plasticiteit en droogte tolerantie. Dit impliceert dat een hoge mate van plasticiteit in response op variatie in een omgevingsfactor niet gunstig is als deze factor vaak varieert. Een mogelijke verklaring hiervoor is dat zeer plastische planten sterk zullen reageren als er een periode van hoge waterbeschikbaarheid is, maar als het vervolgens droog wordt hebben deze planten vervolgens de verkeerde eigenschappen om met droogte om te gaan. In hoofdstuk 4 werd ook onderzocht in hoeverre er een relatie tussen de koolstofisotoop discriminatie $\left(\delta^{13} \mathrm{C}\right)$ en het watergebruik efficiëntie op blad- (leaf water-use efficiency WUEi) en plant (plant wateruse efficiency WUEp) niveau. In beide behandelingen was er sterk positief verband tussen $\delta^{13} \mathrm{C}$ en WUEi, maar de relatie met WUEp was alleen significant in de ample-water behandeling. Duidelijk is dat de toepassing van $\delta^{13} \mathrm{C}$ als indicator van watergebruik efficiëntie nog meer onderzoek vereist.

Concluderend, de resultaten van deze dissertatie laten zien dat de Oegandese $C$. canephora genetisch zeer divers is en een hoge mate van fenotypische variatie in relatie met droogtestress vertoont. Een deel van het Oegandese materiaal, en vooral het materiaal uit Zoka, is in potentie geschikt als basis voor het ontwikkelen van droogte tolerante variëteiten. De data uit deze dissertatie kunnen in de toekomst gebruikt worden voor zgn. associatie studies, waarbij allelische variatie veel concreter aan fenotypische eigenschappen zoals droogtetolerantie wordt gekoppeld. Verder kunnen metingen van genexpressie een beter beeld geven van de mechanismen waarmee deze plantensoort reageert op droogte. Het is daarom van groot belang dat de wilde $C$. canephora populaties beter beschermd worden. Dit kan zowel in situ, door betere bescherming en beheer van de bossen waarin ze groeien als ex-situ door het in deze dissertatie verzamelde plantenmateriaal goed te beheren. De in deze dissertatie gevonden negatieve relaties tussen droogte tolerantie aan de ene kant en groei en plasticiteit aan de andere, is belangrijke kennis voor veredelaars bij het vaststellen van hun veredelingsdoelen. 
Acknowledgements 
In line with an African proverb that says, "it takes a village to raise a child", it has taken almost the world for me to accomplish this PhD journey! It all started when my employer, the National Agricultural Research Organisation (NARO) of Uganda called for $\mathrm{PhD}$ study concepts in effort to build capacity of its scientists. I thus sent an email to Prof. Dr. Paul Struik of the Centre for Crop Systems Analysis, Wageningen University and Research who then linked me to Prof. Dr. Niels Anten with whom we have worked throughout my PhD trajectory. Thank you, Prof. Dr. Paul Struik for the connection it was life changing!

Prof. Niels Anten, thank you so much for such invaluable support and guidance you offered me throughout my $\mathrm{PhD}$ journey. Your office was always open for me for any issue and you always told me "just let me know if there is anything you would like me to do for you". That was a great experience for me to hear such kind words and see acts of humility from a Professor! You always assisted me beyond my expectations. I appreciate the knowledge, expertise and the skills you employed to motivate me think about the implications of research outputs and other related scenarios. Thank you, Niels, for the prompt responses to my writeups and for the informative comments that enabled me to improve my writing skills and presentation of scientific findings. Niels, you also nurtured my sense and appreciation for collaboration by recommending me to consult and sometimes linking fellow PhDs and other scientists with expertise that I needed to resolve a couple of issues. Evidence to this is you linking me to, for example, Merel Jansen, my co-promotor Dr. Jan Vos, Dr. Aad van Ast, Dr. Bob Douma and Dr. Arnoud Boom. Niels, it has been such great pleasure working under your guidance and hoping that the future unveils more opportunities for further collaboration.

My co-promotor Dr Jan Vos thank you so much for being an exceptional supervisor. Your support regarding my $\mathrm{PhD}$ journey is quite challenging for me to write down in just a few sentences! You most times referred to me as "boss" just to nurture my confidence so I could develop into an independent researcher who is in-charge of her research activities. Jan, I appreciate all the sacrifices you took as you adjusted your schedule to endeavour that we hold meetings on a weekly basis. Your critical review and "sharp" comments helped me rethink and focus my phrases and their implications. Your sharp comments remind me of the follow-up emails in which you laboured to check whether the comments had emotionally drained me! Thank you, Jan, for I always feel lucky to have tapped into your wisdom and expertise. I hold profound memories of the invaluable support you offered me during the establishment and management of the study experiments. The supervisory visits you made to Uganda also provided opportunities for me to improve my plant growth monitoring skills. Jan, thanks too for not only being an academic supervisor but a counsellor in some cases. You gave me counsel 
that enabled me to communicate efficiently to my employers and other supervisors whenever I hit a snag during my $\mathrm{PhD}$ journey. Jan, thanks too for introducing me to your wonderful family. I cherish the dinners we had with your wonderful wife Ada, the stories you both shared with me and the site visits we had for me to cool off and to learn more about the Netherlands.

Dr. Pascal Musoli, you have been one of my supervisors and through your guidance and knowledge as a coffee breeder, I managed to improve my $\mathrm{PhD}$ study concept. Thanks, for saving time to review my write-ups, guide my field explorations and guidance as I executed my large screening experiment in Uganda. You pay attention to details and thank you for correcting all the mistakes. Dr. Musoli, thanks for widening my network by linking to me Dr. Valerie Poncet and the entire Research Institute for Development (IRD-France) team, the National Coffee Research Institute (NaCORI- Uganda) and the Uganda Coffee Development Authority (UCDA). With such networks we were able to source extra funding that we needed to conduct my PhD activities. Dr. Emmanuel Lyamulemelye, thanks so much for partially supporting my experimental work and the few times we interacted are much appreciated.

Dr. Valerie Poncet, thank you for accepting to be my co-promoter and your guidance regarding the molecular aspects of my $\mathrm{PhD}$ is much appreciated. Thanks for the support that enabled secure us extra funding from Capes Agropolis foundation that covered my molecular related activities. I thus thank the Capes Agropolis foundation for the support. Valerie, thanks too for linking me to the IRD, Nestle and Embrapa family e.g. Dr. Alexandre de Kochko, Dr. Dominique Crouzillat, Dr Alan Andrade and Ms. Laurence Bellanger with whom we worked to appreciate the genetic variation of Uganda's Robusta coffee in comparison to other known genetic groups. Valerie, working with you added much value to my $\mathrm{PhD}$ study program and it also set the stage for future projects. I also thank Dr. Alexandre de Kochko, Dr. Dominique Crouzillat, Dr Alan Andrade, Dr. Sinara O. de Aquino and Ms. Laurence Bellanger and for their support in various activities related to my $\mathrm{PhD}$.

Dr Aad van Ast, you are a true definition of a kind, well-structured and humorous person. Always willing to transfer his knowledge and practical skills in experimental research in an amusing mode. Aad you always took an extra mile to see that I was comfortable in all spheres of life. You periodically donated warm clothes, gloves, pans etc. and helped me with a couple of administrative issues. Working with you enabled me to appreciate the importance of structure in executing any task most especially research and experimental work. Thanks for the feedback you provided on my write-ups. Aad, thanks too for opening the doors to your wonderful family, I hold fond memories of your wife Ans preparing dinners for me and the sweet stories of how your family had grown. 
Dr. Bob Douma, your expertise in statistics and guidance in how best to: design my second experiment, analyse and interpret data from both experiments is much more appreciated. Bob, from you I learnt how to be comfortable with error messages from R statistical software and this helped me build courage to learn and use the software more efficiently. Bob, thanks too for providing feedback on all my manuscripts.

With pleasure I sincerely appreciate CSA staff members for supporting my stay at Wageningen University. Being part of a hardworking, focused, friendly and active group helped reorient my approach to scientific research. In CSA, I met a team of people, diverse in so many ways but strongly united to deliver through sound scientific research. Special thanks to CSA administrators, in you I found an exceptional team and I feel quite indebted to you! Thanks, so much Ms. Sjanie van Wetten, Ms. Nicole Wolffensperger, Mr. Alex-Jan De Leeuw, and Ms Petra Rozema-Hoekerd. Sjanie, your empathy and inspirational encounters motivated me to keep pursuing the bumpy $\mathrm{PhD}$ path. Nicole, thanks for sharing the tips regarding thesis compilation and the support in other administrative. Petra, I met you in the last phase of my $\mathrm{PhD}$, but our interactions were always memorable. Thanks for the words of encouragement. Alex-Jan, with pleasure I appreciate your effort in handling my financial related issues and words of encouragement whenever we meet during the Thursday monthly drinks.

In CSA, I met and freely interacted with several PhD's and PhD candidates: Dr. Herman Berghuijs, thanks too for all the help in some statistical issues, site visits, nature walks, lunches and dinners we had! Herman, thanks so much for all the support and always going an extra mile to solve my PhD related issues. I tapped into your love for mathematics to resolve issues in my analyses. They were refreshing and memorable. Peter and the unifarm team thanks too for all the help you offered during and after experiments. Dr. Alejandro Morales Sierra, thanks too for the counsel and guidance you provided during our gas exchange studies. Thanks too for the informative comments you provided in that manuscript. Luuk; thanks so much for the moral support and ensuring that I balance work with the exciting CSA drinks moments. Ambra, Asante, Ali, Wang, Lucette, Isreal, Robbert, Morales, Gou Fang, Herman, with whom we shared experiences and addressed challenges.

PE\&RC, Dr. Claudius van de Vijver and Dr. Lennart Suselbeek thanks so much for the support and encouragement and guidance during my $\mathrm{PhD}$ journey. Thanks for all the interactive and holistic PhD courses you organized. I was empowered and admired the mode of delivery of most $\mathrm{PhD}$ short courses. I appreciate the fun, tips and counsel you provided during the $\mathrm{PhD}$ weekends. 
I specially appreciate the support from MSc and Bsc students who were involved in this PhD project: Ms. Eva Goldsmith, Ms. Ludovica Neffri, Mr. Johan Simon, Ms. Daisy Johnson and Mr. Gabriel Alele. Thank you for choosing to study and support some aspects of my $\mathrm{PhD}$ study. Your contribution quickened my $\mathrm{PhD}$ study trajectory and best wishes in your careers.

Amazing Redeemed church Wageningen church: Pastor Farai and Busi Maphosa and the entire pastoral and leadership team, thanks so much for nourishing my soul. I always related with the sermons and the activities we had during my stay in Wageningen. I am so grateful to God for the grace to have found such a church away from my home. The sisters and brothers from Amazing grace, Mr and Mrs Beckee, James, Margret, Gilbert, Nalongo and the entire church thanks for the love, moral support, and making me feel at peace with my soul. My home church, Entebbe Full Gospel Church, Pastor Stephen and Mum Mable Sebagaala, wise gals and the whole church. Thanks so much for the prayers and encouragement.

Dr. John Wasswa Mulumba, through you I was able to widen my appreciation of plant genetic diversity and the potential therein. This was the main thrust that motivated me to develop the concept for this $\mathrm{PhD}$ study. Thanks for the invaluable counsel, periodic review of my progress and monitoring the large screen house experiments in Uganda. Dr. Mulumba, you are meticulous and the detailed feedback you provided on my experiments, manuscripts and official communications have greatly improved my writing and presentation skills.

NARO top management and training committee, through you the Government of Uganda and the World Bank funded the biggest percentage of my $\mathrm{PhD}$ study program through the Agricultural Technology and Agribusiness Advisory Services project (ATAAS). NARO top management and training committee thanks so much for the support, periodic reviews with counsel and your special considerations in times when my study trajectory took an unexpected path. Special thanks to the Late Dr. Emily K. Twinamasiko, Dr. Ambrose Agona, Dr. Yona Baguma, Dr Imelda Kashaija, Mr. Robert Bagonza, Ms. Mary Kiggundu Ms. Godrine Kwebaza, Ms Mary Babirye and Ms. Nakato Percy for the ensuring that my tuition, welfare and other PhD related costs are catered for. Mr. Seggenddo, thanks too for the moral support and encouragement.

NARL, Dr. Wilberforce Tushemereirwe, thanks so much for all the support most especially the extra mile you took in ensuring that the screen house is sufficiently renovated for my experiment. I also appreciate Ms. Justine Waibale, Ms. Olivia Tibeijjuka, Eunice, Irene, Julie support in administrative issues. Dr. Moses Matovu, Mr. Allan Male, Mr. Kibirango Stuart thanks for the support and guidance you offered during my experimental work. My research assistants, L. Musa, Ms. Wanyana Maganyi Olivia, Mr. Katende Samuel, S. Kinconco, Mr. 
Humphrey Were, R. Sekasamba, D. Nasaazi, J.Makya, F. Okoda, E. Oluput, I. Makya,. D. Kasoozi, R. Kakoto, B.Buyinza, Jackie, Habibah, thanks so much for the commitment and great work! My colleagues at PGRC-Entebbe, thanks for taking on my workload and all the related support and sacrifice. I also thank the managers and field guides in the protected areas from where we collected our study samples i.e. Zoka, Budongo, Kibale, Itwara, Kalangala, Malabigambo and Mabira. Thanks for all the support.

Ugandan community at Wageningen, P. Ntakyo, thanks so much for sending me Paul's contact and all the invaluable support while at Wageningen, R. Onzima, A. Nanyiti, RCCO, G. Taulya, K. Kabuuza, M. Ahimbisibwe, D. Nsibo, W. Ocimati, C. Ayesiga, C Ampumuuza, B. Namugumya, H. Bukomeko, T. Awio, Jamada, Felix, Hilda, Emma, Robert, the late Haddy Sonko and all the Ugandans who supported my stay at Wageningen. Thank you for the special moments we shared. Mr. and Mrs Kaggwa, I met you in the last phase of my $\mathrm{PhD}$ and you were such a blessing! Thank you so much.

My family, dad Mr Aarons Sebunza, Mum Mrs Ephrance Sebunza, Abu, Ronald Harold, Kakande, Senga Teopista, thank you so much for all the sacrifices. May the good and faithful God bless you abundantly. Maama and Taata Gayaza, Maama Kawempe my siblings: elder, young brothers and sisters, my children I missed all the beautiful moments as you were growing up but thanks to God mummy is now somewhat free to play and learn with you. Julie and Irene, thanks for always bridging the gap, Dad and Mum Shavonne thanks for always checking on me and the visit. Having my daughters around for those few days refreshed my mind. My husband Precious Peter Yiga and family thanks so much for the love and invaluable support. My brothers Brian Forest Muwanga and Kato Stephen Forest, thanks for being reliable, disciplined young men, I treasure you and all the support you have offered me. May God richly bless you. 
Curriculum Vitae 
Catherine Kiwuka was born on $24^{\text {th }}$ September 1982 in Mulago, Kampala Uganda. She obtained her Bsc degree in Conservation Biology from Makerere University, Kampala -Uganda in 2005. From 2007 to 2008 she worked as Research Assistant/ Project staff at the Plant Genetic Resources Centre and she was later recruited as an In-situ conservationist/Research Officer of the National Agricultural Research Organization. She enrolled for Msc degree in Botany at Makerere University, Kampala-Uganda and obtained the certificate in 2012. In September 2013, she obtained an opportunity to enroll for her $\mathrm{PhD}$ at Wageningen University and Research Centre; Graduate school for Production Ecology and Resource Conservation; Centre for Crop Systems Analysis Group. For her PhD, she explored the Genetic diversity and phenotypic variation of wild, feral and cultivated Coffea canephora in relation to drought stress. 
List of publications 
Merot-l'Anthoene V, Tournebize R, Darracq O, Rattina V, Lepelley M, Bellanger L, TranchantDubreuil C, Coulee M, Pegard M, Metairon S, Fournier C, Stoffelen P, Janssens SB, Kiwuka C, Musoli P, Sumirat U, Legnate H, Kambale JL, Ferreira da Costa Neto J, Revel C, de Kochko A, Descombes P, Crouzillat D, Poncet V. 2019. Development and evaluation of a genome-wide Coffee $8.5 \mathrm{~K} \mathrm{SNP}$ array and its application for high-density genetic mapping and for investigating the origin of Coffea arabica L. Plant Biotechnology Journal, 17: 1418-1430.

Otieno A. G., Kiwuka C. and Mulumba J. W. (2017) Realizing Farmers' Rights through Community Seed Banks in Uganda: Experiences and Policy Issues. Sustainable Agriculture Research, 6(2): 26

Kalema J., Kiwuka C., Namaganda M. and Mulumba J. (2016). Distribution, habitat and conservation of range-restricted species of Eleusine and Pennisetum (Poaceae) in Uganda. Symbolae Botanicae Upsalienses, 38: 93-100.

Otieno A. G., Mulumba J. W., Wedajoo S. A., Lee J. M., Kiwuka C., Ogwal O. R., Adokorach J., Zaake E. and Halewood M. (2016) Networks and coalitions in the implementation of the international treaty on plant genetic resources for food and agriculture in Uganda. Journal of Public Administration and Policy Research, 8(6): 65-79.

Astrid M., Okot F., Kansiime K. M., Kiwuka C., Odong K. and Subedi A. (2015) Research report on climate resilient local seed businesses

Kiwuka C., Bukenya-Ziraba R., Namaganda M. and Mulumba J.W. (2012). Assessment of common bean cultivar diversity in selected communities of central Uganda. African Crop Science Journal, 20(4) 239 - 249.

Mulumba J.W. Nankya R., Adokorach J., Kiwuka C., Fadda C., De Santis P. and Jarvis D.I. (2012). A risk-minimizing argument for traditional crop varietal diversity use to reduce pest and disease damage in agricultural ecosystem of Uganda. Agriculture Ecosystems and Environment. 157: 70-86.

Kiwuka C., Mulumba J.W., Adokorach J. and Nankya R., (2011). Relating crop damage levels on farm to crop varietal diversity measured by richness evenness and diversity for Banana in Uganda, Proceedings of International Symposium on Damage, diversity and genetic vulnerability: the Role of Crop Genetic Diversity In Agricultural Production Systems $15^{\text {th }}-18^{\text {th }}$ February 2011 , Rabat, Morocco.

Kiwuka C., (2010). A comparative study on cultivar diversity and management of Phaseolus vulgaris $L$. (common bean) in selected communities of Mityana district Central, Uganda. M.Sc. Thesis. Makerere University.

Mulumba J.W, Zaake E., Male-Kayiwa and Kiwuka C., 2009. Neglected Food Crops in Africa: A case study from Uganda. Proceedings of the $8^{\text {th }}$ Annual Conference and General Meeting of the Uganda National Academy of Sciences (UNAS), Kampala, Uganda pp. $16-28$ 
PE\&RC Education Statement 
PE\&RC Training and Education Statement

With the training and education activities listed below the PhD candidate has complied with the requirements set by the C.T. de Wit Graduate School for Production Ecology and Resource Conservation (PE\&RC) which comprises of a minimum total of 32 ECTS ( $=22$ weeks of activities)

\section{Review of literature (6 ECTS)}

- The vulnerability coffee and Cocoa to drought stress in the African tropics: Can shading help?

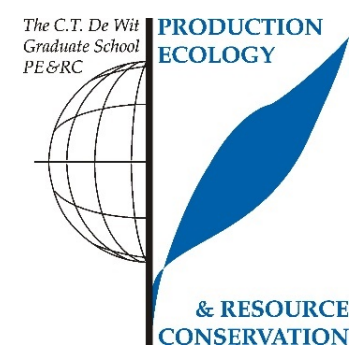

Writing of project proposal (4.5 ECTS)

- Study on the adaptability of Coffea canephora Pierre ex A. Froehner (Robusta coffee) to effects of climate change in Uganda

\section{Postgraduate courses (6.1 ECTS)}

\section{I-GIS; PE\&RC (2013)}

- Bioinformatics tools for analysis of genomic data; National Agricultural Research Laboratories (NARL), Kawanda, Uganda and Biosciences Eastern and Central Africa (BecA) Hub International Livestock Research Institute, Nairobi, Kenya (2014)

- $\quad$ Basic Statistics; PE\&RC (2017)

- Introduction to R for statistical analysis; PE\&RC (2018)

\section{Laboratory training and working visits (4.5 ECTS)}

- $\quad$ SSR genotyping of Ugandan Coffea canephora samples; Nestlé R\&D, Tours, France (2015)

\section{Deficiency, refresh, brush-up courses (12 ECTS)}

- $\quad$ CSA 30306: Advanced Crop Physiology, Wageningen University (2013)

- CSA 30806: Research Methods in Crop Science (2013)

\section{Competence strengthening / skills courses (2.55 ECTS)}

The Essentials of Scientific Writing \& Presenting; Wageningen Graduate Schools (2017)

Reviewing a Scientific Paper; Wageningen Graduate Schools (2018)

- Scientific Publishing; Wageningen Graduate Schools (2018)

\section{PE\&RC Annual meetings, seminars and the PE\&RC weekend (1.8 ECTS)}

PE\&RC weekend; first years edition (2013)

PE\&RC weekend; last years edition (2018)

PE\&RC Day (2017)

\section{Discussion groups / local seminars / other scientific meetings (7.8 ECTS)}

- $\quad 2^{\text {nd }}$ Biennial National Agricultural Research Organization Scientific Conference, Munyonyo, Uganda (2014)

- National stakeholder's workshop on policy issues relating to plant genetic resources for food and agriculture in Uganda, Jinja, Uganda (2015)

- $\quad 8^{\text {th }}$ Trondheim Conference on Biodiversity on "Food systems for a sustainable future: Interlinkages between biodiversity and agriculture", Trondheim, Norway (2016)

- State of affairs for Access and Benefit Sharing of Genetic resources in Uganda, Kampala, Uganda (2016)

- Symposium: Genotype to Phenotype Modelling of Plant adaption, Wageningen University and Research, the Netherlands (2017)

- Symposium: Drought, plant hydraulic traits and vegetation modelling, Wageningen University and Research, the Netherlands (2018)

- Global Alliance for the Future of Food's Strategic Convening on Resilient Seed Systems, Oaxaca, Mexico (2018)

- ClimCoffea project meeting, Montpellier, France (2019) 
International symposia, workshops and conferences (7.7 ECTS)

- $\quad 26^{\text {th }}$ International Conference on Coffee Science, KUNMING, Yunnan, People's Republic of China (2016)

- Tropentag 2016, Solidarity in a competing world-fair use of resources, Vienna, Austria (2016)

- $\quad$ First global workshop for an IFAD supported project entitled "Use of genetic diversity and Evolutionary Plant Breeding for enhanced farmer resilience to climate change, sustainable crop productivity, and nutrition under rainfed conditions.", Rome, Italy (2018)

\section{Supervision of MSc students (9 ECTS)}

- Exploring Natural Variation of Ugandan C. canephora Populations: A Search for Drought Tolerance Traits

- Assessing morphological response of selected of Coffea canephora Pierre genotypes to drought stress

- Assessing physiological response to drought stress on growth and performance of $C$. canephora genotypes 

Funding 
This research studies described in this thesis was majorly funded by the Government of Uganda and the World Bank through the Agricultural Technology and Agribusiness Advisory Services (ATAAS) project under Research Organization (NARO). Extra funding was obtained from the AGROPOLIS FONDATION - CAPES - EMBRAPA through the Climcoffea project 2014 for the molecular work, Wageningen University contributed to the experimental, traveling and publishing costs of this thesis. 
